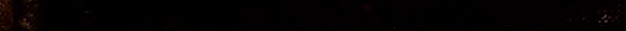


iv 32 in

3 m.

ins

1.

$$
\text { ivit }
$$

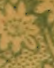

32 .

1)

(1)

(A)

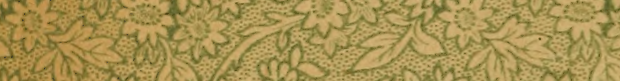

$30 \mathrm{~cm}$ 3. on

(1)

1.

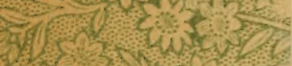

15inz 3 in

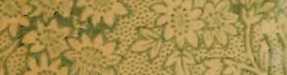

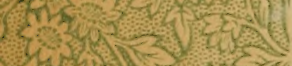

(1)

\section{LIBRARY OF CONGRESS.}

Chap. 2 Copyright No.

Shelf $\$ 53$

UNITED STATES OF AMERICA.

7.

s.

$\mathrm{N}_{3} ; \sum_{1}$

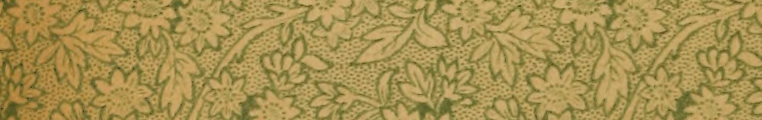

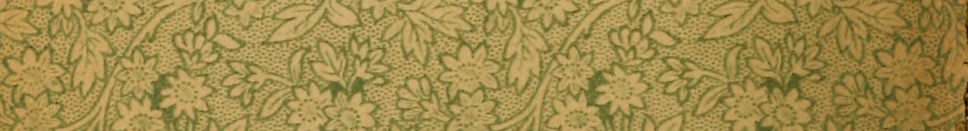

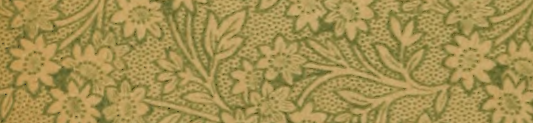

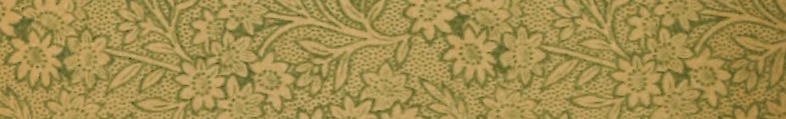

\%

251

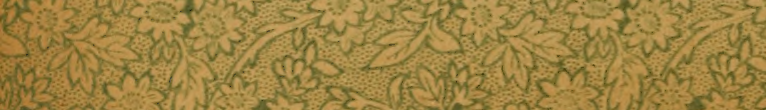

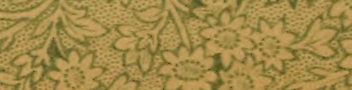

En 





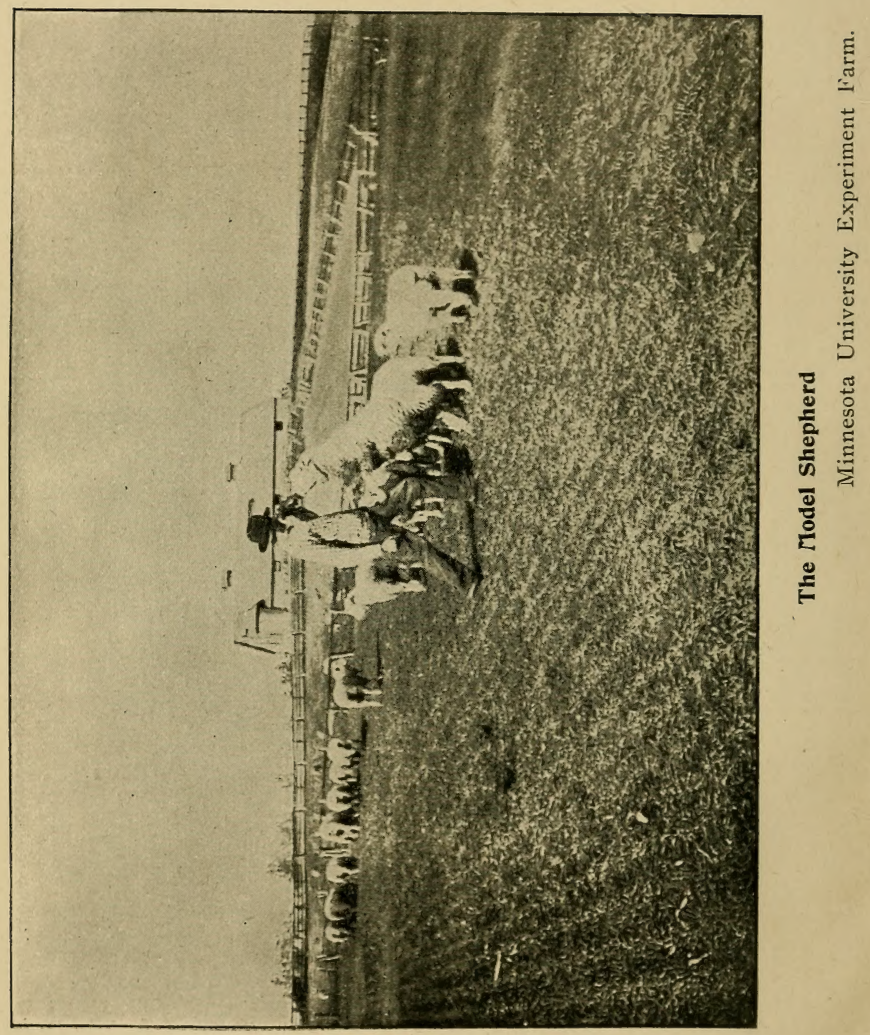




\section{SOILING CROPS}

\section{AND \\ THE SILO}

How to Cultivate and Harvest the Crops; How to Build and Fill the Silo; and How to Use Silage

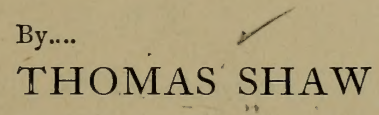

Professor of Animal Husbandry at the University of Minnesota

Author of

"Public School Agriculture" "Weeds and How to Eradicate Them"

"The Study of Breeds" "Forage Crops Other Than Grasses"
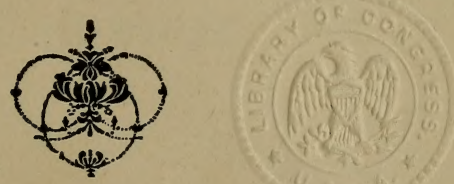

\section{ILLUSTRATED}

New York

ORANGE JUDD COMPANY

1900 


$$
\begin{aligned}
& 62242
\end{aligned}
$$

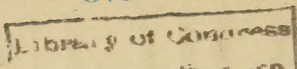

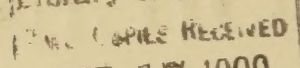

$$
\begin{aligned}
& \text { OCT } 171900 \\
& \text { Copyright entry } \\
& \text { lang. 1. } 1900 . \\
& \text { Not } 19.4 .6 .8 \text {. } \\
& \text { SECrNI COPY. } \\
& \text { Delivensed to } \\
& \text { ORdER DIVISION, } \\
& \text { OCT } 221900
\end{aligned}
$$

Copyright 1900

by

ORANGe Judd Company 
TO

\title{
THE DAIRYMEN AND FARMERS
}

\author{
OF
}

THE UNITED STATES

THIS WORK IS

MOST RESPECTFULLY DEDICATED

$$
\text { BY }
$$

\section{THE AUTHOR}




\section{ACKNOWLEDGEMENTS}

The author desires thankfully to acknowledge the outside sources from which aid was obtained in the preparation of the book. These include sundry bulletins issued by certain of the agricultural experiment stations in the United States, also the helpful work, "A Book on Silage," written by Prof. F. W. Woll of the University of Wisconsin. The sketches were nearly all prepared by Mr. Charles P. Taylor of the University of Minnesota. 


\section{TABLE OF CONTENTS}

\section{PART ONE}

ChAPTER I. PAGE.

Soiling Crops

ChAPTER II.

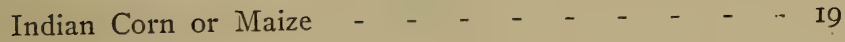

CHAPTER III.

Sorghum

CHAPTER IV.

The Non-Saccharine Sorghums - _ - _ - - $5 \mathrm{I}$

Chapter V.

Plants of the Clover Family - _ _ _ _ _ $\quad$ - 68

ChApter VI.

Leguminous Plants Other Than Clover - $\quad$ - $\quad$ - $\quad$ I02

CHAPTER VII.

Plants of the Brassica Genus - $\quad$ - $\quad$ - $\quad$ - $\quad$ - $\quad$ - I39

Chapter TIII.

The Common Cereals $\quad$ - $\quad$ - $\quad$ - $\quad$ - $-\quad$ I6S

Chapter IX.

Millets - - - $-\quad-\quad-\quad \ldots \quad-\quad-\quad$ - 183

Chapter X.

Field Roots - - - - vii $^{-}-{ }^{-}-{ }_{-}-$I95 


\section{Chapter XI.}

Miscellaneous Plants - $\quad$ - $\quad$ - $\quad$ - $\quad$ - $\quad-205$

Chapter XII.

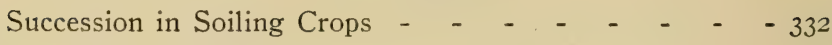

\section{PART TWO}

Chapter I.

PAGE.

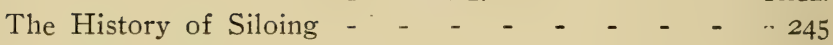

Chapter II. I

The Benefits from Siloing Crops - - - - - - 258

Chapter III.

Facts Relating to Silo Construction - $\quad$ - $\quad$ - $\quad$ - $\quad$.. $\quad$ - 269

Chapter IV.

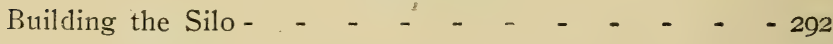

Chapter V.

Crops Suitable for the Silo $\quad-\quad+\quad-\quad+\quad-\quad-322$

Chapter VI.

Filling the Silo $\quad-\quad-\quad-\quad-\quad-\quad-\quad$ - $\quad-336$

Feeding Silage $-\quad \begin{aligned} & \text { Chapter VII. } \\ & -\end{aligned}-\frac{-}{-}-\quad-350$ 


\section{LIST OF ILLUSTRATIONS}

FIG.

PAGE.

I The Model Shepherd-Frontispiece.

2 Squaw Corn for Fodder - _ - _ - - - -20

3 Giant Fodder Corn for Soiling - _ _ _ _ - 27

4 Early Amber Sorghum - - _ - - - - 35

5 Sorghum Grown for Soiling, First Cutting - - 43

6 Red Kafir Corn - _ _ _ _ _ _ _ _ -53

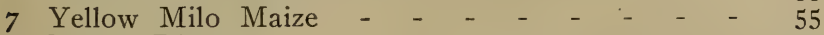

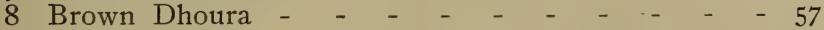

9 Jerusalem Corn - $-\ldots$

Io Alfalfa, Single Plant - _ _ _ _ _ _. _ $\quad$ - 87

II Alfalfa, Grown for Soiling _ _ _ _ - - 99

I2 The Mummy Field Pea - - _ _ - _ - -103

I3 Vetches and Oats for Soiling-Second Cutting - - II5

I4 Sheep Iasturing on Soy Beans - - - - - -120

15 Soy Beans for Soiling _ _ _ _ _ - - 127

I6 Sheep Pasturing on Cowpeas - _ _ _ - - I30

I7 Cowpeas Grown for Soiling - _ _ - _ - 137

I8 A Dwarf Essex Rape Plant - - _ - _ - - I4I

I9 Dwarf Essex Rape for Soiling - _ _ _ _ - I5I

20 Cabbage for Soiling _ _ _ _ _ _ _ _ - 156

2I Oats and Wheat for Soiling or Fodder - _ _ - 169

22 Oats and Peas for Soiling - _ _ _ _ - -178

23 Oats First Pastured, Then Grown for Soiling - - 180

24 German Millet for Soiling _ _ _ _ _ _ - I84

25 Hungarian Millet for Soiling - _ _ _ _ - 186

26 Sand Vetch - _ _ _ _ _ _ _ _ - - 219

27 Jerusalem Artichokes - _ _ _ _ _ _ $\quad$ - 227

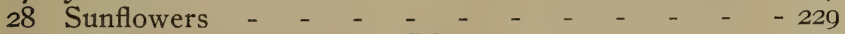

29 Sheep Barn with Round Silo - _ _ _ _ - 294

30 Section of Stave Silo - _ _ _ _ - -296

3I Splice of Stave with Iron Tongue - - - _ - 303

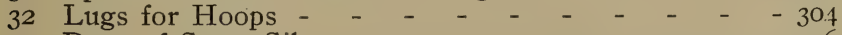

33 Door of Stave Silo - - $\quad$ - $\quad$ - $\quad$ - $\quad$ - $\quad-\quad$ - 306

34 Sketch Showing Stave Silo with Shute, Ladder and Hand Cart - - - - - - - - - - 307

35 Sketch Showing Stave Silo with Roof and Lugs Properly Distributed - _ _ _ _ _ _ -309

36 Section of Wall of Rectangular Silo - _ _ - - 310

37 Elephant Fodder Corn - _ _ _ _ _ _ $\quad 324$

38 Sorghum for Silage - _ $\quad \ldots \quad \ldots \quad-\quad-326$ 



\section{AUTHOR'S PREFACE}

This book is one of a series on agriculture which the author hopes to be spared to complete. It is designed more especially to meet the needs of dairymen when providing green food for their stock, summer and winter, but it is also intended to be similarly helpful to all farmers who keep domestic animals on the arable farm, and it is hoped that the student also at the agricultural college may be able to glean from its pages what will be helpful to him when prosecuting his investigations. Excellent information on the subject of soiling and also on that of the silo has been furnished by various authors, but in a form more or less fragmentary, irregular and incomplete. It has been the aim of the author in the present work to cover these subjects with at least a measurable degree of completeness and system.

In writing a series of books on agriculture, it is not easy to avoid some repetition. In fact, it is practically impossible to do so. For example, when one book treats of forage crops other than grasses and is followed by a second on soiling crops and the silo, as in the present instance, it will be found that many of the crops grown for these respective uses are the same. They are grown on the same kinds of soils, and the methods of growing them are similar. 
If each treatise is to be complete in itself, the methods of growing these respective crops must be given in both, and this necessitates some repetition. It has been, and will be, the constant aim of the author, however, to avoid such repetition to the greatest possible extent. By combining two or more separate treatises in one, repetition could be almost entirely avoided, but the purchaser would then have to pay for matter in which he might not be interested in order to obtain that which was of special interest to him. Of the two plans, the author believes that he has chosen that which will be more advantageous to the general public.

University Experiment Farm.

St. Anthony Park, Minn., Igoo. 
PART ONE

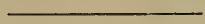

OPS

\section{SOILING GROPS \\ solLNG CROPS}





\section{CHAPTER I.}

SOILING CROPS.

Soiling crops are those which are sown from time to time to furnish food for domestic animals, and which are to be harvested while yet immature and fed to them in the pasture, the paddock, the feed lot or the stall. Corn cut and thus fed to animals at any stage prior to maturity furnishes an illustration of a soiling food. A soiling food is, therefore, another name for a green food. It is not necessary that it shall be fed as soon as harvested, but it is necessary that it shall be fed in the green form. Corn preserved in the silo is essentially a soiling food, inasmuch as it is cut when immature and in that condition is fed to live stock, though it may not be fed for months after it has been cut, as for instance, when it has been preserved in the silo, hence the propriety of combining the subject of soiling crops and the silo in this treatise.

Soiling crops differ from forage crops in that the former are harvested and then carried to the animals which consume them, whereas live stock gather the latter for themselves; and soiling differ from fodder crops in their being cut and fed green, whereas fodder crops are frequently harvested when mature or approaching maturity and are always fed to animals in the cured form. People who are disposed to follow rigidly the teachings 
of the dictionaries will probably take some exception to these definitions, but the time has certainly come when more precision must be given to at least some of the definitions in agriculture, to prevent confusion of ideas. For instance, the definition of forage crops given in our best authorities would make these include soiling crops also. Such a definition is at variance with common usage, and surely the popular idea when consistent and legitimate is of higher authority even than that of the recognized standards.

Adaptation in Soiling Crops.-The growing of soiling crops is chiefly adapted to an intensive cultivation. It may be better associated with the tillage of small rather than of large farms and is better adapted to localities where the population is crowded and markets are near, as, for instance, in the neighborhood of large cities. It was to be expected therefore that the growing of soiling foods would first receive attention in the east, and so it did. But the day is coming, and is near, when in one or the other of its forms it will be most extensively carried on also in the west, and more especially in those sections in which dairying prevails.

Soiling is, of course, only necessary on farms on which live stock are kept more or less numerously. And even on these it may not be much needed when pastures are plentiful and succulent during the greater part of the grazing season. It is more needed in dry than in moist climates, on poor than on rich lands, and where milk is sought rather than beef.

Partial and Complete Soiling.-Partial soiling means supplementing the pastures with green food 
for a part of the season, as occasion may require. Such food may be given once a day or oftener, according to the needs of the animals. The chief object sought in partial soiling is to keep domestic animals abundantly supplied with palatable and nutritious food, when the food from the pastures is inadequate. And where milk production is involved it aims to furnish succulent food after the grass pastures have lost much of their succulence, even though they should still be abundant. Partial soiling is best adapted to a system of cultivation that is intermediate between the extensive and intensive systems; that is to say, to a system that meets the needs of the average arable farm. In all countries with summer climates deficient in moisture it is an essential appendage and material help to clairying. In no other way can the dairyman keep up a maximum milk flow at so small an outlay.

Complete soiling has reference to that system by which domestic animals are sustained on food fed to them in the stall, the feed lot, or the paddock during all the year. It does not imply that all the food so fed shall be given to the animals in the green form, but that green food will usually form a considerable portion, if not, indeed, the greater part, of the ration. Complete soiling is adapted to an intensive system of cultivation; that is to say, where cultivable lands are scarce and dear, and from which it is necessary to obtain a maximum yield while they are being tilled. Its general adoption in this country where land is so plentiful, and in which it is relatively so cheap, is probably remote rather than near, notwithstanding that it has been practiced in some sections 
of the thickly populated countries of western Europe for many years.

Bencfits from Growing Soiling Crops.-The following are the more important benefits from growing soiling crops: I, Food supplies are increased in a marked degree; 2 , in various ways the waste in feeding is lessened; 3 , animals are sustained in better form than where soiling is not practiced; 4 , injury to the land through poaching is prevented; 5 , a salutary influence is exercised on weed eradication; 6 , a saving in land is effected; 7 , a saving in fertility is effected ; 8 , a saving is also effected in the item of fencing; 9, animal production is greatly increased; and, Io, the cost of keeping the family cow is lessened.

Increase in Food Supplies.-Soiling enables the farmer to grow more food than he could by any other system. Usually the growth of plants is hindered in proportion to the extent to which the plants are pastured down while yet immature. And crops that are pastured are further injured by the tramping of the animals that feed upon them. They are injured directly by the bruising which they receive from the hoofs of the animals which feed upon them, and indirectly by the impaction of the land from pasturing it when not dry enough. These facts are simply mentioned without taking space to give the reasons. And since soiling crops are usually cut a little short of maturity it is more practicable to grow two crops from the same land, where soiling is practiced, than where it is not.

The relative increase in food production where soiling is practiced as compared with pasturage can 
not of course be stated otherwise than in the most approximate manner. It will vary greatly with such conditions as soil and season. But it will not be extravagant to say that when animals are soiled all the year in the one instance, and when they are pastured during the season of pasturage, and are then wintered on food grown on other land in the other instance, a given area will sustain at least twice the number of animals through the year by the former system than it will by the latter.

Less Waste in Feeding.-When crops are fed under the soiling system there is less waste than when pastured or fed in the matured form. This saving is effected, first, in the absence of injury through treading as compared with pasture crops; second, in the absence of loss in harvesting as compared with matured crops ; and, third, in the more complete consumption of the food. The injury to pasture crops through treading has already been referred to.

Soiling crops when judiciously managed are seldom so injured by the weather as to be rendered unfit for food. Fodder crops when matured are frequently damaged by rain when being cured. When thus damaged they lose in palatability, in nutrition, and also through mold induced by storing when not yet fully cured.

The more complete consumption of food fed in the green form as compared with food fed when ripe, arises chiefly from the greater palatability of the former. The fodder portion of plants, that is to say, the stems and leaves, is always better relished by animals when fed before they are fully matured. For instance, feed rye to cattle when it has not yet reached 
the earing stage, and it will be eaten with avidity. Feed it when fully out in head and it will be eaten indifferently. Feed it when ripe and little else than the heads will be eaten. Feed the straw after the grain has been threshed, and it will be consumed by the animals only when impelled by hunger. Chemists tell us that fodder plants contain all the food elements that they will possess at the time the ripening process begins, that is to say, by the time they have reached that stage when the stalk begins to assume a yellow tinge at the ground. They should be fed, therefore, as soiling food before they pass this stage, for as soon as they get beyond it there is loss in palatability. And there is loss in digestibility as the ripening stage is neared, that is to say, the proportion of the indigestible woody fiber is increased.

On the other hand, when plants are cut when considerably short of maturity, there is loss from want of sufficient development. Theoretically, the most food will be got from plants when they are cut as soiling food a little short of maturity. In practice, however, this is impossible, as it would too much curtail the length of the period for feeding each crop. But with crops that grow again and again, as with alfalfa, for instance, there is no loss probably in cutting them as soon as they have made sufficient growth to justify the expenditure of the labor involved.

Sustains Animals in Ectter Form.-By the aid of soiling food domestic animals can be maintained in better form than without it. With such aid they can be maintained in a more even condition, the aniinal energy can be more perfectly conserved, and the 
succulence of the foods usually exercises a wholesome influence on the health of the stock.

In the absence of soiling foods it is hardly possible for the farmer to keep his animals through all the year in what may be termed a well balanced condition. When he depends wholly on pastures during the summer season these may fail. When they do his animals suffer proportionately. On the other hand, if the pastures are superabundant there is waste. When pastures lose their succulence, the milk flow from milk-giving animals is proportionately reduced, and no after feeding will wholly restore it, howsoever suitable it may be. As the character of the season cannot be foreseen, farmers are wise who make provision for a possible shortage in pasture by sowing more or less of one or more crops to provide soiling food. If the best possible returns are to be obtained from animals, they must be well supplied with food every day in the year. When animals are fed in whole or in part on soiling foods, they may frequently be kept nearer at hand than when not so fed, hence their needs can be more easily met. When the days are hot they may be more easily housed. In the time of flies they may be more easily protected from the same by keeping them in cool, darkened sheds or stables during the heat of the day. In hot weather they can be left out in paddocks over night, and in cold weather they can be housed. Such attentions have a marked influence in maintaining an equilibrium of condition.

The use of soiling foods conserves animal energy by lessening that waste which arises from undue 
exertion on the part of animals when gathering their food. When the dairy cow has to travel far when seeking food in the pastures, she does so at the expense of food required to sustain the prolonged exertion. And when food is thus used to sustain energy it is very evident that it cannot be used to make milk. Likewise, when growing cattle have to travel beyond a certain limit in order to get supplies for the day, they do so at the expense of flesh. And the same is true of the horse, the sheep and the pig: Live stock should, of course, be given sufficient exercise to keep them healthy and to give them proper stamina. Beyond this, exercise means waste of food, and this waste can be prevented by growing a sufficiency of soiling foods.

Soiling foods, judiciousiy fed, tend to keep the animal system in proper tone, hence thus far they cxert a favorable influence on the health of live stock to which they are fed. In the absence of those foods it is difficult, if not impossible, to keep the system in the best of tone during certain periods of the year. Where soiling foods are not grown there can be no assurance of succulence in the pastures beyond the early summer months. Pastures will not sustain an undiminished milk flow in cows, even when considerably short of the yellow leaf stage. When dry and crisp they are a less valuable food than well cured hay, notwithstanding that the food may be abundant. On such pastures swine will soon lose flesh unless the pastures are supplemented with other food. By growing succulent foorls in due succession and in adequate sufficiency they may be made available for live stock in one form or the other during a large 
part of the year, if not, incleed, through the whole year; hence the beneficial influence which they exert on the health of the animals may be made continually operative. But there are other senses in which the soiling system may become prejudicial to the health of the animals. These are discussed on Page I8.

Injury Through Poaching.-When the soiling system is practiced, lands are not injured by poaching, that is, by the treading of the animals when the hoofs sink below the surface of the land. On all soils poaching is to some extent harmful, and on clays it is quite harmful, since impaction follows on the return of dry weather to the very great injury to the growth of the grasses. As no person can control the weather, the farmer who is dependent on pastures only to provide food for his live stock in the season of growth must needs allow them to feed upon the pastures betimes when they will injure them by treading; and it may be added that close grazing in very dry weather may seriously injure pastures. Particularly is this true of pastures in some parts of the dry west. The farmer without soiling food may be powerless to prevent such a result.

Influence on Weed Eradication.-The soiling system may be made to render material aid in eradicating weeds. This arises, first, from the thickness with which the food may be grown; second, from the season at which much of it may be sown; and, third, from the immature period at which it is reaped.

Soiling food may be sown more thickly relatively than if the same plant or plants were sown to produce a matured crop of seeds. Such sowing secures more of fineness in the food, and in 
consequence more of palatability. The food thus grown crowds weeds because of its thickness, and also hinders their development because of the density of the shade.

Soiling food may be sown at different seasons because of the difference in the habits of the plants thus grown. Several varieties may be sown late. When these varieties are thus sown, ample time is given to sprout and in turn to destroy myriads of weed seeds that may be in the upper section of the tillable soil. In fact, where such cultivation is what it ought to be, the ground will be comparatively clean before the crop is grown or planted.

As soiling foods are cut while yet immature, the weeds which grow in them have not the same chance to mature as though the crop had been allowed to stand until fully ripe. Notably is this true of soiling crops that are sown reasonably early. And when these are removed early in the season, another soiling crop, or a catch crop of some kind may be made to follow the first one. This second crop will also be helpful to the cleaning of the land.

Saving in Land.-Growing soiling foods effects a great saving in land, as it enables the grower to raise much more food from a given area. The saving thus effected is greater relatively in the west and south than in the east and north. This arises from the greater relative adaptability of the east and north to the growing of grass pastures, and from the greater relative adaptability of the west and south to the growing of soiling foods. The extent of the saving will vary with the conditions. But it would not be extravagant to say that ordinarily where 
three acres of grass are required to keep a milch cow in good form for six months, it would be possible to grow enough soiling food to keep the same cow all the year. In some sections of the prairie in the far west, where cultivated grasses have not been grown with marked sticcess, the difference would be even greater. In instances, not a few, it has been found possible to grow ample supplies of food on one acre by the soiling system to feed a cow all year. As the population becomes more dense, and as populous cities multiply, the saving in land effected by soiling in either of its forms will increase in importance, and more in the neighborhood of large cities than elsewhere.

Saving in Fences.-Growing soiling foods lessens the necessity for building fences on farms on which live stock are kept. A marked saving is thus effected in labor and money, the extent of the saving being proportional to the number of animals kept, to the cost of labor and materials for fencing. Unless where the materials for fencing are very cheap, it is a costly affair, both to build and to maintain fences. It is seldom that any kind of fence, strong enough to secure cattle, can be built for less than twenty-five to fifty cents per rod, when labor and material are included, and in some instances the outlay would be much greater. This outlay, or much of it, must needs be repeated at least every other decade, to say nothing of the sums paid out from time to time in repairs. There is also the further objection that on the strip of land on which the fence stands, weeds are much prone to grow, unless considerable hand labor is expended in keeping them down. 
On the other hand, we must not assume that the soiling system will entirely obriate the necessity for fences. Theoretically, where complete soiling is carried on no fencing would be required other than that used in enclosing the yards and paddocks in which the animals are to be exercised, or in which they are to be kept over night in warm weather. But this idea must not be pressed too far, for where sufficient stamina in live stock are to be maintained, animals must have exercise beyond what they will voluntarily take in small paddocks.

Saring in Fortility.-The soiling system effects a great saving in fertility, since it enables the farmer to make more and better manure than can be obtained from live stock kept on the pasturing system, and less of what is thus made is wasted. More manure is made, first, because the animals are at all times on full feed, whereas on pasture they are frequently on short supplies, and, second, because by the soiling system a greater number of animals can be sustained on a given area. The manure made is likely to be more valuable, since along with soiling food greatcr quantities of meal, rich in the elements of plant growth, are usually fed. And there is less waste in the manure made if properly saved, since its value is not then impaired by insects and other adverse influences, as it is when dropped in the field. In many instances the soiling system will enable the farmer to more than double the value of the manurial product nacie, as it enables him to more than double the supplies of food grown.

Increase in Animal Production.-Such a system cannot fail to increase animal production. The 
extent of this increase will be in proportion to its completeness. If it increases the food products 100 per cent, it will also increase the milk or meat production more than Ioo per cent, since the animals maintained will be increased proportionately. They will also be maintained on foods at all times ample in quantity and of correct adaptation. These influences will tend to a further increase of production. The greater outlay involved, however, in securing this added increase should never be lost sight of.

Sustaining the Family Core--In villages, in suburbs of towns and cities, quite a number of the inhabitants keep cows. To such people the cow is a source of untold blessing, because of the utility of the product which she gives. Oftentimes those people are unable to secure adequate pastures. This difficulty may easily be overcome when the owner of a cow possesses a small piece of land. He can then supplement the pastures by growing soiling foods, and with great advantage to both cow and land. Where but one cow is kept, a small area will suffice to supply her needs.

Some Objections to the Soiling System.-To the soiling system there are some objections. Chief among these are the following: I, It involves increased outlay for labor; 2, it requires more constant attention on the part of the attendants; 3 , it is not always easy to adjust the food supplies to the needs of the animals, and, 4 , it may, in some instances, tend to impair the stamina of live stock.

Incrcased Outlay for Labor.-The soiling system cannot be adopted in either of its forms without a considerable increase in the labor of those who care 
for the live stock so fed. Even in the partial form, increase in labor is considerable. In the complete form, it is much greater; and of course increase in labor involves a corresponding increase in outlay. The increase in labor arises, first, from the necessity for cutting the food daily, or at intervals of not more than two or three days; second, from the necessity for handling and conveying it to the animals in the green form; third, from the necessity for feeding and otherwise caring for the animals from day to day in the pasture, paddock, shed or stall; fourth, in caring for the yards or paddocks and in handling the manure. From the sum of this labor, however, in making the comparison, there should be deducted the less amount of the labor necessary in providing fencing. Notwithstanding, the extra labor involved, and the increased expenditure resulting therefrom, is the one great standing hindrance in the way of the more general adoption of the system of complete soiling by the farmers of this country. Nor is the adoption of complete soiling likely to become general until farm labor becomes cheaper and until land becomes scarcer and dearer. But beyond all question, in the opinion of the writer, the day is not very far distant when complete soiling will be practiced by a considerable number of the farmers in every state of the Union.

Partial soiling does not involve nearly so mucti labor as complete soiling, hence it is practiced by a greater number of farmers. Dairymen, especially, cannot well get along without it. The necessity for thus growing and feeding food to supplement the pastures increases with the dryness of the climate. So 
essential is it to the highest success in raising and properly maintaining farm stock that it must eventually be practiced by all or nearly all farmers who do not follow the system of complete soiling.

Tax on Attendants.-Where complete soiling is carried on, the care of the animals must be continuous throughout the season. Every day thereof brings its round of duties, and they cannot be neglected except at the expense of the live stock. Food must be secured for the animals with unfailing regularity, it must be fed to them every day, and usually two or three times a day. To the average farm laborer this work savors so much of the treadmill order that it is distasteful. He looks upon it in the light of a yoke which he does not care to take upon himself. Hence, until those better days come when such labor will be looked upon through a proper lens, for it has its compensations, the adoption of the soiling system in either form will be relatively slow. Adjusting Food Supplies.-Complete soiling calls for the exercise of much thought in securing food supplies and in adjusting them to the needs of the animals. There must needs be succession in foods to keep up a constant supply. No one food is at its best for soiling uses for many weeks in succession. There must also be variety in the foods thus grown in succession. This is essential to the wellbeing of the animals to which the foods are fed. It is further rendered imperative by the different periods of the year when various plants grow and mature sufficiently for being fed at their best. A supply of these foods must always be on hand through sunshine and storm. In some instances, however, 
showers fall frequently and for days in succession, so that it may not be easy to secure food supplies unless when soaked with rain; and it may be also more or less soiled with earth. To properly adjust these matters in the face of varying seasons is no easy task. It cannot be done without the exercise of much forethought.

Impaired Stamina in the Stock.-While, as has been shown, the soiling system tends to promote good health in live stock, it may easily be so conducted as to ultimately injure stamina in the animals subjected to its conditions. Up to a certain limit, utility in live stock is improved through artificial conditions. Beyond this limit, stamina are weakened. Where the border line runs between the most approved conditions of environment and conditions that lead to deterioration, is not always easily determined. Unnecessary exertion on the part of animals when getting this food lessens production. Insufficient exertion lessens stamina. Under the complete soiling system the individual must guard against undue confinement of the animals, or their natural vigor will wane. All history and experience point to increased mortality among animals and also among men in proportion as they are aggregated under conditions of much restraint. The dangers of undue restraint, however, do not apply to animals subjected only to the conditions which partial soiling imposes. And with complete soiling, it is probable that they may, in a great measure, be avoided by giving due attention to the conditions which are necessary to the maintenance of improved vigor in domestic animals. 
CHAPTER II.

INDIAN CORN OR MAIZE.

It would probably be correct to say that Indian corn (Zea Mays) furnishes more food for live stock than any other plant now grown in the United States, and that it will continue to do so through all the years that are yet to come. Taking everything into consideration it will probably produce more food per acre for domestic animals than any other plant, and there are but few foods which can be fed in a greater variety of ways. In furnishing soiling food on unirrigated land, it is in some respects without a rival on the American continent. So great is its value for this use that in the near future very few sections will be found in all the United States in which it will not be grown on a large majority of the farms by those who keep live stock.

Green corn is pre-eminently a food for dairy cows when in milk, owing in part to the close relation between succulence in food and free milk production. But it may also be fed with much advantage to other classes of cattle when pastures are scant, and also to horses of all ages, although to horses at work it should not be given in large quantities, lest a too lax condition of the bowels be induced. It furnishes excellent green food for sheep, when of fine growth. It also furnishes food for swine that is much relished by them, especially when the corn is of the sweet 


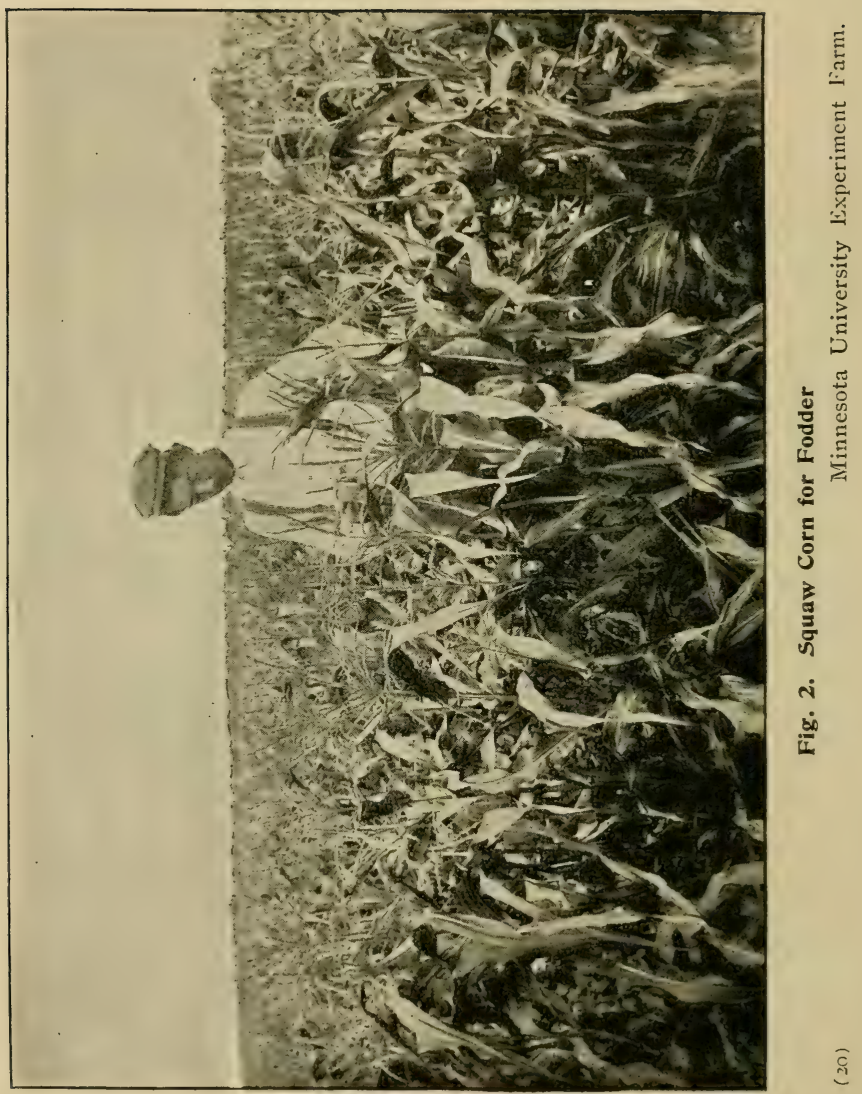


varieties. They will virtually consume the entire product when it is fed to them prior to the maturing of the crop.

Corn grown as soiling food will yield from ten to thirty tons per acre, according as the land is poor or rich and the season is dry or moist. A good average crop may be placed at fiftéen to twenty tons per acre.

Distribution.-Corn can be grown as soiling food in nearly all the tillable portions of the United States, since, with a mean temperature of about 60 degrees, it will become sufficiently advanced for being cut as soiling food in from fifty to seventy days from the time of planting. But where it can be allowed to grow for a longer period, the crop is relatively more valuable. Nearly all the tillable portions of the United States have marked adaptation for growing corn to be fed in the green form. The sections least well adlapted to its growth are those probably which border on the Pacific ocean, between Alaska and California, because of the low mean temperatures that prevail there. In nearly all the tillable areas of Canada, also, corn can be grown in the finest form for summer feeding and in sections too far north to mature the grain.

Soil.-Corn is specially adapted to warm, deep loam soils rich in humus, and that lie upon subsoils of what may be termed porous clay. It is a most voracious feeder on decaying organic matter, hence when it is to be grown, care should be taken to keep the soil well supplied with such food. But it may be grown with more or less success on almost any kind of land not too low in available plant food, not too 
strongly impregnated with alkali, and not overmoist or overdry. It may be made to flourish on the stiffest clays when they are sufficiently pulverized, and on the poorest sands when they have been sufficiently enriched.

Place in the Rotation.-As a fodder or grain crop, that is, as a crop for being fed in the cured form, corn should be grown whenever practicable as a cleaning crop. More commonly it should be planted after one or more grain crops have been taken from the land, and it should be followed by a grain crop in which grass seeds have been sown. Frequently it should be sown on an overturned grass or clover sod. But when sown to provide soiling food it can with much advantage be grown as a "catch" crop, that is to say, as a crop preceded or followed by another crop grown on the land the same season, and in some instances both preceded and followed by another crop. Where the seasons are sufficiently long it may thus be grown with peculiar fitness after a crop of winter rye is pastured, plowed under green, or reaped when mature; after clover is pastured, buried or reaped; after grain crops are pastured off, and in some instances after grain crops are harvested; after a crop of early sown rape is grazed down, and after certain other soiling crops have been removed from the land, as, for instance, peas and oats.

It may also he grown after any kind of a fall or spring sown crop that has failed from any cause. But in areas in which the seasons are quite short, it may not be possible to grow another crop on the land the same season. The crops that may with much 
propriety be sown after soiling corn include winter wheat, winter rye, winter oats, the winter vetch, the sand vetch, rape and crimson clover. Corn may thus frequently be sown as soiling food without interfering with the growth of the crop that would ordinarily be taken from the land.

Preparing the Soil.-When preparing the soil, the aim should be to secure a seed bed moist, clean and fine. When winter rye is plowed under, it should not be later than the earing stage, and in regions deficient in moisture earlier than that, lest through its bulkiness it should cause the land to lie too loosely upon itself and so lose too much of its moisture, or through its woodiness it should fail to decay soon enough to feed the corn crop. If the buried rye is rolled and harrowed soon after it has been buried, the moisture in the soil will be better conserved and the more quickly will the rye decay. These remarks will apply equally to the burial of fresh farmyard manure with much litter in it. But in time of wet weather, it would not be necessary thus to roll and harrow the land so soon after it had been plowed. As the preparation of the soil foi this crop cannot usually begin long before the planting of the crop, special pains should be taken to pulverize the soil and to make it firm, that the germination of the young plants may begin at once after planting, and that the subsequent growth may be rapid.

It should always be the aim in growing a soiling crop of corn to produce a large quantity. It is usually fed in the immature form, hence quality in the food cannot be so much influenced by close or wide 
planting as it is when the corn crop is allowed to mature. Land, therefore, not sufficiently fertile to produce a maximum crop should be fertilized according to its needs. Where it can be obtained, farmyard manure is one of the cheapest and most effective of fertilizers. It may be applied most freely in climates not deficient, or not much deficient, in moisture. It feeds the corn crop better when it has been reduced, or fermented, more or less, before it is applied. On lands lacking in moisture the application of large quantities of farmyard manure in the unreduced form should be avoided, unless it can be applied some considerable time before the planting of the corn, otherwise its bulkiness and slowness of decay may harm the crop more than it will help it.

Commercial fertilizers may also be applied in addition to farmyard manure where the supply of the latter is limited, or alone in its absence. The composition of these fertilizers and the quantity to apply will depend upon the needs of the land. But more commonly complete fertilizers will be preferable, that is to say, fertilizers which contain a certain per cent. of nitrogen, phosphoric acid and potash.

Sowing.-Corn for soiling uses may be sown broadcast by hand and covered with the harrow; with the grain drill, all the tubes or with only part of them in use; or it may be strewn by hand in shallow furrows made by the plow. Which of these methods ought to be adopted will depend chiefly upon such conditions as the conveniences at hand for planting the crop and upon the area to be grown.

Much has been written against the plan of sowing the corn broadcast by hand, also against the plan 
of sowing it with the grain drill when all the tubes are in use. Yet it may be true that a large majority of the farmers who grow corn for soiling persist in growing it thus. And there is probably some reason for such persistence. It is very convenient to sow corn in this way. The stalks, because of their fineness, are more palatable than when of stronger growth, and on good soil much bulk of food is obtained. The objections to this method of planting the crop are: The lack of growth in the corn in severely dry weather, the encouragement given to the growth of weeds, the larger amount of seed required for planting, and the less nutritious character of the food. There is some force in all these objections. Notwithstanding, in the judgment of the author they do not prove conclusively that on well prepared soils corn for soiling should not sometimes be grown thus. But it should not be so grown on land that is frequently lacking in moisture, on land that is low in fertility or on land on which weed seeds lying on or near the surface have not been well sprouted and destroyed before the planting of the corn.

When corn for soiling is planted with the grain drill, some of the tubes only being in use, there is much latitude in the precise methods practiced Sometimes every second tube is used. When pianted thus, the crop will make more growth on soils only moderately supplied with plant food, and it will ailso make a better growth in dry weather. Wien thus planted, of course, the rows are too near to admit of horse cultivation. Such cultivation may be given with the rows even nearer to each other than thirty inches, but when less distant than thirty inches it 
cannot be done with so much freedom or ease. The larger the variety of the corn, the more distant should be the rows, to avoid too much shading from the sunlight; hence there may be instances when corn grown for soiling should be planted more than thirty inches distant.

Sometimes such corn is planted with the drill in what may be termed doubie rows, that is to say, in rows not more than from six to nine inches apart. But the distance between the pairs of double rows should be at least thirty inches. In planting corn thus, with some grain drills at least, it may be necessary to duplicate the amount of driving that would be sufficient to plant the corn in single rows. Other drills, however, may be made to plant at least two double rows at one and the same time. This is done by leaving open the avenues that lead to the tubes which do the planting and closing all the others. Corn planted thus will produce a greater bulk than if planted in single rows, yet this method of planting admits practically the same kind of cultivation that would be suitable for corn grown in single rows.

When the corn is sown by hand, shallow fur-. rows are made with the plow, the seed is strewn thickly in these, according to the desires of the grower, and it may be covered by hand or by drawing a heavy harrow crosswise over the ground. The object sought in planting the corn thus is to secure a thick stand of plants that may, also, be cultivated, when a drill with which to sow the plants is not obtainable. But this method of planting corn for soiling should not be attempted when a large area is to be planted. 


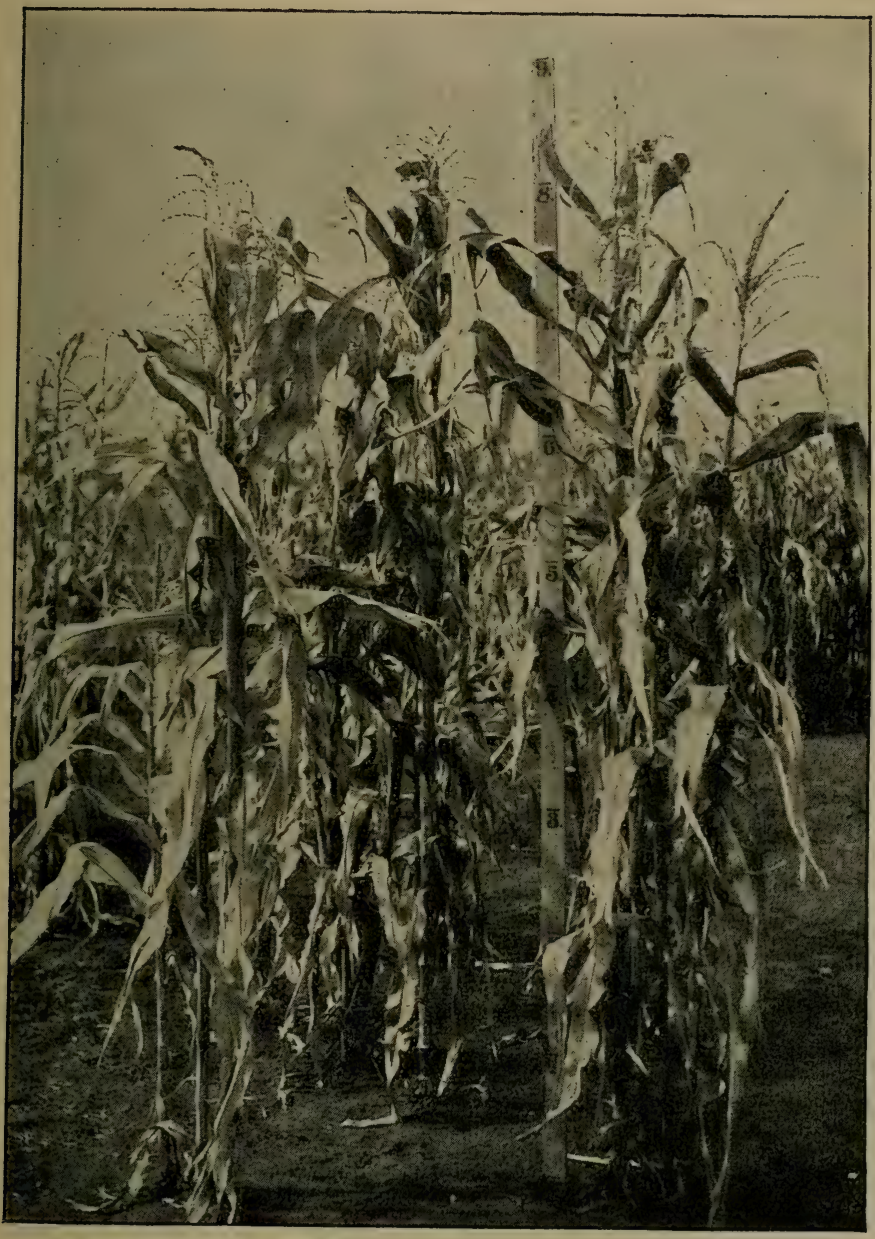

Fig. 3. Giant Fodder Corn for Soiling 
The variety, or varieties, of corn to sow or plant will depend on conditions such as relate to climate and soil. In northerly latitudes it may be wise to plant only the quick growing flint varieties. In more southerly latitudes, it may be necessary to grow only the slow growing dent varieties. When the corn is to be allowed to pass the earing stage, before being fed, it may be proper to choose some of the varieties of sweet corn for planting. But since soiling corn is usually fed before the corn on the ear is of any considerable food value, it is well to select varieties with a leafy tendency of growth, since these varieties will be more relished by the animals to which the crop is fed.

The quantity of seed required will vary with the size of the seed kernels, or, in other words, with the variety of the corn, and with the method adopted in sowing the seed. Probably no method of sowing calls for the use of more than three bushels of seed per acre, or less than one bushel per acre. There would seem to be no advantage derived from growing corn for soiling purposes with the plants less distant than from three to four inches in the line of the row, whatsoever the kind of cultivation adopted, and there may often be good reasons for growing the plants much further apart.

The time for planting corn for soiling will largely depend upon such conditions as climate, soil, and the prospective needs of the animals to which the crop is to be fed. Although in southern latitudes, this crop may be sown for soiling uses far on into midsummer, it should never be planted in the spring before the soil has become sufficiently warmed 
to germinate the seed quickly. Slowness of germination is more or less injurious to the crop, and prolonged slowness of germination may be even fatal to it. It is probably safe to conclude that the season is sufficiently advanced for corn planting to begin when apple blossoms are unfolding their beautiful tints. It may be desirable to have the season for feeding green corn as long as possible. This may be brought about in one of two ways: First, several varieties, which call for varying periods in which to grow, may be planted at the same time; second, but one varicty may be sown at intervals not closer to each other than two or three weeks. The second of these methods is preferable, since the one variety selected may be the most suitable to grow in that particular locality. When corn is grown as soiling food for pigs, the aim should be to secure much grain rather than abundant growth of stem and leaves. It should therefore be planted in hills or rows, as corn is usually grown, to provide ears. From eight to twelve quarts of seed will suffice to plant an acre, and, as previously intimated, the sweet varieties are to be given the preference.

Cultivation.-The harrow and the cultivator are the instruments chiefly used in cultivating corn for soiling. Owing to the short period required by corn to grow, it is seldom necessary to use the hand hoe, when a sufficient use has been made of the harrow. The corn ground should be harrowed a few days subsequently to the planting of the seed. It may be necessary to harrow twice before the plants appear when the germination is tardy, but once is usualiy. sufficient. The crop should be harrowed at intervals 
of only a few days, especially when the weather is dry, even though the land is not foul with weeds that it may the more perfectly retain its moisture. The harrowing should cease when the plants are several inches high. For reasons that will be manifest, the harrow should be light, should have a broad sweep, and when in use the teeth should usually be set to slant backward. It should also be driven across rather than along the drills, that fewer plants may be covered by the harrow. When the crop must be planted on foul land, more seed should be used than would otherwise be necessary, to allow for the freer use of the harrow, and consequently for the loss of a larger percentage of the plants.

When the cultivator can be used, its use ought to begin soon after the harrowing has ceased, and it should continue at intervals until the feeding of the crop has virtually begun. These intervals should usually be not more distant than, say, seven to ten days. The cultivation should be shallow, that the corn roots may not be broken, and that the moisture may be better conserved than it would be by deep cultivation. It should come close up to the line of the rows, that weed growth may be checked to the greatest possible extent.

Fceding.-The feeding of the corn may begin as soon as it is fully in tassel, or even sooner but for the loss in maximum development that would ensue, and this feeding may be continued until the crop is matured. But when fed to swine it may be well to defer the feeding until the corn in the ear is nearly ready for table use. The residue of the green corn, if the crop is not all consumed, may be cut at 
the stage of early maturity, cured in the shock and fed with much advantage to live stock subsequently through the entire fall and winter. The farmer who has a sufficient area of corn grown and properly harvested on the plan above outlined may sustain his horses, cattle and sheep in excellent form, howsoever dry the autumn may be, or howsoever scarce the pasture. But it is very important that the crop shall be harvested at the stage of early maturity, that is to say, when a little under-ripe, and that it be nicely cured. Vastly increased attention is likely to be given to this feature of corn production in the near future, more particularly in the northwestern states, so much characterized by bright autumn sunshine.

When only a small quantity of soiling food is to be fed daily, it may be cut with a scythe and carted to the animals, or thrown to them over the fence which may separate the corn crop from an adjoining pasture. It may be well in some instances to so plan for feeding the corn when choosing the land on which it is to be grown, that is to say, it may be well to sow a strip of corn not too wide beside the pasture and along its entire length. The saving in horse labor that would thus be effected when feeding the crop would be material, but to the plan there is the objection that corn or other green crop fed thus leads to the dropping of an undue proportion of the manure in that part of the pasture on which the green food has been fed. When green corn is cut for pigs, the corn hook will probably be the best implement to use.

When fed on a large scale, the crop must needs be cut with the mower, according to the needs of the 
live stock. Or, as much may be cut at one time as will suffice for two or three days' feeding, especially when the crop is well advanced in growth, as then it does not quickly wilt overmuch, as it would at an earlier period. A moderate amount of wilting rather adds to the relish of the food, and it also lessens the danger from abundant feeding when the green corn is first given to the animals.

The portion fed once or twice a day, as the case may be, will have to be drawn as frequently by horse labor, except when it is fed in racks in a yard, or in the stable mangers. In such instances enough may be drawn at one time to suffice for two or even for three days. But too much wilting must be guarded against, else it will lessen the palatability of the corn. Some form of truck with a platform not far from the ground should be used in carting all kinds of green food, in order to lessen muscular expenditure in handling food with so much water in it.

Where the facilities are suitable, there is no way by which corn thus carted can be fed to live stock with a less expenditure of labor than by feeding it in a pasture. It is then thrown from the dray or wagon and is consumed without any further labor in handling the residue, or in carting the droppings. But of course there is oftentimes considerable loss in the manure. When corn or other green food is thus fed, it should be dumped off in small bunches not too near one another, so the animals may consume it without being molested by one another; and it should be strewn on a different portion of the pasture every time it is fed, to insure greater cleanliness in the feeding, also to secure a 
more even distribution of the droppings. The whole pasture may be gone over in this way. The plan of manuring a field thus is certainly very cheap and efficacious. The loss in fertility is not great if the pasture is to be plowed the same autumn. If it can he arranged to have the food thus spread on the ground in the absence of the live stock, they will not tread on it so much when turned in to feed upon it. The ideal plan, when it can be carried out, is to have two pastures and to spread the food in each alternately when the live stock are in the other pasture.

When the green corn is fed to horses or cattle in manger or racks, for manifest reasons, it is we!1 to have it placed in these when the animals are absent, unless when they are tied in stalls. It may be most conveniently fed to sheep or swine in the pastures, but there may be occasions when it will be found advantageous to feed it in paddocks, feed lots or sheds. The feeding of sweet corn to swine may be continued after the crop has matured, but there will be loss in feeding the stalks unless the ears only are fed to the swine. The stalks may of course be cured and fed to horses or cattle. 


\title{
CHAPTER III.
}

\author{
SORGHUM.
}

Sorghum (Sorghum vulgare var. saccharatum) has not been very extensively grown as a food for live stock on any part of the continent, but for several years past its great value for such a use has been known to a limited number of farmers in various centers, and in many instances it has been fed by those farmers with very satisfactory results. It is probably true that in Kansas more sorghum has been grown to provide food for live stock than in any other state in the Union, but in some of the states which border upon Kansas, and in others farther south, more or less sorghum has been grown for stock within the past few years. The idea has gone abroad, and rightly, too, that sorghum is more delicate and slower in growth than corn. But the generally accepted view based on this idea, viz., that to grow sorghum and to keep it clean involves great labor is only partially correct. When sown on ground well prepared and clean on and near the surface, it requires no more labor subsequent to the sowing of the seed to grow sorghum than to grow corn. But it is frequently necessary to expend more labor in cleaning and meliowing the seed bed for this crop than in preparing the same for corn. If sown on land foul with weed seeds within the surface strata of the soil, the weeds will start in advance 


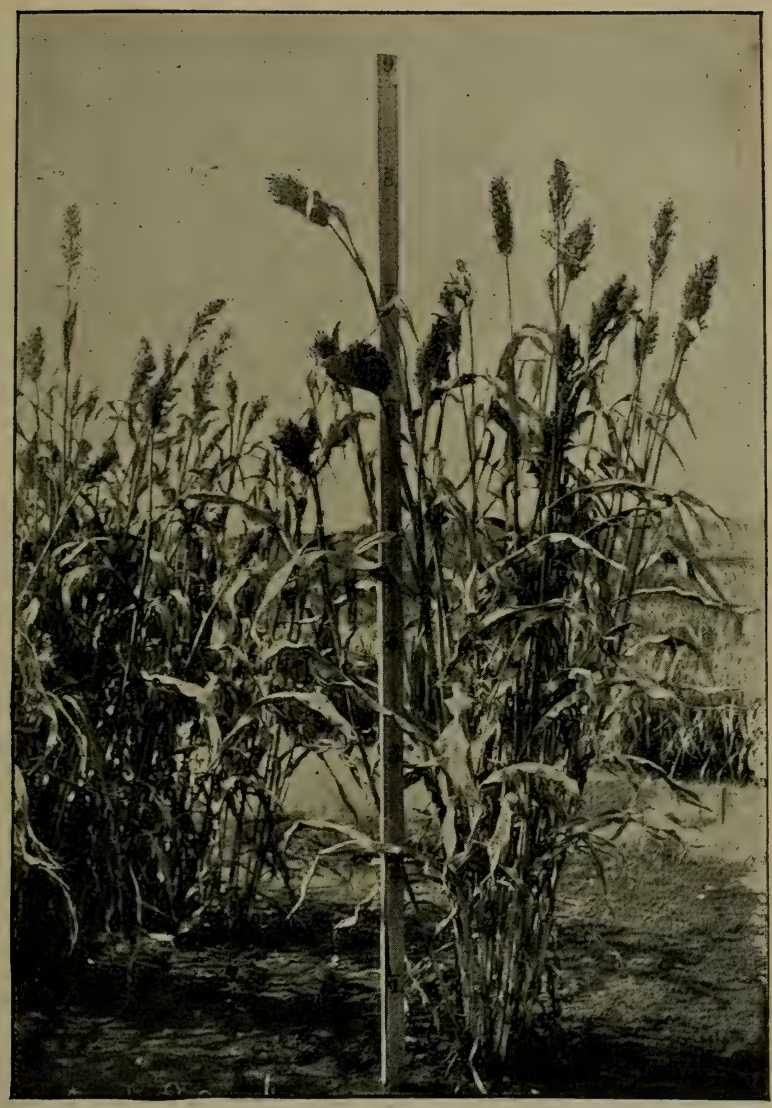

Fig. 4. Early Amber Sorghum 
of the sorghum and will greatly hinder its growth unless much labor is expended in fighting them.

Sorghum stools much when it is growing, hence the growth is finer in character than the growth of corn. This of course adds to its palatability as a food for stock. But its greatest value as a soiling food lies, first, in its power to produce more than one cutting per year when grown under favorable conditions of soil and climate; second, in its ability to grow in climates with a limited rainfall. The plants grow slowly for a time, and the development of root growth is limited; later they take a firm hold upon the soil, and if the weather is warm they rush forward with much quickness and vigor.

Sorghum furnishes excellent soiling food for horses, cattle, sheep and swine. Like nearly all green foods it must be fed with some caution to horses when working. It is becoming more common to pasture sheep and swine upon sorghum than to feed it to them as a soiling food, owing to the marked adaptability of this plant in providing pasture for these animals. But when fed as soiling food to sheep and swine it is much relished, more especially when of tender and succulent growth. Its highest use as a soiling food, however, is in providing supplies for milch cows. They are fond of sorghum and it is good for milk production, and a given area furnishes relatively a large quantity of food.

This plant has been known to produce thirty tons of green food per acre, but the average is under rather than over fifteen tons. In many instances the 
yield would be even under ten tons per acre. Whether the largest yield will be obtained from one or two cuttings per acre will be largely dependent on the character of the season, but with sufficient rainfall larger yields will be obtained from two cuttings, and the sorghum from the second cutting is of increased fineness because of the more abundant stooling of the plants caused by the first cutting.

Distribution.-Sorghum can be grown for soiling food in all the tillable portions of the United States that will produce Indian corn. This means that it can be grown successfully in every state in the Union. It can also be grown in Canada over similar areas, but in those sections of Canada that mark the northerly limit of corn production, it cannot be grown as successfully as corn, because of insufficiently high temperatures in the growing season.

As this plant is possessed of greater power to withstand drouth than corn, it has a higher adaptation for much of the area lying west of the tier of states which border on the Mississippi river and east of the Rocky Mountains. The extent to which sorghum will yet be grown for pasture, soiling food and folder within the area named, can only be surmised. The conditions for its abundant growth in much of the said area are not at all unfavorable. The tillable areas on the continent which are least adapted to the growth of sorghum are those which border on the Atlantic and Pacific coasts and north from Portland in Maine on the one hand and from San Francisco on the other.

Soil.-The soils that possess highest adaptation for corn also possess highest adaptation for sorghum. 
The latter will grow best, therefore, on loam soils which are well supplied with humus, and which rest on a subsoil of readily permeable clay. All, or nearly all, prairie soils are well suited to the growth of sorghum. But the most suitable soils for this plant have more of the sand element in them than those which possess highest adaptation for growing corn. Sorghum may also be grown with success in sandy soils underlaid with sand or gravel and so lacking in moisture that corn could not be successfully grown upon them. On the other hand, in the dry belt there are vast stretches of just such land which are so lacking in moisture that sorghum even cannot be grown on them in the absence of irrigation. On certain other soils, as, for instance, clays of more or less fineness of texture, corn may be grown to better advantage than sorghum. The former will succeed measurably well on clays so stiff as to be quite unsuited to the growth of sorghum.

Place in the Rotation.-When sorghum for soiling is the only crop grown on the land during the season of growth, it may be placed anywhere in the rotation, but preferably between two grain crops, as then it can be grown as a cleaning crop. Its efficacy for such a use will depend much upon whether it is or is not cultivated while growing. In either case, when the land is properly handled weed growth will be diminished. Sorghum may also be grown as a catch crop, but not to the same extent as corn, since some varieties of corn may be grown in a shorter period than any of the varieties of sorghum. When thus grown, however, it may frequently be made to follow such crops as winter rye, whether 
pastured, used for green food, plowed under, or harvested. Sometimes it comes after clover is plowed under or made into hay; or early sown rape that has been eaten down. It may also be made to follow certain early garden crops, and crops intended for producing hay or grain, but which, through lack of promise, have been pastured off. The chief objection to growing sorghum as a catch crop arises from the want of sufficient time, between the plowing of the land and the sowing of the seed, to give ample opportunity for sprouting the weed seeds that lie on or near the surface of the soil. Since corn may be harrowed to a much greater extent than sorghum without injury to the plants, it has higher adaptation than sorghum for being grown as a catch crop; on the other hand, sorghum will grow under conditions so dry as to bring distress upon the corn crop.

Preparing the Soil.-Land in the best condition for being planted with sorghum is clean on and near the surface, is possessed of a fine tilth and is firm and moist. When sorghum is the only crop that is to be grown on the land for the season, it is usually not difficult to so cultivate the soil that it will be in the condition above described when the crop is to be sown. Usually it is preferable to plow the land in the autumn. There will then be time to sprout the weed seeds on and near the surface, and in turn to destroy them before the seed is planted. This can be accomplished by the occasional use of the harrow, and in some instances it may be necessary also to use some form of cultivation. The precise nature of the implement to be used will be measurably dependent upon the character of the soil. While the 
surface soil is thus being stirred, its power to hold moisture is also being increased. And even though it be necessary to defer sowing the seed for a time, in order to secure the requisites necessary to insure a good seed bed, it is better to adopt such a course than to sow the seed on ill-prepared land.

As previously intimated, there is usually not time to prepare the land thus, when sorghum is grown as a catch crop, but some things can be done that will tend to enhance the growth of the crop when it is planted. As soon as the land is plowed it should be rolled and harrowed to prevent the escape of moisture. But if there is already sufficient moisture in the land, it is not necessary to use the roller; and if the sowing of the seed can be deferred for a time, without too much hazard, something can be accomplished by way of cleaning the land on or near the surface. But more commonly it is necessary to sow the seed as soon as the ground can be made ready for it.

While sorghum grows fairly well on land of but medium fertility, since the roots gather much food in the subsoil, the yields are usually proportionate to the fertility in the land. Farmyard manure, when it can be obtained, is one of the best and cheapest fertilizers for sorghum. Commonly it would be applied before the land is plowed, whether used in the fresh or in the reduced form. In the fresh form it may, with much propriety, be buried in the autumn, thus giving it ample time to measurably decay before the crop begins to feed upon it. But on leachy soils and in climates with much rainfall, the aim should be to apply the manure only a short 
time before the crop is to be planted, lest its more valuable ingredients should filter into the drainage water and pass away before they can be appropriated by the plants of the crop which is to follow. It is not a good plan to top-dress the seed bed which is to receive sorghum seed with any kind of farmyard manure, because of the prevalence of weed seeds in the same. But it may in some instances serve an excellent purpose, to top-dress sandy soils with farmyard manure in the autumn, and then to bury the manure that has been so applied in the early spring. The surface soil will thus be so far enriched as to promote a rapid growth.

Commercial fertilizers may be applied alone, or in conjunction with farmyard manure. Complete fertilizers are more commonly used, but the exact nature of the product to be applied will depend upon the extent to which the soil is wanting in the various leading elements of fertility. The aim should be to apply these fertilizers so that they will stimulate vigorous growth in the plants when they are yourig: since, if they have thus been made strong while yet young, their power to extract plant food from the soil at a later period of development will be greatly enhanced. The fertilizer should therefore be sowii when practicable at the same time the seed is sown, and in near proximity to the same, but not too close to it when the fertilizer is possessed of any ingredients of a caustic nature.

For several years the question of fertilizers for sorghum is not likely to give much concern to the growers of the same in the upper basin of the Mississippi river. It is very different, however, with the 
farmers living on the more hungry soils of the lowe: Atlantic and Gulf states.

Sowing.-One of the following methods of sowing sorghtum is 11sually adopted: First, it is sown broadcast by hand and covered with the harrow; second, by the grain drill, all the tubes or only every alternate tube being used; third, by hand in shallow furrows marked out by the plow; or, fourth, by the grain drill in single or double rows with a space of thirty to forty-two inches between them. The first method is usually practiced by those who have no grain drill, since it is convenient to sow the seed thus. The chief objections to sowing sorghum by this plan are, first, the seed is imperfectly covered and at varying depths, hence it grows up more or less unevenly; second, some of the seed in dry weather fails to germinate; third, when sown thus it cannot be cuitivated, which, under very dry conditions, may lead to failure in the crop. The second method buries the seed at a uniform depth, hence the germination of the seed may be expected to be more uniform, but the objections from smothering through the presence of weeds and through injury from dry weather are much the same as when the seed is sown by hand. though less in degree.

The use of only every other drill tube when sowing the seed insures a more bulky growth of the crop, but at the expense of the fine character of the growth. The third method is only resorted to when a small oulantity is to be sown in the absence of a grain drill, and when at the same time it is desirable to cultivate the young crop. The fourth method is followed when a large area is to be grown, and when it is 


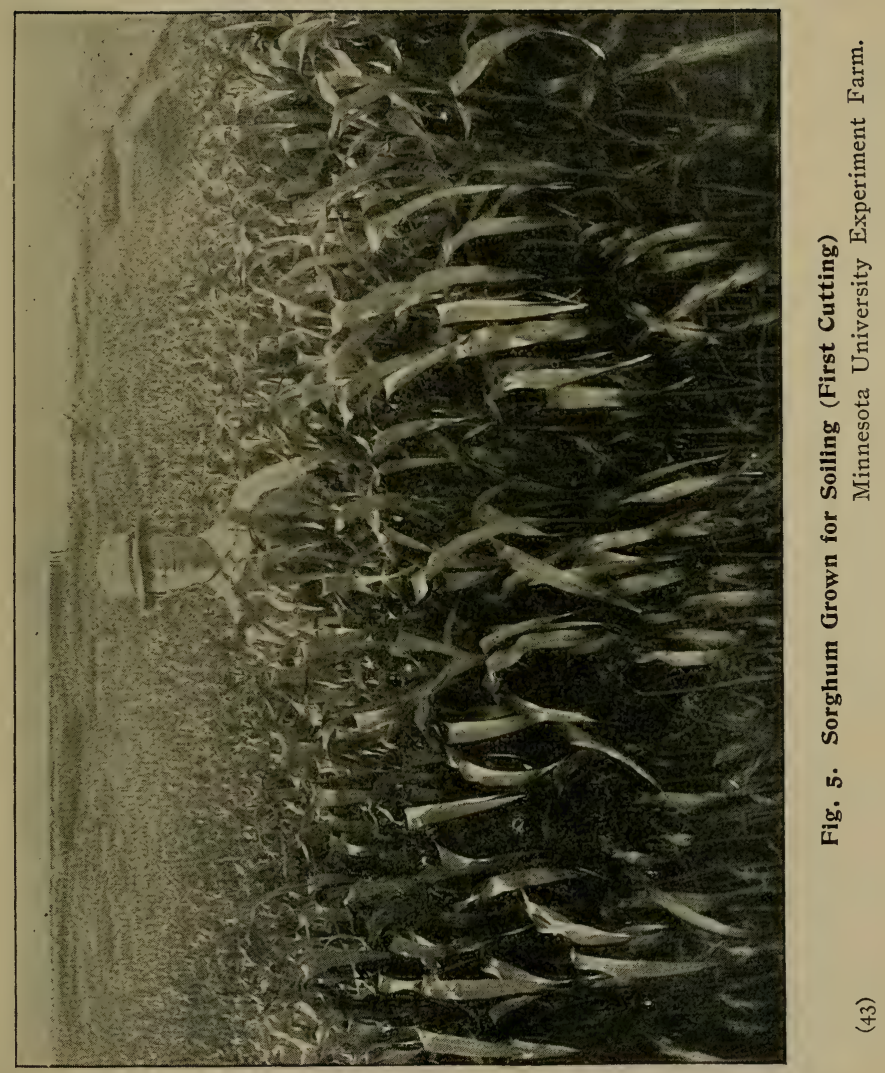


desirable to cultivate the crop. In sowing the seed almost any make of drill may be used. In sowing double rows two adjoining tubes are active, while the tubes that occupy the space between the double rows are inactive, that is to say, not in use. The space between the rows that form the double row is thus from six to eight or nine inches wide, according to the make or pattern of the drill, and the distance between the double rows will be determined by the nature of the soil, the variety of the sorghum to be grown and the character of growth expected from it. The richer the soil, the more distant the rows from one another; the larger the variety of the sorghum the coarser will be the character of the growth produced. The chief objects sought in planting the double in preference to the single row are: To secure an increased yield in weight of fodder, and to secure a crop fine in character. One objection to the system is found in the shelter that is thus provicled for weeds between the two lines of the double row.

Prominent among the varieties of sorghum that are more commonly grown are the Early Amber, sometimes called the Minnesota Amber, the Early Orange, Folger's Early and Link's Hybrid. The first named has marked adaptation for northern latitudes. The second and third are much grown in the states of the middle west, and the fourth is one among several varieties grown in the south.

The quantity of seed to be sown will depend upon climatic conditions and upon the mode of planting. It is manifest the system of sowing broadcast will call for much more seed than the system of planting sorghum in single or double rows. When 
the seed is broadcasted by hand or when it is sown with the grain drill,-all the tubes in use,-one bushel of seed per acre will usually be sufficient, although some growers advocate sowing as much as two bushels per acre. Where the moisture is likely to prove inadequate to the needs of the growing crop, results more satisfactory will be obtained by reducing the quantity of the seed to be sown. When grown in single rows with a wide space between them, a few quarts of seed will suffice per acre, but in growing this crop for soiling uses it will, usually, be found advantageous to sow not less than a peck of seed per acre, whatsoever the method of growing the crop that may be adopted.

The time for sowing the seed will, of course, vary with such conditions as relate to climate and rotation. It is a mistake to plant before warm and settled weather has set in. When sown too early the germination of the seed will be imperfect, the early growth will be sickly in character, and the weeds will push on ahead of the sorghum, so when the crop starts to grow no conditions, howsoever favorable, can make it a success. A crop grown under similar conditions, except that it is not sown until the weather is sufficiently warm, will prove much more satisfactory than the former. The best rule to follow, perhaps, is that which defers sowing the sorghum seed until the corn crop has been planted.

Of course sorghum may be sown for soiling at any subsequent time, so long as there is time enough to secure sufficient growth to pay for the young crop. It must, of course, be harvested before the autumn 
frosts arrive. While green and succulent it is easily injured by frost.

Cultivation.-Harrowing sorghum is the only mode of cultivation that may be resorted to when it is sown on the broadcast plan, either by hand or with the grain drill. It cannot be harrowed nearly so much as corn, owing to the much greater delicacy of the young plants, and when planted with the grain drill the harrow may be more effectively used than when the seed has been broadcasted, for then the plants do not uproot so easily. Sorghum sown with the grain drill may, usually, be harrowed with benefit to the crop just when the first blades are pushing through the soil. The harrow used should be light, of a broad sweep and the teeth of the same should be slanted backward to the greatest possible extent when the work is being done. No little difference of opinion prevails as to the degree of the benefit arising from harrowing the crop after it has got well through the soil. It is at least questionable if sorghum should be harrowed after the plants appear until they get up several inches above the surface. Before that period of advancement they are easily uprooted and also easily buried in the process of harrowing. The quick growth of sorghum will certainly be promoted by harrowing, but the crop should not be harrowed to the extent of making the plants too few to produce a maximum of forage. Where it is intended to use the harrow freely on the young plants, enough additional seed should be sown to allow for the expected loss.

In sections deficient in moisture, it is more necessary to use the harrow freely than in those opposite 
in character. When the crop is threatened with serious injury from the presence of young weeds, it ought to be harrowed. More sorghum will be secured, and that of a superior quality, from a piece of land in which the plants have been thinned overmuch by harrowing than from a similar piece of equal area in which the weeds have obtained the ascendency over the sorghum.

When practicable, the cultivation of sorghum sown in rows sufficiently distant should be carly begun, it should be frequent, and may be continuer almost up to the time of the last cutting of the crop for the season, and it ought to be shallow rather than cieep. After the first cutting of the crop, the benefit from prompt subsequent cultivation will be abundantly apparant. Some hand hoeing may be given betimes with profit in the line of the row, but when the land has been well prepared such work is seldom necessary.

Feeding.-There is no cast-iron rule as to when the cutting of the crop should begin. It should not be delayed, however, until the seed heads are formed when a second cutting is intended. If the sorghum is cut after that period the yield from the second growth will be much reduced. When cut too early the yield from the first cutting is unduly small. Usually the cutting of the first growth does not begin until the crop is from two to three feet high, but it may begin earlier if necessary, and the cutting of the second growth may begin as soon as the seed heads appear, or even earlier. Since, under normal conditions, the crop is cut and fed from day to day according to the needs of the live 
stock, the second growth will frequently be ready to cut by the time the first growth is all consumed, providing the consumption of the first growth has covered a period sufficiently long. This period will vary, but it should not be less than three to four weeks. Sorghum, therefore, from a single sowing, may be made to provide soiling food in the green form for live stock from six to eight weeks. But during periods of severe dirouth, the second cutting may not materialize, or it may, at least, be disappointing in its growth. When but one cutting is made the harvesting may begin as soon as the seed heads are fully formed, and may be continued until the crop is fully matured. But when the sorghum is to be fed to sheep or swine in the green form, they will consume it with greater relish when cut at an early stage of growth. The food is then fine in character, juicy, tender and contains but little fiber. When thus fed one or two more cuttings can be obtained in one season because of the earlier stage of development at which the sorghum is cut. But it is more common to pasture sheep and swine on young sorghum than to feed it to them as soiling food.

When but a small quantity is wanted per day, the scythe is commonly used in cutting the sorghum. When grown along and beside a pasture fence, of necessity the scythe must be used in cutting the food for convenience in feeding the same. When a large amount is required the mower must be used. As the plants do not shrivel readily, enough may be mown at one time to last for two or three days, more especially when the green food is 
to be fed to the cattle and horses. As in feeding corn, it may be fed within a pasture, in racks, feed lots, or mangers in the stables.

Some care is necessary, especially when the feeding begins to limit the amount fed, or to feed it in a somewhat wilted condition, lest it should cause hoven or bloat. Inattention at this point may lead to serious loss, but green sorghum is less liable to produce hoven than clover or alfalfa. The amount that may be given daily need not be limited except by the needs of the live stock, unless for a few days at the first. However, more satisfactory results will follow when some other food less succulent is given. Sorghum may also be fed to live stock with great advantage in the matured form, on what may be termed the soiling plan of feeding. When thus fed it is common to cut the crop with the binder or mower, but more commonly with the latter. The sorghum is then allowed to lie on the ground for several days before being gathered together, especially when it is not well matured, or when the weather is damp. It does not take injury from rain as corn would when thus exposed. The outside of the stem is hard, hence the rain does not penetrate it. But some injury is done through the soil that adheres to it. It is true, nevertheless, that sorghum exposed thus and lying on the ground for a period of two or three weeks in rainy weather has been eaten subsequently and with a relish by live stock. It is drawn into windrows, by using a strong rake, and is then put into large "cocks" or heaps by hand.

When the crop is very heavy, it may be bunched without first having been raked. In such cocks 
sorghum will not ferment or mold as corn does, hence as much as 500 pounds, or more than that, may be put in one heap without any danger of loss from heating. From these the sorghum may be drawn and fed to live stock in the pastures, in the sheds or stables, as desired. This food is greatly relished by the animals at that season of the year, and since it is fed with but little handling it is considered an economical food. Feeding from such a source may be continued until the closing in of the winter. When sorghum is to be fed thus, it is commonly grown like grain, that it may be fine enough to be handled with the fork without difficulty. No other kind of food that can be grown comes in more opportunely for feeding at that season than sorghum. In: the states of the middle west and in those of the south, where winter delays its coming, this method of feeding sorghum is peculiarly advantageous. 


\section{CHAPTER IV.}

THE NON-SACCHARINE SORGHUMS.

The chief of the non-saccharine sorghums are Kaffir corn, Milo maize, dhourra and Jerusalem corn. Teosinte, properly speaking, is not a sorghum, but it will be included in the discussion of the nonsaccharine sorghums because of the similarity in the methods of cultivation and in the uses for which it is grown. Of these plants, Kaffir corn is the best known and the most extensively cultivated, but it would be premature to reach the conclusion that because of this it is the most valuable. It has been cultivated apparently in the United States for a longer period than the other non-saccharine sorghums. Milo maize in some of its varieties is likely to make a strong competitor to Kaffir corn.

These plants are all of comparatively recent introduction into the United States. At least no one of them has been extensively grown in the same until within a comparatively recent period. They are but little known, therefore, to any considerable number of the agriculturists of the country. It will be in order, therefore, to give a short description of each and also to make some reference to the distinctive peculiarities of growth.

Kaffir corn (Sorghum vulgare) is a sturdy growing plant. The stem is thick at the base, tapering toward the top and usually grows to the hight of 
about five to six feet. Since it does not grow so tall as many of the varieties of corn, nor so tall as sorghum, or Milo maize, it is more easily handled than these in the sheaf when fully grown. The leaves are long and large and fairly numerous, but not markedly abundant. It throws up a single spike which bears a head in which the seeds are closely packed. The head is fully six inches long and three inches broad and stands erect, or nearly so. Large yields of seed are obtained, and when ground its feeding value for the various classes of farm stock is nearly equal to that of corn. The plants are but little liable to break down with the wind. They have extraordinary power to grow under dry conditions and to retain succulence in the leaves and stems even after the seed has matured. The leading varieties of Kaffir corn are the red and the white. The red matures earlier than the white, but the latter would seem to produce more seed. The red variety is better adapted than the white to states north from where the most suitable conditions exist for growing Kaffir corn.

Milo maize (Sorghum vulgare or Andropogon sorghum, var.) is a vigorous growing plant. In the tests made at the Minnesota university experiment station in $1897-98$, the plants attained an average hight of about eight feet. The leaves are large, and from the center of the stalk upward they are quite numerous. Each stalk when matured is surmounted by a large head which bears seed profusely. This head has an average length of about six inches and an average diameter of about four inches. When the head first appears it is erect, but when matured 


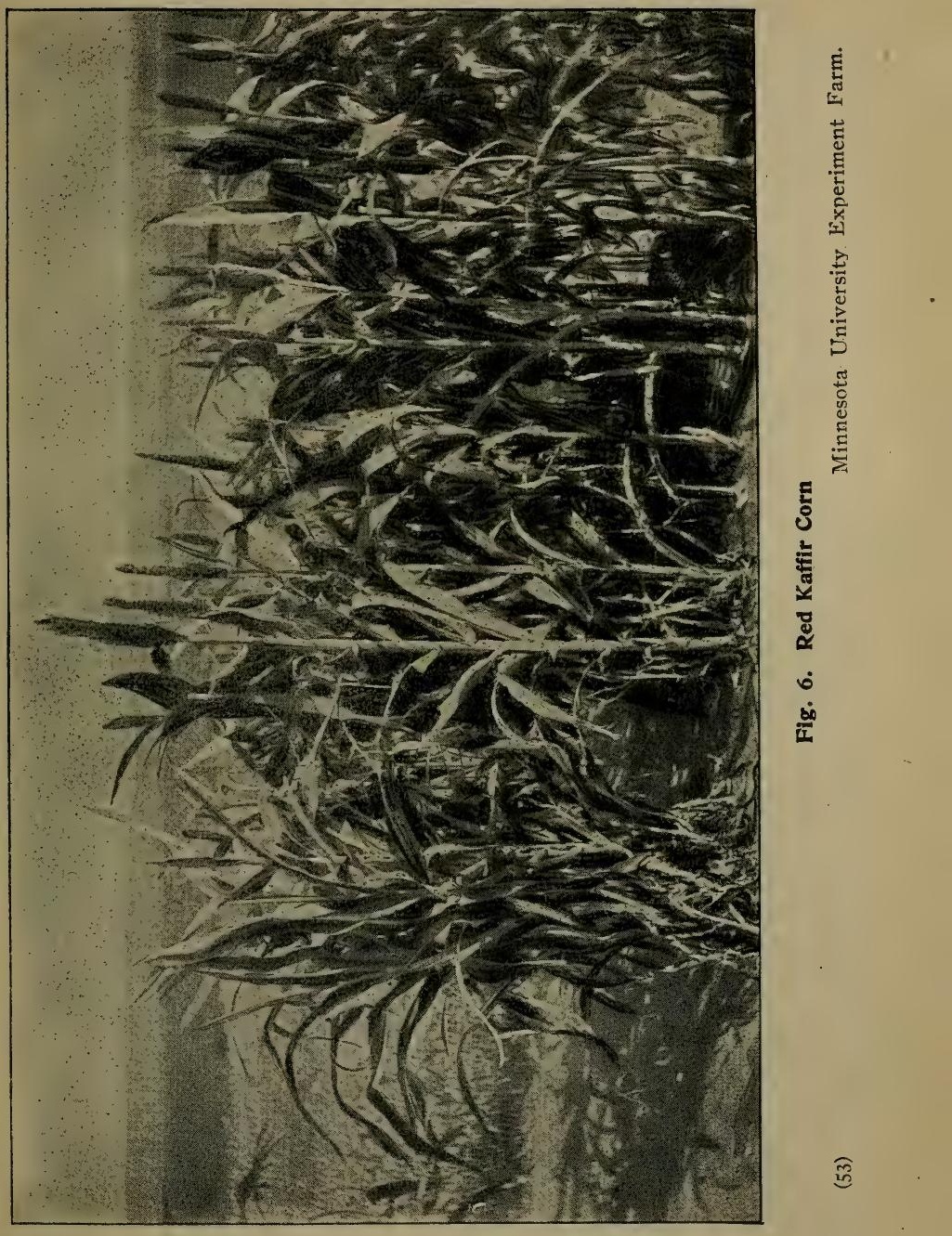


it hangs downward. It is somewhat more open than the seed head which is produced in Kaffir corn.

There are two leading varieties of Milo maize, named respectively the yellow and the white. The former is the earlier of the two. In I897 some of the seed of the yellow variety matured at the Minnesota university experiment station, but not all of it. In 1898 , one plat of the same variety was pastured with sheep. About the same results were obtained as from pasturing early amber sorghum. Another plat was grown in rows three feet distant from one another and harvested like corn. It was found that the numerous leaves around the top of the plants added to the difficulty in shocking and in preserving the fodder from injury by rain. When fed to cattle and sheep they ate it with more relish than they manifested for any of the other non-saccharine sorghums.

Dhourra (Andropogon sorghum, Brot.) is of at least four varieties, the brown, the black, the red and the white. Of these, the brown is more commonly grown. It is so named, doubtless, from the color of the seeds when ripe. It grows less rapidly than Milo maize. At the Minnesota university experiment station in 1897 , the plants grew from six to eight feet in hight. The large and long leaves are not numerous. The seed heads are thick and heavy and oval shaperl. They hang on a stem, which, though erect at first, assumes a shape resembling the neck of a goose as the maturing process goes on. It is a rather slow grower and matures seed about the same time as Kaffir corn.

Jerusalem corn (Andropogon sorghum, Brot.) bears some resemblance to dhourra in appearance 


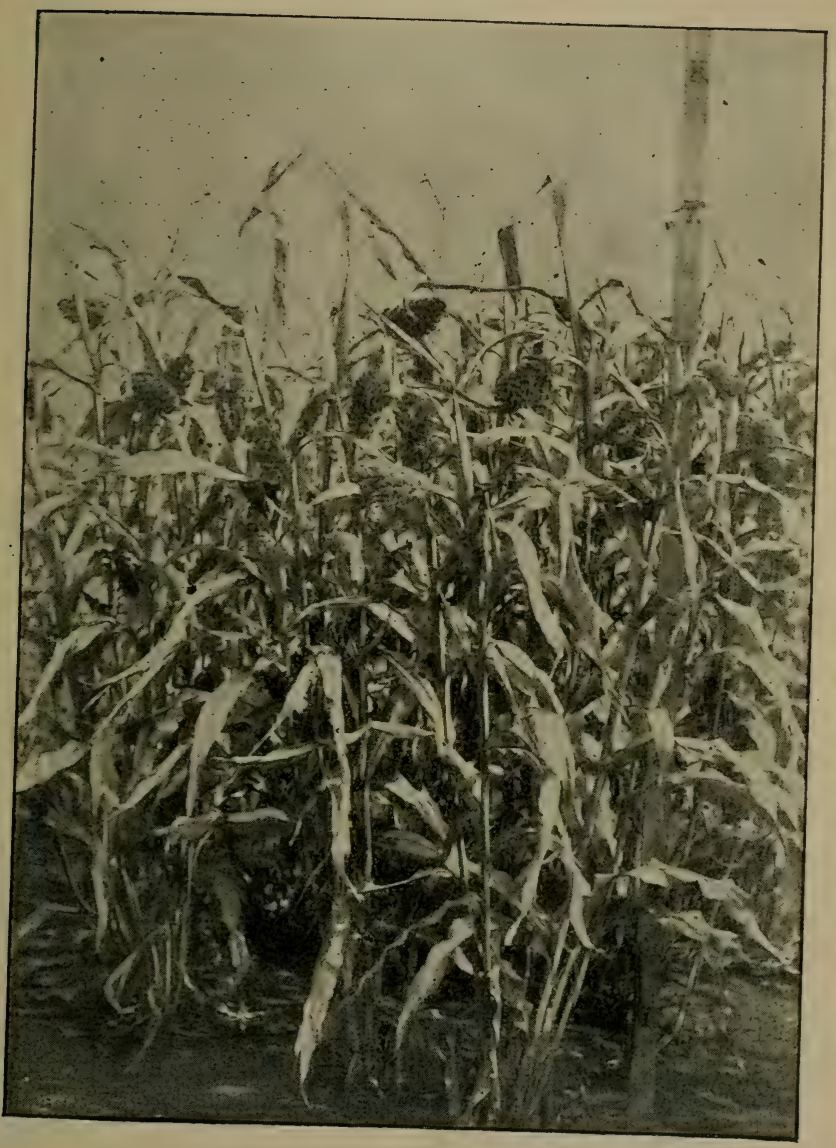

Fig. 7. Yellow Milo Maize

Minnesota University Experiment Farm. 
and also in its habits of growth. It is even stronger in the stem than dhourra and has still less of forage. The seed heads are large, and like those of dhourra, hang on hook-shaped stems. At the Minnesota university experiment station in 1897 the plants grew to the hight of about five feet. Like those of dhourra they grew more slowly than Milo maize or Early Amber sorghum. Jerusalem corm should be grown rather for the seed than for the fodder. It is not probable that either dhourra or Jerusalem corn will be extensively grown for soiling food where Milo maize and sorghum can be grown.

Teosinte (Reana luxurians) is distinguished from the non-saccharine sorghums in the less erect character of the growth, in the extent to which the plants sucker, in the greater fineness and abundance of the long and slender leaves, and in the manner in which the seed is produced. The seed grows on small ears and the ears grow numerously around every top joint of the seed stem. They are enclosed in a husk. There is probably no fodder plant that tillers so much as teosinte. As many as sixty suckers have been produced by a single plant. In the experiments conducted at the Minnesota university experiment station in 1898 , it was found that when planted in rows three feet apart and thinned to fifteen inches in the row, each plant produced from five to twenty-five stalks. Those thinned to from two to three inches in the row produced from two to twelve stalks. The latter were also much more upright in their growth. Seed heads were not even formed on any of the plants. Teosinte would make an excellent pasture and soiling plant for the south 


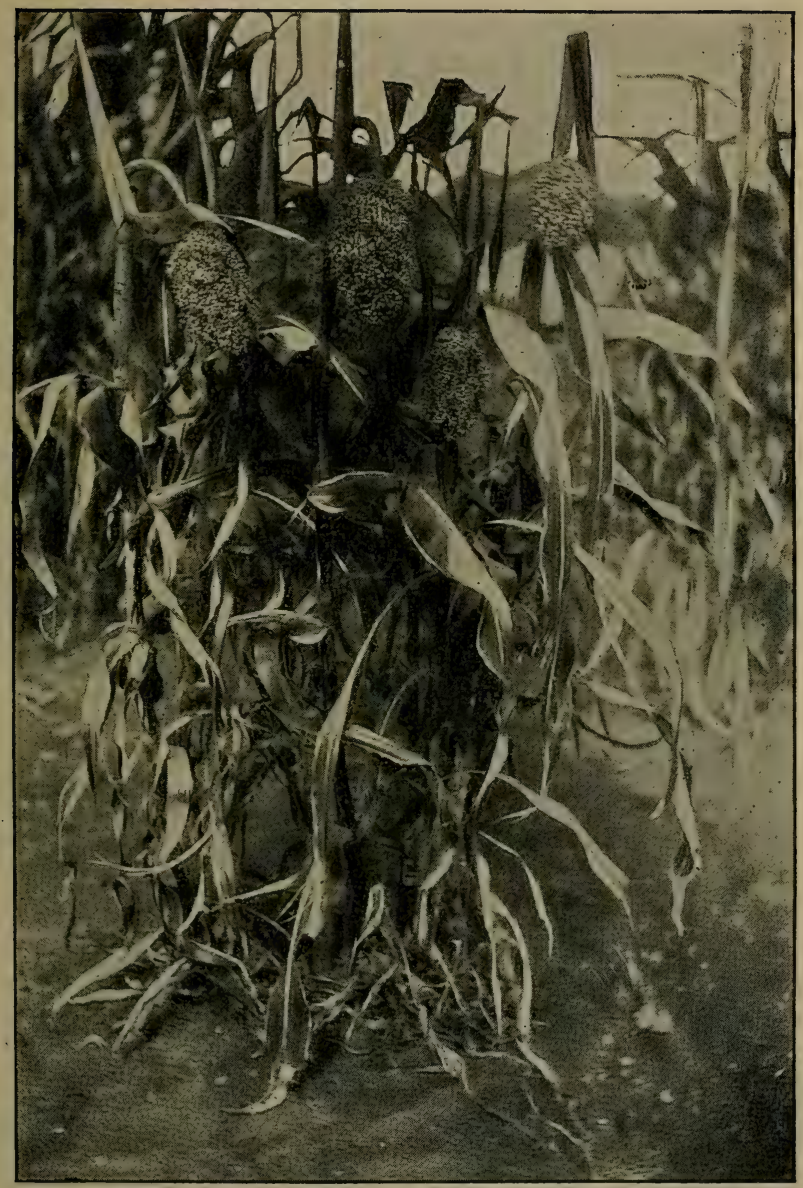

Fig. 8. Brown Dhourra

(57) Minnesota University Experiment Farm. 
but for the low palatability which it possesses. It is thought a greater weight of food can be obtained from this plant than from any of the sorghums or millets that have been tried in the United States.

These plants can all be made to furnish pasture, soiling food, hay and fodder for winter feeding, and when the season is long enough to mature seed, they can all be made to furnish large yields of grain. It is yet premature to say much about the precise relative adaptation of these plants for feeding uses. It would probably be correct, however, to state that Milo maize and teosinte are the most promising pasture and soiling plants, that Kaffir corn is the most promising fodder plant, especially for dry areas, and that dhourra and Jerusalem corn are the largest producers of seed. The seeds of all the nonsaccharine sorghums are excellent for all kinds of farm animals, but unless when given to fowls they ought to be ground befor being fed.

The yields of fodder will of course vary greatly with the variations in soils and in the length of the seasons. They will run from a few to many tons. The largest yields of soiling food are obtained from teosinte and Milo maize.

Distribution.-The non-saccharine sorghums are without exception less hardy than the common varieties of corn. Nor are they so hardy as sorghum is, at least in some of its varieties. It follows therefore, that these plants are not likely to succeed far northward. Only in the Mississippi basin and in the Rocky mountain valleys, with their hot midsummer temperatures, are they likely to succeed in the near future north of the fortieth parallel of north 


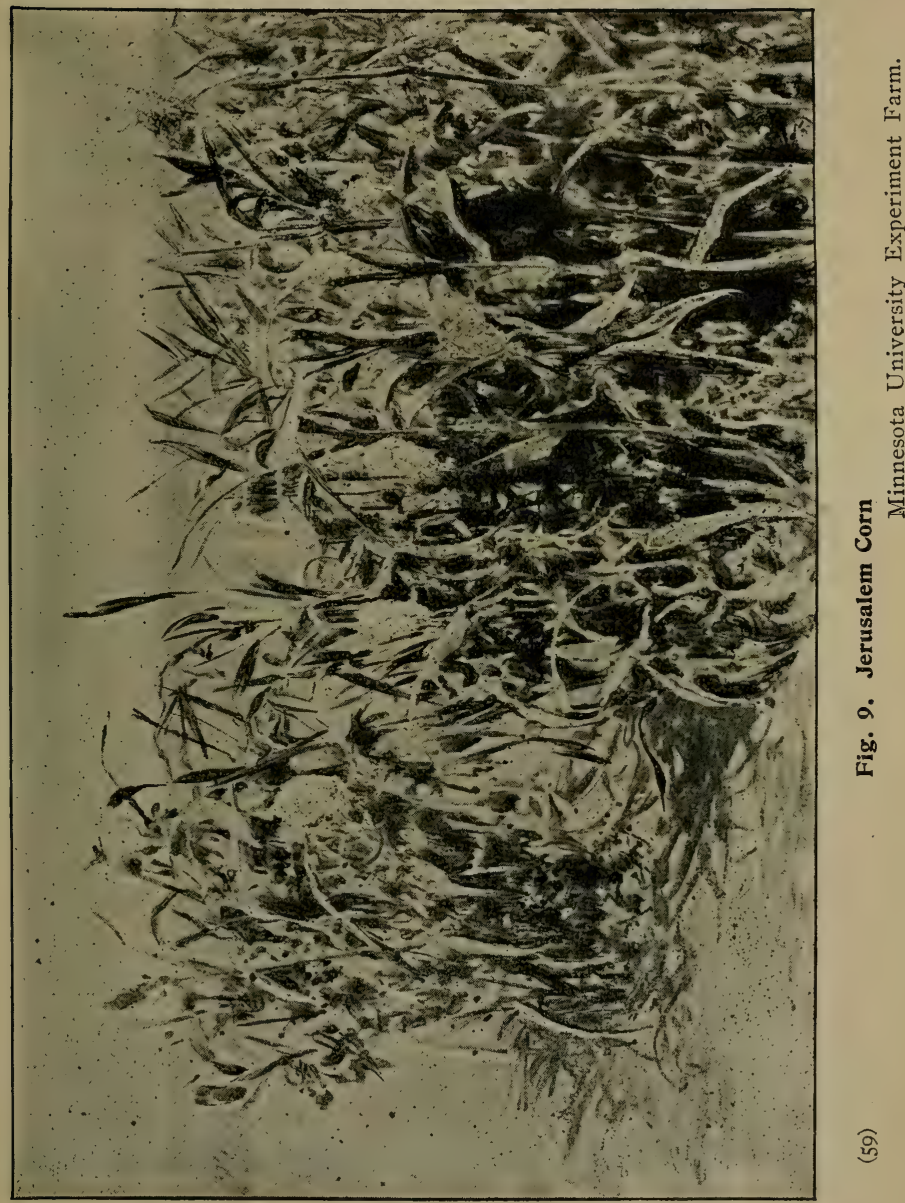


latitude, that is to say, north of the parallel which runs through Springfield, I11.; and even in the Mississippi basin they can be grown with greater success south of that line rather than north of the same. In the trials made with the nonsaccharine sorghums at the Minnesota university experiment farm, all the varieties tested prociuced an abundant growth of green food, as will be evident from what has previously been said in regard to them, but only in a few instances did any of the varieties mature seed. These plants are also more tender than corn and sorghum in the early stages of their growth, and with the exception of Milo maize they would seem to be less palatable than corn and sorghum. In view of these facts, it is only in localities not well adapted to the growth of corn and sorghum that the non-saccharine sorghums are likely to supersede them. It is not probable, therefore, that they will supersede corn and sorghum north from the fortieth parallel of latitude, at least not in the near future. Of course it is impossible to say how much further to the north the line of successful growth may be pushed when these plants become better acclimatized.

The greater power which the non-saccharine sorghums have to grow under conditions too dry for the successful growth of corn, furnishes a sufficient reason for growing them under such conditions. A second reason is found in the greater yields of grain which they furnish in many localities in the south. A third reason arises from the power which they have to grow again when cut. This property, in conjunction with the abundance of the food which 
they produce, gives them a high place as soiling foods or even as pasture plants where they can be successfully grown.

The highest adaptation for the non-saccharine sorghums is found at present west from the Mississippi river and south from Nebraska, with Kansas, Arkansas and Oklahoma as its center. But both east and west from these states they can be grown profitably over considerable areas. Teosinte has higher adaptation to the states which mark the southern boundary of the Republic, but it may be grown successfully as soiling food in the states immediately north of these.

Soil.-All the non-saccharine sorghums would seem to have greater power than corn to gather plant food in a dry soil. They are therefore relatively better adapted than corn to a sandy soil. But it would not be correct to say that they have greater power to grow in a sandy soil than in a sandy loam, nor in a dry climate than in one possessed of considerable moisture. They would seem also to have greater power than corn to gather food in soils low in humus, and yet where humus is present in considerable quantities they grow more vigorously than where it is present only in meager supply. All these plants gather much of their food in the subsoil, hence the nature of the subsoil has an influence on their growth not very much less than the surface soil. Subsoils, therefore, that contain a layer of hardpan which is near the surface are quite unsuited to the growth of these plants.

The most suitable soils are those sandy in texture, possessed of a considerable supply of humus 
and underlaid with clay that is open in character rather than retentive. But some of the non-saccharine sorghums will produce fairly good crops when both the soil and subsoil are sandy. Notably is this true of Kaffir corn. The sandy soils of the Rocky mountain valleys have high adaptation for the nonsaccharine sorghums, and the same is true of much of the land in the southern and southwestern states.

Place in the Rotation.-The non-saccharine sorghums consume considerable quantities of nitrogen while making their growth, hence the aim should be to grow them after nitrogen-gathering crops. Since they will grow better on soils possessed of a fair quantity of humus, the effort should be made to grow them as far as can be done where green manures have been buried, and within a reasonably recent period. They can therefore with much propriety be made to come after crimson clover, the cowpea, the soy bean, the common vetch, the sand vetch and the velvet bean, even though these crops should be harvested. They should also be grown after such crops as winter rye or rape plowed under, and on overturned sod when the conditions may admit of so doing. But they may of course be siven almost any place in the rotation when a due regard is had to the fertility of the soil.

Cultivation is also usually given to these crops during the growing period, hence they may be classed as cleaning crops. This means that they cught to be followed by grain crops where these can be successfully grown, and grass seeds should be sown on the grain crops. But in some sections 
where these crops can be successfully grown, the conditions are too dry to admit of the successful growth of the grasses that are ordinarily cultivated. In such locations some winter crop could be made to follow these crops, since the ground is in excellent condition to receive it, and this could be done with but little additional preparation of the land by way of tillage. These crops include winter rye, the winter vetch, the sand vetch, crimson clover, and in some localities, alfalfa.

Preparing the Soil.-The preparation of the land for these crops is much the same as for corn. The aim should be to secure a free, firm and moist seed bed in sections low in the amount of the rainfall. This can best be secured by plowing the land as long as possible previous to the planting of the seed, and by harrowing the surface of the land thus plowed at intervals of more or less duration. This method of managing land will also be very helpful in removing weeds from the uppermost section of the soil. These crops are planted later than corn and even later than sorghum, hence the season is more prolonged during which such treatment can be given to the land. Sometimes in areas much deficient in moisture the plan termed "listing" is adopted in growing some of these crops, as in growing corn. When this method of planting is followed, the soil is not first plowed. Furrows are turned both ways from the line where the seed is to be planted. The work is done by using a double-mold-board plow, which also loosens the soil for some distance below the line of the furrow. In the soil thus loosened the seed is planted. The object sought is to enable 
the plants to gather moisture under circumstances more favorable than would result from ordinary cultivation.

When rainfall is usually abundant, the aim should be to secure friability rather than impaction in the surface soil, hence it would have to be more deeply stirred during the preparatory cleaning process. But when these crops come after a winter crop pastured off or plowed under, there is not much time for thus attempting to clean the land.

The fertilizers suitable for non-saccharine sorghums are practically the same as those suitable for sorghum. When, however, farmyard manure is applied under very dry climatic conditions, it must not be applied in large quantities lest the too rapid escape of moisture near the surface of the soil should be promoted.

Sorwing the Seed.-The method adopted in sowing the seed of these crops will vary somewhat with the kind of crop, with the percentage of moisture present in the soil, with the percentage in the same that may be expected in the growing season, and with the precise object sought in growing the different varieties. The more branching, for instance, the habit of growth in the plants, the more distant from one another do they require to be grown. The less the degree of moisture the more distant also should they be from one another. If fineness of leaf and stem are sought, the plants may. under some conditions be sown broadcast or with the grain drill on what may be termed the broadcast plan. But when a more vigorous and 
luxurious growth is sought, then the seed should be planted in rows and cultivated. The latter system will be more commonly adopted where moisture is deficient.

When sown on the broadcast plan, the aim should be to plant with the ordinary grain drill all the tubes being in use, or only every alternate tube, as may be desired. When sown in rows far enough apart to admit of cultivation being given, the same implement may be used, but of course various other seed planters may also be used. The rows should be from thirty to, say, forty-two inches distant, according to circumstances, except in the case of teosinte, which should, at least when grown for certain uses, have a greater distance between the rows. But the most suitable distance for placing the rows when growing these crops can only be determined with precision in each locality by actual experience in growing them.

The time for planting will depend on the location and the character of the weather. It would be a mistake, however, to plant the seeds before the weather had become steadily warm. The plants are less able when young to endure cold than corn in nearly all its varieties, and than sorghum in its leading varieties. At the Minnesota university experiment station low temperatures prevailed during two or three weeks subsequent to the planting of these crops in 1897 . Corn in some of its varieties made a fairly good start notwithstanding, and the Early Amber variety of sorghum maintained its hold upon the soil. The non-saccharine sorghums without exception only partially germinated, although 
the conditions were precisely the same. It was necessary to plant the non-saccharine sorghums a second time.

The amount of seed required will vary with the climatic and soil conditions and with the character of the produce sought. The more favorable the attendant conditions, the greater should be the amount of seed sown when growth fine in character is sought, and since the plants of some of these sorghums produce more stalks and foliage than others, it is not necessary with the former to plant so much seed. Notably is this true of teosinte, and in a less degree of Milo maize. When planted in rows where cultivation is to be given other than harrowing, a few pounds of seed will suffice for an acre. But when these crops are sown broadcast, from about one-half bushel to one and one-half bushels of seed per acre are used.

Cultivation.-When the non-saccharine sorghums are planted with any kind of drill or planter, they may be harrowed without hazard to the plants just as they begin to push up through the ground, providing the harrow is light, and that when in use a backward slant is given to the teeth. Later, on certain soils, as those quite loose in character, such as the humus soils of the prairie, scme form of weeder may be used in many instances, more especially when the plants are in rows distant from one another. When thus planted, further cultivation should be given with more or less frequency. It should be sufficient to destroy weeds and to retain moisture in the soil to the greatest extent practicable. Where moisture is usually more or less wanting, the 
crops should in all instances be so planted that they may be cultivated.

Feeding.-The non-saccharine sorghums and also teosinte can be cut for soiling food from one to several times in one season. More particularly is this true of Milo maize and teosinte. The same mode of cutting, carting and feeding may be adopted as in handling sorghum (see Page 47). The cutting may begin at any time after sufficient growth has been made to justify the same, and the residue of the crop not wanted for green food may be allowed to mature. When sufficiently matured, it can be harvested and fed in winter. The ration is improved by feeding these crops in conjunction with one of the legumes, as, for instance, alfalfa, vetches, cowpeas or soy beans. In many instances it would be possible to feed them thus, since one or more of the legumes named can be successfully grown under conditions suitable for the successful growth of the non-saccharine sorghums. 


\section{CHAPTER V.}

PLANTS OF THE CLOVER FAMILY.

Many kinds of clover are now being grown in this country. Some of these are indigenous, but those possessed of highest economic value have been introduced from Europe. While each kind has a mission of usefulness in some section or sections of the continent, only a few are suitable in any marked degree for being grown as soiling food. The chief of these are the common or medium red, the mammoth, alsike, crimson and alfalfa. As the methods of growing the first four varieties are in many respects very similar, they will be considered together. Alfalfa will be discussed by itself, since it differs considerably from the other clovers mentioned in habits of growth, and for this reason requires different management.

MEDIUM, MAMMOTH, ALSIKE AND CRIMSON CLOVER.

Medium red clover (Trifolium pratense) is biennial and perennial in its habit of growth, according to the climatic and other conditions under which it is grown. It differs from the other three kinds in the continuity of its growth throughout all or nearly all of the growing season. Because of this peculiarity it usually produces two cuttings of soiling 
food or hay in one season, whereas, the others only produce one.

Mammoth clover (Trifolium medium) is also biennial and perennial in its habit of growth. It differs from the other clovers in the stronger character of the top and root growth which characterizes it. The food which it produces is in consequence coarser in character, unless when the plants are grown very thickly. It is better adapted than the medium variety to soils that are medium or less than that in fertility. The bloom on both the medium and mammoth varieties is a beautiful red. To the casual observer the only differences apparent in the varieties while they are growing are the larger leaf, stem and head of the mammoth variety.

Alsike clover (Trifolium hybridum) is a perennial plant. The period of its duration is dependent on such conditions as pertain to climate, soil and treatment. All of the clovers under discussion will live longer than they otherwise would if prevented from producing seed. This kind differs from all the others in the greater fineness of the growth and in the beautiful blending of white and red tints in the bloom.

Crimson or Scarlet clover (Trifolium incarnatum) is an annual plant, that is to say, it completes the cycle of its existence within twelve months from the date of sowing the seed, although more commonly it is sown one year and reaped the next. It differs from the other clovers in the shape of the neads, which are oblong and cone-shaped, in the rich scarlet color of the bloom, and in the more hairy character of the stems, a property which 
detracts from its feeding value when grown for hay.

While clover of all the species named furnishes ar excellent soiling food, it is not so commonly grown for such a use, for the reason, first, that the yield per acre is much less than that of many other foods grown for soiling; second, that ordinarily it is so easily cured for hay, and, third, that it is so easily handled when cured. The crimson clover is ready to be cut for soiling food before the spring months have gone, or some weeks before the medium, which in turn is ready in from two to three weeks in advance of the mammoth and alsike. The value of the crimson clover as a soiling food is thus somewhat lessened by the necessity for thus cutting and feeding it when pasture is plentiful and succulent.

Clover furnishes excellent soiling food for horses, cattle, sheep and swine, but when fed to sheep and swine it should be cut at a stage somewhat earlier than when fed to horses and cows, to secure more fineness in the growth. When fed to cattle and sheep it should be somewhat restricted in quantity at first, or else wilted before it is fed, as the unrestrained feeding of fresh cut clover will sometimes cause bloating, which if not speedily relieved may result fatally.

The yield of soiling food from all these kinds of clover varies, of course, with the conditions under which they are grown. It will be approximately correct to place the average yield of the first cutting of medium clover for soiling uses at six tons per acre, and of the second cutting the same season at four tons. But these yields can be increased at 
least 50 per cent by judicious cultivation. The yield from each of the other varieties is somewhat greater than that obtained from the first cutting of the medium clover, but it is likewise somewhat less than that obtained from the two cutlings of the latter.

Distribution.-The clover zone in the United States and Canada covers the entire portion of the arable land. But there are stretches of country, nevertheless, in which clover of any of the species heretofore introduced has not been grown with any marked success. One of these stretches lies east of the Rocky mountains in what is usually spoken of as the semi-arid belt. In this area it perishes from want of moisture. Another stretch lies to the north of Minnesota and North Dakota, where the low winter temperatures forbid the successful growth of clover. In some limited areas of these stretches, some kinds of clover can be grown, but it cannot be said of the same that they have high adaptation for growing clover, nor can any of the clovers now under discussion be grown with marked success in the southern states, unless it be the crimson. The stummer heat is not favorable to its development.

The distribution of the medium, mammoth and alsike species of clover is about the same, but the alsike can be grown somewhat farther north than the medium or the mammoth. Above the 5oth parallel these clovers are not a success, nor are they a marked success below the 38 th parallel, unless in very limited areas. In much of the country between these parallels they can be grown with more or less success, save in the semi-arid country beside the Rocky 
mountains and east of them, and in the cold country lying north and south from the eastern half of the St. Lawrence river. The highest adaptation for these clovers is found south of the 5oth parallel and beside the Pacific, including also the Rocky mountain valleys when supplied with moisture. Next in adaptation comes what was originally the forest country, including certain prairie lands, which. although not originally covered with timber, will produce it readily. This belt lies between the upper Mississippi and the New England states. The New England states and the Maritime provinces of Canada will grow clover, but not with that luxuriance which characterizes its growth in the other areas named. The greatest clover-growing states on the continent include Michigan, Wisconsin. eastern Minnesota, Iowa, northern Missouri. Illinois, Indiana, Ohio, and parts of Montana and Washington. It also grows with superlative. luxuriance in southern Ontario.

Crimson clover thrives best in a climate somewhat warmer than is suitable for the other kinds. The highest adaptation for this plant is probably found in the Atlantic and Gulf states, southward from New York city. It is not usually grown with much success north of the latitude of Columbus, O., that is to say, north of the 4oth parallel. But for a short distance north of that line it may be grown in good form along the Atlantic coast and for a much greater distance north of the same latitude along the Pacific coast. Unless well protected, crimson clover cannot withstand low temperatures. When the medium, mammoth and alsike clover grow at their 
best, crimson clover can seldom, or never, be grown with equal success.

Soils.-All the species of clover under discussion will grow better in soils having in them a very decided clay element. When sufficiently supplied with moisture, these clovers will even grow vigorouisly in clays of the stiffest texture. They grow better in clay loams than in sandy loams, but in fertile sands, such as abound in many of the Rocky mountain valleys, they will make a wonderful growth when plentifully supplied with water. The volcanic origin of many of these soils, however, may account for their wonderful adaptation to the production of clover. The humus soils of the prairie will produce clover abundantly when there is in them enough clay to make them measurably dense, but when this element is so far lacking as to allow them to lift with the winds, they do not possess highest adaptation for clover. In fact, it cannot be successfully grown upon these, unless in exceptional instances, until the land becomes impacted by cultivation more or less prolonged. Soil adaptation in the medium red and mammoth red clovers is about the same. Ordinarily they grow in what may be termed deep, moist, friable clays, underlaid with a subsoil of clay of medium density. They grow least well on soils impregnated with alkali and on infertile sands, more especially when these are ill supplied with moisture.

Those soils usually spoken of as swamp lands have special adaptation for the growth of alsike clover when they rest on a clay subsoil, and when the water table has been sufficiently lowered in them 
by some form of drainage. But alsike clover will also grow well in some of those lands which have highest adaptation for the medium, red and mammoth sorts, more especially those of them that are strongly spiced with clay. The ordinary upland prairie does not seem well suited to the production of alsike clover, more especially when this soil is lacking in moisture. While crimson clover will flourish on soils well adapted to the growth of the other red clovers, it would seem to have more adaptation for sancly soils than these. Much of the soil in the chief centers for growing crimson clover is sandy in texture. This greater adaptation arises probably in part from the great power the plants have to gather food, and in part from the moist character of the climate in crimson clover centers during those portions of the year in which the crop is produced.

Place in the Rotation.-As clover is a soil renovator, the aim should be, first, to grow it on land in which it is specially desirable to increase the supply of nitrogen; second, on land where it is to be followed by a crop that requires an abundant supply of nitrogen in the soil to enable it to produce abundantly. It should also be sown on land that is at least measurably clean, as an abundant growth of weeds in the crop will not only lessen the yield, but will impair its feeding value in proportion as they are present. There is special fitness, therefore, in laying down to clover, land that has produced a crop to which clean cultivation was given, as, for instance, a crop of corn, potatoes or field roots. And the reasons are equally good for following the clover crop with wheat, oats or barley, corn or potatoes. 
In some sections it is common to grow medium red clover, corn or potatoes and small grain in a three years' rotation. When the conditions are suitable the plan is an admirable one. But few methods of crop production will compare with it in the easy maintenance of soil fertility and in the profits that grow out of the system. The other leading kinds of clover, however, are not so well adapted as the medium for such a rotation. The mammoth does not produce a second growth, for being plowed under, as does the common red. The alsike is perennial in its habit of growth, and the crimson is better adapted to another form of rotation, as will be shown below.

The medium and mammoth clovers may, nevertheless, be made to fit into any kind of a rotation. The aim should be to grow them at short rather than at long intervals in the rotation, and for several reasons. First, as previously intimated, they have great power to enrich the land by depositing in it nitrogen drawn from the air; second, they have much power to gather supplies of phosphoric acid and potash in the subsoil, much of which is deposited again in the cultivable strata; third, they improve the mechanical condition of the land by the abundance of the vegetable deposit contained in the roots, and, fourth, the humus thus supplied greatly increases the power of the land to hold moisture, whether it comes from above or below. There is probably no other plant grown that is capable of exercising so beneficent an influence on farming.

The place for crimson clover is, properly speaking, that of a catch crop. It is usually grown as the antecedent of or the consequent to some other crop 
grown the same season. And this is true of it whether it is grown for pasture, for soiling food, for hay or for green manure. It may with much propriety be preceded by such quick-growing early summer crops as vegetables and certain of the early maturing cereals, and followed by such crops as potatoes, corn or any of the sorghums, and on soils low in fertility by cowpeas or soy beans.

Preparing the Soil.-In preparing the soil for clover seed in any of its varieties, the aim should be to secure a seed bed fine, firm, deep, moist and clean. It should be fine that the clover seeds may be more perfectly hidden from the light, and that the tender, tiny rootlets may easily ramify the soil in search of food. It should be firm to prevent evaporation, too rapid from the surface. It should be deep to allow the tap roots to go down readily. But in light sands, or spongy loam soils of the prairie, shallow cultivation would be preferable unless done a good while previously to the sowing of the seed because of the difficulty of sufficiently firming such soils. It should be moist to promote quick germination and rapid growth. It should be clean to secure an abundant growth in the clover and to produce a good quality of food.

The first of these conditions may be more readily secured when the soil is plowed in the autumn, and such plowing is also favorable to securing all the conditions named. Deep plowing can be done much more advantageously in the fall than in the spring, where fall plowing is in order. But in climates with much rainfall in winter, autumn plowing may be less judicious than spring plowing, 
especially where the soil contains much clay. The winter rains cause it to "run together" in a way that increases the labor of subsequent cultivation, and that further imperils the abundant and vigorous growth of the plants. Some soils are so friable that they call for but little pulverization; other soils, as clays, are oftentimes cloddy on the surface. It is especially important that these shall be made fine by the repeated use of the roller and harrow. Firmness in the seed bed may be secured by plowing the land a considerable time previous to the sowing of the seed, or by using the roller freely on it. Autumn plowed lands always furnish a seed bed more firm than those that are spring plowed, a fact of much significance in cultivating the soils of the northwestern prairies. When firming some classes of these soils, by running a heavy roller over them, it may be necessary to follow the roller with a light harrow to prevent them being more or less carried away by the wind. Deep cultivation is secured, of course, by simply plowing more deeply, and in some instances by subsoiling.

In some sections of the prairie the growth of clover is greatly promoted by plowing so deeply that some of the firmer subsoil shall be brought to the surface. But with nearly all classes of soils, if much of the subsoil were brought to the surface at one time the influence on plant growth at the first would be harmful, because of the unameliorated condition of such subsoils. The management that secures a fine tilth and a firm seed bed will also tend to increase the moisture in the land. When the clover seed is sown early in the spring, a clean seed bed can only be secured by cultivation given the previous season, 
but when sowing the seed is deferred until late in the spring or until summer, the seed bed may be made clean near the surface by the frequent use of the harrow between the opening of spring and the sowing of the seed.

When growing clover for soiling, it is very important that heavy yields shall be obtained, since a heavy crop is so much easier to gather than a light one. The former may easily be lifted, and with sufficient cleanness, without using a rake; whereas, the latter would require to be raked, thus adding very much to the labor of gathering the crop, and to the area of land required to grow it. One great advantage from growing soiling crops, viz., that of intensive production, would thus be defeated. It is always expedient, therefore, to make land quite rich that is to grow clover for soiling, when it is not so already, by the addition of fertilizers. Of these, farmyard manure is certainly one of the best; and when applied it will of course feed the nurse crop as well as the clover. The kind or kinds of commercial fertilizer or fertilizers that may be employed with most advantage will depend upon the needs of the land. Nitrogen, phosphoric acid and potash are most frequently needed, but in quantities that vary according to conditions, and in many instances lime acts very beneficially. On some soils the growing of the clover is greatly stimulated by sowing on the young plants when the period of growth is beginning or has already begun, an application of gypsum, usually not less than roo pounds per acre and not more than 300 pounds. In other instances, marked benefit results from sowing wood ashes, 
leached or unleached, on the crop previous to the season of active growth. The application of leached ashes should be about four times as heavy as that of unleached ashes, that is to say, it may run from about 200 bushels per acre upward.

Sowing the Seed.-Clover seed may be sown by hand, by using a hand seed sower, or by the grain drill with, and, in some instances, without an attachment for sowing grass seeds. Which of these methods should be adopted will depend on various conditions, such as relate to soils and soil properties and to the machinery that is available. When the seed is sown by hand, the aim should be to sow with two hands rather than with one, and to distribute the seeds quite evenly. The seed can be carried in a seed box or sack suspended at a suitable hight against the breast of the sower and kept in place by the use of shoulder straps. Much care should be taken to choose a still time for hand sowing the seed, as, for instance, the early morning, and also a condition of soil that hinders its undue adherence to the feet of the sower.

That form of hand seeder which is wheeled on the land on a hand barrow frame distributes the seed more evenly than would be possible in sowing by the method just described, and it can be sown when the winds are blowing at a rate that would forbid scattering the seed by hand at such a time. When the seed can be sown with the grain drill, the saving in labor is very considerable and the work is also done in excellent form. When it is desired to bury the seed deeply, as on spongy prairie soils, it may be thus planted by mixing the clover seed along with 
the grain. When a less covering is sought, as in sowing under average conditions, the seed is allowed to fall in front of the drill tubes, and when a still lighter covering is desired, as when the seed falls on heavy soils, it is covered by using a roller on the land after the seed has thus been dropped upon its surface. And in yet other instances, as when the soil is quite heavy and ample moisture is assured, the seed thus deposited is frequently allowed to lie unburied. But when a light covering can be secured for clover seed, the germination of the seed is more certain and the ability of the young plants to withstand dry weather is increased.

The quantity of seed required will vary with the variety sown, with the richness of the soil, and with the proportion of seed of other grass plants that may be sown along with the clover. When clover is sown alone, from ten to fifteen pounds per acre of the crimson clover are usually sown, but sometimes a less quantity, from ten to twelve pounds of the medium red and mammoth species and from four to six pounds of the alsike. The difference in relative quantities sown arises chiefly from the difference in the relative size of the seeds and the difference in the capacity of the plants for stooling. The richer the soil also the less the quantity of the seed required, and the amount of clover that ought to be sown will of course be reduced as grass seeds are added to the seed sown.

Since clover, when it grows vigorously, is liable to lie down when sown alone, it is considered advantageous to sow along with it the seed of some grass, that the grass plants thus produced may sustain the 
clover. Timothy is more commonly grown thus than any other grass, because of its very general adaptation, but in some localities tall oat grass may better serve the end sought, since it is about as early as clover in its habit of growth. As timothy matures about the same time as the alsike and mammoth clovers, it is more suitable for being sown along with these than with the medium sort. But it should not be sown with the expectation that it will furnish a support to crimson clover, because of the much more rapid growth of the clover. For every pound of the seed that is added to the mixture sown, the clover seed should be reduced in the same proportion, and sometimes the reduction in the clover should be greater relatively. But it is seldom necessary to have the timothy seed form more than onethird of the quantity of seed sown.

The period for sowing clover may be made to cover all the spring months, and in some instances the early summer months, but the medium, mammoth and alsike clovers are more commonly sown in early spring. They should seldom be sown in autumn, as the young plants cannot endure the cold of the winter following. But to this there may be some exceptions. In some instances the seed is sown while the old snow yet lingers, but when thus sown some of the seed is liable to be carried away with the vanishing snows, when the melting of the latter is hastened by warm rains. At other times it is sown when the ground is honeycombed by spring frosts. The seed is thus covered by the action of frost and sun. In other instances it is sown on a light fall of snow, usually spoken of as "sugar 
snow." When the latter melts it frequently carries much of the seed down into the soil. Clover seed is seldom if ever sown thus early, except with a nurse crop of winter wheat or rye. Usually it would be a safer way to defer sowing the seed until the surface of the soil has so dried that when the seed is sown it may be covered with the harrow. The harrowing if properly done is beneficial to the nurse crop as well as the clover seed. But in some instances the harrow cannot be used, as in clay soils, which remain unduly moist in the spring.

When clover seed is sown with a nurse crop of spring grain, as, for instance, barley, wheat or oats, it should be covered more or less deeply; the later the period of sowing the more imperative is it that the seed should be so covered. Where moisture is usually sufficiently plentiful, the plan of sowing clover seed with a nurse crop is commendable. But all nurse crops are not equally favorable to the growth of the clover. Those which are most favorable include barley and winter rye; those which are least favorable include such crops as oats and millet. But when clover is sown with a nurse crop and the weather turns dry, if the nurse crop can be pastured off, or cut at some stage previous to that of maturity, the hazard to the young clover plants will be so far lessened, as they are then deprived to a smaller extent of the strengthening influences of sunlight and moisture. On the soils of the prairie, so light that they are springy to the tread, a good stand of clover may frequently be obtained by sowing it with a crop that is to be pastured, as, for instance, a crop of mixed cereals or rape. The treading of the live 
stock would seem to react beneficially to the young clover plants by impacting the soil near the surface and thus lessening the loss of moisture through surface evaporation. Sheep are considered more suitable for such pasturing than cattle or swine.

But there may be instances when a stand of clover can best be secured by sowing it alone, as when the normal supply of moisture is low. When thus sown, the soil should be made as clean as possible before sowing the seed. It may not be possible thus to clean the land when the seed is sown early, but it may be cleaned, at least measurably well, by surface cultivation, when the seed is deposited late in the season. When sown on weed infested land, the weeds should be kept down with the mowing machine.

Crimson clover is not usually sown earlier than July, and it is not considered wise to sow it later than September, unless in the mildest portions of the south. Near the northern limit of production it is thought more or less hazardous to sow later than August. If the plants enter the winter in a weak condition, the danger is imminent that they will perish before spring. When preparing the land, it is sometimes thought preferable to seek fine surface cultivation without plowing the land. rather than the deep cultivation which plowing secures. In some instances, as on clean land, from which early vegetables have been harvested, the seed may be at once sown and covered with the harrow. In other instances it is sown in the standing corn and covered lightly with the last cultivation given to the corn crop. There may be instances when it would 
be proper to sow it amid grain stubbles and to cover it with the harrow. It is manifest that the methods of sowing this crop are various. To so great an extent is this true that it would not be prudent to try to give directions that would precisely meet the needs of each locality.

Cultivation.-Clover does not require any cultivation in the sense in which drilled corn and sorghum call for the same. But it is important that it shall not be grazed too closely the first season, lest its power to withstand winter weather shall be unduly weakened. In a large majority of instances it should not be pastured or mowed the first year when it. has been sown with a nurse crop. But in some seasons it may grow so rank that by its own weight it would smother underneath the snow, unless pastured more or less. In some localities quite favorable to the growth of clover, it will produce seed the first year unless means are taken to prevent it from doing so. To allow the plants to produce seed the first year will materially tend to weaken their growth the second year. To prevent such a result, such clover should be cut by the mower set high and when it is coming into bloom. The plants cut off should be allowed to lie where they fell. They will act as a mulch to protect the crop. But when clover is sown early and not along with a nurse crop, there may be instances, not a few, when it would be advisable to cut it for hay or green food.

Feeding.-The harvesting of green clover for soiling in all its varieties may begin as soon as the first heads appear, but more food will be secured if the cutting is deferred until the crimson tint on the 
heads is pronounced. The cutting and feeding of the crop as green food may be continued as long as the plants are eaten with a relish by live stock. When ready for being made into hay, it is common not to feed it longer as green food. This stage will be reached by the time that the crop is in complete bloom. It is manifest, therefore, that the period for using clover as soiling food is a short one, not longer usually than from two to three weeks, and if a plat or field of alsike, or mammoth clover has also been sown in addition to the medium red clover, it will prolong the feeding for about an equal period. The two crops, therefore, will provide green food for five or six weeks in succession. The medium red clover will also furnish a second cutting of soiling food which will be available in about six or seven weeks subsequent to the first cutting, when grown under normal conditions. The period of cutting will vary from about June Ist to July Ist north of the 4oth parallel.

The green food is cut daily, or every other day, as may be desired, by using the scythe or field mower, and is fed in pastures, paddlocks or from feed racks in the yards, as may be thought most advisable. In large quantities it is of course drawn on a truck or wagon. When cut with the mower it should not lie many hours in very briglit weather without being "bunched," as it will soon lose so much moisture that its succulence will be too much lessened. A little wilting tends to obviate the danger from bloating in the animals to which it is fed. This danger with cattle and sheep is always imminent in some degree when green clover is fed in a very succulent condi- 
tion and unstinted in quality, when the animals are hungry. And the danger is further increased by dampness caused by rain or dew.

\section{ALFALFA.}

Alfalfa (Medicago sativa), sometimes called lucern, has a higher adaptation for soiling than any other plant of the clover family. This arises, first, from the rapid and prolonged character of its growth; second, from its long-lived character; and, third, from the excellent quality of the food which it produces. Alfalfa is ready for being cut as green food at least two weeks earlier than medium red clover, and in some instances it will yield a cutting every month thereafter during the season. There are some favored sections in the United States in which, by judicious managment, alfalfa may be cut and fed as green food every month in the year. The duration of alfalfa meadows will depend in a great measure on the conditions of soil and subsoil, more especially the latter, while it will sometimes fail within a few years from the date of sowing; in other instances, it will continue to grow and thrive indefinitely. Alfalfa meadows are now in existence which have been mowed every year for more than forty years. But of course the average duration does not cover nearly so long a period. The excellent quality of the food arises in part from its nitrogenous character and in part from its palatability.

In view of the pre-eminent suitability of this plant for soiling purposes, it seems strange that this fact has not been more generally recognized by 


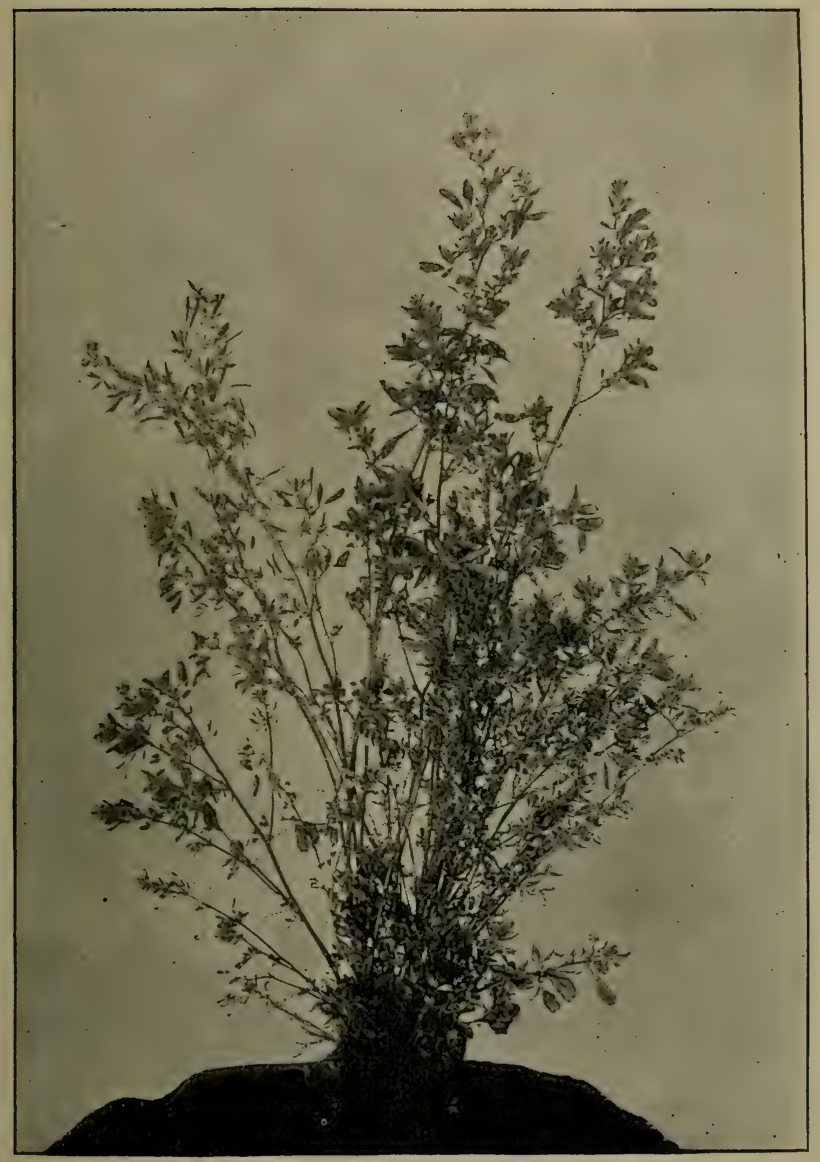

Fig. 10. Alfalfa, Single Plant Minnesota University Experiment Farm. 
farmers. Under favorable conditions it would be easy to obtain abundant supplies of green food from alfalfa from spring until fall at a less cost than it can be obtained from any other source.

Green alfalfa is not only relished by horses, cattle, sheep and swine of all ages, but it is specially adapted to their needs. When fed freely to young animals it promotes a large and vigorous growth. Along with suitable grain adjuncts, it will fatten animals quickly and will give them a fine finish. Lambs can be raised upon this food alone, in addition to the milk furnished by their dams. And with but a limited addition of more carbonaceous food, swine may be raised upon it until ready for the block. Of course during the fattening period, grain must be the chief reliance. But to no class of stockmen is green alfalfa of more benefit than to dairymen. It is excellent for milk production, and the long season during which it is accessible further accentuates its value. Of course, in the green form, it should be fed with some restriction to horses at work, but for all other classes of horses it makes excellent food. It is also helpful when fed to fowls. Other things being equal, meat and milk cannot be produced anywhere more cheaply than in areas possessed of high adaptation for growing alfalfa.

The yields of green food furnished per acre for the season vary with the number and strength of the cuttings to be obtained. There are localities in which alfalfa will grow, and yet the yields obtained are not equal to those which would be obtained from an equal area of red clover. In these it should not be grown. The number of cuttings obtained per 
season in the green form varies from one to seven or eight, but the average may be stated as four, and the yield per cutting may be put at four to six tons per acre. In areas not a few, therefore, from sixteen to twenty-four tons of green alfalfa may be obtained per acre from season to season, and with no other labor after the crop has been established than that of opening the sluices which let in the irrigating waters. Nor are those alfalfa lands likely to become exhausted soon, because of the extent of the subsoil from which they draw food supplies.

Distribution.-But few plants are of wider distribution than alfalfa. While it is not able to endure temperatures so low as some of the real clovers, it will thrive in latitudes too warm and dry to produce these kinds in good form. The growth of alfalfa would seem to be more hedged in by conditions that relate to soil and subsoil than by those which relate to climate. Because of these limitations, alfalfa will yield abundantly in certain areas within a state, and in other areas in close proximity to them it cannot be grown at all. It can probably be successfully grown in portions of each state in the Union. Sa wide is its distribution that it is successfully grown in some portions of Quebec, Ontario and British Columbia in Canada.

But the distinctive alfalfa belt of the United States lies west of the Mississippi and south of the Missouri. It embraces nearly every Rocky mountain valley from Canada to Mexico. It includes areas possessed of subterranean waters, not too distant from the surface, as well as those which it may be necessary to irrigate at certain seasons; also 
certain tillable upland, soils in several states which cannot be subjected to irrigation. The variety knowin as the Turkestan, recently introduced by the Department of Agriculture at Washington, is proving so hardy, that it is now thought it can be successfully grown in areas that are too dry and too cold for the successful growth of the kinds heretofore grown.

While alfalfa will produce well in some rainy climates, it has higher adaptation for those that are dry, up to a certain limit. Drenching rains which literally saturate the ground with water are harmful to it rather than helpful. And in climates where the period of growth is long, this crop is proportionately more helpful than in those where it is short. It is not a little surprising that a soiling crop so useful should not have been grown to a greater extent in the past in the lower Atlantic and Gulf states, since the conditions in certain areas of these are quite favorable. With the greater need that is now being felt for a supply of such foods, the production of alfalfa will doubtless greatly increase in the near future.

Soil.-The soil and subsoil more than anything else are potent factors in determining where alfalfa may and may not be grown. And of these the subsoil is the more important. The reasons will be at once apparent when it is remembered that alfalfa roots grow deeply and that the major portion of the food obtained from the earth by the plants comes from the subsoil rather than from the soil. The soil conditions most favorable to the growth of alfalfa are found in loam soils, inclining to sand or gravel, and spiced with a goodly increment of clay. But alfalfa 
will frequently flourish in clay soils with no slight degree of adhesion in them, providing the subsoil condition's are suitable. The vegetable soils of the western prairies are not usually well adapted to the growth of alfalfa. The volcanic soils of the Rocky mountain region furnish ideal conditions when sufficiently supplied with moisture.

In a subsoil in which alfalfa roots are to grow vigorously, the most important requisite is that it should be easily penetrable. Ideal conditions are sometimes found for starting an alfalfa crop successfully, and yet the plants soon fail because of the impenetrable character of the subsoil. The second great requisite in the subsoil is, it should be deep. The necessary depth will vary, but it should not be less than several feet to provide ample feeding ground for the roots; and a third requisite is that the subsoil should be moist. But at all seasons of the year it should be free from stagnant water to the depth of several feet from the surface. These conditions are best obtained in certain of the almost rainless river valleys of the west. If the soils and subsoils are sandy or gravelly, and underneath them are sheets of water at varying depths, the plants are supplied with moisture from this water through the process of capillary attraction. With similar conditions of soil and subsoil, except that the ground water is absent, the alfalfa plants would perish unless irrigated. This explains why alfalfa cannot be grown in wide areas of the semi-arid country west of the Mississippi, where the soil and subsoil requisites are all that could be desired, but for the absence of the ground waters. 
In the absence of irrigation and also of marked humidity in the climate, what may be termed mild clay subsoils furnish the best subsoil conditions for growing alfalfa. In these it gathers suitable food. These subsoils, oftentimes, possess a sufficiency of moisture through all the season to sustain good crops. Of course, in dry seasons the subsoil moisture may become so reduced as to materially interfere with abundant production. But in climates of average humidity, they are satisfactory for growing this crop.

Place in the Rotation.-Properly speaking, alfalfa can scarcely be said to be a rotation plant, owing to the long period through which it continues to grow. That is one of the objections urged against growing it. But in certain areas favorable to its development, it may be grown for a term of years more or less limited, and then followed by certain other crops for an intervening term of years. As it is one of those plants which gather nitrogen from the air, it is so far a soil renovator. Alfalfa should, therefore, precede some crop which requires much nitrogen to perfect its growth, as, for instance, corn or wheat. Deep-rooted plants may follow alfalfa with much propriety, since they can find ample food in the subsoils even, in which alfalfa roots are moldering, as, for instance, field roots, or rape. And the crop that precedes alfalfa should, if possible, be a cleaning one.

The task of plowing a soil filled brimful of alfalfa roots of strong growth is by no means an easy one. But it may be facilitated by using a plow with a share somewhat serrated in its cutting edge. When the plow is drawn, these serrations will cut 
the roots and so make it possible to turn a straight furrow.

Preparing the Land.-The preparation of the soil that will be the most suitable for alfalfa will depend upon conditions such as relate to variations in soil and to the season for sowing the seed. Speaking in a general way, the seed bed should be deep, moist, clean and of fine tilth. But with upland soils subjected to very dry conditions, stirring the soil to but a little depth, when preparing a seed bed, would be preferable. The firming of the seed bed is peculiarly applicable to the upland soils of the southwestern states, but it will oftentimes be necessary to run a light harrow over the ground, after it has been firmed with a heavy roller, to prevent the wind from lifting the soil and in some instances to prevent the too rapid evaporation of soil moisture. When the seed is sown in the early spring, it is not possible at all times to secure a clean seed bed for the alfalfa, unless it is made to follow a well cultivated crop of the previous season. There may also be instances in which the labor would be wisely expended in summer fallowing the land the previous year. When it is thus fallowed it is important that green crops be sown upon it at the same time and plowed under, that the soil may thus become abundantly supplied with vegetable matter. Such crops as autumn sown rye followed by a quick growing legume are well adapted to such an end.

When the seed is sown late, there is then time to clean the surface soil through the successive harrowings that may be given. Because of the probable duration of the crop when established, and 
because of the recognized tendency in weeds and in some other grasses to increase and thus crowd out the alfalfa, it is very important that the crop be sown upon a clean seed bed.

When alfalfa is sown with a nurse crop, the preparation of the soil that is best suited to the nurse crop is likely also to prove suitable to the alfalfa. But in soils with much adhesion, it may be necessary to further pulverize them before they are in the best condition to receive the seed.

In some instances, it will be better to plow the land in the autumn; in other instances, as where rainy winter climates prevail, plowing ought to be deferred until spring. Sometimes, as in soils that adhere overmuch, deep plowing is preferable and subsoiling may even be very advantageous; at other times, as in tilling soils of the opposite extreme, shallow plowing would be preferable. Usually after crops that have been cultivated, it is only necessary to. finely pulverize the surface soil when preparing it for a seed bed.

In laying down a piece of land to alfalfa, it is very important that at least the surface soil should have in it much available fertility as well as that it should be in fine condition as to tilth, while it is probably true that no plant grown as food for live stock has greater power to gather the elements of support from the soil, the subsoil and the air than alfalfa, it is also true that in the early stages of growth alfalfa readily succumbs to vicissitudes from various sources, as excessive wet or drouth, heat or cold, overshading, or even undershading. The behavior of the plant in after years depends in no 
little degree upon the nature of the start of the first season. If the plants are weak when they enter the winter, they are likely to perish before spring, and if the stand is thin at the first, it is likely to become more so, though in some rich soils it may be improved by adding more seed.

Experience has taught that with this crop also farmyard manure is an exceilent stimulant to growth. On the whole, when this fertilizer is used in the fresh form, it should be applied with the previous crop that it may readily give up to the young plants the unused content of fertility, and that many of the weed seeds in it may be given time to sprout before sowing the seed. When preparing the land for alfalfa it would be a mistake to top-dress the land with farmyard manure, even though much reduced by fermentation, as it will still contain weed seeds that will prove troublesome.

The artificial fertilizers that ought to be applied must be determined by the needs of the land. They include nitrogen, phosphoric acid, potash and lime. The need for applying these is not so great west of the eastern Mississippi watershed as east from that line. The gray ash soils of the farther west are usually abundantly supplied with the requisite food elements. These fertilizers may better be applied before the seed is sown, except the nitrogen, which, in some forms at least, is more helpful when sown on the young plants. Gypsum will benefit young alfalfa plants quite as much as it benefits young red clover. And it may be stated here, that unreduced farmyard manure applied to alkali lands is so far an excellent corrective of their alkalinity. 
Sorving the Secd.-The seed may be sown by hand, with the hand sower, or with the grain drill. Since alfalfa is a somewhat larger seed than red clover it may be covered rather more deeply, particularly on western soils. On some of these it may be sown as wheat, that is to say, by using the ordinary drill tubes used in sowing grain.

On true alfalfa soils, the seed is seldom sown with a nurse crop, but in moist climates this method of obtaining a stand is quite feasible, and in some instances commendable. It is generally deemed preferable to sow the seed without a nurse crop, that the plants may have the full benefit of all the season to enable them to take possession of the soil to the fullest extent possible. Any of the small grains usually sown in the spring will answer for the nurse crop, but of these barley is the best. And there are instances in which winter wheat and winter rye may form the nurse crop. It may frequently be unwise to allow the nurse crop to mature, but the degree of the advancement which it should be allowed to make will depend upon conditions. If a nurse crop is grown it should never be at the expense of the alfalfa crop. And in a large majority of instances it will be wiser to dispense with the nurse crop altogether.

Opinions differ much as to the quantity of seed that should be sown. Amounts named as suitable vary from twelve to thirty pounds per acre. Usually from fifteen to twenty pounds will be found sufficient, the last named quantity being rather more in favor on true alfalfa soils. Twelve pounds per acre may suffice in climates possessed of moist seasons. 
If the plants are sown tor thinly they make coarse hay. Of the two extremes, excessive seed sowing is the least harmful since the tendency is constant for the plants to become thinner.

The seed is usually sown about as early in the spring as the ground is ready to till. But it may be possible to sow the plants so early in the season in certain climates that the newly sprouted plants will succumb to a severe spring frost. But when they do, of course, the seed can again be sown. With alfalfa as with many other plants, better results will probably be obtained by sowing late enough to insure continuous growth. In mild latitudes it may be possible to sow when the late fall rains come, but the hazard to the young plants in the winter following is to be reckoned with.

Cultivation.-Ordinarily no cultivation is given to alfalfa. But in some parts of the continent of Europe where labor is cheap, it is planted in rows, and hand hoed, to give the plants opportunity to develop favorably, but in this country such hand labor would be too costly. It is important that the roots be strong and vigorous when they enter the first winter, as that is usually the greatest period of hazard to the young plants. When grown on upland it is not common to use the crop for food the first season. But it may be necessary and highly advantageous to run the field mower over it once or oftener to prevent the ripening of the weeds that are pretty certain to grow in it. Close cutting would seem to be more beneficial to the young plants than cutting less closely, owing probably to the better adjustment of the relations as to moisture present in the soil and 
the needs of the young plants. Ail the plants that fall before the mower are allowed to remain where they fall. When the crop is grown under irrigation, it is common to utilize one cutting the first year and sometimes two. But the young crops should not be pastured the first year, and on the upland it should not be pastured at all unless at certain seasons of the year. Pasturing in the winter in cold climates is particularly injurious, but in sections where the crop grows at its best, it may be pastured even in the winter, though as previously intimated, frequent and prolonged pasturing is thought to ultimately injure the stand of the plants, even under the most favorable conditions.

Feeding.-Alfalfa is ready for being harvested as soiling food as soon as the blossom buds are formed. It may be cut even earlier than that, more especially when fed to sheep and swine. The feeding should begin as soon as the food is ready, as in suitable weather it rushes very quickly to maturity. But the residue not needed as soiling food may with much propriety be made into hay. With sufficient moisture present, the crop at once begins to grow again, and in from four to six weeks after the cutting of the preceding growth the next crop is ready. Where irrigation is practiced, it is customary to flood the land as soon as the crop has been removed.

As the alfalfa soon gets woody after it has reached the stage of full bloom, the residue not wanted for soiling food ought to be cut for hay even before it is in full bloom, else the quality of the hay will be reducerl. It is apparent, therefore, that the feeding period from each crop or cutting is not a 


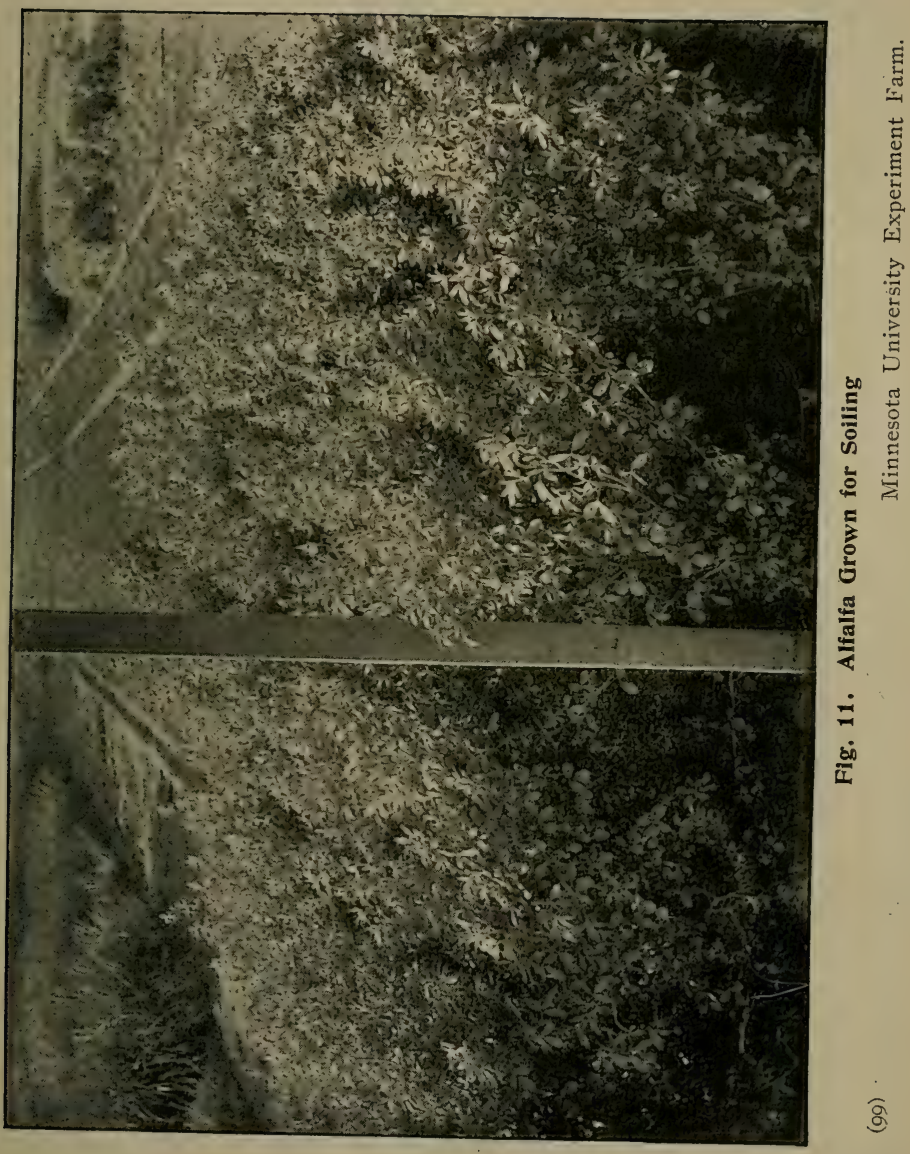


long one, not longer usually than three weeks. If, however, two plats or fields have been grown by cutting one at an early stage of growth, and then cutting the other, and again the first and likewise the second in continuity of alternation to the end of the season, the supply of alfalfa for soiling may under favorable conditions be made to cover the entire season after the first growth is ready for being cut, which is usually in May or June, according to the locality. The same result can be accomplished with but one field by taking care to cut first one portion and then another, that the part first cut may grow up again while the other part is furnishing soiling food. But in the absence of irrigation, it may not be possible to feed this food without interruption.

The scythe, or the mowing machine is used in cutting the crop, but usually the latter. When cut it may be drawn and fed the same as clover, that is to say, by strewing it on the pasture, by putting it into feed racks in a yard or paddock, or by feeding it in mangers. It should be wilted more or less when fed to cattle and sheep, as it is sometimes liable to produce bloating when fed without stint in the green form. Enough may be cut at one time to last for a limited number of days, providing it is not allowed to lie broadcast in the swath where it fell beneath the mower.

Although horses and swine are oftentimes pastured on alfalfa, some growers favor feeding it to them as soiling food unless where the conditions for growth are exceedingly favorable. The treading and close eating of horses are pretty certain to materially shorten the duration of a stand of alfalfa 
When pigs are pastured on alfalfa without intermission, it is not easy to regulate the pasturing so that the food will be kept tender and appetizing. But horses and pigs are pastured to a very considerable extent on alfalfa. Sheep are not very much pastured on alfalfa because of the danger from bloating. When fed as soiling food to sheep and swine, it ought to be cut while younger and more tender than would be necessary when it is fed to horses and cattle.

The long period during which alfalfa may be fed makes it easily possible to feed it in conjunction with other soiling foods less nitrogenous in character, as, for instance, corn and sorghum. The alfalfa may be fed one end of the day and green food at the opposite end of the same. The variety thus secured is advantageous. Alfalfa, even in the green form, may be advantageously used in fattening animals along with some carbonaceous food, as corn, barley or rye, but its highest use is found in growing animals and in producing milk. The owners of extensive alfalfa meadows would seem to be in a position to raise horses, cattle, sheep, swine and to produce dairy products more cheaply than these can be produced by any other system of arable farming. 


\section{CHAPTER VI.}

\section{LEGUMINOUS PLANTS OTHER THAN CLOVER.}

The legumes are a numerous family, and yet the species that have special adaptation to soiling uses are not many. In addition to plants of the clover group, the chief of these are the field pea, the common vetch, the cowpea and the soy bean. The cowpea and the soy bean are in a sense the complements of the field pea and the common vetch, when considered from the standpoint of distribution. These will be considered separately.

\section{THE FIELD PEA.}

Outside the clover family, the field pea (Pisum sativum) is probably the most valuable legume that is now grown on this continent. The estimate thus put upon it is based on the high nitrogen content which it contains, upon the high relative palatability which it possesses and upon the various combinations in which it may be grown. Peas in combination with oats is a favorite soiling food with dairymen, wherever these can be successfully grown together. As a food plant its value is probably greater when grown alone, but owing to the thiling habit of growth which characterizes the pea, it has been found necessary to sow it along with some other plant when used in 


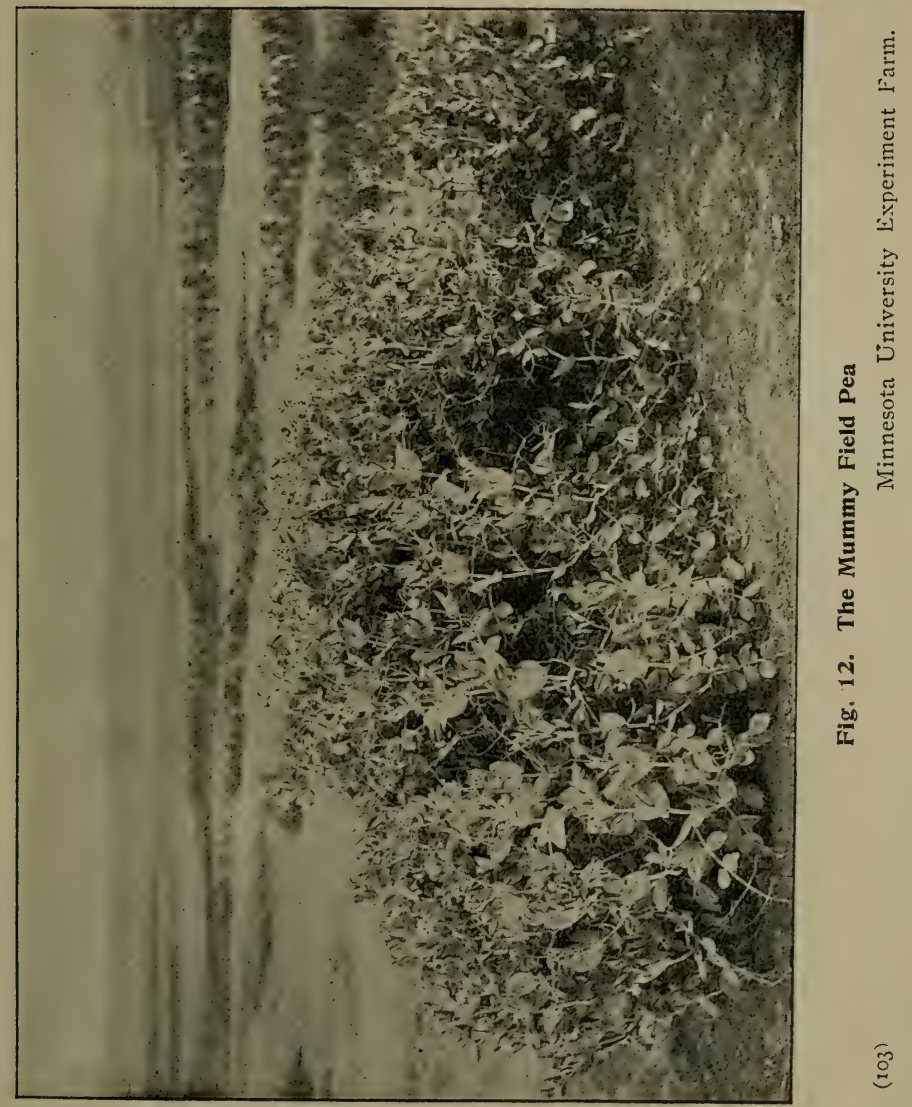


soiling, that the crop may be harvested with greater ease, and that the value of the pea vines as stock food may not be impaired by their lying on the ground.

Whether fed as a soiling food or in the cured form, peas are much relished by all kinds of domestic animals. In the green form, peas are specially suited to the needs of animals giving milk. In the cured form they are specifically a food for sheep, and the ripened grain is unsurpassed as a food for swine. The yield of the mixed crop in the green form is seldom less than ten tons per acre, and probably seldom more than twenty tons.

Distribution.-The common field pea may be grown in excellent form above the forty-fifth parallel of north latitude and from the Atlantic to the Pacific, except in some limited areas in the dry belt east of the Rocky mountains. As a mixed crop for soiling, and even in the unmixed form, it may also be grown many miles south of the line named, at least in certain areas. But below the forty-second parallel, the fruitage of the plants becomes more or less uncertain because of the high temperatures that prevail when the pea is in bloom. On high elevations the crop is not thus affected, hence in such situations peas will produce abundantly far southward. It is found at its best in temperatures that are equable, and in climates moist in character.

Soil.-Loam soils strongly impregnated with clay are eminently adapted to growing peas. They may also be grown with much success on stiff clays. The returns from sandy loams will be favorably influenced or otherwise, according as these soils contain much or little clay. And the same is true of 
the humus soils of the prairie. The volcanic soils of the Rocky mountain valleys and the alluvial soils in many of the river bottoms in Montana, Washington and Oregon have special adaptation for the production of peas. Light, hungry sands are ill aclapted to pea culture. While the vines will grow immensely in slough and marsh lands which rest on clay not far distant from the surface, they do not fruit well in these places, since the energies of the plant are so much directed to the growth of vines. While it is not necessary that soils should be very rich in order to grow peas, they must be supplied with a fair amount of potash and phosphoric acid and enough nitrogen to give the crop a good start. The rest they will gather from the air.

Place in the Rotation.-When peas are grown alone, the aim should be to have them precede a crop that requires much nitrogen to perfect its growth; for instance, a crop of wheat, since, as already intimated, peas are nitrogen gatherers. When grown in combination, almost any place in the rotation may be assigned to this crop. As it is commonly sown early in the season to provide green food, and is also harvested at a correspondingly early period, it may frequently be followed by a crop of rape or fall turnips, and it may with much propriety be followed by a crop of winter rye.

Preparing the Soil.-This crop is more commonly grown as soiling food along with oats, although it may also be grown in conjunction with other kinds of grain. Wheat is not considered as good as oats for being grown in combination with peas, for the reason, first, that it matures less slowly 
than peas, and, second, that when fed as soiling food, wheat is not relished by the stock quite so highly as oats. Nor is barley, since it ripens ahead of peas, and the beards are objectionable after they have reached a certain stage of ripening. Peas and oats mature more nearly at the same period, and as oats stool more than peas and wheat, or peas and barley, they produce a food less coarse in character. But whatsoever the combination fixed upon, the preparation of the land is virtually the same, nor does it usually differ from the preparation that has been found best suited to the growing of small grains. Usually the ground on which the crop is to be sown early should be plowed in the fall. A reep seed bed is preferable, since peas require a clecp covering.

As previously intimated, the fertilizers most needed for this crop are potash and phosphoric acid. But in some instances, nitrogen has to be applied to start the crop vigorously. Farmyard manure is very suitable when it can be obtained; and on many soils land plaster will very much stimulate the growth of the peas when applied to the crop after the plants have grown some distance above the surface of the ground. It would be possible to enrich the ground too much to obtain the best results from this crop. When rankness in the growth is excessive, the green mass often falls down before the bloom or head appears, and when it does, its palatability is materially lessened and the difficulty in harvesting is increased.

Soring.-Various methods of sowing the seed have been adopted, and of necessity to meet the needs 
of conditions not the same. Where the rainfall is normal and the soil is strongly impregnated with clay, the seed of the peas and oat may be mixed and deposited together by the grain drill. In such soils three inches would seem to be a sufficient covering. But in the black loams of the prairie, and especially in the absence of a plentiful supply of moisture, it would seem to be necessary to plant the peas more deeply. This necessity probably has given rise to the practice somewhat common in prairie areas of first sowing the peas on unplowed land and then burying them four inches, and even more than that, in the process of plowing the ground. The oats are then sown in some instances as soon as practicable, and in other instances several days later than the first sowing, and they are buried less deeply. The second method is usually preferable. When sod lands have been plowed in the autumn, or in the early spring, and when the furrow slices have been made narrow rather than wide, and laid at an angle of about forty-five degrees, the seed may be broadcasted by hand and simply harrowed in. It will fall between the crests of the furrow slices, and the harrow, when used properly, levels these and consequently buries the seed sufficiently. But peas should never be sown thus on level surfaces, as the shallow covering given to them by the harrow will be washed off in a considerable degree by the first shower that falls.

The varieties of peas best adapted to soiling uses cannot be named, since different conditions call for different varieties. Usually those kinds that are fine rather than coarse in stem are to be preferred. 
On soils with high adaptation for peas, the medium varieties are to be preferred and on soils opposite in character the larger varieties.

Nor can the proportion of seed to be sown in the mixture be definitely stated. On clay loams, peas and oats are frequently sown in equal quantities by measure, and with satisfactory results. On other soils peas should greatly preponderate in the mixture, and yet again the same is true of oats. From two to three bushels of the mixture are sown per acre, and in some instances even a larger quantity. The best method of sowing this crop and the proportions of seed that ought to be sown can only be determined for each locality by actual test.

It will usually be found that the best yields will be obtained by sowing peas and oats early rather than late, but to prolong the feeding period it is necessary sometimes to sow at successive intervals. The results will of course be influenced by the character of the season.

Some few varieties of peas would probably prove very suitable in providing soiling food, at least under certain conditions when sown alone. The crown pea and the grass pea are of this class. Their straw is more upright and branching than other varieties, and in consequence is less liable to lodge. These two varieties are at least worthy of being given a trial.

Cultization.-When peas have been grown alone or in conjunction with some other kind of grain, and for the purpose of providing soiling food, harrowing the crop once or twice is the only form of cultivation that can be given to it. A light harrow 
should be used. The more weedy the soil and the more rapidly the moisture escapes from it by surface evaporation, the greater will be the benefit from using the harrow. Harrowing has been found particularly helpful to this crop when grown on certain of the soils of the prairie. If the harrow is used but once, it should be so used before the peas have reached the surface. When the peas have been sown and then covered with the plow, and the oats or other factor of the mixed crop is sown later, the grain thus sown may be very conveniently covered with the harrow while the first harrowing is being given to the pea crop. A second harrowing is seldom given, but when it is it should be deferred until the plants have become well rooted, and much care must be exercised in doing the work, or the harrow will bury too much of the grain.

Feeding.-Peas grown alone may be fed as soiling food to swine from the appearance of the first bloom, but the highest feeding value is not obtained from the crop until a considerably later period. When fed in combination with oats or other grain to cows in milk, the feeding may begin when the peas are in full bloom or when the oats or other grain comes into head. The season of feeding may be continued until the crop is nearly ripe.

The scythe or the mower should be used in cutting the crop, according as the quantity to be fed is little or much. And the method of feeding to be adopted is practically the same as in medium red clover.

The crop is easily handled, more so than such soiling crops as corn or cowpeas, since it can be so 
convenient'y lifted with a fork of suitable construction. Also it is one of the safest soiling foods to feed, since it never produces bloating when judiciously fed. When the crop cannot be all used in the green form, the portion that remains should be cut and cured for winter feeding before the grain in the pod or the ear has passed the dough stage. The crop may be mowed and cared for after the manner of hay, or when it stands up sufficiently well it may be cut with the binder. When harvested with the binder, the sheaves should be made small and should not be very tightly bound. When the crop is very badly lodged, the pea harvester may be used to better advantage than any other implement in cutting them. The crop may be fed in a pasture, in a paddock, in racks in the shed or in mangers in the stable.

\section{THE COMMON VETCH.}

Several species of vetches have been grown in this country, but only one of these, viz., the common vetch (Vicia sativa) would seem to have special adaptation for being grown as soiling food. The sand vetch (Vicia villosa) has been given a considerable measure of praise during recent years for its ability to furnish green food for stock, but in the judgment of the author its highest use will be found when it is grown as a pasture plant rather than as a soiling food. The common vetch is frequently alluded to as though it embraced two varieties, viz., the winter and spring sorts, but these were originally probably one and the same kind grown at different seasons of the year. 
This plant has not yet been given the high place in our agriculture which it deserves. As a food plant it possesses excellent qualities, is less susceptible to injury from frost than the pea and is even more palatable and nutritious. It can be grown in various combinations, and is capable of making a second growth in some localities, though not in all, if cut while immature. And when the conditions are favorable it can be grown with much success as a pasture plant, as a soiling food, or as hay for winter feeding. The relatively high price of the seed has, probably more than anything else, hindered the growing of this crop for soiling food. This should not be so, as in states favorable to the growth of the vetch, abundant yields of seed may be obtained.

The common vetch furnishes excellent food for all kinds of live stock kept upon the farm. When fed freely to cows in milk, the yield is increased. It has a peculiar adaptation for stimulating growth in lambs that are being given a forcing diet, and no kind of soiling food is more highly relished by swine.

The product will of course vary much, but when grown alone the common vetch will run from about ten to fifteen tons per acre. When grown in combination with other plants, the return will be influenced by the nature of the combination.

Distribution.-The common vetch can be grown with greater or less success in every state in the Union and in every province of Canada. It makes the most complete growth, however, in cool and humid climates. The provinces of Canada from Lake Huron eastward, and the north Atlantic states 
are well adapted to the growth of this plant. But the highest adaptation, viewed from the standpoint of climate, is found in western Washington and in Oregon. The growth that is produced in some sections of the states is simply extraordinary. The summer climate of the central and southern states is too hot for the successful growth of vetches at that season of the year. But in several of these states, if not indeed all of them, the vetch may be grown with greater or less success when sown in the fall and fed in the spring. The dry climate of the semi-arid belt west of the Mississippi river is not well adapted to the growth of vetches.

Soil.-The soil conditions favorable to the growth of the common vetch are much the same as those favorable to the growth of the common pea. Vetches luxuriate in clay loams and can be grown with a fair measure of success even on stiff clays. Infertile sandy lands are not favorable to the growth of the common vetch, but the sand vetch has much power to grow on these lands. The black humus soils of the prairie, where the clay content is low or entirely wanting, will not produce the best crons of this plant. The gray soils of the Rocky mountain valleys which produce rank peas will also produce rank vetches, and with or without irrigation according to conditions.

Place in the Rotation.- Since vetches are soil renovators, they may be grown with advantage before a crop that requires much nitrogen to perfect its growth, as, for instance, wheat; and because of their ability to grow even on soils not very abundantly supplied with plant food. Vetches may be. 
grown almost anywhere in the rotation. They will make a good growth on overturned sod, but such land is usually wanted for the production of crops less able to appropriate plant food under adverse conditions. When sown in the autumn the winter vetch can with much propriety be sown after a grain crop, and there is ample time between the harvesting of the grain crop and the sowing of the vetches to prepare the seed bed in fine form. The vetches thus sown will be reaped early enough to admit of growing some other crop that same season on the land that produced the vetches. Such a system of rotation is most helpful in cleaning land. When sown early in the spring the crop is also consumed early enough to admit of following it with some kind of catch crop that same season. Winter wheat and winter rye fit nicely into the rotation after spring sown vetches.

Preparing the Soil.--Since vetches are sown sometimes in the spring and sometimes in the autumn, the precise methods of preparing the soil will vary considerably. On fall plowed land the only further preparation necessary is to stir the surface soil deeply enough to furnish a good seed bed. On spring plowed land the aim should be to secure a firm seed bed on the spongy humus soils of the prairie, and to secure a fine pulverization on clay soil that is cloddy. On land plowed in the summer in order to receive seed in the autumn, the aim should be to retain moisture in the land to the greatest extent possible, by the use of the roller and harrow on it after it has been plowed.

Fertilizers, especially those rich in nitrogen, are less needed by the vetch plant than by plants unable 
to gather the same from the air. But lands frequently exist in which the supply of this element in the soil is so low that the retch plants sown on them are unable to make a rigorous start unless some fertilizer is applied previous to the sowing of the retches. If commercial fertilizers are added, potash and phosphoric acid are especially fitted to meet the needs of the plants.

Soring.-The method of sowing depends to some extent on the nature of the combinations of seeds sown. But the aim should be to sow the seed with the grain drill, since, owing to the globular form of the seed.-like leas-it is easily uncorered by rain when it lies near the surface of the soil. But it is not necessary to bury the seed so deeply as the pea is usually buried. From two to three inches would seem to be deep enough in any soil.

Tetches may be sown in various combinations to produce soiling food. The following include some of the more important combinations when sown in the spring:- $\mathrm{I}$, retches and wheat, oats or harley: 2 , retches, wheat and peas: 3 , retches, oats and peas. In figure $\mathrm{I} 3$ the retches do not show though present in quantities equal to the oats. And the following are some of the more important combinations when the crop is sown in the attumn:$I$, retches and winter rye or winter wheat: 2 . retche: and winter oats or winter barley: 3. retches and crimson clover. But there may álso be some instances where it is preferahle to sow the crop without admixture. as when two cuttings are sought from one sowing to provide very tender food for lambs or swine. 


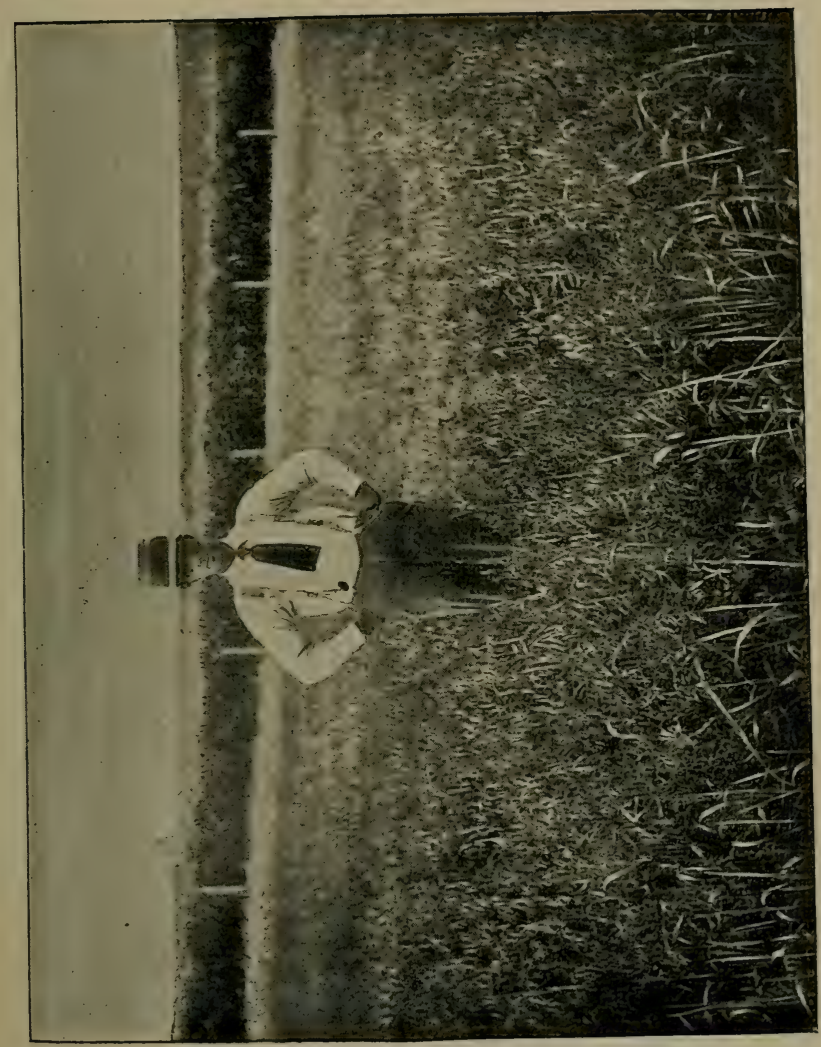



s

ఊే

हี

गे

i

if

Е 
The proportions of seed in the combination that will prove most satisfactory can only be ascertained by actual test in each locality. But the aim should be to make the vetches, to the greatest extent possible, the dominant factor in the mixture, consistent, however, with the retention of upright growth in the crop. The other factor or factors of the combination are intended rather to support the vetches than to furnish food. When vetches are sown with crimson clover, the seed of the latter should be used sparingly lest it crowd the vetches.

The quantity of seed that ought to be sown will vary with conditions such as relate to fertility, moisture and the varieties of plants used in the combination. But it will seldom, if ever, be advantageous to sow less than one bushel of vetch seed per acre, except when peas are used in the combination, and sometimes even more than the amount of the vetch seed named should be sown. When the vetches are sown alone, from one to one and one-half bushels of seed are used.

The best time for sowing the seed is largely dependent on the use that is to be made of the crop, and on the character of the climate. Vetches sown in the spring should as a rule be put into the ground quite early, but in moist climates it is admissible to sow them later and at intervals if necessary. When sown in the antumn they should be given time to get well rooted before the more trying weather of winter arrives.

Cultication.-Harrowing is the only form of cultivation that can be given to this crop, and when all the conditions are favorable to growth, it is not 
necessary even to use the harrow. But there may be instances in which decided benefit will result fron running the harrow over the crop when it is ready to push through the surface soil, and possibly also at a later period. But since the vetch is a somewhat tiny plant when it first begins to grow, much care must be taken in harrowing the crop, or the plants will be buried.

Fecding.-In climates that are moist, the feeding of the vetch crop may begin at a comparatively early period, since it will make a good second growth, but in those opposite in character the wisdom of: such a course would be more than questionable. Vetches cut before they come into bloom are highly relished by swine. More commonly, however, the cutting should not begin until the blossoms have appeared, and it may be continued until the crop has reached an early stage of maturity. In the later stages of its growth, it furnishes very rich food, and even in earlier stages it furnishes valuable food. The crop may be cut with the scythe or mower, and may be fed in the same manner as peas. It is more easily handled than various other grain crops since it is sufficiently adhesive to admit of being lifted easily, and yet it is not so adhesive as to make it difficult to lift a separate forkful. When fed only to swine where a limited number is kept, or to sheep that are being fitted for the show, it is customary, and the practice is a good one, to sow the vetches somewhere contiguous to the farm buildings for convenience in feeding.

When it so happens that more of the crop is on hand than can be used in the green form, the surplus 
should be cut at an early stage of maturity and cured for winter feeding. When thus fed it makes it itself almost a perfectly balanced ration for some kinds of feeding. It is particularly excellent for cows in milk and for sheep. When thus fed, the crop may be conveniently harvested with the pea harvester which will do the work of cutting almost as quickly as though it were a hay crop. But when the crop is well supported by some other grain growing along with it, the binder may be made to harvest the same with manifest advantage.

THE SOY BEAN.

The soy bean (Glycine hispida) has only been tested in this country during recent years. Its growth has been confined to comparatively limited areas, hence but a relatively small number of the agriculturists of the country have any knowledge of the plant, based upon practical experience. The following facts, however, have been fairly well established in regard to the soy bean:

I. It is not adapted to a climate in which the temperature is low in summer, or in which the season of growth is short. 2. It is able to gather the food of sustenance in relatively poor land, although it will of course give better returns from rich land. 3. It can withstand drouth and excessive wetness in the soil better than many other plants grown as food for live stock. 4. The flowers are not much liable to injury at the critical period, owing to peculiarities of structural development, hence they are more sure of fruiting than those of many other food plants 
and they also possess the power of self-pollination. 5. It has much power to draw nitrogen from the air and to deposit the same in the soil for the benefit of succeeding crops. 6 . It is one of the richest of foods grown for live stock. 7. It may be grown as pasture, as soiling food, as hay or as greeri manure; it may also be grown for the grain whicli it produces.

The soy bean, very often designated the soja bean, is an annual plant. When all the conditions are favorable it will grow to the hight of four feet or more, but the average hight of the plants is from two to three feet. It is branching in its habit of growth, the stems are somewhat coarse and the leaves are large and fairly numerous. The pods are short and broad, and each pod contains from two to five seeds which vary much in color according to the variety. The yield of the beans varies of course with the nature of the soil, the season and the method of cultivation adopted. Crops have been grown which produced as high as forty bushels per acre, but the average crop is probably Iess than half that amount.

The soy bean makes an excellent food for cattle and swine, probably also for horses and sheep, although experience in feeding it to horses and sheep is as yet somewhat limited. The green food and the hay are excellent for cow in milk; the same is true of the seeds when ground and fed with some less concentrated food. Soy bean meal should probably be always thus fed. Except the peanut, there is perhaps no other vegetable product grown in this country which contains such high percentages of 


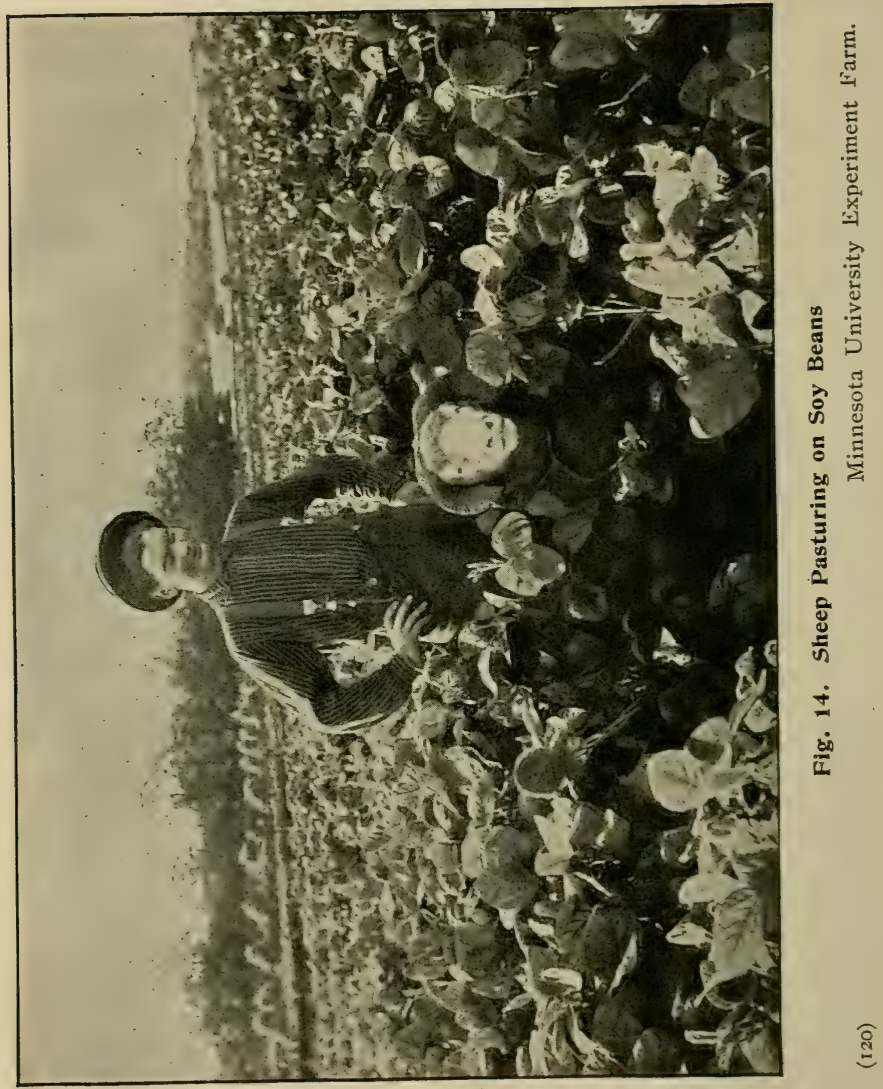


protein and fat in a form so highly digestible. It is considered superior in nutritive qualities to oil meal, and in some tests that have been made it has compared well with cottonseed meal. But the fact must not be overlooked that the handling of the crop, when grown, is more exacting and laborious than the handling of some other soiling crops.

The yield of the green crop per acre varies much with the conditions, but usually there is no difficulty in growing ten to twelve tons per acre on average land. But the value of this plant in producing food for live stock is measured less by the yield than by the richness of the food.

Distribution. - Since the soy bean is a child of the sun, it cannot be grown successfully in far northern latitudes. The highest adaptation for this plant will, in nearly all instances, be found south of the fortieth parallel of north latitude, that is to say, south of the latitude of Columbus, O., and Springfield, Ill. The varieties heretofore introduced have not been grown with any marked success north of the line which marks the southern boundary of Minnesota, or, in other words, north of the forty-third parallel. This means that in the meantime it has no important mission as a food crop for any of the provinces of Canada or for any of the states that border on Canada. But some of the varieties at present grown may become so acclimatized that the limit of successful growth may be pushed considerably further northward. The necessity for this, however, would not seem to be so vital as further south, because of the ease with which other green 
foods may be grown in the northern states that are more easily managed than the soy bean.

In the intervening area between the parallels named the early maturing varieties only can be successfully grown, and of course with highest success toward its southerly limit; and in that part of the prescribed area which lies in the Mississippi basin the crops will be superior to those grown in other portions of the same, and chiefly for the reason that the summer temperatures in the said basin are relatively high. While the soy bean will grow well in the hot summer temperatures of the Rocky mountain valleys under irrigation it is not so much needed in them because of the luxuriance with which other legumes may be grown that are more easily handled. The climate of the Pacific slope west of the Cascade mountains is ill adapted to the growth of the scy bean.

Soil.- The soy bean will thrive at least measurably well on almost any kind of soil, providing this soil has in it a liberal supply of potash, phosphoric acid and lime. It will, however, thrive best on soils which may be termed medium in texture. Nearly all classes of soils found on the open prairie have high adaptation for the growth of this plant, and the same is true of all soils that will produce good crops of Indian corn. It may be successfully grown on land too low in fertility to produce clover or cowpeas. Instances are recorded in which plants have been grown in disintegrated trap rock and in coal ashes, and yet some of the light soils of the southern states may be so deficient in phosphoric acid and potash, and even nitrogen, as to 
make it worth while to apply those ingredients before planting the crop. Nor should it be planted on soils in which hardpan comes near the surface, since in such instances the roots which naturally feed deeply: could not easily penetrate the soil. Swamp lands well drained, produce an abundant growth, especially of stems and leaves, hence these are specially adapted to growing soy beans for soiling food.

Even peat soils, under certain conditions, may be made to produce paying crops, and owing to the excellent drouth-resisting properties of the plant, it may be grown on soils too deficient in moisture for the successful growth of the cowpea. . But it is not wise to grow it on soils already rich in nitrogen. To clo so would be a waste of that very important element of fertility.

Place in the Rotation.- Since the soy bean must be grown in warm weather, where it is to be grown at all, its place in the rotation is all the more easily defined. Since the soy bean may be grown with highest success when given cultivation, it should generally be grown as a cleaning crop; since it is a legume and has much power to increase the nitrogen content in the soil, it should precede grain crops; and since it can make progress amid heat and during dry weather it may frequently be grown as a catch crop. It will, therefore, naturally follow such crops as have been grown in southern latitudes to provide autumn, winter and early spring pasture, as winter rye, winter oats and winter barley; and this plant may be made to follow grain crops that have been harvested at maturity, as, for instance, rye, winter wheat or winter oats; and it may even be made to 
follow spring grain that has been matured, providing there is yet moisture enough in the soil to bring about successful germination in the seed. The ground does not as a rule of necessity require to be plowed when preparing it for the grain crop that is next to be sown, since the bean crop generally leaves it in a loose condition.

Preparing the Soil.-Since the soy bean is frequently grown as a catch crop, the seed bed for it must in such instances be prepared with dispatch. This calls for a free use of the harrow and roller after the land has been plowed. But it may not be necessary in all instances to plow the land when preparing it for soy beans. The surface should be made smooth and fine for the reception of the seed. When the soy bean crop is the only plant to be sown on the ground for the season, a fine opportunity is furnished for freeing the land in a single season from the presence of many kinds of noxious weeds. This may be done in part by plowing the land for the soy bean crop in the autumn or in the early spring and then running the harrow over the same as often as the weeds begin to grow until the beans are planted. The subsequent cultivation given to the crop will tend to complete the cleaning process so well begun before the planting of the same. It is not usual to apply any fertilizer when growing this crop, but as previously intimated, it may be necessary in some instances to apply potash, phosphoric acid, or lime, if not indeed all three of these ingredients.

Sorving.-When designed for soiling uses, the soy bean should be planted in rows and usually with the corn planter, the bean planter or the grain drill. 
The distance between the rows will vary according to the strength of the soil, the variety of the bean and the date of planting. The extremes of distance may be placed at about twenty-four and forty inches and the mean distance at thirty inches. When grown for seed, the distance should be more than when the crop is grown to provide green food or hay. The variety planted will depend on such conditions as soil, climate and the uses for which the crop is grown. As a rule, what are known as the dwarf varieties are preferred for grain production in the north and the medium varieties are preferred in the south. Of the former the Early Dwarf is a favorite and of the latter the Medium Early Green. The last named variety has proved satisfactory when grown as soiling food as far north as Amherst, Mass. The Medium Early Black is also in favor in many localities. It is almost impossible, however, to give the names of varieties with precision at the present time, as the same variety is frequently spoken of under different names. The large varieties are adapted only to situations in which a long period of growth can be given to them. The medium varieties will frequently mature under normal conditions in from ninety to one hundred days, but oftentimes they require a longer season in which to complete their growth. When growing this crop, much attention should be given to the variety chosen. Many of the failures in attempting to introduce the crop have resulted from the planting of varieties not suited to the conditions of the locality.

Considerably more seed is used in growing the zrop when it is to be fed in the green form than in 
growing it for the grain. From about sixteen to twenty-four quarts will suffice for the latter purpose, while not less than thirty-two quarts are usually sown to provide green food. Some growers favor thick planting to encourage an upright and tall rather than a branching growth, because of the greater ease with which plants of the former type can be harvested.

The soy bean should never be planted until the arrival of warm settled weather, and the planting may proceed as long as there is a reasonable hope of sufficiently maturing the crop before the autumn frosts arrive. In Kansas, for instance, crops planted on wheat stubble in July have been matured.

Cultivation.-Wherever the soil does not lift with the wind, the roller should both precede and follow the planting of soy beans, unless where moisture is abundantly present. The cultivation given should of course be generous and prompt, since the beans grow so quickly that this work cannot be very long continued. In some instances it is possible to use a harrow on the land between the time of planting the seed and the appearing of the young plants above the surface. The instances are also frequent in which the harrow may be driven over the ground with much advantage to the plants after they have got four or five inches above the surface of the ground, but it should be driven along rather than across the rows to prevent the horses from treading down the plants. But when the harrow is so used, the teeth should be set with a backward slant.

Feeding.-When the crop is grown for the seed it may be cut to much advantage with a self rake 


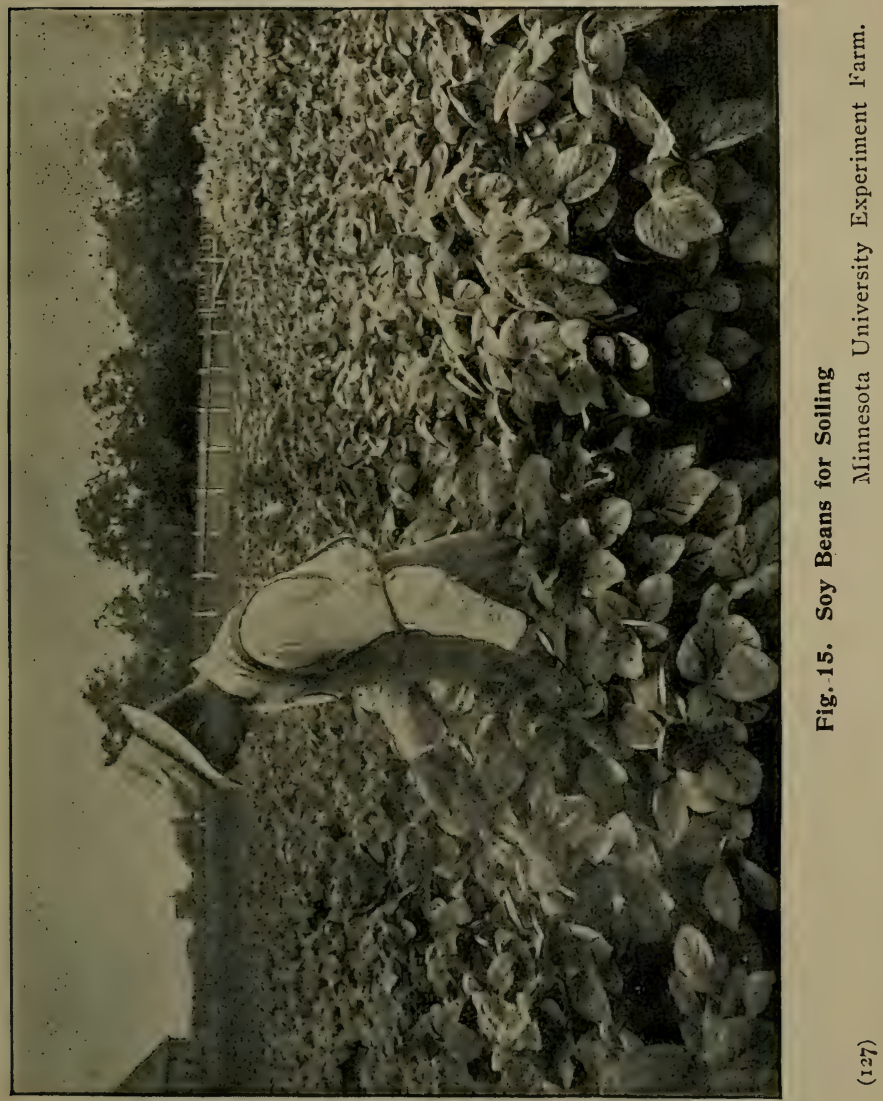


reaper. But when grown for soiling or for hay it is more commonly cut with the mower. When fed green, the cutting may begin as soon as the period of early bloom, and it may continue until the crop is sufficiently matured for making hay. When cut for hay, the seeds should be about half grown in the pods. If the cutting be deferred to a later period, many of the leaves will drop off and the stems will become woody. Any excess in the crop of green food should be cut for hay rather than allowed to ripen.

Since the yield of seed from crops thus grown will not be abundant, the crop should not be allowed to wilt overmuch when it is fed green, lest there should be some loss from the leaves dropping off. The method of feeding is much the same as that followed in feedling peas. When soy beans are fed to swine, the season of feeding may be continued until the crop is matured. But it is more common to allow the swine to gather the seeds for themselves when the crop has reached an advanced stage of maturity.

\section{THE COWPEA.}

The cowpea (Dolichos Chinensis) has been grown for many years in the south, hence it has long since been carried past what may be termed the experimental stage of growth. It is fast coming to be regarded as an indispensable factor in any system of cultivation that can be adopted in the southern states and which is likely to prove eminently successful. Its great value to the farmers of the south arises from, I, its ability to grow on poor soils; 2 , 
its power to grow under adverse conditions; 3 , its great value as a pasture and a fodder plant for live stock; 4, the magnificent service which it renders to the soil when plowed under as a green manure. There are but few places in the entire south where the land is tillable in which this plant may not be grown with more or less success. The proper use of the cowpea and of its complement, the soy bean, to the greatest extent possible, would revolutionize the agriculture of large areas in the south, where the soil is sandy and lacking in fertility.

The cowpea furnishes excellent pasture for cattle, sheep and swine, but when pastured by cattle the waste of vines is greater than when fed as soiling food. It also furnishes good hay, when properly cured for horses, cattle and sheep. But it is not as easily handled as the common field pea in the north, nor is it so easily cured. The grain is also excellent for milk production and for growing swine. Its use for these purposes in the form of meal has not become general, owing first, to the considerable labor involved in handling the crop, because of the long and intertwining nature of the growth in many of the varieties grown, and, second, because of the incomplete machinery for harvesting the crop in the best manner possible. There would seem to be no valid reason why the pea harvester should not be generally used in harvesting the cowpea.

It is scarcely possible to give figures that would represent the average yields of the crop per acre in the green form, owing to the many varieties that are grown and to the great difference in the habits of 


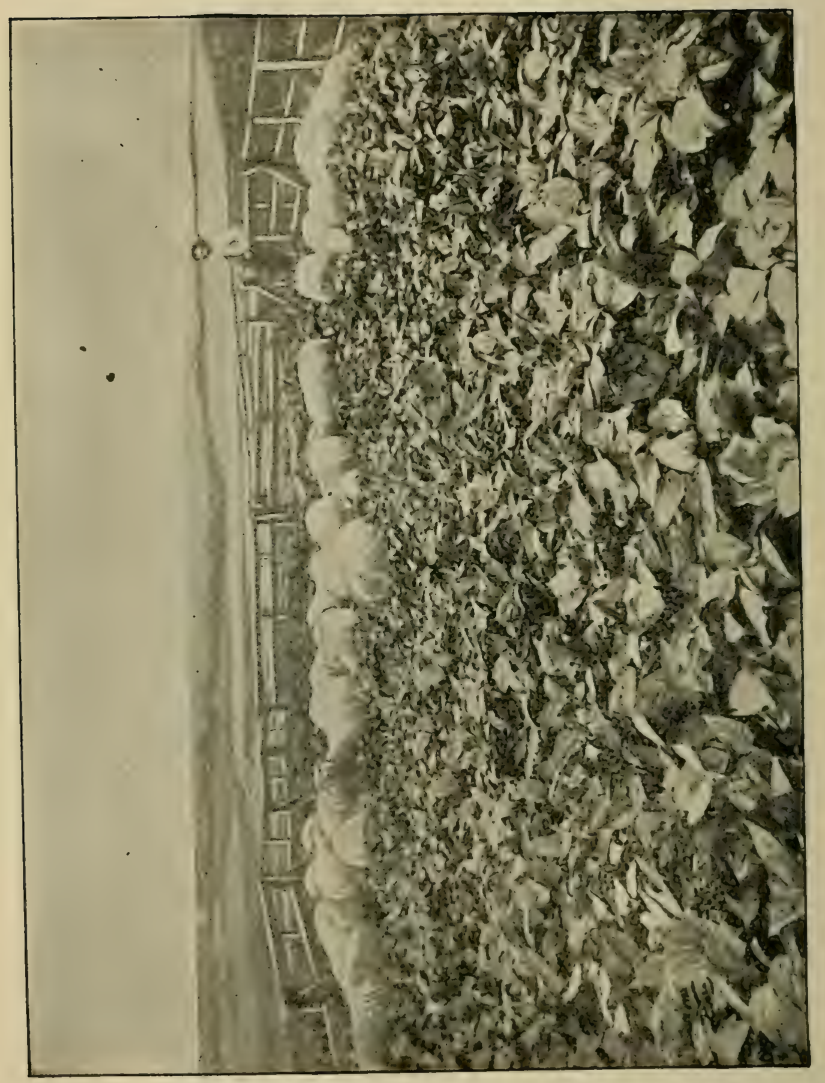

严

을 
growth in these. With the large varieties it is sometimes possible to grow twenty tons per acre, but the average will be much less than that amount.

Distribution.-The northerly limit of successful growth in the cowpea would seem to be the southerly limit of successful growth in the common field pea. The line which forms this border-land of high development will run irregularly across the continent, but it is not far distant from the fortieth parallel. The cowpea has been grown in the northern areas of Nebraska, Iowa, Illinois, Indiana and Ohio and even in Connecticut, but in these localities the aim is rather to grow it as a soil renovator and to a less extent as a soiling food than as a grain crop. In the southern half of the states named, Connecticut excepted, it is grown by many farmers, but the most favorable conditions for completest development in the large varieties is found further to the southward, as far south probably as the latitude of St. Louis in Missouri, that is to say, south of the thirty-eighth parallel.

In the warm valleys of the Rocky mountains the cowpea will doubtless grow vigorously under irrigation, but it is not likely to come into general favor in these areas, because of the presence of alfalfa in so great abundance, and yet in the more southerly of these valleys, it may come to be grown extensively to provide a grain eminently suited to the finishing of pork reared upon alfalfa. When thus grown, swine could be made to harvest the crop where it grew. But in these valleys it is not at all probable that the cowpea will soon be produced as a soiling food. In Canada and in the states bordering on that country, any variety of the cowpea that has beeis 
introduced has not been grown with highest success, and the same is true of the western slope of Oregon. But recent experiments conducted by the author at the Minnesota experiment station have been decidedly encouraging. They were made with such varieties as the Early Black and the Red Ripper.

Soils.-Soils that are suitable for growing soy beans are also stiitable in nearly all instances for growing cowpeas. (see Page I22). Loam soils and more especially clay loams, will produce the largest crops. Fairly good crops may be grown on soils too low in fertility to produce good crops of grain.

Place in the Rotation.-As with other legumes, the aim should be to grow the cowpea so that it will prove a renovating crop to the soil. It should, therefore, come as a rule between two grain crops. But it may also be grown as a catch crop, where a crop previously grown has failed; or it may be grown as an intermediate crop after a crop has been harvested and before another autumn or winter crop has been sown. The cowpea can be grown with much satisfaction on land from which early vegetables have been removed and also after a crop of such fruits as strawberries. It is also grown on soils that have become too unproductive for successful cropping with grain. When thus grown it is usually plowed under to renovate the soil, but even though the crop be used for soiling purposes or for hay, or even though it be matured for its grain product it will still leave the land in a much better condition as to fertility than before the crop was grown on it. 
Although cowpeas will grow luxuriantly on overturned sod lands, it will usually be a mistake to grow them on these, as the vegetable matter which they contain may be turned to excellent account in growing grain crops. But it may be wise in some instances to grow cowpeas after crimson clover, in the hope of further enriching the land for the next crop. The cowpea is also frequently sown among the cotton and corn plants while they are yet immature. In latitudes far south, one crop of cowpeas may be grown for soiling uses if cut early and a second crop from the same plants for being plowed under.

Preparing the Soil.-In preparing the soil for the cowpea the aim should be to secure a fine and a moist seed bed. The roller and harrow, if judiciously used, may be made greatly helpful in securing both, and more especially after the arrival of the dry season. When sown after garden crops, it may not be necessary to plow the land, but simply to disk and harrow it:

It is seldom necessary to apply nitrogen to the soil in which this crop is grown, but in some instances it is necessary. Since the cowpea takes considerable quantities of potash and phosphoric acid out of the soil and since it does not restore these when the crop is removed from the soil on which it grew, except in so far as it brings them up from the subsoil, the fertilizers applied should contain these elements in liberal degree. It will be in order, therefore, to apply such fertilizers as ground bone, bone ash, fish guano and superphosphate when fertilizers are needed. Farmyard manure will usually give 
excellent results, but it can seldom be spared for the crop of cowpeas.

Sowing.-Cowpeas are commonly sown with the grain drill. If sown broadcast and covered with the harrow, and rain should fall soon after the crop has been sown, many of the peas will lie upon the surface and will fail to sprout. When sown for pasture, all the drill tubes are used in sowing the seed, but when the land is measurably clean and the other conditions are favorable, it may be advantageous to sow only with alternate tubes. The same mode of sowing is sometimes adopted when the crop is sown for soiling uses or for the production of hay or grain. But when ground is to be cleaned, or when moisture is not abundant, the crop ought to be drilled in rows far enough apart to admit of cultivation. With the large varieties these rows may in some instances be made as distant from one another as thirty inches, and even thus far distant, the vines will in time completely cover the ground. But the distance between the rows must be measurably determined by the variety of the peas and convenience in cultivating them.

In growing this crop for soiling food, it will oftentimes prove advantageous to sow the seed of some other forage plant along with them, as, for instance, millet, sorghum, or Kaffir corn. These plants help to sustain the peas and consequently to improve the quality of the vines and to increase the quantity of the grain. Kaffir corn is very suitable for being grown thus, owing to the stiff growth of stem which it sends upward and to its power to grow in dry weather. About ten pounds of seed 
will usually be sufficient to mix with one bushel of the peas.

The quantity of peas that should be sown will depend chiefly on the objects sought in sowing. But more seed will be required of the large varieties and by soils low in fertility. From one to one and onehalf bushels are usually sown when the crop is to be pastured or plowed under. In a majority of instances, one bushel of seed per acre will suffice to grow soiling food or hay. When cultivation is to be given between the rows, the quantity of seed required will be proportionately reduced.

When the crop is to be plowed under, the large and late maturing varieties ought usually to be sown in the southern but not in the northern states. The Wonderful, sometimes called Unknown, is one of the best of these. But when soiling food, hay or grain is sought, the kinds known as "bunch" varieties-that is to say, branched and bush-like rather than vine-like-should usually be sown. They are more productive of grain than the former and are more easily harvested. The best of these, especially for northerly latitudes, are the Whippoorwill, the Early Black, the Red Ripper and the Black Eye. The Clay variety is in favor farther south. But there is yet some confusion in the various names applied to the cowpea.

If cowpeas are sown before the weather and soil are warm, the seed will rot in the ground, or the plants will start so feebly that they will not grow subsequently into a vigorous crop. After the corn has been planted it will be sufficiently early to plant cowpeas. In latitudes far south they can be sown 
even months later, but not in the north. The bunch varieties will often mature in ninety to one hundred and twenty days from the time of planting.

Cultivation.- Whether cowpeas are sown broadcast by hand, by the grain drill with all the tubes in use or in rows far enough apart to admit of subsequent cultivation, the harrow may in many instances be used with advantage before the plants push up through the surface of the soil. A light harrow may also be used when the plants are four or five inches above the surface, and more especially when the peas are planted in rows so that subsequent cultivation can be given to them, as then the horses may be driven along the rows when drawing the harrow so as not to tread down the peas.

When subsequent cultivation is given between the rows, it must be done with promptness, as the peas, owing to the vine-like character of their growth will soon lie along upon the land and so preclude further cultivation. TThen strong weeds of a noxious character infest the line of the rows they ought to be removed if they are likely to mature their seeds before the peas are harvested. Due attention should be given to this particular, whatsover the kind of crop that is being grown.

Fceding.-The feeding of cowpeas may begin as soon as the first bloom appears. When cut thus early the crop will grow up again, though not under all conditions, and may be cut a second time if the growth will justify using it thus. A second advantage from early cutting is found in the greater ease with which the green food may be handled when it is being fed, since the intertwining of the vines is 


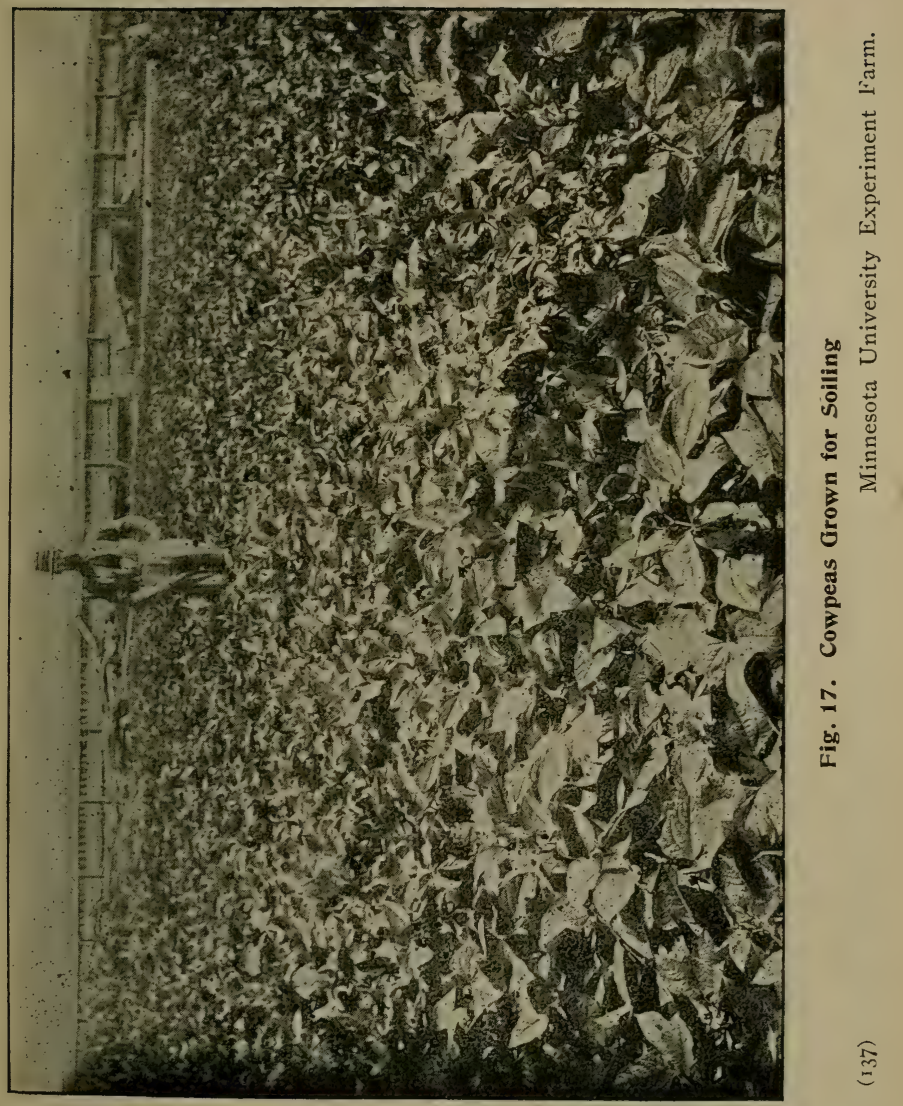


not so pronounced as at a later period. It should be remembered that at the period of early bloom the plants have not nearly reached that stage when they possess a maximum of nutrition. The feeding may be continued until the crop is nearly mature. Any residue not wanted for green food may be cut and cured for hay. When the major portion of the pods contain peas more than half grown, the crop is ready for being cut for hay. It may also be harvested for the grain as soon as one-half, or more than that, of the pods are fully ripe. The ripening of the pods, as with the common field pea, is more or less uneven.

The cutting on a large scale is commonly done with a field mower. But when the crop is not in any way supported by another crop sown along with it, the mower very frequently leaves more or less of the peas uncut. The pea harvester will do the work of cutting much more cleanly and economically. Because of the difficulty of handling the crop when feeding it green, there is a disposition on the part of many to allow the stock to do the harvesting. The waste resulting is not all loss, since the soil is enriched more or less when the waste is buried with the plow.

As in feeding other green foods, this crop may be fed on a pasture, in a paddlock, in sheds or stables, in fact, wherever it is most convenient. 


\section{CHAPTER VH.}

PLANTS OF THE BRASSICA GENUS.

But two plants of this genus have heretofore been grown to any very considerable extent on this continent to provide soiling food or pasture for live stock. These are rape and cabbage. It is possible, nevertheless, that other plants of the same genus may yet be introduced that will prove quite helpful in providing green food for the same. Some of these, as kale for instance, have been thus utilized in Europe, and there would seem to be no good reasons why they should not be so used in some areas of this country, but until more is known as to their behavior under American conditions, they could only be discussed in a speculative way. Rape and cabbage, therefore, will only be considered in this chapter.

\section{RAPE.}

There are several varieties of rape (Brassica napus,) but only one of these, viz., the Dwarf Essex, has been found possessed of sufficient value to give it the place of distinct precedence among all the varieties tried under American conditions. All varieties of rape are annual, that is to say, they complete the mission of life within twelve months from the date of sowing. But there may be instances, as when certain varieties are sown earlv one season, where 
they will not mature their seeds until a later period the following season. The varieties which are chiefly grown for seed only, and which are used principally in making oil, usually mature the seed within sixty to one hundred and twenty days from the date of sowing, but those which are grown rather for pasture or for soiling uses, will not mature seed the same season they are sown. The former are possessed of but little value as food plants.

The Dwarf Essex rape bears a close resemblance to the rutahaga in the first weeks of its growth. So close is the resemblance at this time that it probably would puzzle an expert to tell the two plants apart. As time goes on, however, the growth of the rape is more upright, and it becomes more stalky and tall. Ordinarily it grows to the hight of eighteen to twenty-four inches, but it may be so stimulated by fertilizers as to make it reach nearly twice that hight. The root is strong, the branches of the same being numerous and some of them go a considerable distance downward as well as laterally in search of food.

Dwarf Essex rape furnishes most excellent soiling food for horses, cattle, sheep and swine. Its feeding value has been stated by high authority to be fully twice that of clover, although chemical analysis does not give to it so high a value. As soon as animals become accustomed to it, they grow exceedingly fond of it. Its power to produce milk when fed to millk-giving animals is very high, and its power to produce fat is, in a sense, remarkable. When it is fed to cows in milk, some caution must be exercised as to 


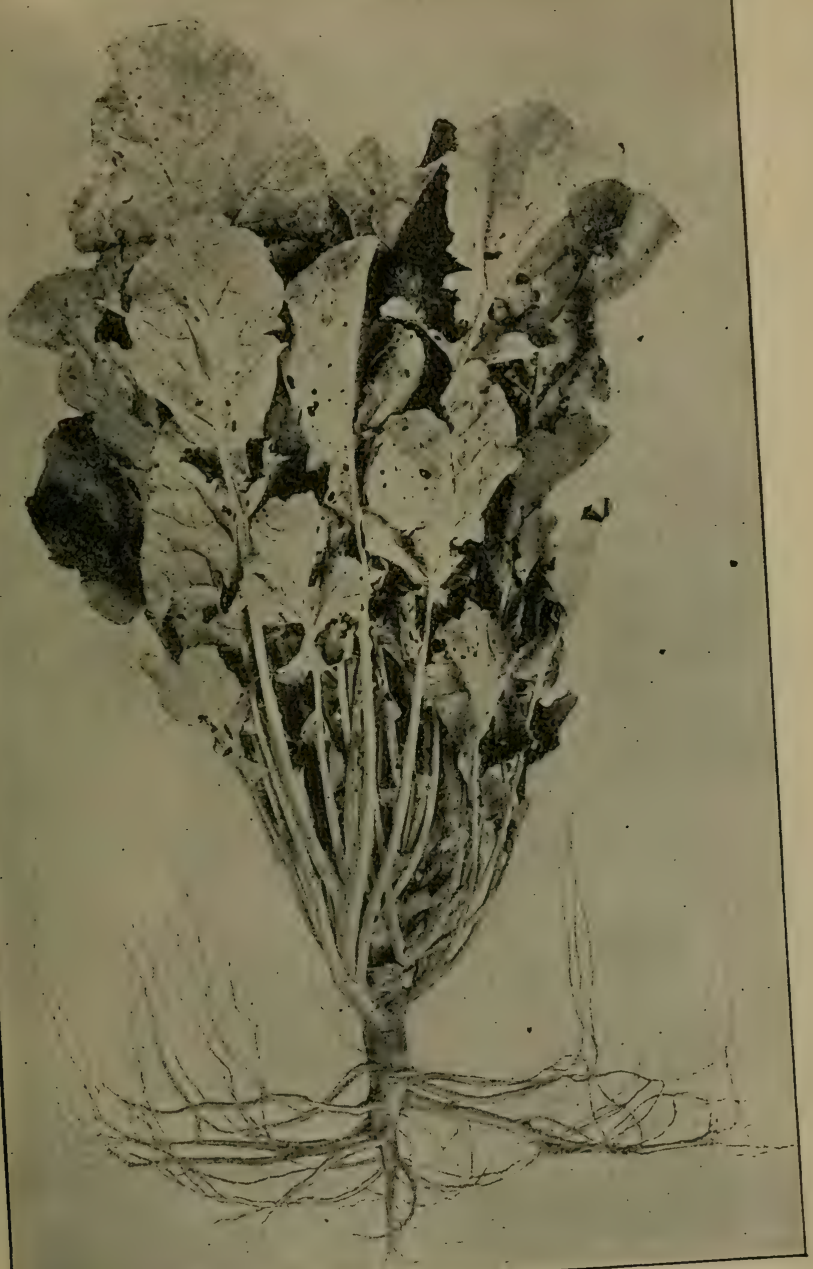

Fig. 18. Dwarf Essex Rape Plant Minnesota University Experiment. Farm. 
the manner in which it is fed, or the milk will be tainted more or less. Many dairymen, who send their milk regularly to a cheese factory, feed it to their cows once or twice a day after the cows have been milked. These dairymen state that no complaint has been made as to the quality of the milk. But some dairy authorities claim it should not be fed to cows giving milk at all, as the danger of taint is imminent. The truth will probably be found, in this as in so many other instances, to occupy middle ground. If the rape is fed just after the cows have been milked and in moderation, while the milk flow will be well sustained, there will probably be no perceptible taint in the milk. But if fed in excess, while the milk flow will be further increased, the milk will carry in it more or less of the odor of the green rape.

The yield of the mature crop is proportionate to the favorable nature of the climatic conditions, the richness of the land, and the nature and extent of the cultivation given to the plants. Ten tons an acre is a very moderate yield. Twenty tons an acre are frequently obtained, and there are instances in which the yield has been increased to thirty tons per acre. When the exceedingly rich character of the food is kept in mind and when this fact is coupled with the large yields that can be obtained, the conclusion is legitimate, viz., that but few crops can be grown that will yield a greater food value per acre.

Distribution.-It is questionable if there is any state in the Union or any province in Canada in some part of which this food cannot be successfully' grown at some season of the year. It may with no little propriety be termed a cool weather plant, hence 
the best yields are obtained north of the fortieth parallel of north latitude. All the states of the Union bordering on Canada, and likewise all the provinces of Canada bordering on the United States, have high adaptation, though not equally high, for the growth of rape. In the states further south it ought to be grown in the early part of the season, before the weather becomes dry and hot, or in the autumn after rain has begun to fall. In mild winter latitudes this plant should be made to provide soiling food through all or nearly all the winter.

Rape also grows in fine form in the higher Rocky mountain valleys when it is irrigated, and sometime.s in the absence of irrigaton, but the great abundance of the alfalfa crops in these makes the growth of rape less essential than it would otherwise be. The highest adaptation for this plant will probably be found on the Pacific coast from southern Oregon to Alaska. The humidity of the climate there and the mild character of the season makes it possible to grow enormous crops of rape.

Soil.-Rape will grow freely in any soil that will produce a good crop of turnips, that is to say, it will make a vigorous growth in deep, moist loam soils, with a considerable mixture of sand in them. It will also grow with even greater vigor in some classes of soils not well adapted to rutabagas, as for instance, the black humus soils found in sloughs, and the muck soils of marshes, that have been drained. It would probably be correct to say that in these, rape finds its highest adaptation. It grows luxuriantly in nearly all the varieties of soil found in the prairies of the west, also in the sandy soils of the 
Rocky mountain valleys when supplied with moisture. It does not usually make a good growth in unyielding clays, and light infertile sands have still less adaptation to the growth of rape than stiff clays. It is almost useless to sow rape on a poor soil. On the other hand, the yield of the crop is likely to be proportionate to the richness of the land when the other conditions that relate to growth are favorable.

Place in the Rotation.-The place given to rape in the rotation will in no small degree be dependent on the object for which it is grown. When grown to provide pasture one can scarcely imagine a rotation in which it may not with propriety be given a place. It is probably without a rival in its adaptation for being sown as a catch crop. But it is rather as a soiling crop than as a pasture crop that its place, in the rotation, is now to be considered. Whenever the crop is cultivated it ought to be made a cleaning crop, and, therefore, may be sown with no little propriety on land that is foul. In all, or nearly all, such instances it ought to be followed by a grain crop on which grass seeds also are sown. But when sown broadcast, and on many of the rich soils of the west, it may be thus grown with perfect propriety. It should only be sown on land that is measurably clean. This crop will grow nicely on overturned sod, old or new, timothy, clover, blue grass, or indeed any other kind of grass, since it is a ravenous feeder on decaying vegetable matter in the soil.

Rape may be made the sole crop grown on the land for the season, or even for soiling purposes it may be made to follow some other crop, as rye pastured or barley harvested, or clover from which 
one cutting has been removed. When sown thus late, in very many instances cultivation should be given to the plants to stimulate growth. When sown after any of these crops, the results will largely depend on the character of the weather that follows. There may be seasons when the attempt to grow rape in this way will not be successful.

Preparing the Soil.-In preparing the land for rape the aim should be to secure a fine, firm and moist seed bed, with as much cleanness as can be attained under the circumstances. When rape is the sole crop grown on the land for the season, usually the above conditions can be attained, unless the crop is sown very early in the season. More commonly they can best be attained by plowing the land in the autumn.

The exceptions are climates with rainy winters. It being more common to sow rape to provide soiling food for late summer and autumn rather than for early summer feeding, a sufficient interval transpires between the opening of spring and the sowing of the crop to sprout many of the weed seeds lying near the.surface of the soil, and in time to destroy them by the occasional use of the harrow. But when the crop is broadcasted early in the season, as is often done, the aim should be to sow it on clean land. When rape follows another crop harvested the same season, the interval for preparing the land is too short to give opportunity to clean the same. Within a few hours of the plowing of the land it should be impacted with the roller, or with the roller and harrow, to keep in the moisture. This should never be omitted, unless when the soil is abundantly 
moist. And when the rape crop is planted in drills on such land with enough distance between them to admit cultivation, the said cultivation, when given, is further very helpful to the retention of moisture, as well as to the more vigorous growth of the plants. It is, also, peculiarly helpful in such a season in cleaning the land. Rape should not be sown in summer weather on cloddy land as the seed will not germinate under such conditions.

When rape is grown for soiling food, the aim should be to secure all the growth possible. Hence it should be sown on land naturally rich, or made so by applying fertilizers. Rape has special adaptation for being grown on lands enriched with heavy applications of farmyard manure. In fact, the luxuriance in the growth of the plants is usually proportional to the degree, to which the soil has been enriched. This plant would almost seem capable of growing in a manure heap. And because of its great power to appropriate food, manure applied in the fresh form would seem to answer the end sought about as well as when it is applied in the reduced form. But to this there are some exceptions. Manure, fresh and containing much litter, should not be applied in great bulk, except in rainy climates, lest it hinder to so great an extent the impaction of the soil as to allow the too rapid escape of moisture. Slough and swamp soils are oftentimes so rich that an application of a fertilizer on these would be thrown away.

Commercial fertilizers are of course helpful to this plant when farmyard manure cannot be obtained, and also when it can be obtained, but not in sufficient quantities. A light application of farmyard 
manure in conjunction with a light application - of artificial fertilizers is probably superior to a heavy application of either alone. On lands which require such treatment superphosphate is oftentimes drilled in with the seed, but not in too close proximity to it. Nitrogenous fertilizers, on which rape feeds ravenously, are usually applied on or near the surface, and just at the time of sowing the seed or later. But in moist weather only should nitrogenous fertilizers be applied on the surface.

Sorving.-Rape seed is sown by one of two methods, that is to say, it is broadcasted, or sown in rows far enough apart to admit cultivation between them. The second method is preferable when land is possessed of only moderate fertility, when it is foul with weeds, and when the period of growth is short. The cultivation stimulates growth sometimes in a remarkable degree, and cleans the land. The first method will answer very well, however, when the land is reasonably clean and rich, and more especially in moist climates. Where the seed is sown in rows, these are placed variously from twenty to thirty-six inches apart, according as there is present a prospect of an average or more than an average crop. The stronger the growth the wider apart do the plants require to be.

In some instances the drills are raised. In other instances they are made on the level. When raised they are commonly made with a double mold board plow with a marker on it, to mark the line of the next plow furrow. The raised drills render cultivation somewhat easier, more especially when the plants are young. But 
where moisture is less than normal, the germination of the seed will be much more certain if sown on the level. The seed is usually sown in raised drills by the ordinary turnip drill, drawn by one horse. Two rows are thus sown at once. But the hand drill can be used in the absence of a horse drill. When sown on the level the land may be marked out and the seed sown with the hand drill, or it may be deposited with certain of the grain drills, when driven by a driver sufficiently skilled to make rows straight and evenly distant; varying widths between the rows and crooked rows greatly lessen the effectiveness of the subsequent cultivation. The most perfect machine for doing this work has probably not yet been invented. The seed should be buried from less than one inch to two or even more in depth, according to the character of the soil and climate. When sown broadcast the seed may be scattered by hand, or sown with a hand grass seed sower. In either instance it is covered with the harrow, whether the seed is sown in drills or by hand, unless when the ground is quite moist, it should be rolled before and also immediately after sowing the seed, to hinder evaporation near the surface. Rolling the land thus in dry weather is greatly important, but there may be instances when a light harrow should follow the last rolling given the land.

The quantity of seed to be sown will depend upon varying conditions, usually from one to two pounds per acre will suffice when the crop is grown in drills. When broadcasted the quantity will vary from three to five pounds per acre. The first men- 
tioned quantity will suffice when the soil is rich and clean, but when these conditions are not present the last named quantity may be preferable, to admit of harrowing the crop to some extent after the plants have made a good start.

The time at which this crop may be sown varies exceedingly. In all climates it may be sown as early in the spring as grain crops, and in moist climates it may be sown as late as the end of summer. The crop usually requires from eight to ten weeks to complete its growth, sometimes however, a shorter period will suffice and again a longer period is necessary. Keeping in mind this thought one can decide when the crop should be sown. The early sown crops may be turned to excellent account in providing pasture or soiling food for swine, when clover does not grow readily. In mild climates it may be sown in the autumn. To provide soiling food when most needed, the seed is usually sown in May or June. But by varying the dates of sowing, this one plant may be made to furnish soiling food almost without interruption from the close of spring to the end of autumn. In the dry, hot summer months it is sometimes impossible to get a stand of plants. But even though the seed should lie in the ground without germinating for weeks, it will start up vigorously as soon as moisture reaches it.

Cultivation.-When the crop is broadcasted the only cultivation possible is to harrow it after the plants have obtained a fine hold on the soil. The harrowing should be done with much care. It will destroy some of the plants, but when the seed has been sown thickly enough, this will be no rea! 
detriment to the crop. A light harrow should be used, and the harrowing must not be deferred until the young weeds get a firm hold upon the soil.

When the crop is sown in rows, the cultivation should begin as soon as the young plants can be distinctly traced along the line of the row. It should be shallow and as frequent as once a week or once in two weeks, until the tops of the plants have so reached out as to preclude further cultivation. The harrow may also be used with advantage in some instances on a rape crop sown in drills and on the level. When so used it should be drawn across the rows and prior to the cultivation ordinarily given. The effect will be to take out myriads of weeds along the line of the row that would otherwise be undisturbed. The plants will be somewhat thinned, but this should not result in the injury of the crop. It is not usual to hand hoe rape, not even along the line of the row or to thin it, but if so treated the plants will grow all the stronger. Whether the labor would give an adequate return will depend upon conditions. When the cleaning of the land is one of the chief objects sought in growing rape some hand hoeing should be found profitable.

Fecding.-The cutting and feeding of rape plants may be commenced as soon as they have made sufficient growth to justify such a course. More especially is this true of rape that is to be fed to swine in the absence of other green food. It may be cut and fed thus when not more than one foot high. If not cut too near the ground, it will grow up a second and even a third time. If mowed closely, however, the growth will be much weakened. 


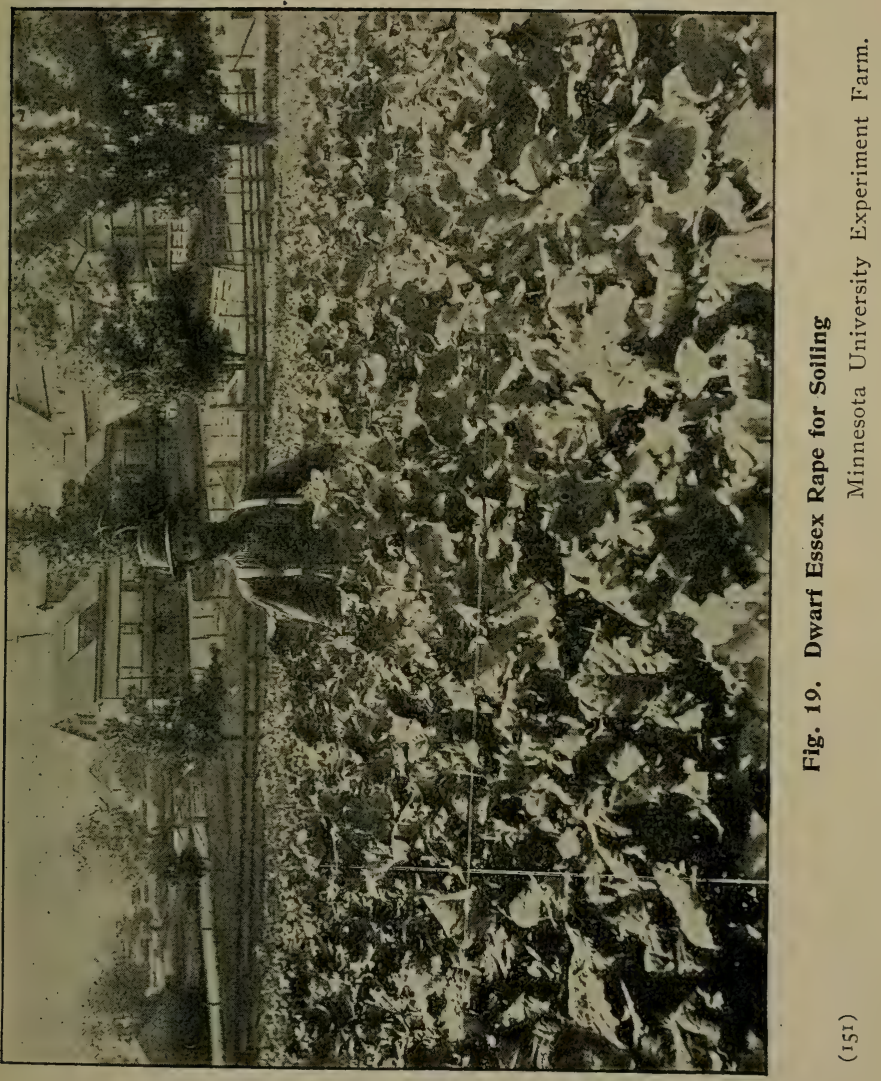


More commonly, however, rape is virtually allowed to reach its growth before the feeding is begun, and it is questionable if more or even as much food can be obtained by cutting this crop once or twice when immature, as when it is allowed to practically mature before the feeding begins. By maturity is meant, in the present instance, a stage when further growti ceases. This point once reached, there will likely be greater or less loss in hot weather before the crop can be fed, as the lower leaves, especially, will become yellow and crisp, and in some instances, the plants will be attacked by the white aphis. When indications of such attack are present, the crop should be fed with all haste, otherwise it may soon become valueless.

To avoid such risk, in hot weather it may be well to commence feeding the plants before they have completed their maturity. But in cool moist weather a large majority of the plants will so retain their greenness, that the feeding of the crop may be made to cover two months, at least without much loss in food value. It may be well to mention here, that any unused residue of the crop in the late autumn may be cut before severe frosts arrive, thrown into heaps and fed from these, even after the snow has fallen to a considerable depth. But where the cold of winter is usually intense, this could not be done with profit. The plants like those of sorghum are slow indeed to spoil when thus handled.

The crop may be cut with scythe or mower according to the amount wanted, and if put into heaps soon after it is cut, in the field, the feed yard or the sheds, it will retain its palatability for several 
days. If the crop is cut with the mower, better work can usually be done when it has been sown broadcast. as then none of the stems lie so near the ground as to escape being cut. When the drills have been raised it is not easy to cut the crop with the mower.

Rape may be fed as other green food, that is to say, on a pasture, or in a paddock, feed yard, shed or sty. But care should be taken not to feed too large a quantity at first; not to feed when wet, and not to feed to hungry animals all they will take, lest bloating should be produced, which, if not speedily relieved, will almost certainly lead to the death of the animal. There is some danger also that scouring will be produced when green rape is fed in large quantities. The scouring is not nearly so likely to manifest itself when the stock is also being pastured on grass more or less dry, or where there is being fed at the same time a considerable quantity of hay. And it is not a little surprising how much dry food, stock will consume when being freely fed on green rape. Nature seems to furnish a craving for food that aids in correcting the tendency to an unduly lax condition of the bowels which may have been induced by feeding rape. And this will be found true also when other kinds of green food are being fed. So certainly does this craving manifest itself that it is questionable if it would not pay at all times to feed some dry food when animals are being fed an abundance of juicy green fooc.

It may not be generally known that this plant can be fed green with much profit to young colts more especially after they have been weaned. It is equally good for calves under like conditions. If 
given an abundance of green rape calves or colts will grow very quickly and will also improve in flesh. It makes a grand food for sheep being fitted for the fairs, for weaned lambs that are wanted in good form for early selling, and for lambs that must needs be confined to avoid infection from parasites on certain pastures. When fed as soiling food, the feeding can be so regulated that the element from bloating will be completely eliminated. Rape is also possessed of peculiar value when fed as soiling food to swine. When so fed a large saving is effected in grain food, development is more continuous, and the vigor of the animals is better sustained.

The rape plant is oftener pastured than cut and fed as soiling food, frequently it will be more advantageous to use it in the latter form. There is really no limit to the extent to which this plant may be used other than that which is fixed by the desires of the owner.

\section{CABBAGE.}

Cabbage (Brassica olcracea) is probably seldom grown for the express purpose of providing sustenance for live stock. In nearly all instances crops of this plant are grown to provide food for the human family. Yet in certain areas it may be grown with much advantage to furnish soiling food for various classes of live stock. Because of the great power' which the mature plants have to withstand frost, they will furnish green food at a season of the year when it can seldom be obtained from any other source outsicle of the silo. By exercising some care and forethought in storing cabbage, as described 
uncler the head of feeding, it may be used as green food for several weeks after the ground has frozen.

But even though the crop has been grown chiefly as human food, when the areas thus planted are large, the residue of the crop after the heads have been taken, is possessed of a value for feeding uses that will far more than repay the labor of feeding it to live stock. This residue, though it varies greatly in relative value, is frequently worth fully fifty per cent of the whole value of the crop, when used as food for live stock. In growing cabbage, therefore, the recommendation to "gather up the fragments that nothing be lost" is peculiarly fitting.

Because of the considerable labor involved in growing cabbage the crop is adapted to intensive rather than to extensive conditions. The farmer having a small farm located near a town or city, and having on that farm few animals, can usually grow this crop to better advantage than the man whose conditions are the opposite.

Cabbage furnish excellent food for horses, cattle, sheep and swine. It has a nutritive ratio of I :5.2 and, therefore, is in itself almost a perfectly balanced food for milch cows. It is not only relished highly by the various classes of animals mentioned, hut when fed to those giving milk, as to cows, ewes and brood sows, it has much power to produce an abundant flow of milk. The heads when chopped fine furnish a peculiarly grateful and appetizing food for young lambs. The yields obtained per acre are in some instances simply enormous. Crops of forty to fifty tons have been grown, but these figures are much above the average. 


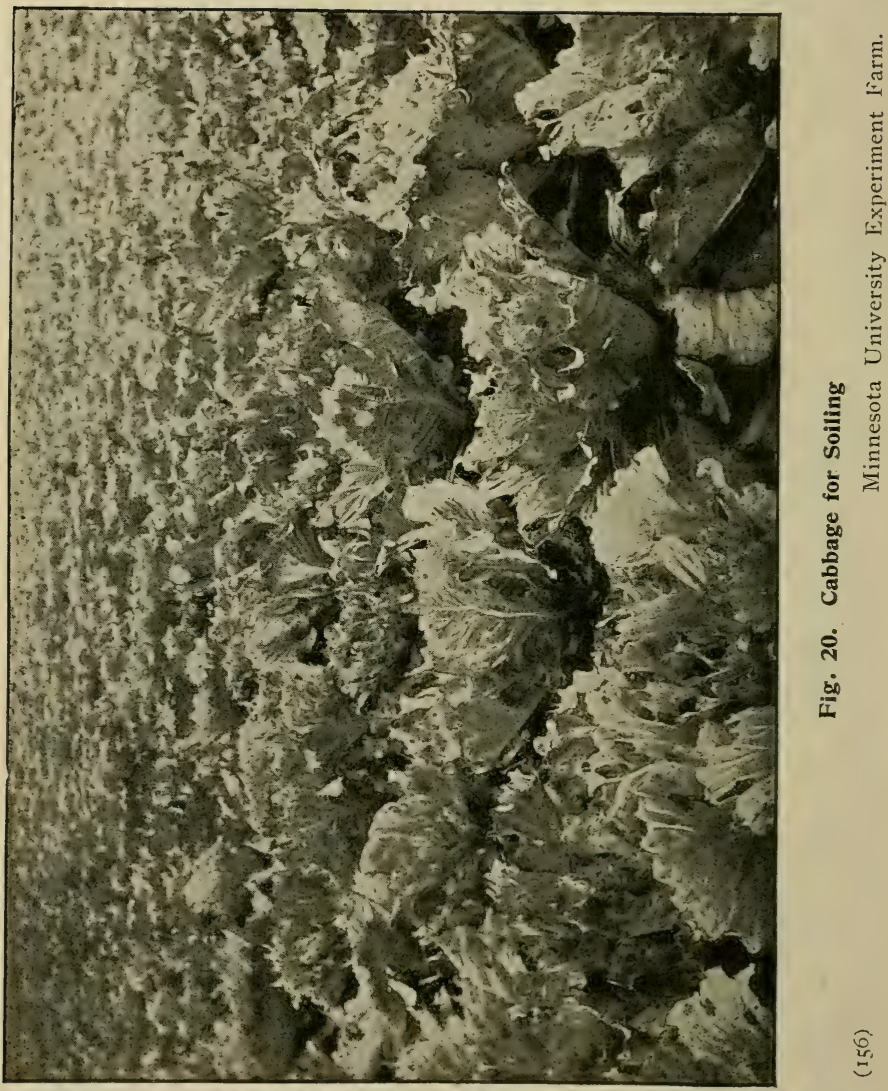


Distribution.-This crop is wide in its distribution. There is probably no state in our republic and no province in Canada in which it may not be grown, and with considerable success. While it has highest adaptation for cool and moist climates, it will, nevertheless, grow better relatively in warm climates than rape. But in these the enemies of the plant, such as the aphis and the cabbage worm, are much more troublesome than in northern latitudes where the mean summer temperature is lower. This crop may be grown in best form in the states of the Union which border upon Canada and in the provinces of Canada which border upon the United States. But excellent crops can be grown uncler certain conditions in states much further south. In fact, there are but few states in the Union which, in some of their more elevated valleys, do not furnish just the right conditions for growing cabbage.

Where the crop can be successfully grown as human food, it may also be successfully grown as food for live stock, for the requisite conditions to produce either crop are essentially the same. But it should be carefully observed, that because a cabbage crop has given a financial profit when grown for the human family, it does not follow it will also give a financial profit when grown as food for live stock. Such an assumption would not, of necessity, be correct, since it involves the consideration of relative values of cabbage in the market and of meat and milk produced by the cabbage when fed.

Soil.-Cabbage like all plants of the Brassica genus luxuriate in a fertile soil, and more especially 
in one abundantly supplied with humus. The alluvial soils of narrow valleys and river bottoms furnish for them a most congenial home. The same is true of the deep rich black loams of the virgin prairie and of slough lands. They also revel in the muck soils of swamps that have been drained. They can be grown on rich loams in fine form, and good crops can even be obtained from clays of no little density, but not without much labor. Fair crops can also be grown on all lands well adapted to the production of Indian corn, but more fertility, relatively, is required to grow a good crop of cabbage than will suffice to grow a good crop of corn. The lands with least adaptation for cabbage are those which are light, leachy and low in fertility. Good cabbage soils are usually if not always underlaid with clay, not too near and yet not too distant from the surface. Good crops may be grown on upland soils naturally dry in character, but only by the aid of abundant fertilizing.

Place in the Rotation.-The cabbage crop like all other crops that are given much cultivation should be made a cleaning crop. It should invariably be followed by a crop of grain of the non-leguminous order, unless there are good reasons for doing otherwise. The grain crop should have grass seeds sown along with it to produce hay or pasture. But owing to the peculiar power which cabbage, in common with all plants of this family, have to feed upon decaying vegetable matter, there is a peculiar fitness in growing a crop of cabbage on overturned sod. Any kind of sod will suffice, but of course, the more 
dense the better adapted it is for the purpose. Good clover sod has much adaptation for the production of good crops of cabbage.

Preparing the Soil.-When cabbage is grown specially for soiling food, late crops are much preferred to those that mature early. What will now be said on the preparation of the soil will have more especial reference to the growing of late crops. In preparing the land for this crop the soil should as a rule be deeply broken. To this there may be some exceptions, as for instance, when sod land is overturned but a short time before the crop is planted on it, and more especially, when the soil has in it a strong admixture of clay. The ideal treatment under such conditions is to plow the sod only moderately deep and to follow the ordinary plow with a subsoil plow. The crop of clover or grass should be allowed to make as much growth as possible before it is turned under. As soon as the land is plowed, the roler should follow the plow as closely as possible. The green mass thus turned under will begin to decay quickly and the young cabbage plants will find in it most congenial food and drink. Good crops of cabbage may be grown after crimson clover has been cut, or even after the medium red has been harvested. The chief difficulty to be met in sowing crops this late is that of sprouting the seed, since the weather at that season is usually dry. In other instances cabbage may be grown with profit when green rye has been buried that had been sown the previous autumn. But the rye should be buried while yet quite succulent, or it will not decay with sufficient quickness. There may 
also be occasions when the ground should be plowed in the fall, as for instance, when the land is very foul. It may then be at least partially cleaned in the spring before the seed is sown. And when old sod lands are covered with a dense turf, it may be a good practice to plow them in the fall, to give the roots more time to decay before the planting of the crop. When such lands have been plowed, the surface soil should be cut up deeply and finely by some implement adapted to such work. The roots of the young plants can then push their way through the soil much more readily and the decay of the sod will be much hastened.

It is not easy to make the land too rich for cabbage by the application of fertilizers, but it would be easy to so apply fertilizers that there would be waste of the same. For instance, if farmyard manure. commercial fertilizers, or both were applied in excess of the needs of the crop on a leachy soil and in an area possessed of a rainy climate, much of the excess of fertility unused by the crop would be washed out of the soil before the planting of the next crop. That the plants may be abundantly supplied with food, and that such waste may be avoided, the practice has become common when growing cabbage to apply much of the fertilizer along and near the line of the row where the plants are to be grown. But where fertility has thus to be distributed with so much care, it is at least questionable if cabbage can be profitably grown as a food for live stock. On many of the prairies of the west, especially in the slough lands of the same, enormous crops can be grown without the application of any kind of fertilizer. 
PLANTS OF THE BRASSICA GENUS. I6I

Farmyard manure is an excellent fertilizer for cabbage, but unless applied some time before the planting of the crop it should be somewhat reduced before being used. Many eastern growers compost farmyard manure with night soil and muck, or certain forms of fish waste, and when sufficiently near the sea they add kelp. Purely commercial fertilizers will not give returns so satisfactory, in the entire absence of farmyard manures, as when the latter is present. When both are applied the manure is commonly plowed in and the commercial fertilizer placed in and near the line of the row which is to receive the seed. These fertilizers are thus made specially helpful to the plants while they are young and the barnyard manure is more helpiful at a later period. Such fertilizers as guano, superphosphate with much nitrogen in it and hen manure are excellent for such a use, and so are wood ashes. Cabbage feeds freely upon the three essential elements in complete fertilizers, but most freely on potash.

In any case, if the soil is not rich where a crop of cabbage is to be grown, it should be made so, since an ample supply of fertility not only fortifies the crop against such vicissitudes as unduly dry weather, for instance, but it is also necessary in order to produce a profitable crop.

Soring.-It is, at least, questionable if it will pay to grow cabbage for green food only, in localities where they cannot be easily and surely grown by the method of sowing the seed in rows rather than by that of transplanting. Of course it is different when the crop is grown mainly for the market, the residue only being fed to live stock. 
In some localities plants grow so readily and so surely, that the crop may be grown by sowing the seed where the plants are to remain. It may be thus grown in many instances as surely and easily as a crop of turnips or rutabagas. The western and northwestern states have special adaptation for the growing of cabbage crops by this method. In other localities their insect enemies are so numerous that it is almost necessary to start the plants where they can be given protection, and then after they have made a good start to transplant them into the field.

The seed may be sown by first marking off the ground, then using a hand drill which deposits the seed in the line of the marks that have been made; some grain drills may be used to sow the seed without the seed beng mixed with anything. With other patterns of drills it is necessary to mix the seed with some such bulky substance as salt. The rows should not be closer to one another than thirty inches, nor more distant than thirty-six inches. The seerl should be buried to a depth varying from less than one inch to more than two inches, according to the nature of the soil. A roller should also in nearly all instances be run over the soil before and after sowing the seed.

The late varieties are to be preferred, and among these the larger sorts; as for instance, the Drumhead and Savoy. The early varieties do not grow sufficiently large. They are also lacking in an abundance of leaf growth, nor do they keep so well as the large and late varieties do. The best variety for each particular location, however, can only be ascertained by actual test. 
From one to two pounds of seed per acre will be sufficient. The first mentioned quantity should be ample under average conditions, but it may be necessary sometimes to sow fully twice that amount.

The time for sowing the seed will depend considerably upon the place which is given the crop in the rotation. The young plants are somewhat tender for a time, hence hard frosts in the spring will destroy them. But they will withstand slight frosts without harm. The seed should not be sown, therefore, much sooner than the regular season of corn planting. There may be instances where the crop sown thus early will mature too soon to best serve the end for which it was grown. When plants reach a maximum growth in hot weather, many of the outer leaves wither and are lost as food. Sowing should not be done at a period so late as to hinder the crops from making good heads, since the food value lies more in the head than in any other part of the plant. But this crop may, with more propriety than some others, be sown somewhat late, owing to the great power which it has to continue to grow in the late autumn.

Should the small black beetle (Epitrix spec.) attack the plants when young, they ought to be dusted promptly, and while the dew is yet on, with air-slaked lime and wood ashes. And should the plants suffer later from the attacks of the cabbage worm (Pieris rapae, Linn.) they ought to be sprayed once or twice with kerosene emulsion or paris green. Paris green would be the more effective application of the two and there will not be any real danger in using it thus when the cabbage are not to be fed for 
some weeks subsequently. These remedies will prove effective unless under extremely adverse conditions.

Cultivation.-The relation, between abundan: yields, and the nature and extent of the cultivation that is given to the cabbage crop, is both close an! intimate. As soon as the young plants distinctly mark the line of the row the cultivation should begin. And when weeds are superabundant, if the land is stirred by the hand hoe close up to the plants and for a short distance on both sides of them, the labor thus expended will be amply rewarded in the more vigorous growth of the plants, and in the greater ease with which they can be thinned. The cultivation should be frequent and should be continued as long as it can be done without breaking off any considerable number of the lateral leaves of the plants.

The thinning of the plants should ordinarily begin while they are not yet more than three or four inches high. If left unthinned for a much longer period they become more or less spindling and do not produce so large a head. But when the cutworms are numerous it may be well to defer thinning to a later period than would be advisable in the absence of such an enemy. The thinning is almost entirely done by the use of the hoe. The individual using it strikes forward and pushes backward as in thinning turnips; the plants not wanted fall hefore the hoe. The distance to which they should be thinner will depend upon the variety, upon the time during which the crop may continue to grow, and upon the nature of the soil and season. The distance will vary, say, from eighteen inches to thirty inches. 
PLANTS OF THE BRASSICA GENUS. I65

The average may be stated as twenty-four inches. When thinning the plants, the skilled workman will detect at a glance a single plant growing about the right distance from the one last left to grow. He can then without hesitation cut out all the intervening plants. Though this single plant should vary one, two, or even three inches from the exact distance fixed upon, it would be better to leave this plane than to leave one of a cluster in the exact spot, but from which the plants around it must needs be pulled out by hand. Anrl if a blank should occur it can easily be filled during the thinning process.

The workman strikes his hoe downward into the soil and lifts out the earth above it. He then strikes it down beneath a single plant which otherwise would be cut out and lifting it up on his hoe with the adherent earth sets it down into the hole previously made. Young plants may thus be removed at almost any hour of the day, and-without much wilting of the leaves.

Feeding.--When the crop is sold in the market, the feeding of the unused portion should begin at once, the leaves being gathered with a fork and conveyed directly to the stock, or stored in a flat pile for subsequent feeding, not more than a foot in depth. If allowed to lie on the ground underneath a hot sun, they would soon wither and entirely lose their feeding value.

But when the crop is to be fed in its entirety, the plants may first be cut off at the surface of the ground or underneath it by the use of a sharp hoe or spade. A strong spud would probably do the work more effectively than either the hoe or the 
spade, and with more ease to the operaior. The plants are then carted to the feeding place, whether it be in a pasture, paddock, yard, shed or stable.

All classes of live stock will devour the plants, leaving only the woody stalks, unless in the case of young lambs. For these they should be minced. When fed to corvs giving milk, care should be taken lest too many be fed, and the cabbage should be given just after each milking. When thus fed to milch cows a considerable proportion of the whole ration may consist of cabbage without imparting to the milk any disagreeable taint. Every care should be taken to avoid feeding cabbage leaves which are partly decayed to cows giving milk, or most unpleasant odors will arise in the milk.

The feeding of the crop may begin as soon as it is mature or a little previous to maturity. The feeding may continue without interruption until the crop is entirely consumed. If winter threatens to close in before the crop has been all fed, it should at once be carted to some place convenient for feeding, and also sheltered from the cold winds, as by the side of a straw stack, and there piled up if need be several feet deep and then covered with straw. The teeding from this pile may go on without interruption until the crop is consumed. The duration of such feeding, however, is largely affected by climate. In latitudes where the winters are mild, cabbage may be stored for future feeding by stacking them in the form of a ridge roof on the surface of the ground, or from some distance below it, and may be covered with one or two feet of straw, rough litter, or marsh hay, according as one or the other of these may be 
convenient. To economize space it will be well to break off the outer leaves before the plants are thus stacked with the heads downward. If cabbage freeze when thus stored, no serious harm will follow. While thus frozen, cabbage should never be fed to any kind of live stock, not eren swine. And it should be remembered that alternate freezing and thawing are greatly injurious to this plant.

Cabbage may be kept even more surely and probably more simply in some climates, by lifting them with the potato fork and standing them in a double or treble line, with the root upward and with all or nearly all the leaves retained. The cabbages are brought to a ridge by adding a third row when there are but two rows on the ground, or by adding two rows and then another when there are three rows on the foundation. They are then covered as described above. And sometimes a plow furrow may be turned toward the cabbage on either side with manifest advantage. 


\section{CHAPTER VIII.}

THE COMMION CEREALS.

The chief of the common cereals grown in this country, are wheat, oats, barley and rye. They are produced as winter, or spring varieties according to the circunistances under which they are grown. All of these may be grown singly for soiling food, or they may be grown in various combinations. Peas and vetches may also be included in some of these combinations, and when they can be so included, much is added to the value of the food; as shown in Chapter VI. The least valuable of these crops for soiling uses are rye and barley. Rye turns woody so soon after the ear has formed, that it becomes unpalatable; and the feeding value of barley is lessened soon after it somes out in head, because of the presence of the beards found in nearly all varieties of this cereal. For feeding purposes these mixtures are usually valuable in proportion to the peas or vetches which they contain. This arises from the more nitrogenous character of the latter, their greater palatability, and the large yields of the fodder which they produce in pea and vetch soils.

The combinations in which these crops may be grown are various. There may be instances in which several of them may be grown together, but usually only two or three varieties are thus grown. 


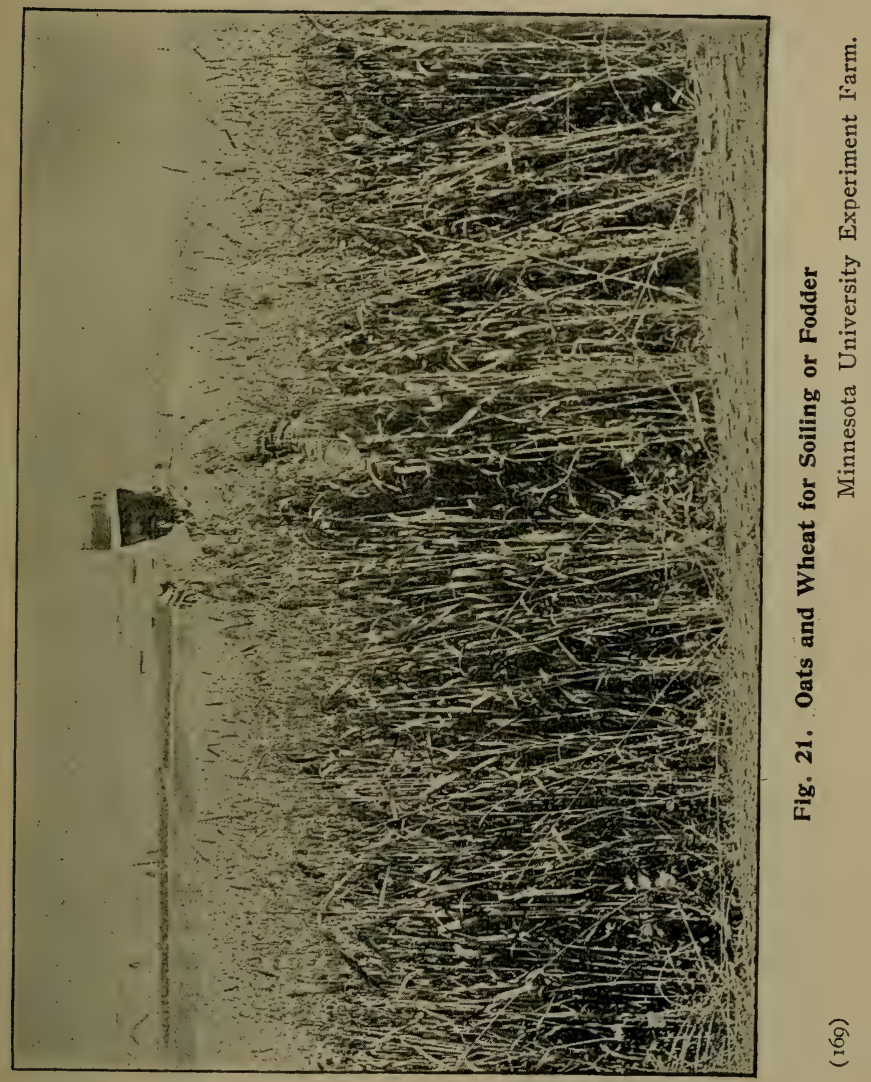


Three of these combinations stand higher in favor than the others. I, A combination of peas and oats; 2. a combination of retches and oats; and 3, a combination of wheat and oats. The last named combination is frequently grown where peas or retches cannot be relied upon to furnish soiling food.

Several adrantages arise from growing these plants in combination. I, L'sually there is a greater production of food from a given area. 2, They can be grown more thickly, hence the straw is fine: and is better relished by stock. 3. They furnish a better balanced food than when grown alone.

The green food produced by these mixed crops can be fed to all classes of live stock, but it has relatively higher adaptation for dairy cattle, because of the free milk giving that results from feeding it. Mixed crops may be fed to sheep and swine, but only when in a quite succulent stage of growth, or when it is almost entirely composed of peas or retches. Theat, oats. barley and rye become so woody when well advanced in growth, that sheep and swine do not relish them. It is more common to pasture both on these mixtures than to feed them in the form of soiling food.

The yields will of course vary with the conditions. The minimum crop that it would be profitable to grow may be fixed at, say, six tons per acre. A good crop should run from ten to twelve tons per acre. But it is sometimes possible to double these amounts.

Distribution.-Wheat, oats, barley and rye possess a wide distribution. The distribution of 
peas and vetches has already been considered in Chapter VI. All these grains unless it be peas, can be grown in both the winter and spring varieties. The four first named can be grown in some portion, or portions of every state in the Union and of every province of Canada. South of the fortieth parallel they do not generally grow so freely as north of that line, hence they are not so valuable for producing green food as some other crop or crops better adapted to soils that are frequently low in plant food, or lacking in moisture.

Wheat is usually considered too valuable to be used as soiling food, and yet there are some localities, where it can be more cheaply grown for such a use than almost any other kind of food. These localities include much of the land in the northerly portions of the semi-aricl belt east of the Rocky mountains, the Palouse and Walla Walla areas of Washington, and limited areas in northwestern Oregon. In all these areas wheat is grown as liay, and where it furnishes a highly prized food for hay it will also furnish a very suitable soiling food. There are other areas so perfectly adapted to the growth of immense crops of oats that this plant can be made to furnish green food more cheaply than any other. Such are certain river valleys west of the Cascade mountains. Barley, although it grows very rapidly, is commonly too low in production to make it a profitable soiling crop, but it will produce green food under a greater variety of conditions than any of the other cereals under consideration. In addition to its being low in palatability there is the objection that it is commonly in season for feeding when grass is plentiful. 
Soil.-Wheat, oats, barley and rye may be successfully grown on a wide range of soils. Each kind, nevertheless, has its favorite soil. Wheat luxuriates in deep, moist, pliable loam soils, well spiced with clay and well stored with vegetable matter. The loose lying soils of nearly all the western prairies have high adaptation for wheat production. Soils ill arlapted to the growing of wheat inciude those that are sandy and poorly supplied with nitrogen, those that are shallow, with hardpan coming near the surface, and those that contain an cxcess of water at any time during the growth of the plants. Oats also grow most luxuriantly on soils that are best suited to the growth of wheat. But since the oat plant is a more gross feeder than the wheat plant, it will produce a better growth relatively than wheat on soil ill conditioned, mechanically and imperfectly supplied with plant food. Barley will grow better relatively on soils rich in humus and in readily available fertility. Black loam soils, with enough sand to keep them in a good mechanical condition, have high adaptation for barley, and since this grain feeds near the surface rather than far down, much depth of subsoil is less essential to the growth of barley than to the growth of wheat and oats. The soils with least adaptation for barley include those deficient in humus and which contain an excess of clay. Since the crop grows rapidly, if it is to be a success, the young plants must be able to send their rootlets quickly and in all directions between the soil particles.

Rye is beyond all comparison the most vigorous feeder of the four cereals under discussion. It 
will stand more abuse than wheat, oats or barley; that is to say, it will grow better than any of these when sown on soil not well prepared, poorly supplied with plant food, and under adverse climatic conditions. Rye will grow well on all soils possessed of high adaptation for wheat, oats or barley. It will also give a fairly good return on soils too light and poor to produce good crops of those cereals.

When these plants are grown in combination the aim should be to grow them on soils generously supplied with plant food. The value of a soiling food is usually largely proportionate to the abundance of the yield, hence the mistake of sowing under conditions that do not give promise of an abundant yield. One variety will find its favorite food in such a soil and will appropriate the same. A second variety will do likewise, and so with a third and fourth. Since these appropriations draw in different degrees on the same food elements, each is enabled to get its share and thus to contribute to a large aggregate yield. In growing these crops as green food, it should be remembered that since the object is to get a large amount of green food without regard to grain production, the best soiling crops will be obtained on lands too rich for the highest grain production.

Place in the Rotation.-These crops may be given almost any place in the rotation, since they are c11t hefore weeds can ripen in their midst. A foul condition of the land at the time of sowing, though objectionable, is not so seriously objectionable as in growing sone other crops. These crops may be 
grown in a sense as catch crops; that is to say, after early pasture crops, as winter rye. Or they may be sown early and be followed by some other crops; as for instance, rape, winter wheat or winter rye, and in certain areas by winter vetches or crimson clover. When these crops precede a winter crop, there is usually ample time to prepare the land well before the winter crop is sown. 'They may also be followed by the bare fallow. And in some instances they may be sown late in the season to provide green food late in the fall. These crops are essentially cleaning crops, and they thus help to clean the land without special effort on the part of the grower to reach such a result.

Preparing the Soil.-The preparation of the land for these crops is simple, as it is for all crops that fit in almost anywhere in the rotation. Usually the deeper, the finer, the more moist, the richer and cleaner the seed bed, the more satisfactory will be the results when the crop has been sown. And as a rule these conditions can be more perfectly secured when considerable time elapses between the plowing of the land and the sowing of the seed. But there are soils in which deep plowing but a short time before sowing the seed would be harmful rather than helpful to the crop. Such are light sands and heavy clays. When these crops are to be sown after another crop previously harvested the same season, moisture in the soil will be conserved to a much greater extent by using the roller and harrow freely as soon as possible after the land has been plowed.

On lands of average fertility these grain crops may of course be growil quite sucessfully without 
further enriching the land. But it may be profitable to add fertilizers when the facilities are at hand, to stimulate abundant production. Farmyard manures are excellent when applied in a form suitable to the needs of the land. Where much rainfall is expected the manure may be applied in the fresh form, but when moisture will probably be deficient, it should be applied in the reduced form.

The commercial fertilizers most commonly used are those which are designated complete fertilizers, but the nitrogen content in them should usually be high to meet the need of these crops. And when moisture is present in a sufficient degree, these crops may be further stimulaterl by sowing on them nitrogen in some form, after the plants have made a good start. It is not usual, however, to go to much expense in specially enriching the land for this class of green crops, because of the short duration of the period of growth.

Sorving.-The seed may be broadcasted when the facilities for drilling it are not at hand, but in nearly all instances it will be found preferable to sow the seed with the drill. The drill buries it more uniformly as to depth and covers it more perfectly. Ordinarily when these grains are sown as mixtures, it is labor saving and more satisfactory in various ways to mix them before they are sown.

The most suitable kinds to sow will be those which past experience has shown to be the most vigorous growers. These will vary with variations in climate and soil. No one variety of any kind of grain can be found that will grow equally well in all 
parts even of a single state. In choosing varieties preference should be given to those which stool much, and produce growth of a fine character, providing they are not too weak in the straw to prove satisfactory.

When these grains are sown singly, the quantity of seed that may best be used can be given only approximately. The same is true of them when sown in combination. In some soils the plants stool much more than in others and grow with much more vigor. The quantity of seed therefore, that will best serve the end sought will have to be ascertained by actual test. It will seldom be found profitable to sow less than two or more than three bushels per acre. The latter quantity or a close approximate to it will usually prove more satisfactory than a less quantity of seed. But when vetches form a chief factor in the crop, a less quantity of seed may suffice, because of the small relative size of the vetch seed.

When wheat and oats are sown together, it is customary to sow about equal quantities of each. This will give a preponderance of the oat element in the crop, because of the greater stooling power of the latter, and this is so far satisfactory since green oats are considered more palatable than green wheat. When peas and oats are sown together, the most suitable quantity of the seed of each will be determined chiefly by conditions which relate to the soil arlaptation. as previously intimated. Because of the nitrogenous character of the peas and because of their high palatability, the aim should be to have the peas form the preponderating element in the food. The same is also true of vetches. It may be 
necessary, therefore, to.sow the peas or vetches as three to one or two to one by measure, as compared with the oats in the mixture. On the other hand certain soils may be so much better adapted to growing peas or vetches than ciats, that in order to secure the necessary support for the former, more than half of the seed by measure must needs consist of oats. When peas and vetches are both sown along with oats, the proportions that ought to be sown of each in the mixture should be determined by conditions that relate to soil and climate, and to the character of the food sought.

Usually the common cereals are sown to provide soiling food as early as possible in the season, though of course they are frequently sown later; in certain instances as late as midsummer. To prolong the season of feeding, it is common to sow a portion 'only of the seed at first, and the remainder two or three weeks later, or it is sown at two interyening intervals rather than one. The chief objection to the plan is found in the decreased production of the later sowings, but to this there are some exceptions.

Another plan sows a quick maturing variety as barley, and at the saine time a mixture that grows more slowly, as peas and oats. The period of feeding may thus be made to cover from, say five to eight weeks, and if the quantity sown should be in excess of the needs of the stock, it can be turned to excellent account by harvesting it for winter fodder when the grain, or much of it, is in the milk stage. Barley is probably the most suitable of all the common cereals to provide green food in the autumn: 


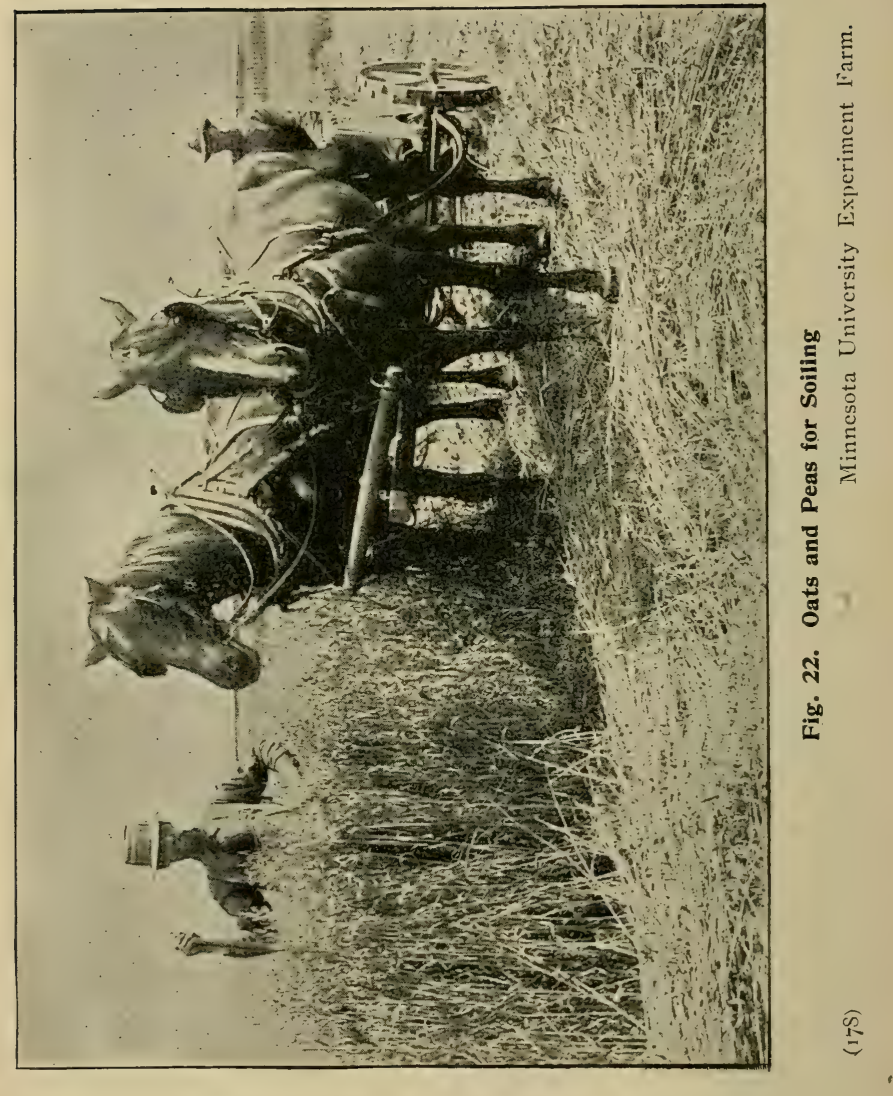


and in moist climates only, can it be sown for such a purpose, as for instance, in New England.

Cultivation.-Ordinarily no cultivation is given to these crops after they have been sown. But there may be instances when the harrow can be used on them to advantage, more especially when peas and oats have been sown together and buried with the grain drill at an even depth. If harrowed with more or less thoroughness just as the first young plants begin to appear, the growth of weeds will be checked and the moisture in the ground will be better conserved. Before the weeds can make a good start again the plants get so far ahead of them as to materially hinder their growth. But if the ground is unduly moist, the harrow cannot of course be used thus. A light harrow should be used, generally, having teeth slanted backward.

There may also be instances when it would be more profitable to plant the crop in rows sufficiently distant to give them more or less horse cultivation. Such a method of growing these plants would be especially helpful where moisture is not present in sufficient quantities to produce a maximum growth. Crops thus cultivated would no doubt produce much more abundantly, in a dry region, but the system helongs rather to the future than to the present. The machinery for bestowing such cultivation has not yet been perfected.

Feeding.-With regard to the best method of feeding these crops, much that has been said under the head of feeding in the chapter on corn will be equally applicable to them. The cutting of rye as a soiling food should begin as soon as the first growth 


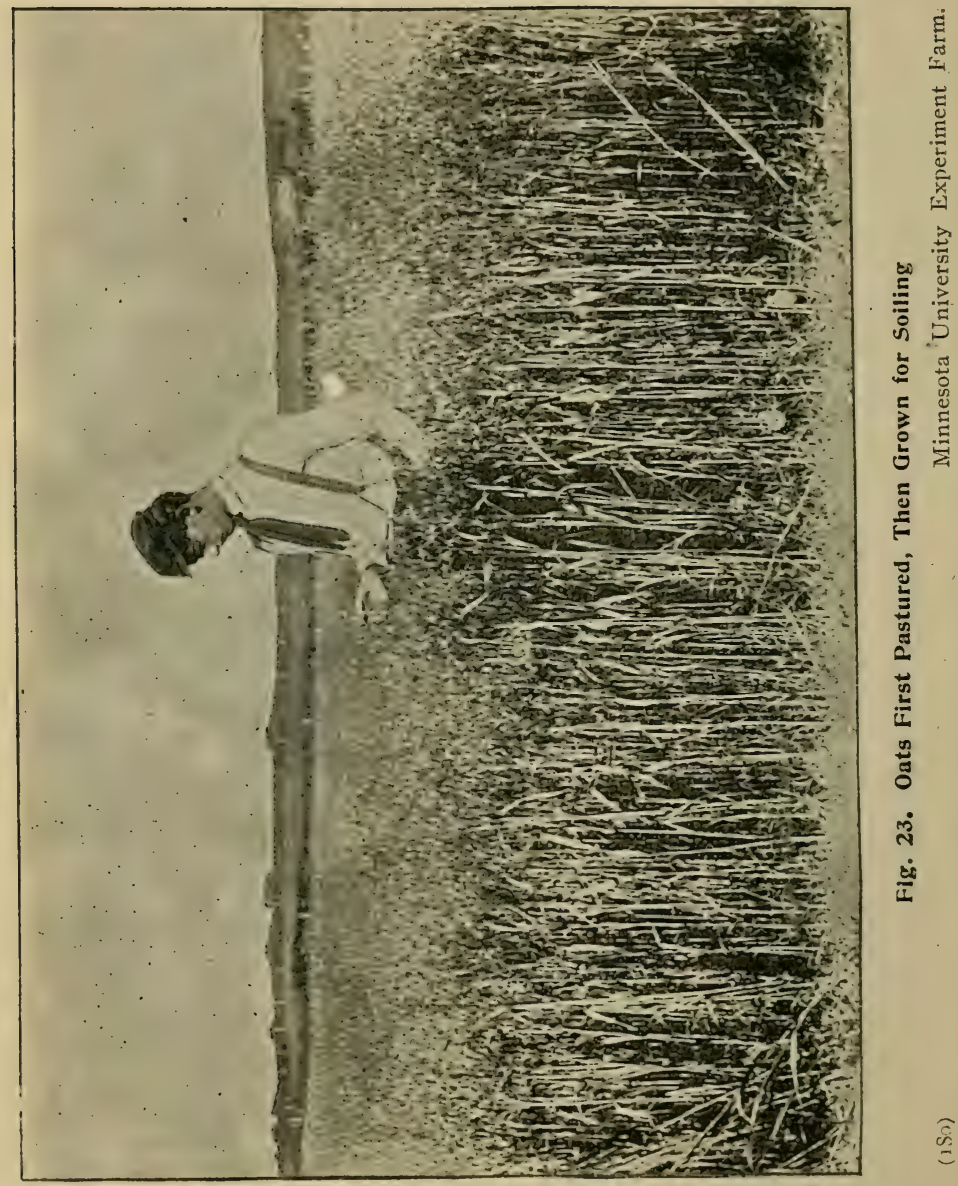


will justify such a course, and it should not be fed for any considerable time after it has reached the earing stage, unless it is to be run through a cutting box and fed with other food, as "chaffed" hay. When thus prepared, and meal is added to the mixture, it would then be possible to feed green rye until the grain began to form in the ear, and possibly for a longer period. If fed alone after it has fully come out in head, animals do not relish it sufficiently to make it a desirable soiling food. Barley also should be fed at a stage before the beards begin to stiffen.

When food is grown in mixtures the grains composing these will not always be possessed of equal advancement, careful discrimination is necessary on the part of the grower as to when the cutting should begin. Usually when peas, or vetches in the mixture have produced some blossoms and when the heads of other kinds of grain are ready to leave. the leafy envelope which surrounds them, the cutting of the crop may begin. At the stage indicated as suitable to begin cutting these crops, they have not reached that stage when they contain the highest food value, but to leave them longer before beginning to harvest them would, too much, curtail the duration of the period in which they could be fed with profit in the green form.

Like other green crops they are cut with the scythe or mower, and drawn in the usual way. When these crops grow very rankly they are occasionally thrown down with storms which increases the labor of cutting them. In some instances the mower can only be driven on two sides of the plot or field, if the crop is to be cleanly gathered. 
The food when cut may be lifted with sufficient cleanness when a fork is used, with several tines in it, that is to say, a fork made somewhat after the plan of a barley fork. The green food may be fed without any wilting, but a moderate amount of wilting is in no way injurious to it.

When there is a surplus of green food it may of course be allowed to reach a stage of early ripening, and may then be harvested for winter use. In harvesting the same the mower or the binder may be used according to the attendant circumstances, but if the binder is used the sheaves should be made small rather than large, tied loosely rather than tightly, and cured in oblong rather than in round shocks. Wheat and oats grown together ought to be cut for winter food at a stage somewhat earlier than peas and oats to insure enough palatability in the straw. When the stems of the plants turn yellow for a short distance above the ground, the crop is ready for harvesting. Peas and oats thus harvested make a splendid fodder for winter feeding. It is easily cured and handled, and is at once highly palatable and nutritious. 


\section{CHAPTER IX.}

\section{MILLETS.}

Millet is one of the most important and valuable soiling crops grown in this country. Its great value as soiling food arises, Ist, from the palatable and nutritious character of the food which it produces; 2nd, from the shortness of the period required to grow it; 3rd, from the large amount of food that can be grown upon rich land; 4 th, from the wide distribution of the crop; and 5 th, from the many and various places which may be assigned to it in the rotation, consequently when it becomes better known, it will be used as soiling food to a much greater extent than it is at the present time.

Millet is of many species and varieties, not a few of which have been but little tested in this country, and consequently they are not as yet well understood. The classification of the millets is still regarded as incomplete by the Department of Agrostology at Washington, but for the present the said Department has grouped them as the foxtail, the barnyard, the broom corn and the pearl groups. To the foxtail millets belong such sorts as the Common, the German, the Hungarian and the Golden wonder varieties. These are relatively small and fine in their habit of growth. German millet is characterized by an abundant leaf growth. Hungarian millet produces heads of a dark shade, hence 


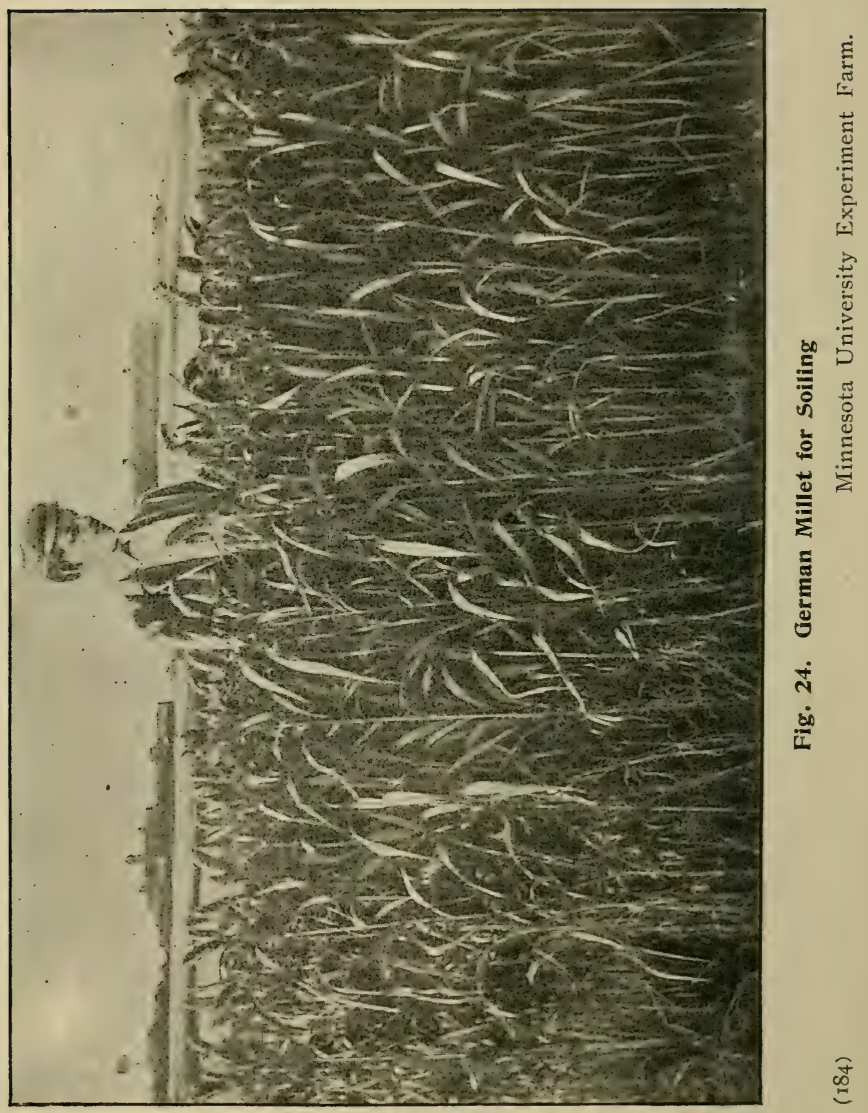


it may easily be distinguished from other foxtail millets after the earing stage. Golden wonder millet is a great seed producer but it is probably less valuable as a soiling food than the other varieties of the foxtail class.

The barn yard millets include the varieties derived from the common barn yard grass (Panicum crus-galli). The African millets are also included in this class. They are characterized by an abundant growth, but are somewhat coarse in character The broom corn millets are rather grown for the grain they produce than to provide soiling food, but they also may be made to furnish soiling food. The pearl millets are but little grown as yet in this country. Some of the varieties produce an abundant growth, but they are not considered so palatable as cultivated millets of the foxtail class. They have not been much introduced as yet into American agriculture, hence little can be said as to their adaptation and value. But one variety of this group will be considered in Chapter XIII, when discussing plants whose value in providing soiling food has not been fully demonstrated.

Distribution.-Few plants grown as food for live stock on this continent are of wider distribution than millet. Since it can be sufficiently advanced in growth for being cut as soiling food in from fifty to ninety days from the date of sowing, there are but few localities in the United States in which it may not be grown with entire success. And since it is in a pre-eminent degree a plant of the sun, the climatic conditions least favorable to its growth in our country will probably be found in 


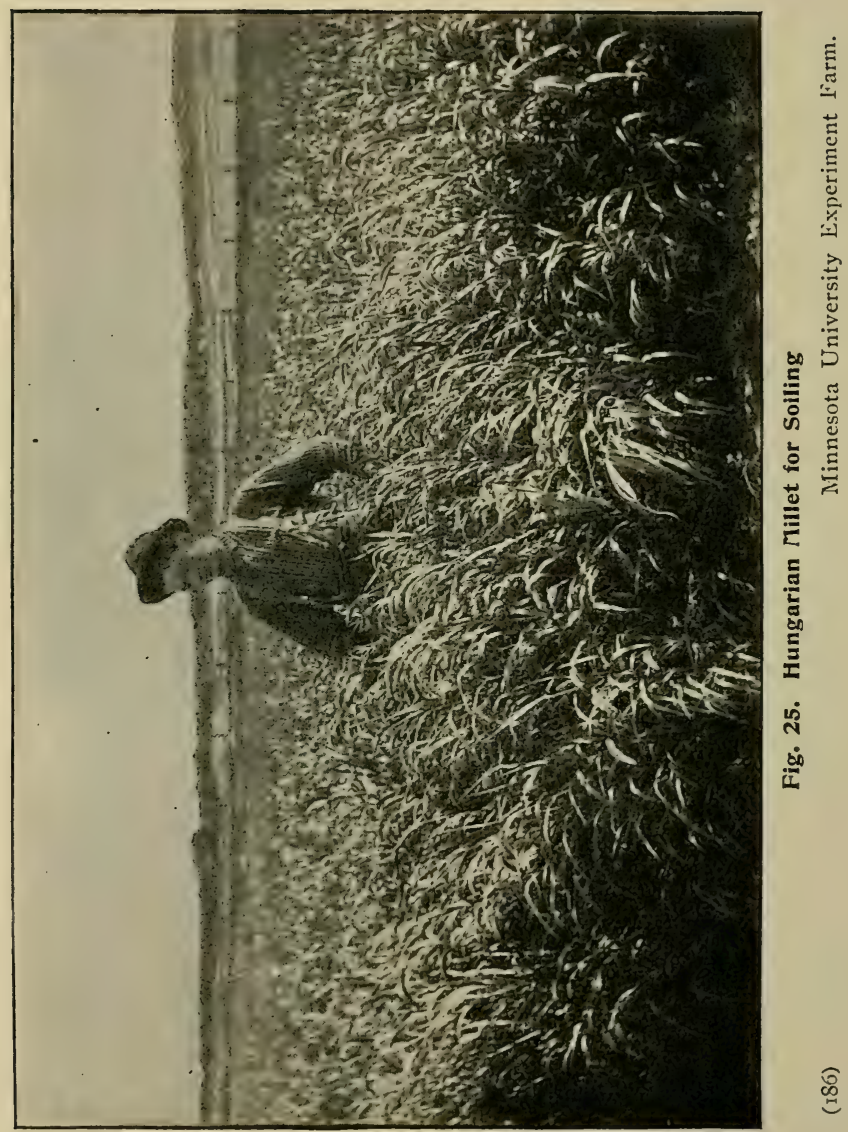


Oregon and Washington, between the mountains and the sea. In all the other portions of the United States the season of high summer temperatures is sufficiently prolonged to force millet crops quickly into maturity, unless it be upon the mountain uplands. The climate of all the central and southern states is markedly favorable to the growth of millet.

The highest adaptation of soil and climate together are probably found in the Mississippi basin, from Lake Itasca to the Gulf of Mexico. Millet is an indispensable adjunct to the hay crops grown within this basin, and it is an indispensable factor in growing soiling foods for stock. The less favorable the conditions for the successful growth of hay crops the more indispensable does the millet crop seem to be. The climatic conditions in what are usually spoken of as the southern states are equally favorable, but not so of the soil conditions, hence the growth of millet is not so common in these as it would otherwise be. The crop has not been grown to nearly the same extent in New England and the arljacent states as in the Mississippi valley, because of the stiffer soils, and in many instances because of the more hungry soils of the former. The millet crop can also be grown with a fair measure of suc. cess in nearly all of the cultivated parts of Canada. The lowest adaptation is found in British Columbia and in the Maritime Provinces beside the Atlantic, and the highest adaptation in the prairie provinces eastward from the Rocky mountains to Lake Superior.

Soil.-Millet in all its forms requires a rich soil and a soil easily penetrated by the roots of the 
plant in order to grow it in the best form. Soils abounding in vegetable matter and naturally warm and friable, and which furnish plant food abundantly in a readily available form, are best adapted to the growth of millet. Such soils abound in much of the prairie region which extends from the Gulf of Mexico far northward, although in seasons that are moist, good crops of millet may be grown even on stiff clays. But these soils are not well suited, as a rule, to the growth of millet. In nearly all instances too much labor has to be bestowed upon such soils to prepare a seed bed sufficiently fine and moist. They are not sufficiently penetrable to the roots of the millet, and the plant food in them is not sufficiently available. Light and hungry sandy soils are ill adapted to the growth of this crop, and the same is true of soils unduly moist and cold. But immense crops can be grown on the muck soils of drained sloughs and marshes. Millet can be grown nicely under irrigation in the warm mountain valleys of the west. But in these it is not specially needed because of the abundant product of alfalfa obtained from them.

Place in the Rotation.-Millet in nearly all its varieties may be given almost any place in the rotation. It may be the sole crop for the season, or it may be grown as a catch crop. It is more commonly grown as a catch crop, since in many sections the season is amply long to grow a crop of millet after another crop has been removed and before an autumn crop has been planted on the same land.

Millet is seldom made the sole crop grown upon the land, except in instances where the husbandman has been unable to sow other crops in season, because 
of excessive wetness in the soil, or because of some other reason. But when it is thus grown it may in a sense be marle a cleaning crop, even though sown broadcast, since there is more or less time for sprouting the weed seeds near the surface of the ground before the millet is sown, and when the seed is sown in rows and cultivated it may always be made a cleaning crop.

Millet may be sown with much propriety after such winter crops as rye, the winter vetch, the winter oat, or crimson clover when these have been pastured or cut for green food. Under favorable conditions it may be sown after the first cutting of medium red clover or even after grain crops that have matured early, and it fits in nicely after newly sown meadow crops in which the "stand" of grass has been a partial failure, and which in consequence has been grazed down. With equal fitness it may come after spring sown grain which from any cause may have failed. Fall wheat is sometimes sown after millet, but the plan of sowing it thus is not a good one, since millet, like flax, preys heavily upon the fertility of the soil. It has also been noticed that it leaves the soil much depleted of its moisture. It may with much greater propriety be followed by winter rye, which has greater power than winter wheat to gather food in the soil, and with equal propriety it may be followed by a leguminous crop, as the common winter vetch or the sand vetch.

Preparing the Soil.--Since millet is grown so variously in the rotation, only directions that are general rather than specific can be given relating to the preparation of the land for the seed. It should 
he the aim of the grower to prepare a seed bed clean, moist, fine and smooth. The clean seed bed can only be reached by the frequent use of the harrow for some time previous to the sowing of the seed. But when millet is grown as a catch crop the season for preparing the seed bed is usually too short to admit of thus cleaning the land. The means used to secure a clean seed bed will also tend to conserve moisture in the same, and the judicious use of the roller will also tend to secure the same end.

In cloddy soils, a fine seed bed can only be secured by the judicious use of some form of clod crusher or harrow and roller. In a dry time it would be labor lost to sow millet in cloddy soil. A level seed bed is secured by careful plowing and by supplementing such plowing with drawing some form of leveler over the soil. When any considerable perior elapses between the plowing of the land and the sowing of the seed, the land may be fitted as desired, but it more often happens that the seed must be sown so soon after the plowing of the land that it hinders the fitting of the same in the very best form.

It is not usual to aiply fertilizers directly in sowing a millet crop, more especially in the nort? and west. In the north, fertilizers are applied to crops that are considered more important. In the west they are not much needed. But on ordinary soils the yield from this crop will be greatly increased by the judicious use of fertilizers. When they are used it should be in the readily available form, owing to the shortness of the season in which millet makes its growth. If farmyard manure is applied it ought to be in the reduced form and incorporated as much 
as possible witn e surface soil, since millet gathers its food near the surface rather than far down in the soil. When commercial fertilizers are used, they should usually contain a relatively high content of nitrogen, and there are instances in which what are termed nitrogenous fertilizers are needed.

Sowing.-Millet is more commonly sown broacicast and by hand. But it may be sown by certain kinds of grain drills in common use. The following objections apply to hand sowing: I, The seed is not buried so evenly, hence the germination is less perfect than when the seed is sown with the drill; 2 , a considerable proportion of the plants start so near the surface that the loss of plants is greater if the harrow is used subsequently; 3 , the plants have also less power to withstand drouth.

Whether all the drill tubes should be used in sowing millet or only a part of them depends to a considerable extent on the kind of the millet. The small sorts are usually sown with all the tubes in use, but the larger ones are frequently sown in rows far enough apart to admit of easy cultivation. These rows are in some instances made thirty-six inches apart, but more frequently the distance is not more than thirty inches. The small millets, as the Common, the German, the Hungarian, the Golden Wonder and the Broom Corn, are more commonly sown when the crop is not to be cultivated. But the larger kinds, as the Japanese, should be preferred when subsequent cultivation is to be given. The smaller sorts furnish the more palatable food, but the larger ones produce the better yields, and the crops that are cultivated can withstand dry conditions much better 
than those that are not so cultivated. The kinds best suited to the needs of any locality can only be determined by positive test.

When millet seed is sown broadcast by hand, not fewer than sixteen quarts of seed are sown per acre, nor more than thirty-two quarts. From twenty to twenty-four quarts may be called average quantities. Thick sowing results in a finer growth in the plants, but it is only to be practiced when enough moisture may be looked for to supply the needs of the crop. When the seed is sown in rows far enough apart to admit of cultivating the crop, a few pounds of seed will suffice per acre.

It is useless to sow millet before the ground and weather are both warm. When the weather is raw and cold for some time after sowing the millet, the germination is pretty certain to be imperfect, and the subsequent growth unsatisfactory. It is usually better not to begin to sow millet until the corn planting has been finished.

Cultivation.-Millet that is sown broadcast cannot even be harrowed with a light harrow after the seeds have sprouted, without destroying a considerable proportion of the plants. But when sown with the drill, the plants will not be thus disturbed if the harrow is drawn over the ground with the teeth at a considerable angle, before the plants have reached the surface of the same. And the crop may even be harrowed at a later period if the work is done with sufficient care. But on many soils some form of weeder will do the work more satisfactorily when the seed has been broadcasted. When millet seed is not dear, if more seed were sown than would be 
deemed sufficient, then the crop can be harrowed with benefit to the same after the plants have become well rooted. Notwithstanding the destruction of plants, there will still be enough left, and they will grow much more vigorously than if the crop were not harrowed.

Cultivation should begin on the crops sown with that object in view soon after the harrowing has been completed. It ought to be frequent and thorough, and shallow rather than cleep. It will not be necessary to give the crop any hand hoeing unless it is infested with some form of perennial weed which it is desirable to exterminate, as usually it will be ready for being cut before annuals growing in it will have matured their seed.

Feeding.-The cutting of millet as a green food may begin as soon as any considerable number of the heads have appeared and it may be continuerl until the crop is ready for being made into hay. Any portion of the same not wanted as green food should be thus disposed of unless it is wanted to produce seed. Millet is sufficiently advanced for being made into hay when all the heads are fully out. As it usually heads out unevenly, the tiny heads appear considerably later than the large ones. Or it may be cut when the heads present a slightly golden tint on looking over the field. If the crop is cut earlier than the stage mentioned, it is lacking in "body," that is to say, weight and full nutrition. If cut at a later period the stems become woody and the seeds shatter more or less while the crop is being cured and stored. The scythe or the mower are to be used! in cutting millet as green food. It is drawn and fed 
as other green food, in the pasture, paddock, yard, feed rack or stable mangers. It is better not to allow the crop to wilt overmuch before being fed. But wilting millet of a growth rank and coarse in character will add to its palatability. There is virtwally no danger from feeding it green.

If two kinds of millet which mature at different periods are sown separately and at the same time, the period of feeding will be prolonged. The same end may be attained by sowing the same sort with an interval of three to four weeks between the periods of sowing the seed. The period for feeding green millet may thus without difficulty be made to embrace from six to eight weeks except where the season of growth is very short. When the season of growth is long, the period of feeding may be prolonged accordingly. But care should be taken to harvest millet before the autumn frosts arrive, as it is easily injured by frost. 


\section{CHAPTER X.}

FIELD ROOTS.

More commonly field roots are grown to provide winter food for live stock, but in some instances they are also grown to provide soiling food. The chief of these are rutabagas, turnips, mangels, sugar beets and carrots. Parsnips are too deeply rooted to admit of their being profitably grown as soiling food, and the same is somewhat true of sugar beets and carrots. The growing of these crops involves much more labor than the growing of a crop of rutabagas, turnips or mangels. And since rutabagas require a period considerably longer to mature than turnips, the latter are preferred for summer feeding. Turnips and mangels are therefore more highly adapted to providing green food than any of the other field roots that have been named. No one of these crops has been grown to any considerable extent in the United States for green food, nor has any one of them been grown for any purpose to anything like the extent to which its feeding value would justify. Ontario, Can., is beyond all comparison the greatest root-producing district in North America.

The labor involved in growing and feeding these crops will probably form an effective barrier against their general introduction as soiling food, and yet there may be instances when it would be the part of wisdom to grow them. While for all kinds 
of live stock kept upon the farm, roots furnish excellent food, they are more commonly fed in the green form to swine, though sometimes also to cows and calves, also to sheep that are fitted for being shorn. They are eminently suited to the needs of young animals, such as calves and lambs, whether fed in winter or summer. Since these crops can oftentimes be grown as a catch crop, and since they furnish a large amount of food per acre, an adequate return may frequently be obtained for the considerable amount of labor involved in growing them, especially when the holdings are small and when green food is to be provided for a limited number of animals.

As the tops and roots are both fed as green food, large yields are often obtained per acre, in some instances as much as twenty-five tons, but the average crop is considerably less than that amount, the yield depending largely on the variety grown.

Distribution. - The rutabaga, sometimes called the Swedish turnip, is best adapted to cool and moist climates. On this continent, the best crops can be grown north rather than south of the forty-third parallel of latitude, that is to say, north of the southern boundary of Minnesota.

The turnip (Brassica rapa), sometimes called the fall turnip, since it is fed in the fall rather than in the winter and spring, can be grown in nearly all the states of the Union, in several of its varieties, but it, too, is hest adapted to moist and not excessively hot climates. In the southern part of the United Staies, turnips can he grown in best form on the uplands, unless when grown chiefly in 
the autumn after the hottest weather for the season has gone.

The mangel (Beta oulgaris) will endure more heat than the rutabaga, or turnip, hence it has a wider distribution than those crops, but the mangel also may be grown more satisfactorily where the summer temperatures are not excessive, hence the best mangel crops may be looked for north of the fortieth parallel.

The sugar beet may be grown in good form in what may be termed "wine climates," that is to say, in climates well adapted to the production of the grape. But, like mangels, sugar beets may be grown much further north than grapes, except when vines of the latter are specially protected in winter.

The carrot (Dancus carota) also grows best where the summer weather is moist and temperate, but, like mangels, carrots can be grown in season in some part or parts of every state in the Union. The highest adaptation for field roots in North America is found in Oregon, Washington, the New England states, British Columbia, Ontario and the Maritime Provinces of Canada.

Soil.-All kinds of field roots can be grown in good form on deep, moist, loam soils, and possessed of that degree of admixture of clay and sand which keeps them in a friable condition. But the exact soil conditions best adapted to the growth of each are not exactly the same. Clay soils, for instance, may be made to produce good crops of mangels, but not of turnips, and the proportion of sand in the soil that would aid in furnishing high adaptation to the growth of carrots would be excessive for the best results in growing mangels. Heavy clays are not 
well adapted to the growth of any kind of field roots for soiling uses, since the labor in preparing them for the seed is usually over-much, and the plants grow slowly in them. On the other hand, infertile sands do not produce enough growth. Black loam soils, such as abound on the prairie, have high adaptation, hut they are apt to be much infested with weeds. Slough and swamp soils will produce large quantities of such ford after they have been drained, but in them the growth of top is relatively greater than in other soils. Peat soils, until reduced, are usually not good root-producing soils. But the gray sands of the Rocky mountain valleys will produce field roots abundantly when supplied with water.

Place in the Rotation.-Field roots should always be grown as a cleaning crop, whether grown for the roots only or for the roots and tops; in other words, whether they are grown for winter feeding or for summer and autumn feeding. But when grown for the last named use, they cannot, for various reasons, be made so complete a cleaning crop for the land, unless they are the only crop grown on the same during that season. The natural place for field roots, therefore, is after grain crops and on soils that need renovation, not only in the sense of being cleaned, but also in that of being fertilized.

These crops take much fertility out of the land and therefore cannot be successfully grown on depleted soils, unless these soils have first been enriched. But it is a very propitious time to enrich lands when root crops are to be grown upon them, since, owing to the cleaning given to the soil, the crops which follow are enabled to feed upon the 
unused increment in the manure rather than weeds. Grain crops naturally follow root crops, and where clovers and grasses grow well, these are usually sown at the same time as the grain, singly or in various combinations. But field roots, more especially turnips, may frequently be grown as a catch crop. For instance, a good crop of turnips may frequently be produced after the removal of the first cutting of the clover. The clover roots furnish very suitable food for the turnips.

Preparing the Soil.-If the roots are to be grown for winter feeding, the soil may be plowed in the fall or spring, according to the climatic conditions and the kind of the crop. When the winters are open and accompanied by considerable rainfall, spring plowing will be the best. But where the ground remains frozen from autumn until spring, autumn plowing will be the best. The condition of heavy soils may in some instances be improved by plowing both in the autumn and in the spring.

The aim should be to secure a clean, fine and moist condition of the land, as the seeds will not germinate in cloddy surfaces with but scant moisture. The more free from weed seeds the soil can be made before sowing the seed, the less will be the labor of tending the crop while it is growing. There is no time for sprouting weed seeds after spring opens in growing a crop of carrots, since they must be planted early. Nor is there time for the same when any of these plants are grown as a catch crop. But in growing mangels and sugar beets as the sole crop for the season, there is time for at least a partial sprouting of the weeds. There is more time for 
this in growing rutabagas because of the late planting season, and still more time in growing turnips, since the turnips are planted later than the rutabagas.

Farmyard manure is excellent for such crops. Where the land is plowed in the fall, the manure should be applied before the plowing is done, except when the soils are leachy. The manure should then be spread on the surface after the land is plowed. It may also be spread on the land in autumn or winter when it is to be plowed in the spring. When thus applied in the fresh form in the autumn it becomes incorporated in the soil by the cultivation given to the land before sowing the seed. But unreduced manure should not be thus applied in climates over-dry. Complete commercial fertilizers are the best for the production of field roots. They require a liberal feeding of phosphates, hence finely ground bones have been found specially helpful in the production of field roots.

Sozuing.-In localities with ample moisture it is considered preferable to sow the seed of all kinds of field roots in raised drills when grown as food for live stock. But where moisture is not abundant in the growing season, it is deemed preferable to sow the seed in unraised rows, as the needed moisture escapes more readily from the former. But when sown in raised drills the cultivation given may begin somewhat earlier and the hand hoeing is more easily done. The raised drills can be more quickly made by using a double mold-board plow and a marker. The distance between them will vary with the kind of roots grown and with other conditions, but usually it is not less than twenty, or more than thirty inches. 
The seed is commonly sown in the raised drills with a machine which deposits the seed in two rows at a time. This machine is drawn by one horse and is furnished with two rollers, each of which fits down over one raised drill and impacts it in advance of the drill spouts, and also with a light roller which runs behind. In some instances it will prove advantageous to run a heavy land roller over the drills before and after sowing the seed. When the weather is dry, the more closely the seed drill is made to follow the drill plow the surer will the germination be. When sown in rows on the level, the ground may first be marked out by some kind of marker and sown with a hand drill when the area is not large. But when the area is extensive, the seed should be sown by seed drills adapted to such work. Some kinds of grain drills will sow seeds thus small. With other drills it is necessary to mix the seed with some more bulky substance, as salt or road dust, before using it. But whatever the mode of sowing adopted, the straighter and more uniform the rows the more easily and perfectly can the cultivation be done.

The variety that should be sown will vary with localities and can only be determined by actual test. The most popular variety of turnips at the present time, especially in the northern and northwestern states, is the Purple Top Strap Leaf. The favorite variety of mangels in the same is the Mammoth Long Red. As rutabagas, sugar beets and carrots are seldom grown as soiling food, it is scarcely necessary to add more on the subject of varieties. But in passing, it may be mentioned that much soiling food per acre may be obtained from some of the half 
long varieties of carrots and without great labor when they can be sown on clean land. Such carrots are easily lifted.

The same amounts of seed may be sown whether the roots are used for soiling food or for winter feeding. These amounts will vary with the variety, the soil, the condition of the same and with the climate and weather at the time of sowing. But the following may be named as approximately representing the maximum and minimum quantities of seed to be grown per acre of the different species of field roots that are being considered when grown as food for domestic animals: Rutabagas and turnips, two to four pounds; mangels and sugar beets, four to six pounds; carrots, two to four pounds.

The time for sowing the seed will vary according to the varieties and other conditions. Carrots should be sown as a rule early in the season, mangels and sugar beets a little later. Rutabagas are usually sown two or three weeks later than the normal season of corn planting, and turnips still later than rutabagas. The last named crop will frequently attain a maximum of growth in ninety days. Carrots, on the other hand, require much of the growing season to complete their growth, and in many climates all of it.

Cultivation.-As soon as the plants have hecome far enough advanced to distinctly mark the line of the row, the cultivation should begin. Horse cultivation is usually given first. It should, of course, be shallow and should come as close to the line of the row as possible without giving disturbance to the plants. The remaining weeds should 
then be cut out on both sides of the row with the hand hoe and without waiting to thin the plants. If the hand hoeing thus given is carefully done, it may not be necessary to bestow upon the crop any more hand labor until it is ready for being fed. If the plants are thinned as when they are grown for winter feeding, the proper distance at which to thin them will vary with circumstances. The following may be given as the maximum distance at which the plants of the various species may be thinned: rutabagas and turnips, twelve inches; mangels, twelve inches; sugar beets, nine inches; and carrots, eight inches. The average distance to leave between the plants is about two-thirds of the distance named as the maximum. It is seldom necessary, however, to thin the plants when they are grown as soiling food.

The horse cultivation given should be frequent and should continue until the leaves of the plants come together or nearly together between the rows.

Feeding.-The feeding of field roots is a very simple but somewhat tedious process. They are pulled up by hand and laid in piles, or thrown directly into a hand barrow, or some form of wagon or truck. drawn by horses. Field roots should only be thrown in piles for future drawing when it is not convenient at the time to have the means of conveyance at hand, or when there may be opportunity to lift the plants a few days in advance of the feeding. This may be done in late autumn without serious injury to the plants, but not when the weather is warm. The roots are of course handled with forks after they have been lifted. 
They may be fed in a pasture or paddock with much advantage when the surface is well sodded and the ground is in consequence clean. They may also be fed in the cattle manger or pig trough, but when so fed some watchfulness is necessary in cleaning out the loose earth from both manger and trough, that drops off the plants.

The feeding of the crop may begin at any time after the roots have made a growth somewhat advanced. If the feeding begins too early, there will be a loss of nutriment from want of advancement in the growth of the crop. If such food is fed in excess and more especially at the first, it will induce scouring in the animals so fed. It should only be given to cows in milk after the milk has been withdrawn to avoid taint in the milk.

These crops can probably be fed with more relative advantage to such animals as calves, sheep and lambs and swine, than to matured cattle. The former consume so much less per animal than the latter that it is more practicable to feed roots to them. As a food factor in feeding growing swine and brood sows, they are peculiarly helpful, more especially when the root portion, that is to say, the edible part of the root, has made large development. But in no case should such food be made the sole factor in feeding any kind of live stock. 


\section{CHAPTER XI.}

MISCELLANEOUS PLANTS.

The plants discussed in the previous chapters can all be made to furnish soiling food in some sections of the United States with more or less profit. In addition to these are other plants, possessed of more or less adaptability in providing such food, but their exact value for this use has not been determined. The number of these is not very large at the present time, but it will doubtless be increased as the years move on. These plants will now be briefly discussed. The following includes those which have been considered as possessed of sufficient promise to merit a place in the discussion; viz.: White or Dutch clover, sweet clover, Japan clover, sainfoin, trefoil, the horse bean, the velvet bean, kale, the sand vetch, the flat pea, white mustard, the lupine, spurry, the artichoke, prickly comfrey and sunflower. Some of these plants will doubtless be found possessed of no little value in providing soiling food when they come to be better understood. Something will also be said of sacaline, the plant whose merits have been so overdrawn by some seedsmen and others interested in selling it.

White Clover.-White clover (Trifolium repens), sometimes called Dutch clover is so well known that it is not necessary to give any detailed description of it. It is native to both Europe and 
America. It is already distributed more or less over nearly all the cultivated portions of the northern and central states, and in many sections of the southern states it has also been successfully introduced. It would seem to have the highest adaptation for clay loam soils which were formerly covered with forests of hard wood trees, or of hard and soft woods growing together. When these were cleared away it seemed to come in, as it were, spontaneously, but never to the extent of becoming a hindrance to cultivation. The ordinary black loam soils of the prairie are not so well adapted to its growth, although it may be grown on these with more or less of success. The soils of the Rocky mountain valleys would seem to have supreme adaptation for growing this plant when supplied with sufficient moisture, and the same is true of the arable lands west of the Cascade mountains.

White clover is probably the hardiest of all the species of clover, hence it can be grown far to the north. As is generally known white clover is commonly grown for pasture and usually in conjunction with blue grass. Where it has been grown in rotations that do not cover many seasons, it does not ordinarily require to be sown again when laying down pastures, as in these the plants will soon appear and sometimes to the extent of forming one of the chief food elements. The plants not only produce others from seed, but also by means of runners which at intervals send down roots into the soil and form fresh plants. But when it is to be grown as a factor of a hay crop it ought to be sown along with the other seeds that are designed to furnish the hay, 
otherwise it is not likely to furnish any considerable proportion of the same the first season.

Because of the relative lack of bulk in the crop, it is seldom sown by itself for the express purpose of providing soiling food, nor is it often sown in conjunction with other clovers or grasses for such a purpose. Nevertheless there may be instances when it would be eminently wise to sow it in conjunction with common red, or alsike clover, when it is to be cut for soiling food. It adds to the fineness of the food and also to its bulk. It matures a little later than medium red clover, hence there is probably some advantage from sowing it with the alsike. But it should never be sown to provide soiling food, except under conditions of marked adaptation for growing it successfully. When thus sown not more than one or two pounds of seed are required per acre, as the seeds are quite small relatively. The quantity of the seed of the other kind sown should also be reduced by about twice the quantity of the white clover added to the other seed sown.

Sweet Clover.-Sweet clover (Melilotus alba) sometimes called Bokhara clover, is branching in its habit of growth, and it is of wide distribution. No plant of the clover family will grow over so wide an area and under conditions so unpromising. The heat of summer and the cold of winter would seem to be alike unable to kill it. While it can be grown on the stiffest clays, it will also grow and thrive on sandy soils so light that the winds will carry them, and so lacking in plant food as to be quite bare of grass during all the year. It will also flourish in regions so dry as to forbid the successful growth of 
other clovers in the absence of irrigation. And moreover, it is a plant that not only fills the soil with a mass of strong roots which penetrate the same in various directions and which go down deeply into the subsoil to gather food, but it has also much power to gather nitrogen from the air and to deposit the same in the subsoil.

Notwithstanding the great powers of growth with which sweet clover is endowed, it has been but little cultivated as yet to provide food for domestic animals. The odor of this plant is highly fragrant, but the stalks and buds possess a bitterness of taste which seems, to a considerable extent at least, to detract from its palatability. The stems also become woody at a comparatively early stage of development.

Heretofore sweet clover has been chiefly grown in America to provide food for bees, but in some instances it has been sown to hinder the washing down of the earth from embankments, which wall in the cuttings made in building railroads. More commonly it is found growing in vagrant fashion along the roadsides and in waste places, where it is maintained through self seeding. Because of this vagrant habit of growth, sweet clover has been proscribed as a weed pest by the laws of several states.

It would seem too bad to allow a plant possessed of so many redeeming qualities to be forever treated as a fugitive. The author cannot but feel hopeful that some time in the future when the seed becomes more plentifuland consequently cheaper, sweet clover will be sown on wide areas in the semi-arid belt along with small grain such as wheat, oats and barley, to help to sustain fertility and to increase the 
content of moisture in the soil by means of the increase in humus which it brings to the soil. This can be done by sowing the sweet clover at the same time that the grain is sown in the spring and by plowing the crop under the following spring after it has made a vigorous growth and in time to plant corn or sorghum.

Whether sweet clover can be made to furnish green food for live stock in the summer season is problematical. No class of domestic animals is fond of it, but taste in animals, as in individuals, is largely the outcome of habit. May it not be possible, therefore, so to develop in these a relish for this plant which would justify growing it to feed to them as soiling food? In sections where the other clovers will grow, it would probably be a waste of time to try experiments of such a character, but in other localities it may be eminently proper to conduct them. This plant is sometimes made into hay which is consumed on the farm. Why then should it be looked upon as a waste of time under all conditions to experiment in feeding sweet clover as a soiling food?

Japan Clover.-Japan clover (Lespedeza striata) has been grown in some of the southern states for several years. Little or nothing has been published regarding its behavior in the northern states. But in such of the latter as produce the leading sorts of clover in good form, it is pretty certain that it would not be profitable to grow so diminutive a plant as Japan clover, even though it should be able to withstand the rigors of the winter climate. That it can withstand those rigors is not probable, since notwithstanding the number of years 
during which it has been grown in the southern states no one apparently is growing it in the northern states.

Japan clover is a low growing plant whicli seldom exceeds the hight of sixteen inches. It is an annual, but when not grazed down too closely or cut too early it has much power to reseed itself. Since it grows readily on hard surfaces, this property may be turned to good account. It is considerably branched and has a blue flower. It may be grown on dry soils, but will of course make a more vigorous growth on good loam soils. On the former it only attains the hight of a few inches, and is used as pasture. On the more productive soils it is grown for hay. From twelve to fifteen pounds of seed are sown per acre.

Where Japan clover furnishes sufficient bulk to justify growing it for hay, it may also be grown as soiling food. It will not of course produce nearly so much food per acreas the sorghums, either saccharine or non-saccharine, but it may be grown on soils where these would not produce abundantly without being fertilized. And it may also be grown with much less outlay for labor.

Sainfoin.-Sainfoin (Onobrychis satiz'a) is a plant that grows rapidly and vigorously under suitable conditions. It is sometimes called Aspersette or Esparsette. It is a legume of the clover family, and is much branched and spreading in its habit of growth. The flowers are of a beautiful crimson tint and it seeds profusely under favorable conditions. In some parts of Europe, notably in the south of England and in France, it has long been 
grown to provide pasture for sheep and green food for horses and cattle. It has special adaptation for dry calcareous soils.

Sainfoin bears no little resemblance to alfalfa in its habit of growth. Like alfalfa it will provide two or more cuttings of soiling food or of hay in a single season, and when established will retain its hold upon the soil for a number of years, though not for so long a period as alfalfa. The same care is also required in making it into hay, or many of the leaves will be lost while it is thus being cured. Because of its early and quick growth it is ready for being cut earlier than red clover. It is thought to be adapted to conditions more dry than would be suited to growing alfalfa in the absence of irrigation. It is rather adapted to mild than to cold climates.

But little can be gleaned from the reports of the agricultural experiment stations with reference to the growth of sainfoin. It would almost seem as though it had entirely escaped the attention of experimenters in this country, and yet there is likely to be a place for it in our agriculture as a pasture and also as a soiling crop. It is claimed that when pasturing it there is no danger from hoven or bloat as when pasturing alfalfa, or red clover.

Sainfoin has been grown with much success in the neighborhood of Deer Lodge, Mont., and it is not improbable that it can be grown with equal success in nearly all the Rocky mountain valleys northward from Montana and also between the coast range and the Pacific. The seed is frequently sown while yet in the sac, and when thus sown from 
four to five bushels of seed are used per acre. Much care is necessary in saving the seed, as it shatters out easily and it also heats readily when stored. The loss in germinating power in the seed when it is thus managed is responsible for many failures in growing this crop.

Trefoil.-Trefoil (Medicago lupulina) some-times called yellow clover is of several varieties. There are but few places in America in which it has come markedly into favor. Like white clover (Trifolium repens) it is of wide distribution, but the localities are still very numerous in this country in which trefoil has not been tried. It has much affinity for limestone soils when once introduced into these. So persistent is it oftentimes in its habit of growth that it is in a sense troublesome where growing crops are to be cultivated.

Trefoil is recumbent in its habit of growth, and in many localities it is a diminutive plant, but in congenial soils it attains a considerable size. It is more commonly grown along with various other plants in pastures that are intended to be permanent in character. Its ability to maintain itself in these helps to increase its value as a pasture plant. Because of want of bulk in the growth produced, trefoil is not likely to become popular as a hay plant or as a soiling food. But doubtless there are areas in the United States and in Canada where it would pay to sow more or less of the seed of trefoil along with other clover seed that is sown to furnish soiling food. When thus grown it would add to the bulk and to the fineness of the growth in the crop. It may yet be sown on the western slopes of Oregon 
and Washington between the mountains and the sea.

The Horse Bean.- The horse bean (Vicia faba) is doubtless so named from the extent to which it can be used in feeding horses in countries where its growth has been found profitable. It is sometimes called the Scotch bean, from the extent to which it is grown in that countiy even almost to the exclusion of all other sorts of the bean family. The damp and temperate climate of Great Britain and especially of Scotland has peculiar adaptation for the growth of the horse bean. It is a hardy and vigorous grower. The plants sometimes attain a hight of four feet and even a greater hight. The pods are numerous and contain from three to five beans of a large size. The average yield per acre in Scotland is not far from thirty bushels.

The Scotch bean has been found to furnish an excellent food for horses and other domestic animals. It is best adapted to strony loam soils of good drainage. It is usual to grow the beans in rows twentyfour to thirty-six inches distant from one another, and to cultivate the crop as other beans are cultivated. The aim is to have the beans about two inches apart in the row. To grow them thus would require from two to three bushels of seed to the acre.

The horse bean has not been much tried under American conditions. It has been grown to a considerable extent however by dairymen in the vicinity of Montreal, Can. In the more dry climate of western Ontario, however, the crop has not proved a success. The author has not been able to secure a good growth of straw or of leaves in western 
Ontario or in Minnesota, but has seen plants growing vigorously in the Puget Sound country in Washington. Wherever the summer temperatures run high. the horse bean will not succeed. In this fact we have the explanation of the greater success which attends its growth in Scotland than in the south of England or in Ireland.

In North America the climatic conditions best adapted to the growth of this plant will probably be found in the New England states, in the Maritime provinces of Canada, and in the country bordering on the Pacific north from Portland, Ore. and west of the most northerly range of the Rocky mountains. In those areas this plant should certainly be tried as a soiling crop. In growing it some large variety of peas sown along with the beans would probably add to the bulk of the fodder without lessening the quality of the same.

The Velvet Bean.-The velvet bean (Mucuna utilis) is a vine-like plant which has been grown for several years past in some sections of the Gulf: states as a trellis shade. During recent years it has come to be regarded with more or less favor as a food for live stock, as a mulch for orchards, and as a means of fertilizing and otherwise improving them where the land can be tilled. While it is not considered suitable for providing pasture, it is favorably spoken of as a soiling food, and the hay is said to be superior to that made from cowpeas, since it is less coarse in character. The seeds are very rich in protein, and both vines and grain are said to be much relished by live stock. It has been given very high praise as a source of fertility, owing to 
the great power which it is said to possess of drawing nitrogen from the air.

When grown as a food crop the velvet bean sends out runners in every direction as watermelons do, and the vines thus thrown out are frequently ten to twenty feet long. They eventually cover the ground with a rank mass of vegetation fifteen to twenty inches deep. The seeds should not be planted nearer to fruit trees of a dwarfish habit of growth than five or six feet, lest trouble should arise from the vines climbing up into the trees and extending around the branches. It begins to fruit not far from the root of the plant, and pods appear in clusters at intervals all along the length of the vine. These pods are brown and velvety in character, hence probably the name, velvet bean. It has been affirmed that the yield of seed on average soils is from twenty to thirty bushels per acre.

Because of the dense shade which the velvet bean produces, it has been found valuable in smothering various kinds of noxious weeds and grasses, particularly Bermuda grass (Cynodon Dactylon) and nut grass ( $C y p$ erus rotundus). The dense covering which it furnishes to the ground retards in a marked degree the escape of moisture. In diry weather therefore the service thus rendered is invaluable to orchards.

The velvet bean is commonly planted in rows. Five feet has been named as a suitable distance between them. From three to five beans are planted in hills at short intervals along the line of the row. The seed should be planted early in the season bui not until the weather has become warm. The 
cultivation given is the same as for other beans until the runners extend so far that it cannot be longer continued.

It has been claimed that the velvet bean can be successfully grown when all the conditions are quite favorable to the growth of Indian corn, but this claim is probably extravagant since even in Louisiana the plants do not always mature all the seed produced. It is questionable if the velvet bean in its present form can be made to render substantial benefits to agriculture as far north as the fortieth parallel of latitude. That it will be greatly helpful to the farmers of the Gult states is more than probable, but rathe:- as a soil cleaner and a soil renovator than in producing soiling food. Owing to the vine-like habit of growth which it possesses it is likely to prove somewhat difficult to harvest. It will not be easy to cut the vines cleanly, and it will be more difficult still to handle them when cut.

Kale.-Kale (Brassica oleracea) is of the same species of plants as cabbage. In fact, kale may be said to mean any variety of headless cabbage with curled or crinkled leaves. And yet, paradoxical as it nay seem, there is a variety of kale grown in Great Britain poptularly spoken of as the "thousand-headed kale." It is so called from the many miniature heads which it produces on its numerous branches. It is much prized by flockmasters as a food for lambs. Some varieties of kale are very attractive in color and also in the crinkled character of the leaves. In the United States kale has been chiefly grown heretofore in gardens for its leaves which are boiled as 
potherbs. Thousands of acres are grown annually but chiefly for culinary uses.

The author has not been able to obtain any information with reference to growing it for pasture from an American source other than what has been furnished by the Mirnescta University Experiment station. The experiments there conducted have sustained the view that kale has much of adaptation for our conditions, but not more probably than Dwarf Essex rape. When sown early in the season at the aforementioned station, the plants reached a maximum of growth by early midsummer, and when not fed soon after reaching that stage of development, not a few of the leaves shrank and withered, but not to the same extent as dwarf essex rape leaves grown under similar conditions. When sown later, the plants retained their greenness and freshness until the closing in of winter. The growth was on the whole not quite so rapid as the growth of rape, but the pasture furnished was equally relished with rape pasture.

There is but little doubt that kale can be grown with more or less success in the climate of the United States wherever rape can be grown in good form. It would also seem to be equally probable that it will furnish soiling food that may be fed in the same way as rape. So far as tried in this country, kale does not seem to have any advantage over rape as a food plant, that would justify discarding the latter and growing the former in its stead.

The Sand Vetch.-The sand vetch (Vicia villosa) is being tested by several of the experiment stations, more especially by those in the southern states. 
It has aiso been tested in a limited way by individual farmers. Some who have tested this plant speak encouragingly of its value as a hay crop. In the judgment of the Author its highest use as a food plant for stock will be found in the pasture which it furnishes, and this opinion is based on the results obtained from growing it in various ways at the Minnesota University Experiment station.

It is an annual but should be sown in the autumn rather than the spring in climates where it will survive the winter, but when sown in the spring a good growth is frequently made. The plants grow but slowly for a time, but when once firmly rooted runners are thrown out in ail directions and the ground is covered with a dense mass of vegetation. But the runners become so intertwined that it is almost impossible to cut them or to pull them apart when cut. Because of this the sand vetch is not likely to become popular as soiling food when sown alone. But if sown as a mixed crop, as with oats or some other kind of grain, the grain acts in a considerable degree as a support to the tendrils of vetch. When thus grown, the mixed crop may be cut without much difficulty and used as soiling food or as hay.

When sown in the spring and thus used the plants make much aftergrowth which may be pastured until the advent of winter by sheep or cattle. When sown alone not less than four pecks of seed should be used, but when sown with another crop the amount of the vetch seed to use should be decreased proportionately as the seed of the other crop is used. The relatively dear price of the seed in the past has hindered the extensive growth of this plant. 


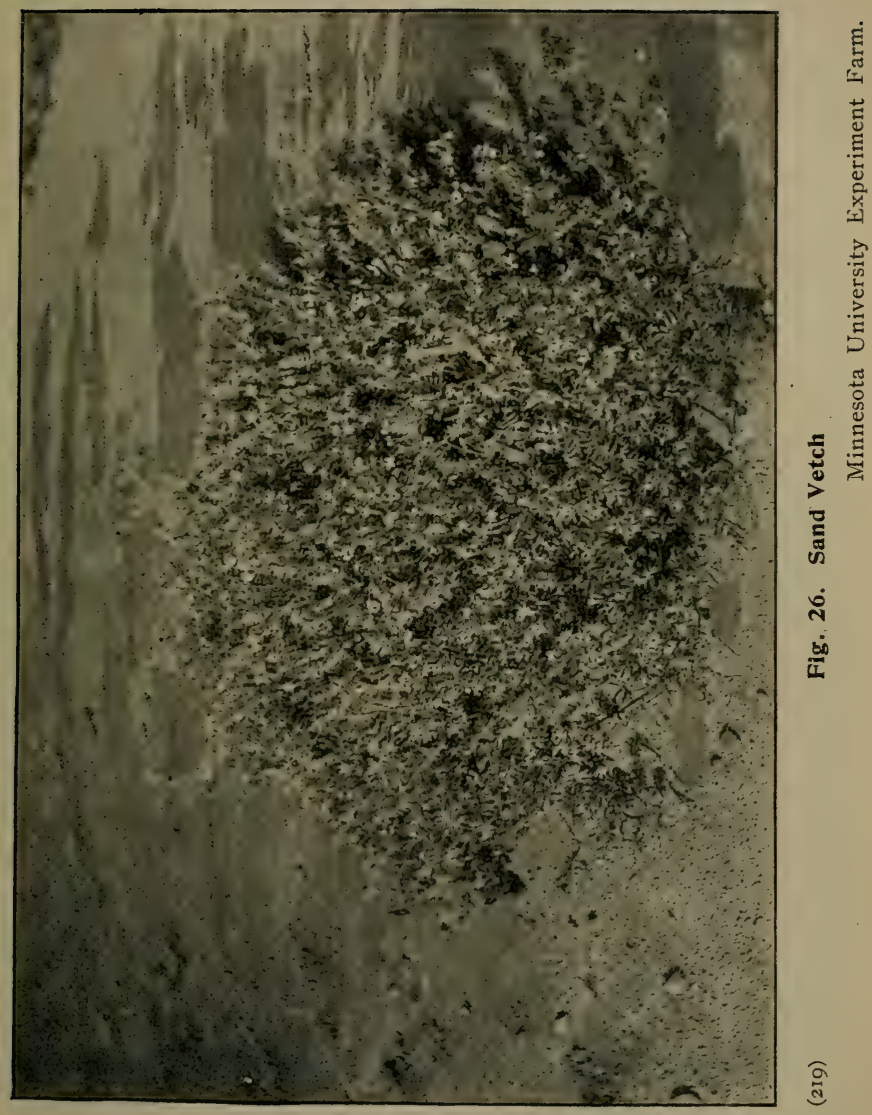


The sand vetch will probably survive the winter except in situations much exposed north of the fortythird parallel, and in certain areas it will probably live one or two degrees further to the north. It has always perished in the winter in the trials made at the Minnesota University Experiment farm, but on the Pacific coast it ought to succeed as far north as Alaska. East of the Rocky mountains it is not likely to prove of much value to the agriculture of Canada.

As the name implies, the sand vetch has much power to grow on sandy soils, and soils low in fertility. Its highest use will probably be found in enriching such lands since it is a legume. Its next highest value will probably be found in the pasture which it furnishes, more especially in southern latitudes. But it will also be grown more or less for soiling food and for hay and more especially in conjunction with some other crop.

The Flat Pea.-The flat pea (Lathyrus sylvestris), although tried more or less fully by not a few of the agricultural experiment stations in the United States, has not come into much favor. Some of the experimenters pronounce against it and others speak discouragingly with reference to it. No one who has tried this plant in. America is enthusiastic over it. In no instances have more than two good cuttings been reported per year.

The flat pea is a perennial. It is partly upright and partly vine-like in its habit of growth. The stems intertwine considerably but not so much as do those of the sand vetch (Vicia villosa). The plants bear no little resemblance to those of the grass pea, but are considerably larger and coarser. They 
are slow in becoming established, but in soils adapted to their growth they will live for many years, although American experience has not yet determined how many, unless in states where the winters are too cold for growing it successfully. Though it stands the winters of southern Ontario it cannot be depended upon to endure those of northern Minnesota.

The seed is more commonly sown in rows from thirty to thirty-six inches apart, and in sowing the same the aim is to have the plants only a few inches apart in the row. The seed germinates slowly. When this fact is linked with the slow growth the plants make the first season, the necessity for clean cultivation during that period of the development will be apparent. The plants gradually extend so as to occupy all the ground. In some areas they produce seed but shyly, more especially where the rainfall is abundant and the growth of the crop is vigorous.

That the flat pea will ever be extensively grown as a producer of soiling food in the northern states and in the middle states east of the Mississippi river is at least problematical, and for the following reasons:- I, The plants do not usually produce a full crop until the third year from the time of planting, and the seed is likely to be dear for several years to come; 2, other crops can be grown more easily, that are quite as productive of forage, that are more easily handled and that are more highly relished by live stock; 3 , the lack of palatability which experimenters complain of will tell against the introduction of the plant, but this may be overcome in part at least by persistent 
feeding for a period more or less prolonged; 4 . the plants are not easily harvested owing to the intertwining habit of growth in the tendrils. Nevertheless it would not be prudent to claim that there is no place for the flat pea in our agriculture. It may yet be grown to provide soiling food or pasture in the south and also in the far west. The sands of the semi-arid country may yet be made to produce this crop where, in the absence of irrigation, they will not produce much else. It is at least worthy of further trial in the volcanic soils of the western mountain plateaus.

White Mustard.-White mustard (Sinapis $a l b a)$ is grown more or less as a food for live stock in many of the countries of Europe. Heretofore it has been grown chiefly in gardens, only, in America. But in this country, as in Europe, it may doubtless be turned to good account in furnishing food for live stock. But when so fed it should be as a part of a ration rather than as the whole. When thus fed in proper combinations, it acts as a corrector of digestion. When fed with rape, for instance, it lessens the danger from bloating. When grown as a green food therefore it should be along with some such crop as rape, and the two plants can be cut and fed together. But there is a higher value from growing white mustard along with rape which is to be pastured off. When thus grown the tops of the mustard plants being taller than those of the rape are likely to be eaten first, so that the danger of bloating is thereby lessened. Mustard is not sufficiently nutritious to rely upon it as the sole food fed for any prolonged period. Since it is a quick 
growing plant, it will in time come more or less into favor as a crop to grow for plowing under, but not until the price of seed falls lower than it has been in the past.

White mustard may be sown any time after the danger of spring frost is past. And the crop should be fed or plowed under before the frosts of autumn blight it. Since it grows rapidly it may be grown as a catch crop and in various ways. A few pounds of seed will suffice to sow an acre when the mustard is the sole occupant of the land, and when sown along with another crop as rape, or kale, the proportion of the mustard seed should not be more than one-fourth or one-fifth of the whole. Although mustard will grow vigorously on almost any kind of soil possessed of a fair amount of plant food, and although it will make considerable growth, even on soils low in fertility, it has a peculiar affinity for loam soils abounding in lime. It grows so rapidly that under some conditions it will be in full bloom in six weeks from the date of sowing. It should be fed rather before than at the blossoming stage, since the stalks quickly become woody. It is probable that mustard fed in large quantities to cows in milk would impart something of a pungent taste to the milk. When plowed under the plants should not be allowed to get beyond the blooming stage.

There is no danger as with black or brown mustard that the seeds will remain in the soil and thus make trouble. White mustard may be distinguished from the black or brown by the rough hairs which cover the stems of the white kind, and by the peculiar shape of the pods which terminate 
in a broad two edged shaped beak. The seeds are larger than those of black mustard and are white externally.

The Lupine.-The lupine is of many species and is native to both the old and new worlds. Some of the sorts are domesticated, others of them still grow wild. The white lupine (Lupinus albus) is probably the most valuable among the cultivated species. It is an annual. The lupine derives its name from lupus, a wolf, and because of its voracious qualities. The long tap roots of the white lupine go down deeply into the soil and there they gather plant food, much of which is deposited in the surface soil. It also produces a very considerable quantity of vegetable matter the decay of which adds fertility to the soil.

The cultivation of the white lupine in Portugal has been the means of restoring vast tracts of worn out soils. It has also been much grown in Germany to increase the producing power of sandy tracts low in fertility. In Italy, Sicily and other Mediterranean countries it is extensively cultivated for forage, as green manure and also for the seeds.

The attempts made by the author to grow the lupine at the Minnesota University Experiment station have. not been successful. The plants made but little growth, and yet it is almost certain that there are extensive areas in the United States in which the growth of the lupine would be eminently successful and helpful to the cause of agriculture. These can only be determined by experiment. 
Spurry.-Spurry (Spergula arvensis) is a quick growing plant which may be raised successfully on lands too light and hungry to produce good crops of clover even where the climatic conditions are suitable. It has special adaptation for the light soils of Great Britain and in Denmark, Holland, Belgium and some parts of Germany and Russia it is extensively grown as pasture for cattle and sheep. It is also grown as soiling food, as fodder and as green manure.

Spurry is a little plant with innumerable branches and foliage very fine in character. It seldom grows to a greater hight than twenty inches, and the average hight is considerably less. The plants have some resemblance to those of flax and the same is true of the seeds. The blossoms are white and are very tiny. The stems interlace somewhat so that one is apt to trip in walking through a field of spurry in an advanced stage of growth. It is frequently ready for being pastured or cut as soiling food in from six to eight weeks from the date of sowing the seed.

The attempts made at the Minnesota University experiment farm to grow spurry have not met with much success. Those made on the light sandy soils at Grayling, Mich., have been more successful. The highest success in growing the plant in the United States will probably be attained on light sandy soils and under climatic conditions which furnish ample moisture. Whether it will ever be grown at all extensively in this country, in providing soiling food, cannot now be predicted with certainty. But it is highly probable that it will be 
made to render more effective service by growing it as a pasture or as a green manure.

The Artichokc.-The Jerusalem artichoke (Helianthus tubcrosus) has been mentioned as possessed of some value in providing soiling food and forage, but the stalks are too large and woody to meet the requirements of a good soiling or forage crop. Cattle will doubtless consume the outer portions of the stems and branches and may in time become fond of them, but they are unable to con-. sume the coarse woody stems. And there is the fur-ther objection that the stalks are difficult to handle.

This plant however may be turned to excellent account in providing forage for swine or winter food for other classes of live stock. When consumed by swine they feed upon the tubers where they grew. The artichokes are thus eaten in the autumn and winter and even in the spring where the climate does not forbid the same. The plants will render higher service in thus providing food in areas favored with mild climates, but they may be successfully grown in some part or parts of every state in the Union and of every province in Canada. There are several varieties. The Brazilian is the most commonly grown but the French Improved will give larger yields when grown on congenial soil.

Prickly Comfrey.-Prickly comfrey (Symphytum officinale) has been grown successfully as a soiling food in Great Britain and other countries of Europe for many years. Some experiments have been made in growing it in the United States, but the reports from these are conflicting. These 


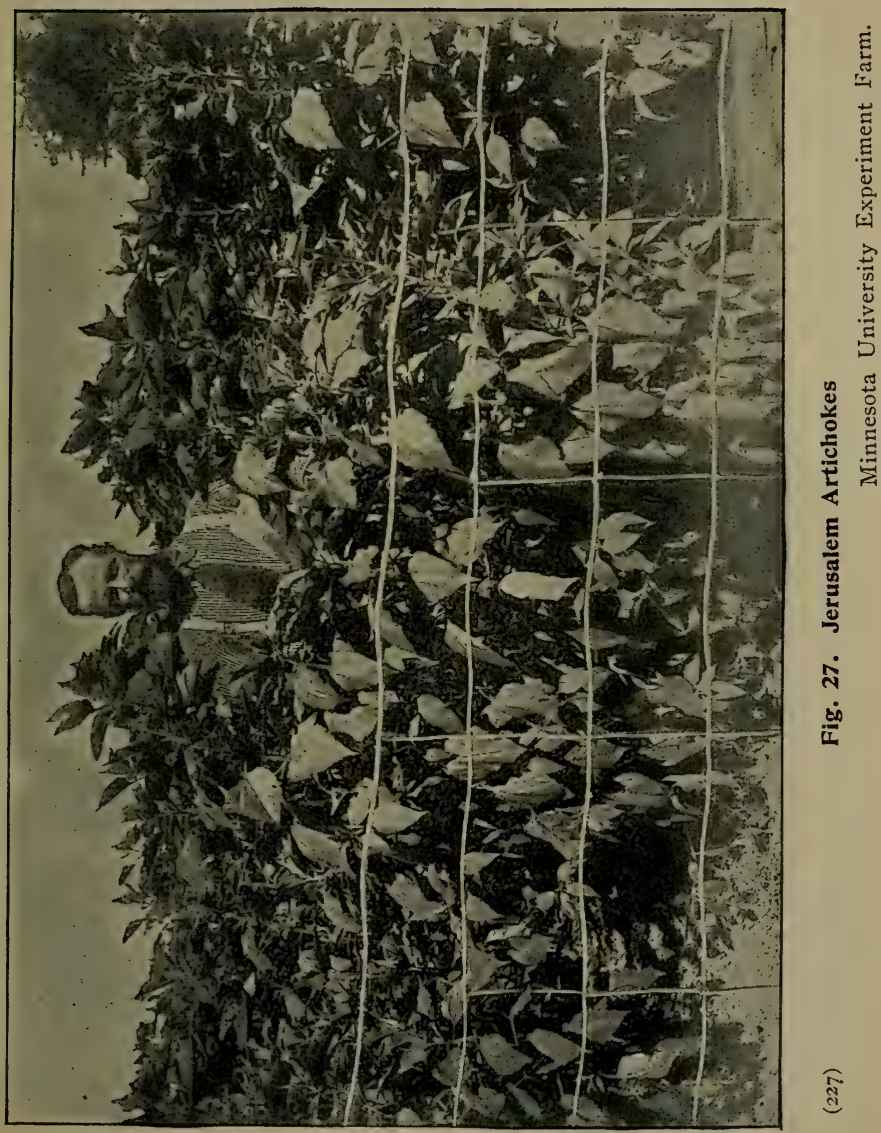


reports agree first in regard to the productiveness of the plants, and second in regard to the ability of the same to grow on light lands not possessed of high fertility. They also agree in speaking of the little relish which live stock manifest for prickly comfrey when it is first fed to them. But they do not agree as to its value for soiling uses. When fed to live stock at the Ontario agricultural college farm, the live stock did not manifest any fondness for it. Some other experiment stations have reported similarly. It may be that domestic animals may be educated to eat it, so that ultimately they will manifest a fondness for it. Were it otherwise there would seem to bo no good reasons for growing it to the considerable extent to which it is grown in several of the countries of Europe.

Prickly comfrey is a large leaved plant which grows to the hight of three or four feet. The leaves are long and narrow, and mucilaginous in character. The leaves only are eaten. Enormous crops can be grown. This plant is propagated by means of the roots and in about the same manner as rhubarb, that is to say, pie plant. The roots are Heshy, something like dock roots, and they go down to a considerable distance into the soil.

This plant is not likely to be grown as a soiling food, at least to any great extent, on the arable soils of the northern and central states, where other and better soiling plants are or may be grown so numerously. It may be different however in the southern states where cultivated grasses of the better yielding varieties grow but shyly. A plant that has rendered service in providing soiling food even in England 


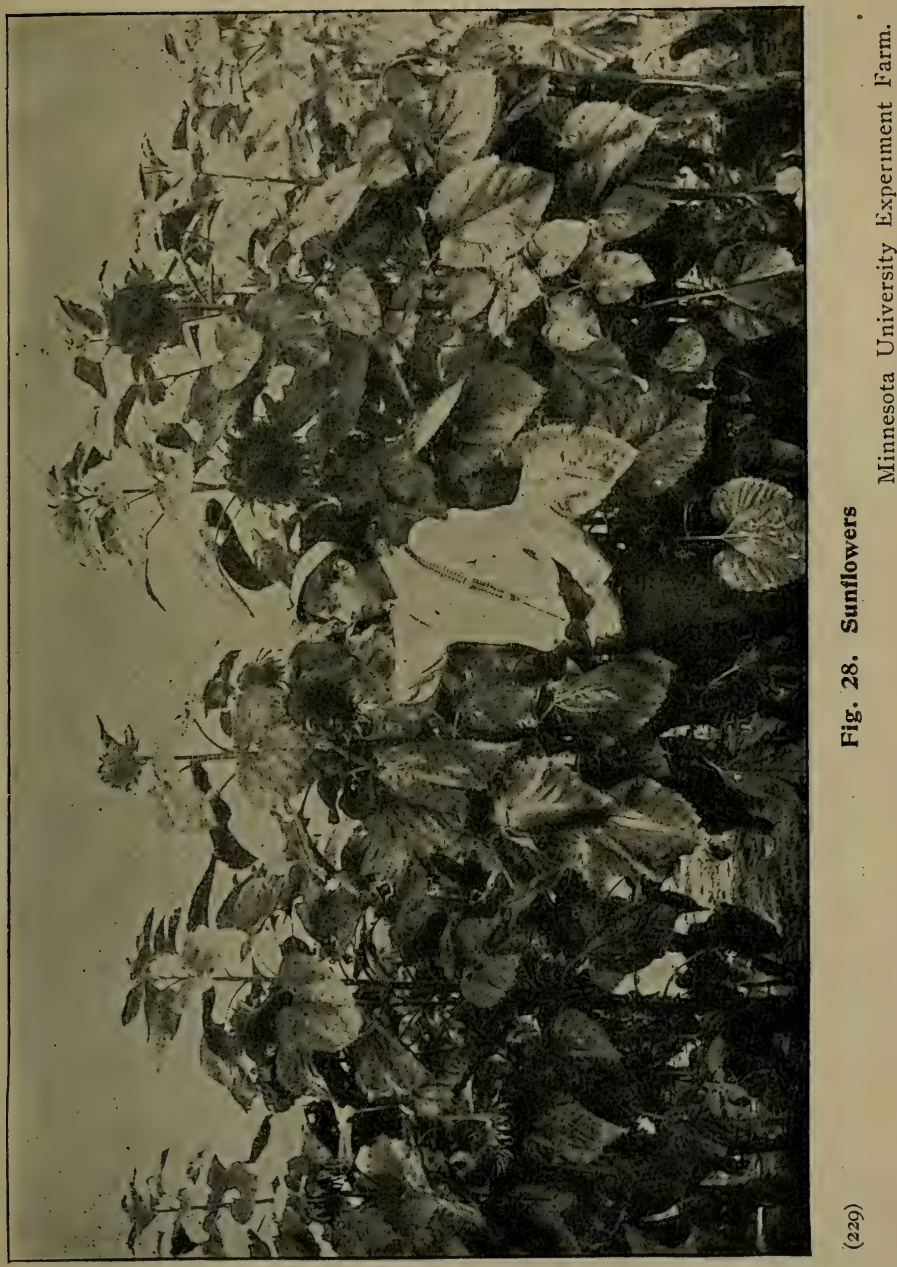


where soiling foods grow in such variety, is at least well worthy of a fair trial in all those sections of the United States which are possessed of fair adaptation for producing it.

The Sunflower.-The sunflower (Helianthus anmuns) though not suitable for soiling food because of the woody character of the stems is sometimes grown to be made into silage. Like the artichoke it is so well known that it will not be necessary to describe it. The stems are so woody that they are even considered unsuitable for being made into silage, hence the heads only are used for that purpose. Because of this and for the further reason that the work of harvesting is tedious, as now practised, it is questionable if sunflowers will ever be generally grown as a soiling crop. The difficulties in the way of gathering the seed expeditiously will deter many from even attempting to grow this plant for any purpose notwithstanding the relatively large yield of valuable food that a good crop produces. The Russian is the favorite variety grown at present in the United States.

The sunflower is of wide distribution and may be grown in a great variety of soils. The humus soils of the prairie are well suited to its needs. It has much power to grow under dry conditions.

Sacaline.-Sacaline (Polygomm Sachalinense) is a plant that is said to have originated in the island of Saghalin in the Pacific and not far from the coast of Asia. It resembles a shrub rather than a forage plant in the form of its growth. By. the time the autumn arrives the stems that have not been cut during the season are but little less woody. 
Fresh shoots are sent up every year however, to take the place of the old ones. The most extravagant statements have been made by certain American seedsmen regarding the great value of this plant for forage. They represented it as possessed of special adaptation for semi-arid climates, as being capable of producing several cuttings of foliage every year, aggregating enormous yields, and as being able thus to produce for an indefinite period.

Sacaline has been tested however by nearly all the experiment stations in this country and they are almost a unit in the verdict that it has no important mission to fill on this continent. It does not grow nearly so rapidly as was represented, and the stems become so woody at an early period of their growth that they cannot be eaten by live stock. In no trial made by the Author at the Minnesota Experiment station did the animals show any fondness for even the leaves of this plant. It is propagated chiefly by root cuttings. It is recommended to plant these in rows far enough apart to admit of cultivating the plants. But the agricultural value of sacaline would seem to be so low that to describe further the methods of growing it would be only a waste of space. 


\section{CHAPTER XII.}

\section{SUCCESSION IN SOILING CROPS.}

It will be the aim in this chapter to designate the various crops that may be grown as soiling food in one season and also the succession in which they may be grown. The task is not easy because of the great difference in the clinratic and soil conditions in the various states of the Union and in the provinces of Canada. The only way in which such a designation of soiling crops can be made that will be even approximately correct, is to divide these states and provinces into groups, and then to name the succession in the soiling crops that can be most profitably grown in each. This division or grouping of states and provinces, will of necessity have to be based upon similarity in the soil and climatic conditions peculiar to each. When those states and provinces have been thus grouped, the succession fixed upon can only serve as a general guide, because of the frequency of variations in soils in states that lie contiguous and also in different parts of the same state.

In nearly all parts of the United States and Canada, a succession of soiling crops can be grown which will furnish green food from spring until the closing in of winter. The season for growing these crops will of course vary with the differences in latitude and also in altitude. Along the northerly 
limit of the cultivated area in Canada it will be very short, and as the southern boundary of the United States is approached, it may be made to cover nearly all the year. It will be the aim in this chapter not only to point out the succession in which soiling crops may be grown, but to so designate the order to be followed in the same, so as to enable the grower to feed each plant in its proper season, and consequently when the greatest benefit will be obtained from feeding it.

It should be understood however that the succession of soiling crops given below in each of the divisions named is intended to furnish a general rather than a specific guide as to the order in which they should be grown. It would be impossible to lay down hard and fast rules that would in all instances furnish an absolutely sure guide to the grower, and for the following reasons:-

I, There are individual plants which in favorable locations may be made to furnish green food during all the season of growth. Such are alfalfa and rape. In these areas other plants may also be grown at the same time. In such instances therefore, the question with the feeder is rather a choice of plants than a succession of the same. 2, Other plants, as vetches, grow vigorously under some conditions, spring and autumn, but not in the summer, hence they are in season for being fed twice a year. 3, When soiling foods are grown as catch crops, the variations in the season of sowing them will prove a disturbing factor to any order of succession that may be fixed upon. 
Grouping Statcs and Provinces.-The order followed in grouping the various states of the Union and the provinces of Canada, will be substantially the same as that given in the book on "Forage Crops," previously published by the Author. It is as follows:-

Section No. I includes all the arable country north of the Potomac and Ohio rivers, and east of Indiana and Wisconsin. In other words it includes the New England states, the states of New York, New Jersey, Delaware, Maryland, Pennsylvania, Ohio, Michigan and Ontario, Quebec and the Maritime or Atlantic provinces of Canada. Section No. 2 covers the country west of the states of Michigan and Ohio, north of the Ohio and Missouri rivers and east of the Dakotas and the province of Assinaboia in Canada, that is to say, it covers the states of Indiana, Illinois, Wisconsin, Minnesota. Iowa, part of Missouri, and the province of Manitoba in Canada. Section No. 3 includes the states south of the Potomac, Ohio and Missouri rivers, and east of the ninety-fifth meridian of west longitude. It therefore includes the states of Virginia, Kentucky, Tennessee, North Carolina, South Carolina, Georgia, Florida, Alabama, Mississippi, Louisiana, Arkansas and part of Missouri. Section No. 4 embraces the states west of the ninety-fifth meridian of West Longitude, east of the Rocky mountains and south of the Dakotas. In other words it embraces Nebraska, Kansas, Oklahoma and Texas. Section No. 5 covers the country north from Nebraska, west of Minnesota and Manitoba and east of the Rocky mountains, that is to say, it 
covers the states of North and South Dakota and part of Montana and Wyoming, also the Canadian provinces of Assiniboia, Saskatchewan and Alberta. Section No 6 includes the Rocky mountain valleys north from Salt Lake. It therefore includes these valleys in Wyoming, Montana, Idaho, Oregon, Washington and British Columbia. Section No. 7 . embraces the Rocky mountain valleys south from the latitude of the Great Salt Lake. In other words, it embraces these valleys in the states of Colorado, New Mexico, Arizona, Utah, Nevada and California. Section No. 8 covers the narrow strip of land west of the Cascade mountains and north from California, that is to say, it covers the western parts of Oregon, Washington and British Columbia.

Succession in Section No. I.-In Section No. I the climate is more humid than in areas farther west, and the soil has more of the clay content in it than is usually found in prairie soils. This section therefore has high adaptation for plants of the clover family and for other legumes, as peas and vetches. It has high adaptation also for cereals grown alone or in the mixed form. These crops therefore should be used to the greatest extent possible in producing soiling food. Corn may be grown for soiling uses in nearly all the tillable portions of this area, and the same is true of rape, millet, field roots and cabbage, and in a less degree of sorghum. The entire section therefore has much adaptation for the growth of soiling foods.

The succession in which soiling crops may be grown in this section is as follows:-Winter rye, alfalfa, medium red clover, mammoth, and alsike 
clover, peas and oats or peas and vetches, corn, sorghum, millet, rape, field roots and cabbage. Some of these crops could be grown so as to be in season at successive intervals: Alfalfa and rape are of this class, others are in season simultaneously, as for instance peas and oats, mammoth and alsike clover. The principal soiling crops in a more restricted succession would contain, peas and oats, or vetches and oats, corn or sorghum, and rape or field roots. Where crimson clover can be grown it will be ready for feeding next after winter rye.

Succession in Section No. 2.-The medium red, mammoth and alsike varieties of clover grow well in nearly all parts of states included in Section No. 2, but not in the province of Manitoba. Crimson clover only succeeds in the more southerly areas of the same, and even in these it is not absolutely reliable. Winter rye, mixed grains, millet, rape, cabbage and field roots grow vigorously, but not with an equal vigor in all the area included. The same is true of corn and sorghum, although these grow much better southward than northward. Peas and vetches grow fairly well but better northward than southward. The cowpea and the soy bean in some of their varieties grow nicely in the southern part of Indiana, Illinois and Iowa, but not so well farther north. Alfalfa grows only in sectional areas. It is evident, therefore, that the succession in the northern third of this section would not be the same as in the southern third. In the former the order in which the leading soiling crops would be ready would be as follows:-

Winter rye, peas and oats or peas and vetches, 
corn or sorghum, millet, rape, field roots and cabbage. And the more important of these would include peas and oats or peas and vetches, millet and rape. In the latter the order would be:-Winter rye, medium red clover, mammoth, or alsike clover, peas and oats, or peas and vetches, corn, sorghum, millet, rape, field roots and cabbage. In the central third of the section the most favored varieties would include, peas and oats, corn or sorghum, millet and rape. In the southern third of the same these would include medium red clover, the soy bean, or cowpea and corn, or sorghum. Where crimson clover and alfalfa could be grown, these would be ready for being fed immediately after winter rye.

Succession in Section No. 3.-Winter rye, winter oats, crimson clover, the common winter vetch, the sand vetch, corn, sorghum, the cowpea, the soy bean, rape and cabbage can be grown with more or less success in nearly all sections of the several states comprised in this section. The non-saccharine sorghums and millet in some of its forms can also be grown at their best in certain sections, but not so generally as nearly all of the various plants previously named. Alfalfa grows admirably in many localities, but does not succeed in others, and the same is true of field roots, and in many sections Japan clover, the velvet bean and teosinte grow with much vigor. More especially is this true of areas that lie within the Gulf states.

For the northern half of Section No. 3 the succession would be:-Winter rye, winter oats, crimson clover, the common winter vetch, the sand vetch, corn, sorghum, one or more of the non- 
saccharine sorghums, the cowpea, the soy bean, millet, rape, field roots and cabbage. A limited succession would include crimson clover, the soy bean or the cowpea and corn or sorghum in one or more of its varieties. The succession for the southern half of the section would be to a certain extent the same as for the northern half, but in the former more prominence relatively should be given to the sorghums than to corn, and in some sections the velvet bean and possibly teosinte and Japan clover should be given a place in the succession. Where alfalfa can be grown with entire success, as for instance on the bottom lands of Louisiana, this plant alone could be made to provide soiling food for live stock during much of the year.

Succession in Section No. 4.--In Section No. 4 the variety of plants that can be grown as soiling food is not quite so large. In much of this area the clovers, except alfalfa, could scarcely be taken into account. The millets, at least in the common varieties, would not prove a marked success, because of the dry conditions. The common winter vetch and the sand vetch would not render much service, chiefly because of the want of moisture. Much prominence ought to be given to alfalfa, especially in Nebraska and Kansas, and to certain of the nonsaccharine sorghums as kaffir corn and milo maize, in all the area, because of the marked adaptation for these plants. The soy bean has on the whole higher adaptation to these states than the cowpea. The moisture is also too little to admit of growing rape at its best and the summer temperatures are also too high. 
The succession of soiling foods would be somewhat as follows:-Winter rye, alfalfa, the sand vetch, the cowpea, corn or sorghum, one or more of the non-saccharine sorghums, pearl millet and teosinte. A more limited succession would include, alfalfa, corn or sorghum, the soy bean and one or more of the non-saccharine sorghums. These crops, except corn and the soy bean, may be made to furnish more than one cutting a year.

Succession in Section No. 5.-The succession of soiling plants in Section No. 5 is still more restricted than in Section No. 4. The several species of clover are virtually excluded except in some of the river bottoms toward the mountains. In these alfalfa may be grown. The non-saccharine sorghums, the soy bean and the winter vetch must also be excluded. The cereal grains of the small varieties, corn, millet, rape, field roots and cabbage are the only soiling foods which can be grown in nearly all the area covered by this section.

The succession in the eastern half of the section would be:-Winter rye, mixed grains as peas and oats, millet, corn, rape, field roots and cabbage. The more restricted succession would include:-Mixed grains, corn, millet and rape. In the western half of the area, the principal crops would be mixed grains and corn, and in the river bottoms alfalfa could be added. Quick maturing varieties of corn would have to be grown in nearly all parts of this section. Sorghum could also be grown in the southern portions. Millet grows admirably along the eastern border. But winter rye could not always 
be depended on westward in the section, because of the want of moisture in the autumn.

Succession in Section No. 6.-In the mountain valleys in this section, alfalfa, medium red clover, peas and vetches will probably furnish the chief soiling foods through all time. In the valleys lying southward these crops will be grown under irrigation. On the bench lands adjacent to the mountains, they will be supplied with moisture from seepage waters percolating downward because of the melting of the snows upon the mountains. In the valleys lying northward these crops will in many instances be grown without irrigation.

The possible succession of soiling crops would include winter rye, the winter vetch, alfalfa, medium red clover, alsike clover, mixed grains as peas and -ats, the sand vetch, rape, field roots and cabbage. The more restricted succession would include alfalfa, medium red clover and peas and oats, or peas and vetches. In the valleys lying southward, much prominence should be given to the winter vetch, and some use could also be made of corn. Alfalfa alone could be made to supply soiling food during nearly all the growing season. Especially is this true of the valleys north of the Canadian boundary. In the semi-range lands of Washington and Oregon where the conditions are dry, and where irrigating waters cannot be supplied, and where also the nights are cool, the succession would have to be restricted to such crops as mixed grains of which wheat would be one of the chief, Austrian brome grass, (Bromlis inermis) and rape. 
Succession in Section No. 7.-Much of the soiling food grown in this section would have to be produced through irrigation. Alfalfa alone could be made to meet the requirements, so marked is its adaptation to the conditions of soil and climate. But to create variety such foods as the soy bean and certain of the non-saccharine sorghums could be introduced.

The possible succession in soiling crops would include, winter rye, alfalfa, mixed grains, as for instance oats and the sand vetch, corn, sorghum, the non-saccharine sorghums, the soy bean, pearl millet, teosinte, rape, field roots and cabbage. The more valuable of these crops would be alfalfa and the sorghums. These could be grown side by side and could at certain times be fed simultaneously.

Succession in Section No. 8.-In no part of the continent can soiling foods, leguminous in character, be produced in so great variety as in this section. All the leading varieties of clover grow admirably, and the same is true of the leading varieties of the vetch and pea. The sand vetch will doubtless grow well, but because of the ease with which the common vetch can be produced it is not necessary to grow it unless in areas sandy in character. Rape, field roots and cabbage grow in great perfection. But the summer temperatures are low for corn, sorghum, the non-saccharine sorghums and millet. Alfalfa and crimson clover have not been much trierl as yet, but will doubtless succeed.

The possible succession of these crops therefore will include winter rye, crimson clover, alfalfa, medium red, alsike, mammoth and white clover, I6 
perennial rye grass, peas and oats, peas and vetches, rape, field roots and cabbage. Medium red clover alone could be made to furnish soiling food during much of the season, and the same is true of the vetch if both the winter and the spring varieties are sown, and it is also true of rape. The restricted succession would include medium red clover, vetches and oats, peas and oats, and rape. 
SILOS AND SILAGE

\section{PART TWO \\ -}

\section{TAD \\ LAGE}

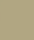

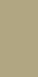

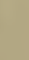

SILOS AND SILAGE 



\section{CHAPTER I.}

THE HISTORY OF SILOING.

Any discussion of soiling crops that did not also coninider silos and silage would be incomplete, since it is probably true that more green food is fed in the United States in the form of silage than in any other form. It would not be possible with accuracy to state the number of silos in the United States at the present time but it is probably not less than one hundred thousand, and it is rapidly increasing. There is probably no state in the Union without its quota of silos. This fact is very significant when it is called to mind that over ground silos had not been built in this country prior to 1876 .

Plan of the Discussion.-It will be the aim of the Author to discuss this question from an unbiased standpoint. In reading the various excellent publications that have appeared on the subject in the United States the thought is forced on the mind by all or nearly all of them that they are in a sense pleas for the silo. The men who have written them have been enthusiastic advocates of the silo, and in their enthusiasm they would seem to have overlooked or kept in abeyance the fact, that silos are not equally needed, or equally helpful in the various states of the Union or even in all sections of each state. This enthusiasm is not only pardonable but it has unquestionably been positively helpful in hastening the 
introduction and distribution of silos. And these in turn have proved greatly helpful to farmers and more especially to dairymen.

The present discussion however will not be a plea for the silo. It will look into both sicles of the question for it is true that silos are not equally necessary, that they are not equally helpful, that some conditions of farming do not call for their construction and that only certain kinds of crops can be preserved in them with uniform success. The aim will be therefore to discuss the question as it is, and not as the Author might desire it to be.

Definition of Terms.-A silo is a structure designed for the preservation of food in the green and succulent form. The term is derived from the Greek word siros a pit for holding grain. In some instances it is simply a pit or hole dug in the grounrl where the drainage, natural or artificial, is sufficient to prevent an undue accumulation of moisture. In others it is a structure of wood, stone or some other building material or a combination of these standing out by itself or within a barn or stable of which it may be said to form a part. More commonly it is now built entirely above ground although sometimes it goes down for some distance into the earth. The modern silo is usually a structure rather than a pit, as the original idea of preserving food in pits in the ground is but little practiced now, at least in this country.

Ensilage or Silage, as it is now more commonly called, is green and succulent food preserved in a silo in a green and succulent condition. It is 
preserved in the uncut form or after it has been run through a cutting box and is packed more or less tightly according to conditions such as those that relate to the variety of the food, its succulence, and the depth of the silo. Soon after the green food has been placed in the silo fermentation begins and the temperature rises. The air within the mass is thus expelled and when it is, chemical change virtually ceases. The product thus preserved may be kept indefinitely, providing air is not allowed to penetrate it. Because of this it is important that the sides and floor of the structure shall be practically air-tight. The air is usually prevented from entering from above to any considerable depth by covering the silage with some less valuable vegetable substance as more fully described in Chapter V.

The principle in making silage is the same virtually as in canning fruits or in making sauerkraut. When the temperature in the mass rises until it attains I22 degrees Fahrenheit the action of the ferments is arrested. As soon as the available oxygen is exhausted chemical change ceases and sweet silage is the result. If however from any cause, as for instance an excess of moisture in the plants, the temperature does not reach 122 degrees Fahrenheit, the acid ferments will not be killed and the result will be sour silage. Sour silage is not only less valuable than sweet silage, but there is usually greater waste in making it.

The terms sweet and sour as applied to silage are only relative terms. There is no line of distinction between them so sharply drawn that it may be said where the one hegins and the other ends. 
There is no silage of which it may be said that it is entirely free from acidity.

Formerly the term ensilage was frequently used to indicate the process of storing food green and succulent in the silo. As distinguished from silage the latter was the food and the former the process of making it, but the use of the term ensilage is becoming obsolete. Ensilage and silage are now regarded as synonymons.

Siloing or Ensiling food is the process of making it into silage, that is to say, it is the process of putting it into the silo and of curing it in the same. While it cannot be said that these terms have been extensively used by speakers and writers they would seem to express very concisely the idea involved. Why then should any objection be made to using them?

A Siloist is a person who makes and feeds silage. The term has not been used heretofore to any considerable extent. Possibly it may never become popular since the making and feeding of silage is more commonly an adjunct of farming, rather than the principal work of the farmer, and those who make silage are also usually farmers. The term is certainly wanted however or some equivalent to it for conciseness of statement when designating the relation of those engaged in making silage to the work in hand, why then should it not be adopted?

Antiquity of Siloing-It is not known when the method of preserving green food by putting it in the silo originated. It cannot therefore be known who was its originator. History is likely to be forever silent on this point. Ancient writers speak of 
the practice of burying grain in underground pits to save it for future use, or from enemies. It is possible therefore that the idea of the possibility of curing food on the principle now practiced in making silage was the outcome of the accident of hiding it from enemies and then finding it in good condition for use after it had been buried for a period more or less prolonged.

There is ample evidence to show that semibarbaric races in various countries have not only known of this method of preserving food but to some extent they have practiced it. Notably is this true of certain of the peoples of northern Europe, as for instance, those located in the regions around the Baltic sea, where rainy harvests render it difficult to preserve fodder for animals in the dried form. Their necessities therefore caused them to give some attention to a question that under other conditions would have attracted no attention whatever.

Utilization of the Idea.-For about a century the preservation of green food by the same method substantial'y as that followed in making sauerkraut has prevailed to some extent in various parts of Germany. But it was not until the approach of the middle of the present century that attempts were made to preserve food thus on a large scale. The introduction of the manufacture of sugar beets into central Europe is doubtless responsible, in part at least, for the greatly increased attention that then hegan to be given to preserving food by burying it in pits. It was found a necessity in utilizing sugar beet tops and sugar beet pulp to the best advantage. But even then the process spread slowly owing 
doubtless to the great labor involved in curing green food by the method then practiced.

The Earlier Silos.-The earlier silos used by the people of France, Germany and some other countries in Europe were simply pits or trenches dug in the ground. The material was spread in these in uniform layers and was trodden or otherwise compressed so as to lie compactly. The green food was put into those pits by successive stages as for instance day by day or at intervals more prolonged. The amount put in at one time was limited to not much more probably than one foot in depth. The object sought by filling thus gradually was to secure a more perfect settling of the mass through the fermentation engendered.

When the pit was full it was common to cover the green food with a layer of straw or some other dry porous substance. Boards were then laid over the straw and a pressure applied which was not less than one hundred pounds to the square foot. The pressure was commonly secured through weighting with some heavy substance, as by placing stones on the boards or by covering them with earth. The earth thus used was distributed over the pit to the depth of one to two feet.

In some instances the sides and floor of the pits were puddled with slay, and sometimes, the sides were lined with boards. During the later years of siloing on this plan the trenches were occasionally cemented but this was not until a considerable period had elapsed subsequently to the more general introduction of this method of siloing. Such were the first silos made in the United States. They were 
patterned more particularly after the silos built by Goffart the great French siloist whose work is again referred to. His silos were $39.4 \mathrm{ft}$ long, I6.4 it broad and $\mathrm{i} 6.4 \mathrm{ft}$ deep and they were much circled at the ends. But the laboriousness of the process made it irksome to those who adopted it, and, because of this, American ingenuity set to work to emancipate the siloist from the bondage of so much hard labor when curing green food. The result has been that the adaptation of the silo to the needs of the general farmer has been almost entirely the outcome of American skill.

The Modern Silo.-When silos first began to be built on the modern plan, that is to say on the plan of a structure rather than on that of an underground pit it was deemed necessary to make the walls of stone and to excavate so that the silo would be, in part at least, below the level of the ground. And even as late as $188_{5}$, the practice of covering with boards and then weighting with earth or stones was universal. The idea of making these structures narrow and deep so that pressure would be secured from the silage itself had not yet dawned on the minds of experimenters. The cost of the structures then used was so great and the mode of filling the silo and feeding the silage so cumbrous that it was feared by many that the silo would be helpful only to those possessed of considerable means, rather than to the great mass of farmers.

It would be interesting to know more of the successes and failures in building silos and making silage during that peculiarly tentative period in American siloing between $\mathrm{I} 880$ and I890. To get 
this information would mean a search through the file copies of the entire American agricultural press. Much of it has doubtless never been published, since men are prone to cover up the story of failure rather than to hang it up as a beacon for the guidance of others. No question however was more discussed by contributors to the agricultural press during that revolution period in American siloing, and no question was more controverted. Even the most sanguine advocates of the silo during the decade referred to could scarcely have hoped so soon to witness the completeness of the triumphs won by the modern silo. None would then have dared to predict that the last lays of the century would look out over not fewer than one hundred thousand successful silos in the United States.

It is claimed that the first silo built in America on the modern plan was made in 1876 and that it was erected by F. Morris of Maryland. The first wooden silo built west of the Alleghany mountains was that erected by John Gould of Aurora Station, O., in I884. The province of Ontario took its full share in helping forward the evolution of the American silo. V. E. Fuller, then of Hamilton, erected the first silo built in that province on his Oaklands Jersey farm in I88I. It was located in the bay of the barn and in making it the ground was excavated far down through gravel hardpan. The walls and floor were lined with bricks and the bricks were overlaid witl: concrete. Though Canada is not essentially a corn producing country like unto the states in the corn belt, many silos have been successfully built and operated in Ontario. The marked attention given to 
the dairy industry in that province is largely responsible for such a result.

The chief centers for silos in the United States are, of course, the dairy centers, as for instance, New York, Pennsylvania, Wisconsin and Illinois. But many silos are now being built in states further west, as for instance, Minnesota and Iowa. In the New England states the number of silos is also relatively large.

American Progress in Siloing.-The marvelous progress in siloing in the United States during recent years is not accidental. The time was ripe for the introduction of the silo. A wave of dairy advance was beginning to sweep over the continent when discussion began as to the merits of the silo, and dairymen must through all time be deeply interested in securing succulent food for their cattle. The attention of a large and intelligent section of the community was therefore at once secured as soon as the discussion began on the practicability of providing green food summer and winter for dairy stock.

The great extent to which Indian corn is grown in this country proved favorable to success in the earlier experiments in making silage. It is now generally conceded that Indian corn is par excellence? the silo plant. The great success achieved by American siloists is in a measure due to this fact, but of course it does not account for the great progress made in improving the silo or in preserving silage.

Mistakes Made by Early Siloists.-As was to be expected many mistakes were made by the earlier siloists. The silos were unnecessarily costly as 
already intimated. They were sunk too low in the ground. So little attention was given to the preservation of the foundation of wood silos when they were first introduced and to providing ventilation for the walls that decay was unduly rapid. The silos were too shallow, hence the pressure of the silage was not enough to secure the best results. The surface dimensions were often so large as to make it difficult to properly preserve the exposed portion of the silage while it was being fed. Corn and other green food was oftentimes put into the silo in a form too green, hence it became unduly sour. And in other instances the food was put in too dry which induced mold. These mistakes may now be generally avoided by the siloist who intelligently makes use of the information now available. But it must be acknowledged that many things are yet to be learned about siloing by the average siloist before he will be able to make first-class silage with uniform and unvarying success.

Literature on the Silo.-Since the introduction of the silo into the United States no question pertaining to agriculture has been more generally discussed. At the outset these discussions emanated chiefly from the men who had experimented wit? silos and they appeared in pamphlet or book form and also in the agricultural press according to circumstances. Later, experiments were conducted and somewhat numerously at a considerable number of the agricultural experiment stations. The results from these experiments were given to the public in bulletin form. It is evident therefore that much of the literature produced on the subject is fragmentary 
and of necessity somewhat crude in its character. More recently however a few individuals have published books on the subject which cover the same with more or less completeness. But almost without exception it would be correct to say these are pleas for the silo rather than unbiased discussions of the broad question of silage and the silo.

In the juidgment of the Author nearly all of those who have written thus upon the subject in the United States have overestimated the feeding value of corn and its power to maintain animals in good health when fed continuously as the principal food ration. They have also apparently placed too little value on soiling crops, more especially the legumes. They have underestimated the worth of pastures by viewing them simply as producers of so much food without having sufficiently considered the beneficent influence which they exert mechanically and otherwise upon soils. And they have not sufficiently emphasized the losses from making poor and spoiled silage. However, it is but fitting to say that the enthusiasm which has shut its eyes to these and kindred truths relating to the siloing of crops has been most helpful in fastening public attention on a method of preserving fodder which is certainly capable of bringing great benefit to our agriculture.

It is now generally conceded that the first book ever written on the silo is from the pen of M. Auguste Goffart, an agriculturist of Sologne, near Orleans, in France. The manual of the Culture and Siloing of Maize is the title of the book in English. It appeared in 1877 and it contains the results of many years of careful experiment in growing and 
preserving green crops. The appearance of this work did much to arrest the attention of agriculturists not only in France but also in other countries. Although sundry experiments in preserving green crops in Germany and also in some other countries had been conducted previously to the publication of Goffart's book, there can be no doubt that its appearance served in no slight degree to draw public attention to the advantages resulting to the agriculturist from preserving crops thus in the green form. Because of M. Auguste Goffart's early, persistent and abundant labors in this work he has been frequentiy designated "The father of modern silage." His book was translated into English in I879, by J. W. Brown of New York City.

In I875 "The French Mode of Curing Forage" was published in the annual report of the Uniter States department of agriculture. This it is thought was the first discussion of the subject in the United States which treated it in a comprehensive and systematic manner, although previously various articles had appeared in the agricultural press. These related chiefly to European experience. Dr. J. M. Bailey published a work on the subject in I88o. Dr. Manly Miles of the Michigan Agricultural college wrote a work cn silos, silage and ensilage which appeared in I889. Prof. A. J. Cook then of the Michigan Agricultural college published in 1889 "The Silo and Silage" and in I 890 a revised edition of the same. This book treats of silos as then constructed and of silage, as then made, in a very practical way. The "Book on Silage" by Prof. F. W. Woll, of the Michigan Agricultural college, was 
published in 1899. It is by far the most comprehensive discussion of the question that has yet appeared from the pen of any American author. Other publications have also appeared in Europe on the question, but they are not noticed here since the methods which they recommend are on the whole not nearly so well adapted to American conditions as those submitted by American authors.

I7 


\section{CHAPTER II.}

THE BENEFITS FROM SIL.OING CROPS.

The benefits from siloing crops are many. Prominent among them are the following:- I, The crops that are thus stored may be harvested in what may be termed a wholesale way. 2, They may be cured, without loss, in showery weather. 3, Green food may thus be furnished all the year from this one source. t, The food is rendered more palatable and in a sense more healthful when fed as a part of a ration. 5, The silo is economical of space. 6 , I $t$ is also economical of labor when the food is being fed to the stock. These benefits are however to some extent offset by certain disadvantages. These will be noticed as well as the benefits, and some practical deductions drawn from the discussion.

Wholesale Harvesting of Crops.-When crops are cured in the silo the labor of harvesting is of necessity done in a wholesale way, that is to say, it is usually done within a short period, with but little interruption in the work, and with a minimum of waste of time on the part of men and teams. The necessity for first curing the food and then handling it again in storing is thus obviated. But these benefits are in a measure offset by the difficulty in securing the necessary machinery and men to do the work in season. Especially is this true with the 
occupants of small farms, and the difficulty increases with the multiplication of silos in any community. It can be obviated in part, but not wholly, by doing the work on some system of co-operation between farmers who are near neighbors.

Cured in Showery $W$ cather.-Such crops as are suitable for being made into silage may be stored in the silo under conditions of weather quite adverse to the dry curing of the same in the ordinary way. Particularly is this true of such crops as are easily injured by rain, as clover for instance, and the cowpea. The work of storing may go on in some in. stances without any interruption other than what is caused by the work hands seeking shelter from the falling rain. But in other instances more or less of delay would be necessary, as it is possible to store some crops in the silo with too much of moisture in them. Some kinds of crops can thus be saved with but little harm that would otherwise be ruined by excessive wet, and they may also be handled at such times with but little increase in the labor involved in handling them.

Grecn Food All the Year.-The silo may be made to furnish green food all the year, and under some conditions more easily than it can be furnished from any other source. There are localities in which soiling crops other than corn or sorghum cannot be readily grown with marked success, and there may be instances in which it would not be convenient to grow them or to command the time required to cut and feed them when grown. Under such conditions a supply of silage in excess of the needs of the stock during winter is helpful, more especially to 
men, whose cows would otherwise be wholly dependent on pastures which may fail with the advent of dry weather.

There is 10 method of providing green food even for summer feeding that is so economical of labor. Silage can be taken from the silo and fed to cows in much less time than soiling food could be provided from any other source. And when meal is given at the same time, it may be fed more profitably when mixed with the silage than when fed along with other soiling food, without first running the same through a fodder cutter. To prepare green food thus by cutting it up would be impracticable when harvested day by day, unless when a very large quantity was used daily, and where there is an ample supply of help.

Live stock will also eat such food with avidity. Instances are on record where cows have shown a preference for corn silage over grass, and there is no period of the year, not even when grass is at its best, that they will not eat with evident relish more or less of corn silage when well preserved. The silo therefore may be made to furnish soiling foorl every day in the year, since it will answer quite well to begin feeding from a silo the day after the filling of the same has been completed, and even while the filling process is under way.

But it does not follow that because live stock may thus be provided with green food that it will not be eminently proper to provide and feed other green food. Corn is not in itself a balanced ration, nor is corn silage and grass, and even though these did furnish a balanceu food, a variety is usually 
THE BENEFITS FROM SILOING CROPS. 26r

preferable to one or two kinds, and a change of food to sameness in the diet.

If air is excluded from silage it will probably keep for an indefinite period. Nevertheless there would seem to be no good reasons for trying to preserve silage for more than one year under ordinary conditions. The additional space required for storing silage intended for feeding more than one year would be unnecessarily costly, nor would any commensurate benefits accrue from so doing. There would seem to be no more necessity for providing storage for silage to last more than a year than for provicling the same for crops that are cured in the dry form.

Food More Palatable. - When food is properly preserved in the silo it is certainly more palatable than when fed in the dry form. This means that a less proportion of the food will be wasted in feeding. In fact, there should be but little waste in feeding silage in any instance and in many instances none at all. However the liability of improper curing must not be lost sight of. It is easily possible to make silage that will not be palatable, as for instance, when it is excessively acid, or when it contains more or less of dry mold.

When food is thus fed in a succulent condition, up to a certain limit at least, it acts beneficially on the digestive organs. It tends to relieve constipation induced by feeding dry food when made a part of the ration, and consequently it acts beneficially on the health of the animals. But when fed in excess, as when it is made the sole ration for any lengthened period, or when it is inferior in quality, 
such feeding may injure the animals and even seriously. The difference in the effects produced on digestion by feeding the same kind of food in the green and dried forms respectively, is well brought out in the feeding of grass when in the most complete state of succulence and in feeding the same as hay.

Economy in Storage Space.-The silo is economical of space in storing food. In other words it requires a much less area to store food in the green form than to store it when dried. This means therefore that a given amount of green foorl can usually be stored in a silo at a less cost for the storage accommodation than would be entailed in providing storage room for the same in the dried form.

This advantage is however to some extent offset by other considerations. First, it is necessary to make some provision by way of storage for other food. When thie expense of providing storage for both green and dry food cannot be borne by the farmer, he can better do without the storage for the green food. Second, the silo in some of its forms wears out more quickly than structures made to receive dry food. The saving in storage space effected by the silo is most apparent when large quantities of food are to be handled.

Economy in Labor When Feeding.-The silo is economical in labor when feeding the food. It can usually be located so that the food is nearer to the place of feeding than it would be possible to store equal quantities of dry food in the cured form. It is easily handled because of its lack of bulkiness and 
THE BENEFITS FROM SILOING CROPS. 263

because it is more commonly fed in the cut form. More especially is this true of silage fed from a truck in properly constructed stables. It also obviates the necessity of cutting or chaffing, as it is sometimes called, other fodder to provide a bulk factor with which to mix the meal fed, since the meal so fed can be mixed with the silage. But these benefits do not apply equally when the silage is made in the uncut form, that is, when it is put into the silo without running it through a cutting box.

PRACTICAL CONSIDERATIONS.

The following considerations based, in part at least, on what has already been said on the benefits from soiling crops will now be discussed, viz.:I, The benefits from the silo do not apply equally in all parts of the country. 2, Because of this, while in some sections silos are, in a sense, indispensable, in others the wisdom of building them may well be called in question. 3, In the present state of our knowledge, therefore, the relative distribution of silos (if the term may be thus used) in the United States and Canada can only be given with approximate correctness.

Benefits Do Not Apply Equally.-That the benefits from the silo do not apply equally is easy of demonstration. These will be relatively greater:I, When more or less difficulty is usually experienced in curing crops in the dried form. 2, In localities where building materials are relatively dear. 3, Where the winters are relatively long. 4, Where the staple crops grown are not easily preserved 
without loss in the dried form. And 5, Where a large number of the farmers relatively are engaged in dairying.

In the region of the Great Lakes the precipitation is frequently so great as to imperil crops while they are being cured. In nearly all of the Rocky mountain valleys rain is practically unknown in harvest time. The necessity for siloing crops in the former therefore will always be greater than in the latter. In the New England states snow falls abundantly and sometimes in the form of sleet. Because of this corn in the shock is oftentimes renderd inaccessible during certain portions of the winter. In the semi-arid belt the snow fall is usually light. In the latter therefore the silo is much less of a necessity than in the former.

In timber areas lumber and other building materials are relatively cheap. Far out on the treeless prairies they are relatively dear, other things being equal therefore, the benefits from the silo should be greater on the prairie than in the timber country, since about three times as much food can be stored in the silo as in an equal space in ordinary farm buildings.

North of the fortieth parallel of latitude soiling food cannot usually be provided from the fields earlier than May nor later than November. The further northward from the said parallel that any place is located the shorter does the season become for providing such food.

On the other hand the further south from the same parallel that any place is situated, the longer is the season during which green food may be provider 
directly from the fields. The season, therefore, for providing soiling food directly in areas as far northward as in Canada, does not cover a larger period than three to four months, other things being equal, therefore, the further northward the location the greater will be the necessity for siloing the food.

Some crops are much more difficult than others to cure in the diry form. Such are corn, sorghum, the non-saccharine sorghums, the cow pea and the soy bean. The necessity for silos therefore is usually greater when these are staple crops than when they are not. The non-saccharine sorghums however have greater adaptation for dry conditions, as shown in Chapter IV, Part I., hence it is not so necessary to make these into silage, since the weather is favorable to curing them in the dried form.

Some sections of the country are almost exclusively devoted to the production of dairy products. Other sections produce virtually none of these. The close relation between succulent foods and successful dairying is generally recognized. It follows therefore, other things being equal, that the necessity for the silo will grow with the growth of dairying.

Silos Not Alrcays a Necessity.-From what has been said in the preceding paragraphs it will be evident that silos are not nearly so much of a necessity in some places as in others, and it would not be going too far perhaps to say that in certain areas they are not a necessity to any extent. It is evident that in the moist New Eirgland states which produce corn in good form for the silo, the necessity for silos will be greater than in the moist climate on the Pacific coast in areas too cool for the successful growth of 
corn. It is equally apparent that in the states which border upon the Great Lakes, the necessity for the silo is much greater than in the semi-arid belt east of the Rocky mountains, or in the Rocky mountain valleys where irrigation is practiced. In the former corn grows abundantly. In summer there is usually sufficient moisture and in winter the snow frequently falls deep and piles up around the corn shocks. In the latter the precipitation almost ceases in summer, and the snow fall is usualiy light. Dairying is not much practiced in the semi-arid region, nor is it ever likely to be the dominant agricultural industry in the same. It would not be incorrect therefore to affirm that there is no great necessity for silos in the dry areas west of the Rocky mountains, nor would the necessity for them seem to be very great in those sections of the western and southwestern states which produce alfalfa abundantly. The latter can be cured almost without hazard in those rainless summer areas, on the other hand there may be instances even in the semi-arid region and in the dry southwestern states where silos may be made to render good service.

In some of the corn growing prairie states, it has been argued that silos are a necessity because of the amount of soil that is frequently deposited on the corn or sorghum shocks by the prairie winds, and the argument has some force. But the difficulty may be met by stacking the corn or sorghum as soon as cured.

Distribution of Silos.-By the term distribution of silos is meant their relative adaptation to the needs of various sections of the country. The 
THE BENEFITS FROM SILOING CROPS. 267

discussion of this question will be simplified by dividing the country into sections where the conditions favorable or otherwise to the growing of silo crops and to the curing of the same are not greatly dissimilar. The division submitted below may seem somewhat arbitrary, but it will probably be found at least approximately correct.

Division No. I will cover those portions of the United States and Canada east of the Mississippi river and Lake Superior, and north of the Ohio and Potomac rivers. Division No. 2 will embrace those states east of the Mississippi river and south of the Ohio and Potomac rivers. Division No. 3 will cover the states of the Union and the provinces of Canada west of the Mississippi river and Lake Superior.

In Division No. I, the silo will always render greater service than in Divisions Nos. 2 and 3. The moist climate that covers much of the area, the relatively long winters with the rain, sleet and snow that characterize them, and the general diffusion of dairying throughout the division, emphasize the value of the silo. There is no state of the Union, or province of Canada included in this division in which the silo may not be made to render excellent service, especially to those who keep live stock in any considerable numbers.

In Division No. 2 the silo will be less helpful relatively than in Division No. I, because of the shorter winters and the less attention given to dairy-ing, and they will be more helpful than in Section 3 , because of the more rainy character of the climate.

In Section No. 3, which covers all the best alfalfa producing areas in the United States, silos 
are needed the least, for reasons already given. In a portion of the states which border upon the Mississippi river the harvests are practically rainless. This is true even of the strip of country west of the Cascades in which the precipitation is frequent and almost excessive during the season of growth. In the same area lumber is also very cheap, hence the provision for the storage of crops in the cured form, need not be costly. 


\section{CHAPTER III.}

FACTS RELATING TO SILO CONSTRUCTION.

Before building a silo the most careful consideration should be given to the location, and form of the same, and to many things that have an important bearing on the work. These are such as relate to the size of the silo; the materials to be used in building it; the nature of the foundation and of the floor required; the character of the lining; the necessity for partitions and the method of constructing them; the placing of the doors and also their form; and the character of the roof, when a roof is necessary. A brief discussion of these questions, therefore, will precede what will be given in detail in Chapter IV, and, in regular sequence, regarding the construction of those forms of the silo which experience has shown to be best suited to the needs of the farmer.

Locating the Silo.-The locating of the silo wili depend on conditions such as relate to the amount of barn or stable room available, the relation of the stables to the mows, and to other places where food is stored, the presence or absence of a basement in a barn, and the nature of the climate.

Other things being equal, the silo should be placed as near as possible to the center of feeding, when it can be located in close proximity to the 269 
mangers in which the food is consumed, the saving in the labor of feeding is very great, as compared with the same when the silo is more distant. The location of the silo, therefore, should be given the most careful thought.

In cold latitudes the necessity for good barns and warm stables is much greater than in those that are mild. In the former, therefore, it will be much easier to find room for the silo inside than under conditions the opposite. When the silo can conveniently be built under cover, that is to say, when it can be made a part of the barn, it ought to be so built. Locating it thus should prove economical, as it will not require to be roofed, unless the top of the silo should project up above the roof of the building of which it forms a part. The wall of the building may usually be made to form one wall of the silo, when the latter is square or rectangular in shape. The exposed surface of the silage, when it is being fed, will usually be sufficiently protected from frost, and the work of feeding may be done without discomfort in the coldest weather.

A basement barn furnishes ideal conditions for building a silo when the stables for the stock are in the basement. and, in passing, it may be mentioned that when basement barns are properly planned, they are economical of space, in cost of roofing material, and also in construction, at least when their greater duration is taken into account. They are also labor saving while the food is being ferl, and they are a source of much comfort to the animals kept in them in summer, as well as in winter, when the management is as it ought to be. These opinions may not 
be generally accepted, but it is more than doubtful if any one of them can be gainsaid.

The silo may be made to occupy a section of the basement, and it may be located in the center of one side of the same, or in the center of that part occupied ty live stock. In round, or octagonal barns, the silo is usually placed in the center. In all instances in which the silo is built in the basement it is made to extend upward also into the barn over the basement, and in any event, the doors should open into a feed room or passagervay. It is usually more convenient to handle the food when the silo can be located so that it will be adjacent to the room in which meal and other food is mixed for the stock. In outbuildings without a basement, the silo may be made to occupy a part of the bay or mow, but under these conditions it can seldom be located so conveniently for feeding as in a basement, for reasons that will be manifest. And usually the roof of the silo will of necessity be above the roof of the outbuilding, in order to secure sufficient hight in the silo.

When the silo must needs be located outside the barn or stable, it should be placed as near to it as possible. If square or rectangular it may be built against the outbuilding. The wall of the latter duly lined will then form one wall of the silo. The doors will then open into the outbuilding. If the silo is round, it should, if possible, be placed near to the outbuilding. The distance therefrom should at most be not more than a few feet. A roofed passageway may then be constructed from the silo to the outbuilding, and into 
this passageway the cloors of the silo should open. The passageway should be amply provided with light. When silos are located outside the barn, stable or shed in which live stock are fed it is simply impossible to locate them so conveniently to the center of feeding as when they form a part of one or the other of those buildings.

Different Forms of Construction.-In form, silos have been built square, rectangular, octagonal, and round or circular. Until within a comparatively recent period the rectangular form was usually adopted by those who built silos, but, since about I 890 the round silo has come so generally into favor that in a very considerable degree it is superseding the rectangular mode of construction.

The square silo may be somewhat more cheaply constructed than the rectangular silo of equal capacity, since the wall space is not so much. When the conditions are suitable for placing it, and where the size is nicely adjusted to the amount of silage required, the square silo would seem preferable to the rectangular form. But if a division is to be made in the silo, it will prove more costly to make it than in a rectangular silo, since the space across it is relatively greater. Both square and rectangular silos are more commonly placed inside of a barn or stable, and within these it is not generally so easy to secure space of the proper dimensions for a square as for a rectangular silo.

The rectangular silo has been found specially arlapted for being placerl within a building that is in process of erection or that is already built. When wanted, partitions can be put into it at a minimum of 
FACTS RELATING TO SILO CONSTRUCTION. 273

cost, because of its shape. The objections to the rectangular as well as to the square silo are, first, that difficulty has oftentimes been found in keeping the walls from spreading, and so letting air into the silage, and second, that the silage does not settle so readily in either of these forms of silo as in a round silo, hence there is more waste in the silage. Particularly is this true of the corners. Notwithstanding these objections, rectangular silos will probab!y be built for many years to come, hence the method of building them will in due time be given with some minuteness in details. And what will be said of the construction of rectangular silos will also apply to the construction of square silos.

The octagonal silo as the name implies is a silo with eight sides. The chief advantage gained in this form of construction, as compared with the square or rectangular silo is found in the iess acute character of the angles within the same. Also from the nature of their construction, the walls are so strong that they are not liable to spread, at least, not in a silo of ordinary dimensions. Moreover, some saring in lumber is effected by increasing the space between the girts from the bottom upwards. But there are two strong objections to this form of silo. First, it is ill adapted to being placed within a building becatse of its shape, and second, the ventilation of the spaces within the walls is difficult. because of the peculiar construction of the frame. The lining is nailed onto girts rather than onto upright studs, and these girts being horizontal when in position in the wall, give rise to the difficulty mentioned. Because of these objections, it is not I8 
probable that cctagonal silos will be numerously built.

Round silos can usually be built more cheaply than those that are rectangular. They have greater relative capacity, and no form of silo can be built that to so great an extent facilitates the even settling of the silage. The chief objections to round silos are, first, that they cannot in many instances be placed within a building without loss of space, and second, that it is scarcely practical to use partitions in them. If the round silo is placed in the center of a circular building, its position there will result in no waste of space, and but little space will be lost if the silo is partly within the building and partly without. But when placed in a mow, or bay, or cellar, it may not be easy to use to the best advantage the space in that part of the square in which the round silo is, and which is not covered by the same. In stave silos partitions cannot be used, as their presence would interfere with the occasional tightening of the hoops which is frequently necessary when using them. In round silos of frame construction a partition could be used. But such a partition would materially hinder the even settling of the silage. Notwithstanding the objections stated, the round silo is likely to be the most in favor in the future. It will therefore be carefully considered in the proper place.

The Size of Silos.-In determining the size of a silo not yet built, several considerations present themselves. These inclucle the size of the herd or flock which at present and also prospectively is to be fed from it, the probable duration of the period 
FACTS RELATING TO SILO CONSTRUCTION. 275

each year during which silage is to be fed, and also the settling of the silage after it has been put into the silo.

It should be remembered that if a silo is to be filled quickly, the silage will settle to about onethird of its entire depth. If material is added for silage a second time and perhaps a third time, it may be possible to have the settled silage fill the silo to at least three-fourths of the entire hight of the same. This, however, will vary with the hight of the silo. The deeper the silo the less will be the unoccupied space at the top when the silage has settled. The capacity of the empty silo, therefore, will be about twenty-five per cent. more than that of the filled silo. and this fact should not be overlooked in determining the size of the silo about to be built. Twenty-five per cent. may be considered too large an allowance for loss of space in the settling of the silage, but something will have to be added for waste from spoiled silage while curing, and from exposure in feeding, hence, a silo should usually be built with at least one-fourth greater capacity than would suffice to supply the needs of the stock, could it be filled to the top with good silage.

The amount of silage that may be fed daily to a dairy cow varies from, say thirty to fifty pounds per day. Forty pounds per day may be set down as average. The weight of a cubic foot of settled silage varies with the depth of the silo and the part from which it is taken and also with the amount of moisture in the silage. The variation runs fron say thirty to fifty pounds. It would therefore be at least approximately correct to say that a cubic 
foot of settled silage will weigh about forty pounds, or, in other words, that a cubic foot of such silage will supply a head of cattle with all that it ought to have of that kind of food for one day. On such a basis the proper size for a silo not yet built can easily be computed.

If the silo is square or oblong, the length in feet inside multiplied by the width and again by the hight, will give the entire number of cubic feet in the silo. The number of days during which an animal is to be fed on the basis stated above multiplied by one will give the number of cubic feet of silage required to feed one animal for the requisite time. This divided into the cubic feet in the silo after one-fourth has been deducted from the same, will give the whole number of cows to be feed thus for the time fixed upon.

For example:- Suppose a silo is to be built to meet the needs of twenty cows for six months in the year. One cow will consume the silage in I8o cubic feet in that time if fed forty pounds of silage daily, and twenty cows will consume the silage in 3,600 culbic feet. But since one-fourth of the space is waste one-third of 3.600 cubic feet or 1,200 cubic feet must be added to give the capacity of the silo required which would make 4,800 cubic feet. Now suppose twenty-five feet is fixed upon as the hight for the silo and twelve feet as the width inside, one foot in length of such a silo will hold 300 cubic feet of silage. To hold 4.800 cubic feet therefore would require a silo sixteen feet long inside.

To find the contents of a round silo in cubic feet, multiply the square of the diameter, in feet, 
by the hight in feet, then multiply the product by .7854 which gives the cubic contents. For example, suppose it is required to find the contents in cubic feet of a round silo fifteen feet in diameter and twenty feet high, the square of fifteen, the diameter, equals 225, which multiplied by the hight, twenty feet, gives 4,500 . This multiplied by .7854 gives 3534.3 cubic feet. But one-fourth must be allowed for waste space and waste silage, which leaves 2650.725 cubic feet as the capacity of the silo for good silage. This silage will average about forty pounds to the cubic foot which will give 106,029 pounds or 53 tons.

While it may be easily possible to adjust the size of the silo to the present or prospective needs of the stock, it is sometimes wiser to build two or more silos rather than to try to put all the silage into one. In feeding silage, about two inches indepth of the exposed surface should be removed daily to prevent waste from unduly prolonged exposure, and when feeding silage in warm weather, about three inches of the same should be removed daily. In a large silo such a depth of surface would probably be in excess of the needs of the stock. In such an instance, therefore, it would be better to erect two small silos, if built on the plan of the round structure, than to build one large silo of equal capacity. But in rectangular silos the difficulty mentioned may be obviated by putting in one or more partitions.

Materials Used in Silos.-Silos differ first, in the materials used in their construction, and second in the form given to them. The materials that have been used in building silos include wood, 
stone, concrete or grout, bricks and metal. More than one class of the materials named is sometimes used in building the same silo. They are designated chiefly by the material used in their construction. For instance a stone silo though lined with bricks is usually spoken of as a stone silo.

Metal silos, according to Prof. Woll, are built of homogenous steel plate, lapped and double riveted so as to make them tight. They are objectionable, at present, because of their cost; because of the ease with which frost penetrates them and because of the quickness with which they corrode. It has been computed that they cost about twice as much as stone silos of similar capacity, while the latter are much more enduring. Being easily penetrated by frost, this one objection would render them unsuitable for use in a northern climate. Nor has any preservative been found up to the present time that can be applied to them ide which will effectively resist for any lengthened period the corroding influences of the silage juices. Because of these objections, metal silos will not be further considered.

Concrete or grout silos have the walls made of small stones held together by well tempered mortar. In localities where the materials of construction abound, it may be proper to use them, but since in cold climates the walls must be protected by an outer lining of wood with an air space between, their construction, at the best, is costly. When used they should be built circular in form, if practicable in the location chosen, to facilitate the even settling of the silage, and they should also be lined inside with cement, or, if unprotected outside, with bricks and 
then cement. Since the materials for concrete silos are only found in certain localities, and since the essential features of construction are the same as in stone silos described later, the building of concrete silos will not be further discussed.

Brick silos, as the name would indicate, are made of bricks. They have not been extensively tried, it may be, because of the costliness of the material. In northerly latitudes they too would also probably require a lining of boards on the outside to keep out the frost; as is sometimes the case with concrete and stone silos, but the walls could, of course, be made thick enough to protect the silage unless such a method should prove too costly. In some instances stone silos have been lined with bricks and with manifest advantage. This feature of the use of bricks in silo construction will be referred to again.

Stone silos are, of course, built of stone and mortar. Almost any kind of stone of suitable dimensions may be used in their construction. The chief objection to stone silos is their costliness. Notwithstanding, when the wide distribution of stone is considered and when its durability is also taken into account, it would seem to be eminently adapted to the building of silos. In the southern half of the United States the outside lining of wood, which some authorities claim is necessary in the northern states, could certainly be dispensed with. Experience is further demonstrating the fact that stone silos may also be erected in the northern states without the necessity of protecting them with an outer lining of wood. (See Page 320.) Stone silos are therefore likely to grow in favor. The mode of 
building them therefore will be discussed at some length. (See Page 3I7.)

Wood silos are such as are constructed wholly of wood, but usually resting on a foundation of stone or concrete. Because of the relative cheapness of construction in the past, there is an overwhelming preponderance in the number of the silos that have been built of wood. The kinds of wood chiefly used in their construction have been pine in certain of its species, as the white and yellow, the southern cypress and the Douglas fir. But any kind of wood will answer that is durable, cheap and that does not warp. The spruce of the Puget Sound country would probably prove very suitable ancl possibly the hemlock also. The chief objection to wood silos is their want of durability. In the not distant future they must also become more costly with the increasing dearness of lumber, and as they do stone silos will grow in favor. The construction of certain forms of the wood silo will be discussed at some length.

Foundation for Silos.-Whatever the form of silo built, it ought to rest on a foundation that is not subject to decay. The foundation therefore should not be of wood. Stone will be the material most commonly used, though there may be some instances in which bricks, would be even less costly. Usually the foundation is sunk beneath the line of frost, but this is not always necessary. In soils which hold much water, every care should be taken to carry it away, as fast as it accumulates, by tiles laid for the purpose. When silos are sunk into the ground, it is not necessary to have the foundation go down 
FACTS RELATING TO SILO CONSTRUCTION. 28 I

more deeply than the floor of the silo. And the wall up to the surface should be of stone whatever may be the materials used in the structure above the ground. If the wall is carried up for a short distance above the surface of the ground, and is then banked with earth it will be better protected from surface water. The aim should be to keep the wood portion of silos away entirely from contact with the earth lest decay should be induced. The foundation is usually made wider than the structure which it sustains, but not in all instances. The precise character of the foundation for the different forms of silos discussed will be explained when treating of these. (See Pages 297, 310 and 318.)

Floors in Silos.-If the earth that forms the floor of a silo is dry all the year, no other floor is needed unless rats should begin to make trouble. If there is a liability to the presence of an undue amount of moisture, measures must be taken to carry it away, or much damage will result to the silage. Tiles may be laid around inside the silo and at some distance from the wall. Provision must then be made for carrying away the water that collects in these through some outlet which leads to lower ground. And where grout and cement floors are made in silos, the necessity for drainage is all the greater in order to protect the floors as well as the silage. In silos built on the level, drainage is not usually necessary. And in many instances it will be found that the drainage made to protect the wall will also furnish sufficient drainage for the floor of the silo.

When it is thought best to put in a floor, the 
materials may consist of what is termed grout or concrete. The cement floor may be made by covering the ground to the depth of several inches with coarse gravel or small stones. These are covered with a good coating of water lime, not less than two or three inches, and over all is put a layer of good cement of say half an inch or more in thickness. Where bricks are used they should be laid in cement, and two layers would probably prove more satisfactory than one. Floors so expensive however are seldom necessary.

It has been claimed that the floor of the silo should slope downward toward the center to facilitate the even settling of the silage, but whether the end thus sought is certainly attained can scarcely be said to have been proved. When silo floors are thus shaped, drainage where it is necessary, should lead from the center. If the floor is rather higher at the center than the sides, then drainage into tiles laid around inside the walls would be facilitated.

Linings for Silos. - The various materials that have been used for lining silos include boards, cement, water lime, shingles, brick, metal and tarred paper.

Board linings are by far the most frequently used in silos, and except in the case of cement they have been found the best. Various forms of board linings have been used. The best results have been obtained from using one thickness of matched lumber with tarred paper under it, or two thicknesses of matched boards with tarred paper between. The first is of course the cheaper method and should therefore be given the preference wherever it will suffice 
FACTS RELATING TO SILO CONSTRUCTION. 283

to exclude frost. The surface of the boards should be smooth to facilitate the settling of the silage.

Cement lining has on the whole proved satisfactory, more especially on silos built of stone and lined, or not lined with bricks. More commonly it is used to line stone, brick or grout silos. The acids in the silage have in many instances softened the cement on the surface next to the silage, so that to a greater or a less extent, the cement particles have crumbled. Because of this it has been recommended to apply cement every alternate year, or as often as necessary, as whitewash is applied. One instance however is reported in which the cement has not crumbled thus. W. C. Edwards, M. P., of Rockland, Ont., built a stone silo in I89o. Inside it was lined with bricks and the bricks were in turn lined with Portland cement of a good quality. In a recent letter to the Author, Mr. Edwards says: "We have not applied whitewash or cement at any time to our silo walls since the silo was first built. There has been no cracking whatever or falling off of the cement." This one fact coming as it does, from a reliable source, would raise a doubt as to whether the scaling off reported in the experience of many, has not been caused by using an inferior quality of cement, or by not properly preparing it for use. The question will stand further investiga. tion.

Water lime has not proved serviceable as a lining for silos. It has been found that the acetic and lactic acids in the silage dissolve out the lime particles, thus leaving the lining a layer of crumbling sand. In this condition it very readily absorbs silage 
juices, and is so easily penetrated by the tines of the fork used in handling the silage, that much of it scales off.

Plaster is even more objectionable than water lime, more especially when applied to wooden walls. It disintegrates even more readily and therefore peels off more easily. The springing of the wooden walls cracks the plaster when it occurs. The acids wet the lining and render it more liable to injury from frost, and when they penetrate to the underlying lath they hasten its decay.

Shingles answer fairly well for lining, but they add to the expense of the same. Where shingles are used, matched lumber and tarred paper must also be used, hence lining with shingles would seem to be superfluous, and there is more or less danger that they will be loosened or torn off by the fork in removing the silage.

Bricks not coated with cement do not make a good lining for the silo. They become damp and do not sufficiently exclude the air, but they would seem to be much less objectionable than unplastered stone, even though the stones were smooth. Bricks draw dampness too easily and do not readily exclude frost. Much of the silage adjacent to such walls would spoil and in time the acids from the silage juices would cause the mortar between the stones to crumble and would thus make the walls rough. Brick or stone walls should be kept lined with a high quality of cement.

Mctal lining for silos has not thus far proved a success. Sheet iron and tin have been tried. Professor F. H. King, of the Wisconsin Experiment 
station, who is high authority on such questions, has said that none of the available metals are in themselves proof against the acids of the silo and that it is scarcely possible to make paint adhere to them. In the meantime therefore expenditure on such linings would be unwise.

Lining with tarred paper has also proved unsatisfactory. It cannot be kept in place without more or less of furring, and this interferes with the settling of the silage. The paper is also adversely affected with the silage juices, and this in turn injuriously affects the wood under it.

The stave silo from the very nature of its construction does not call for any kind of lining, and this is in itself a strong argument in its favor.

Perservatives for Linings. - It was popular at one time to apply some preservative to the inner lining of silos in the hope of better preserving the wood in the same. The more common of these include coal tar applied alone while hot, or with resin added, or dissolved in gasoline and boiled linseed oil. It is also applied with black oil added equal in quantity to the coal tar. It has not yet been demonstrated that any of these applications have materially aided in promoting the end sought. It has even been thought that in some instances their application hastened decay. The fact is simply stated without waiting to give the reasons. When these so-called preservatives are used they may be applied with a suitable form of mop or whisk broom.

In stone silos the cement lining may, when necessary, be made to last longer by applying a whitewash of cement as often as the lining shows any 
indications of crumbling, but the fact would now seem to be assured that where a heary coat of cement of good quality is applied to the inner wall of a stone silo, it will last many years without any renewal.

Partitions in Silos.-It may be regarded as an open question whether partitions should be used at all in silos. The more these are increased the more will corners he multiplied, the greater will be the resistance offered to the even settling of the silage. They also add to the cost of the silo and unless strongly built they must needs be braced on one side while the silo is being filled, or filling must take place in a sense simultaneously on both sides of the partition. In round silos whatever may be the mode of construction, partitions are objectionable since they make corners where otherwise there would be none, and in the stave silo they cannot be used. It is further claimed that they are not necessary, since after the silage has settled one section of it may be fecl at a time without great los's providing it is cut down perpendicularly with a sharp hay knife, on the other hand partitions may be so built as to become an important source of strength to rectangular silos as is shown in Chapter IV. It has been argued that it would be better to build a second silo than to put a partition in one, but this view is certainly not correct except in the case of round silos, since one large silo can be built with a partition more cheaply than two small ones without one.

When partitions are used they may be constructerl variously. I, They may be built the same as the walls of the silo, that is to say, with studding lined with matched boards having tarred paper 
underneath. The studs may be less in size than the wall studs, and the dead air space should be left open above except when the silo is being filled to lesson the liability to decay. Iron rods may be made to run through the studs in the partition with some form of washer running up and down the wall for some distance on either side of the silo. These walls would very effectively keep the walls of the silo from spreading. 2, Partitions may be made by spiking $2 \times 4$ scantlings on top of one another from the bottom of the silo upwards. Iron rods may also be used in this form of partition. They may run along in grooves, made for them in the scantlings. 3. Partitions may be made in narrow silos by using planks two inches thick. These are held in place by grooves made in upright timbers which are duly fastened to the wail at either end. If these timbers are beveled away from the grooves the settling of the silage in the corners will be facilitater. The grooves may also be made by spiking two scantlings three cornered in shape to the wall at a suitable distance from one another. They can be ol)tained by sawing a scantling diagonally from end to end. When partitions are made, the boards, scantlings or planks user in making them should be planed on the side which comes in contact with the silage, to facilitate the settling of the same. When the silage has settled and is then fed out from one side of the partition, the pressure against the latter from the silage on the other side is not likely to disturb it seriously. It is only when the silo is being filled that this danger must be carefully guarded against. 
Doors in Silos.-Whatever the nature of the silo the cloors have some features in common. These inclucle the following: I, They should usually he placed one above the other and on that side of the silo contiguous to the passageway. There may be instances in which it may be necessary to have doors on the opposite side of a large silo, but tllese will be infrequent. 2, The aim should be to confine the number of the doors within the limits of strict necessity because of the difficulty of excluding air at the openings thus made. 3, When it can be made so, the door inside should have a beveled rim fitting into a corresponding bevel on the door when the door is in place. The bevel on the door should be from the inner rim outward. When a door is thus beveled the greater the pressure of the silage against it the more perfectly will the air be excluded. Other peculiarities of construction will be referred to when discussing the various forms of silos described in Chapter IV.

Roofing Silos.-When built inside of a barn or stable it is not necessary to provide a roof for silos. When built without, and more especially in climates subject to frequent and also to prolonged storms, i: will probably prove more satisfactory in the end to provicle some form of the same, and the materials to be used will be dependent to a considerable degree on the form of the silo. These will be enlarged upon when the details of construction in the various forms of silos are discussed.

But it does not seem to be necessary under all conditions to provicle even outdcor silos with a roof. The opinion prevails that not to do so would result 
in much inconvenience and loss from storms, and that in cold climates much loss would result from the freezing of the silage. Nevertheless, in western Ontario and probably elsewhere, many stave silos have been erected which have not been provided with a roof. These are between the forty-third and forty-fifth parallels of north latitude, and some of them have been in use for several years. The owners claim that no serious inconvenience or loss has occurred from the causes named. The heat generated in the silage seems to be sufficient, except in very extreme weather, to protect the same from injury by frost. When the winter climate is colder than that of southern Ontario, there would probably be inconvenience and loss from frost in roofless silos. On the other hand, if, in the wide areas further to the south, it should be found that such silos meet the ends sought, it may not be necessary under certain conditions to go to the expense of building a roof.

Decay in Silos.-Many of the earlier silos were built of wood and lined with boards. Those built of stone were also in some instances lined with wood. The lining in many of them, as shown by Prof. F. H. King in Bulletin No. ro of the Wisconsin Experiment station, showed some decay at the end of the second filling. It would probably be correct to say that the lining in silos will decay in proportion. I, As sealer! dead air spaces are enclosed between the linings of the walls; 2 , as stone walls are faced inside with wood; 3 , as inner lining boards come against sills, beams or girts; 4 , as spoiled silage is left piled against the lining within the silo; and 5 , 
as earth is banked against the outer lining. Sealed dead air spaces have been made by putting strips of furring laid on tarred paper between the two thicknesses of boards which form the inner lining of the silo, and by lining stone silos with wood inside so as to have a space between the boards and the wood. These can be avoided, as experience has shown that a single lining of wood with tarred paper under is usually a sufficient protection to the silage when the wooden silo has also an outer lining of boards, and that in stone silos frost can usually be warded off by lining with bricks inside coated with cement. But dead air spaces must needs be made in the walls of wooden silos with studding lined within and without, and also when stone silos are lined without. These cari however be easily prevented by providing ventilation.

Such ventilation may be furnished by making the sills and plates a little narrower than the studs. Openings thus made for the escape of the air below and above should of course be next to the outside sheeting. Where provision is not thus made for ventilation, it may be made by boring a small hole through the outer lining below and above and into the space between each pair of studs. Openings thus marle should be protected by some kind of wire netting to prevent depredation from rats and mice. Moreover, if no ventilation is provided in a silo underneath the roof or in the roof, decay will be rapid from the abundance of the gases which rise up out of the fermenting silage.

Notwithstancling the rapicl clecay in many of the earlier silos, it is easily possible to build wooden 
silos so as to resist decay for many years. The first silo built by Mr. John Gould, Aurora Station, O., has not been repaired since it was constructed in I884, and it is still in a good state of preservation. Since the stave silo has no dead air spaces, it is expected that it will better resist decay than silos that are lined, but some time must elapse before this will be certainly known. Nor is it ordinarily necessary to create dead air spaces in stone silos. When properly built, therefore, they should last for generations. 


\section{CHAPTER IV.}

BUILDING THE SILO.

But three kinds of silos will be considered in this chapter, viz., the round wooden silo, the square or rectangular wooden silo, and the round stone silo, and, for the reason that nearly all, if not indeed all, the silos erected in the future will pretty certainly be built on one or the other of these plans. The Author inclines to the belief that nearly all the silos built in the immediate future will be made of staves held in place by hoops, hence it will be the aim to give the necessary information relating to the building of these with some degree of minuteness.

THE ROUND WOODEN SILO.

When all the conditions are favorable for locating the round silo, that form of silo should be chosen. It has the following advantages:- $-\mathrm{I}$, It is more cheaply built than the square or rectangular silo since it requires less material whether built of staves or otherwise. Even when built with a frame there is much saving in studding material, because of the less size of the studs used. 2, The circular form is much more favorable to the even settling of the silage, and therefore more favorable to its perfect preservation. This arises, in part at least, from the 
entire absence of corners in the silo. 3, The tendency in the walls to spread is entirely taken away. In the stave silo the hoops when kept properly in place prevent such a result, and in round silos built with a frame the lining within and without has a similar effect.

Of the two kinds of round silos, viz., that kept in place by hoops, or the silo built with a frame, the Author most unhesitatingly prefers the former and for the following reasons:- $\mathrm{I}$, It is more simple in its construction and can be built more economically than the other form of round silo. 2, It is easier to exclude the air, because of the opportunity that is always present to tighten the hoops when necessary. 3 , It is believed that decay will be less rapid in the stave silo. And 4, Experience has already demonstrated that the frost will penetrate some forms of the round frame silo more easily than a silo made of staves. The advantages of the stave silo therefore over the round silo are so clearly drawn that it would probably be safe to predict that the former though of more recent introduction is likely to almost entirely supersede the latter. Since, however, the round frame silo still has some advocates, it may, be well to give in brief outline the essential features of construction in building the same.

BUILDING THE ROUND FRAME SILO.

The round frame silo consists of a framework of studding resting on a stone foundation and linerl within and without with boards laid over tarred or building paper. The frame rests on wooden sills 


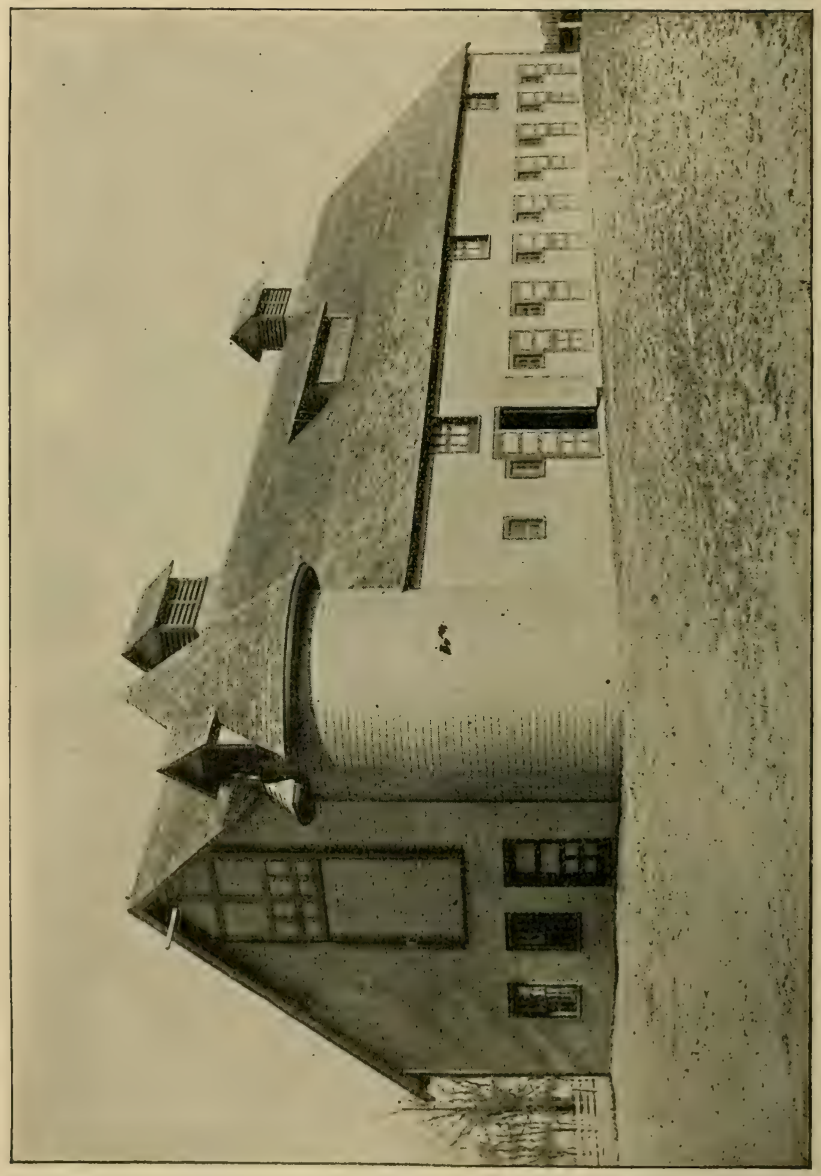

हू.

을

돌

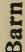

के

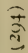


which of course must be circular in form. It is not necessary to have studs of greater size than $2 \times 4$ inches, nor is it necessary to have them so close as in the rectangular silo. The inside should be lined with two thicknesses of boards put on horizontally and with joints broken in the same. The boards should be about six inches wide and half an inch thick, and should have tarred or building paper between the two layers, or underneath the layer adjacent to the studs. In cold climates it would probably be necessary to have paper on the inside of the studs and also between the board linings. In mild climates one thickness of boards laid on tarred paper would probably suffice for the inner lining. The outer lining may consist of the same material put on as drop siding and with tarred paper underneath or otherwise, according to the nature of the climate. Ventilation must be provided. (See Page 290.) When the silo is built inside there may be some conditions in which it will not be necessary to put on any outer lining. The roof, like the silo, will be circular, and it will usually be necessary to have a roof when the silo is built outside.

\section{BUILDING THE STAVE SILO.}

The stave silo may be located within or without although more commonly it is placed outside of the stable or barn. Sometimes it is located in one corner of the outbuilding partly within and partly without the same. It may of course be made large or small and may go down into the ground or be placed on the surface. In building it there is 
296 SOILING CROPS AND THE SILO.

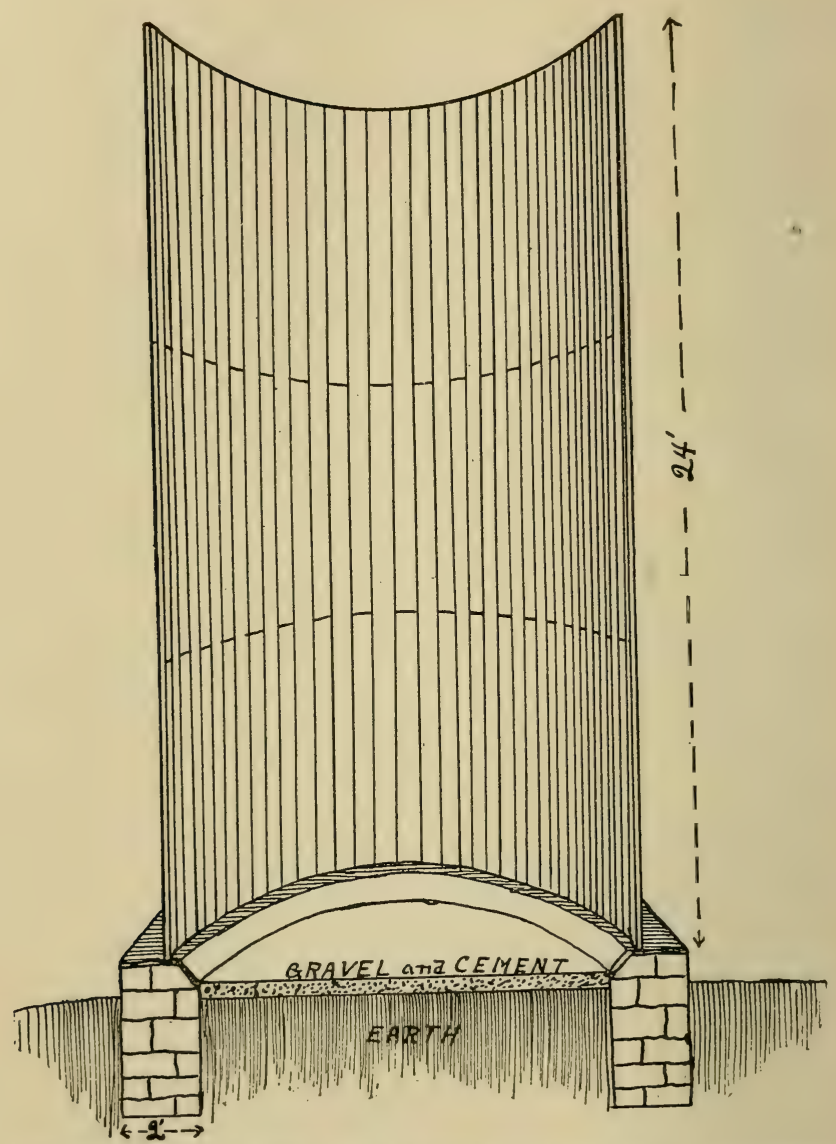

Fig. 30. Section of Stave Silo, showing Foundation Floor and Splicing of Staves 
much latitude in choice of material for staves, in character of hoops and in furnishing of the roof.

The Foundation.-The character of the foundation for the stave silo should be determined largely by the character of the soil, and the size of the silo. Stave silos have been placed on the surface of the ground without any excavations whatever other than that made by removing a few inches of the soft surface soil. But in such instances they have stood on a double thickness of bricks laid first in mortar and then in cement. The mortar below should rest on broken stones or gravel. This plan would seem to answer where the soil is perfectly dry and the silo is of moderate dimensions. In other instances the wall is sunk several inches, that is to say, far enough to go down to a firm subsoil. This plan will probably suffice where the subsoil is dry and winter frosts are not severe. In yet other instances the wall goes down a little lower than the frost is expected to penetrate. The wall should be sunk thus far in all soils that are liable to be much disturbed by the action of the frost. When it is necessary to sink the wall several feet below the surface of the ground, it will usually prove economical in the end to excavate inside the wall to the same depth to which the wall has been sunk. But when thus excavated care must be taken to have the inner surface of the wall made smooth with a lining of cement, and to have the circle made by the inside of the staves correspond exactly with the circle of the stonework when lined as indicated.

The stone foundation should not be less than two feet broad and should come up several inches 
above the surface of the ground. Flat stones are preferable to round ones, but round stones will answer. The wall may be flat on top, but many favor making a shoulder on the outside as shown in figure 30 . The staves of the silo should stand inside the shoulder and close against it. If, when the hoops are drawn tightly, the staves should be drawn away from the shoulder; the space should be filled by pouring thin cement into it.

When building the foundation wall, some authorities recommend digging a trench of the desired depth and filling it with stones, putting the largest stones in the bottom. Smaller stones are worked into the intervening spaces, or they are filled with gravel. In either case they are pounded down until quite firm. When the wall is finished, a thin cement is made and poured over the wall so as to go down in the interstices. When it has set, stronger cement is spread over the surface with a trowel. It is questionable, however, if cement thus applied has any advantage in cheapness or otherwise over the good old-fashioned mortar for holding in place the stones of a foundation wall.

When a shoulder is not used on the wall the time for striking a circle to serve as a guide in setting up the staves is opportune, while the cement or mortar on top of the foundation wall is still soft. In making it a stake may be driven into the center of the floor of the silo. The circle on the wall is then marked by some suitable implement attached to a cord which moves around on the central pivot while the circle is being marked. 
The Floor.-The floor may be of earth where the soil is dry, of concrete covered with cement or even without such a covering, or of bricks laid in cement. (See Page 282.) Where the soil is dry earth would answer well enough for a floor were it not for the danger arising from depredations of rats and mice especially the former. Because of this danger, the propriety of making a floor secure against such depredations should be carefully considered.

The Staves.-The staves should be of some material that is relatively cheap and that is not too difficult to obtain. At the present time, white pine is probably the favorite wood in the northern states. cypress in the southern states and the Douglas fir in those of the far west. But other kinds of pine may be used, as the red, the yellow, the Norway and the southern, and also other soft woods, as spruce and hemlock. It is important that the material shall be sound and free from knots that are liable to drop out, and seasoned lumber is preferable to that not seasoned.

The most suitable size for the staves will be at least measurably dependent on the size of the silo and the character of the climate. The larger the silo the broader may the staves be, and the warmer the climate the less is the thickness required. Six inches may be named as the maximum limit for the width of the staves and four inches as the minimum. The usual thickness is two inches, but in mild climates one and one-half inches will suffice. Where the material can be obtained at reasonable prices, the staves should be as long as the silo is high, but since 
such lumber is frequently relatively costly and difficult to get, it may frequently be necessary to purchase stares of two different lengths and to splice them. Where practicable, the staves should be sized, and when they are to be spliced the necessity for thus sizing them is increased. IVhere this cannot be done, care must be taken to keep them even inside when putting them in place. It is absolutely necessary that they shall be planed on the inside and also at the sides, but it will be advantageous also to have them planed on the outside if they are to be painted. It is not necessary to bevel them on the sides unless the diameter of the silo should be quite small. It is thought that even tighter joints are secured in the absence of beveling, nor is it necessary to tongue and groove the staves.

Setting Up the Staves.-In setting up the staves, various methods have been adopted. That now described is one of the simplest:-Erect a scaffold by setting up scantlings at the corners of a square that will exactly enclose the silo. Then just outside the outer circle of the silo and at the points where it touches each side of the square, set up smaller scantlings. Those at the corners may be $4 \times 4$ inches and those intermediate $2 \times 4$ inches, but scantlings of other dimensions may be used so long as they are strong enough to answer the end sought. Whether or not these scantlings splice by overlapping they should go u1) about as far as the silo is to be high, and they should be set exactly plumb. They are held in position by boards nailed on the outside. Boards one-half inch thick are then nailed on the insicle of the four intermediate uprights. When in 
position they form a crucle circle. One of these circles should be toward the bottom of the silo, and one toward the top, and in silos that are high there should be a third circle similarly formed midway between these. A stave is then set up erect and plumb. It is held in position by driving a short nail through the hoop into the stave, but the nail must not go through the stave. Another stave is similarly put up and fastened, and in the same way all the staves are set up. As soon as the hoops are put on they draw the nails in the temporary hoops away from the staves, so that the former are easily removed. When in position the staves may be flush with the inside of the foundation, may stand in the center of the same, or may rest against a shoulder of the foundation as may be desired. In Bulletin No. I67 of the Cornell university experiment station it is recommended that in setting up the staves of a silo, four staves shall be used on opposite sides of the same which shall be several inches thicker than the other staves of the silo. The hoops of the silo are carried through these uprights, which makes it easily possible to tighten the hoops without the aid of keys, but they add materially to the labor of construction. It would seem to be at least questionable if such uprights will come into common use.

Splicing the Staves.-When it is necessary to splice the staves in a silo, one of at least two methods may be adopted. First, the ends may be cut squarely and with precision in a miter box. In this way a reasonably smooth joint is made. The joints where the staves thus meet are broken, that is to say, in one instance the short stave is put at the top of the 
silo and in the next at the bottom of the same. The short staves should be about one-half the length of the longer ones. The staves thus alternate all the way around the circle. The alternate joints thus describe two circles around the silo as shown in Fig. 30. This form of joint should be covered with flat hoops of band iron to aid in excluding the air. When the staves have been carefully sized, this form of splice may possibly be found to answer, but this does not yet appear to have been conclusively proved by experience. Whatever may be the form of the splice adopted, provision must be made for having it come where it will not interfere with doors and where the joints may be thus covered with hoops of band iron.

A second form of splice is made similarly, but with the following addition: Saw about threefourths of an inch into the end of each stave the wide way. A piece of sheet iron of the same width as the stave is placed into the incision thus made as the ends of the two staves are being brought together (see Fig. 3I). It may yet be found that sheet iron thus used may corrode too quickly.

Hoops.-At least three kinds of hoops have been used in stave silos. These are the round, the flat and the woven wire. All three of course are iron. Round hoops are usually from five-eighths to three-fourths inches in diameter, and are held in place by lugs or castings, as shown in Fig 32 . These have eyes through which the ends of the rods come. When it is desired to tighten the hoops, the burrs are tightened with a wrench. It is claimed that round hoops are more easily tightened than flat ones, 
BUILDING THE SILO.

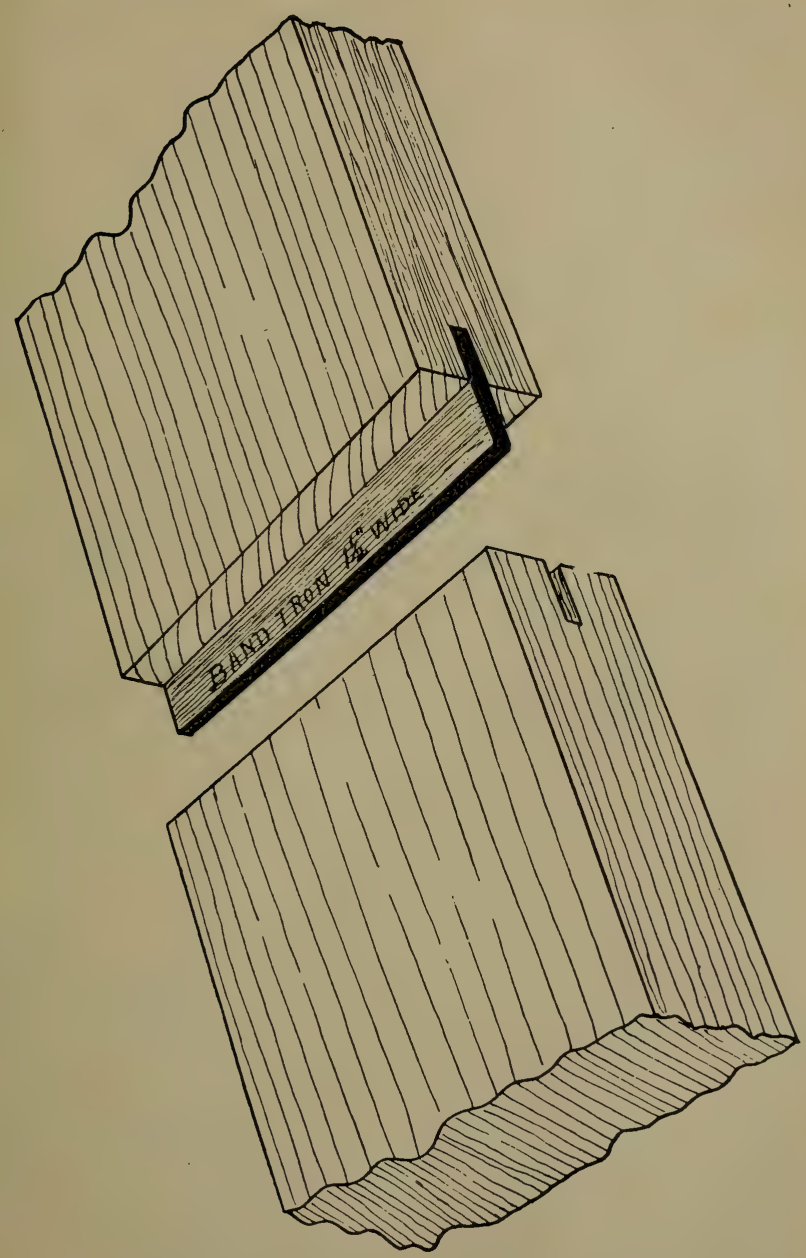

Fig. 31. Splice of Stave with Iron Tongue 


\section{SOILING CROPS AND THE SILO.}

but they also cut into the staves, which is somewhat objectionable.

Flat hoops are usually made of band iron oneeighth of an inch thick and varying in width from, say, two and one-half to three and one-half inches with the size of the silo. These two are held in place by lugs which differ in some respects from those used to hold the round hoops in place, but the principle involved is the same. For a silo sixteen feet in diameter, each complete hoop which encircles the
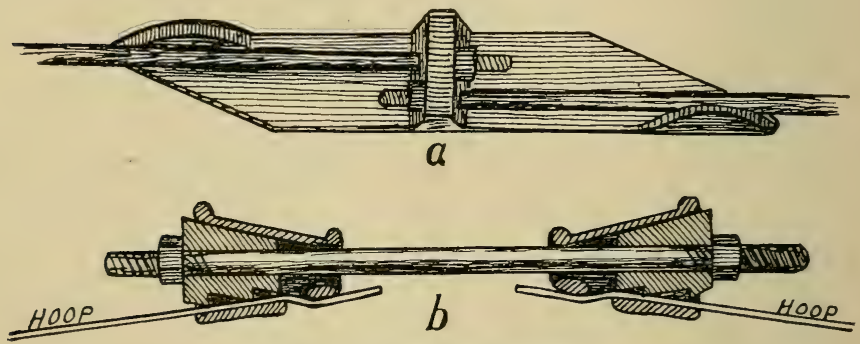

Fig. 32. Lugs for Hoops

$a$, Cast-iron lugs for round hoops.

$b$, Wedge lug for flat hoops.

same should consist of two separate pieces, and for one with a much greater diameter, of three such pieces. There is then less of a strain on the threads while the burrs are being tightened. The lugs of the various hoops should also be distributed rather than rise one above another in a straight line.

Woven wire hoops are sometimes used when the silos are small. These vary in width with the requirements of the silo. The power which some kinds of woven wire have to contract and expand 
with the needs of the silo has led to their being used by some silo builders.

The distance of the hoops from one another should be regulated almost entirely by the size of the silo. The greater the diameter of the silo and the higher it is the closer should the hoops be placed, especially toward its base. For a silo sixteen feet in diameter the lower edge of the first hoop should be within about six inches of the base of the staves. The space between the lowest hoop and the one next above it should be two feet. The space between each additional hoop added, and the one next below it should increase six inches. But four feet should be the limit in distance between any two adjacent hoops in such a silo. On the approach of the season of filling the silo, it should be examined and the hoops tightened when this may be necessary, but it should be borne in mind that it is possible to draw the hoops too tight, since the staves will swell somewhat after the silo has been filled.

The Doors. - The doors should be in line, one above another. They should be no larger than will suffice to admit of the easy ingress and egress of the person who removes the silage. Doors eighteen by twenty-four inches on the outside will usually be amply large. The bottom of the first or lowest door should be not less than three feet from the bottom of the silo, and in some instances, as when a horse cart is used for drawing the silage, it ought to be higher than three feet. But when the pit of the silo is sunk down some distance below the surface of the ground the bottom door should be placed as low as possible. The distance between the doors should 
not be less than five feet, and the space for these ought to be so calculated as not to interfere with the placing of the hoops, and vice versa.

The doors should be cut out after the staves have been put in place and drawn tightly together. They should be cut with a bevel on each of the four sides and the beveled sides of the door should be outward when it is in place. The pressure of the
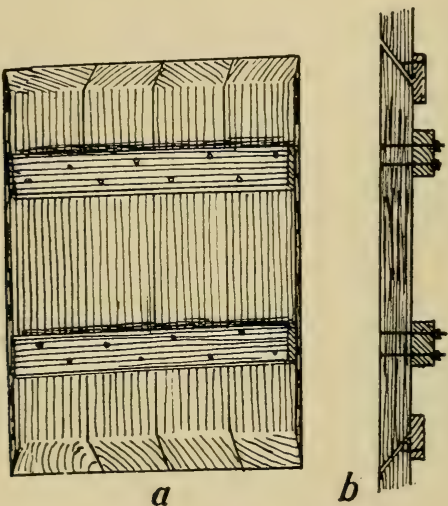

Fig 33. Door of Stave Silo

$a$, View of outside of door; $b$, side view of door.

silage when settling will then assist in the exclusion of the air at the doors just in proportion to the extent to which the said pressure exists. To aid further in such exclusion of air, a strip of tarred paper should be tacked on each of the beveled edges of the door. Before sawing out the door, two cleats should be bolted across the staves on the outside. These are shown in the door as represented in Fig. 33. The end of the bolt which receives the burr 
should be outward, and the heads of the same countersunk on the inside. The doors should be carefully numbered on the outside so that each will be used

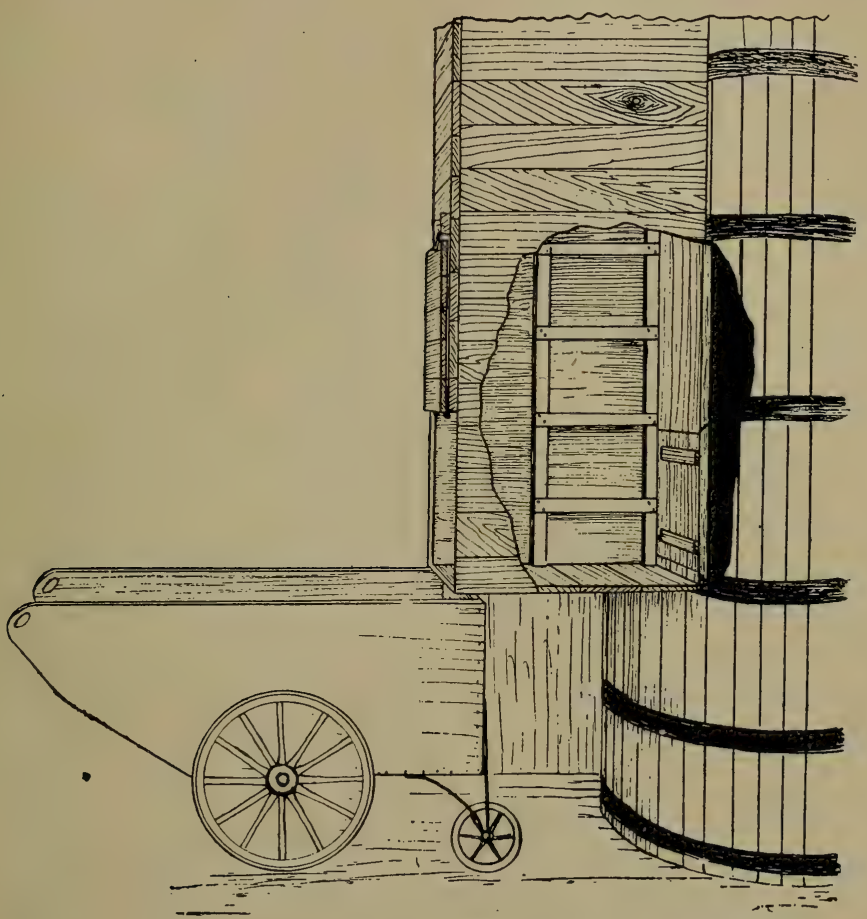

Fig 34. View of Stave Silo

With shute, ladder and hand-cart.

only in its proper place, or they may be so fastened with chains to the outer wall as to hang suspended when for the time being they are not in use.

The Shute,-In a large majority of instances 
it will be advantageous to make a shute down which the silage falls when it is thrown out at any of the doors. The shute is simply a box with three sides, extending upward from below, the lower door of the silo and covering the doors. The proper size will be about two feet square. A ladder should extend upward on one side of the shute and inside of it on which the person climbs when going into or coming out of the silo. Usually a floor is put into the shute and from this the silage slides outward into a cart placed under the same to receive it. When the silo stancls outsicle the stable and near to the same, the shute should come down into the passageway, as shown in Fig. 34. This passageway between the silo and the building need not be more than seven feet high inside. It should have windows in it to admit ample light.

The Roof.-In climates not too cold nor too rainy, stave silos may be left without a roof. (See Page 288.) For silos that are located quite near to the stable, a roof may be made as shown in Bulletin No. I67 of the Cornell university experiment station, that is to say, it may be made as follows: Four scantlings suitably placed on the outside of the silo may be bolted to the staves of the same. They should extend downward some distance from the top of the silo and upward some distance above it. The pair nearest to the stable should be higher than the outer pair. Other scantlings to serve as plates or supports to the roof are then spiked across the top of each pair of uprights. A third support in the same line of ascent is then fastened to the side of the stable. Over these supports a roof of boards 


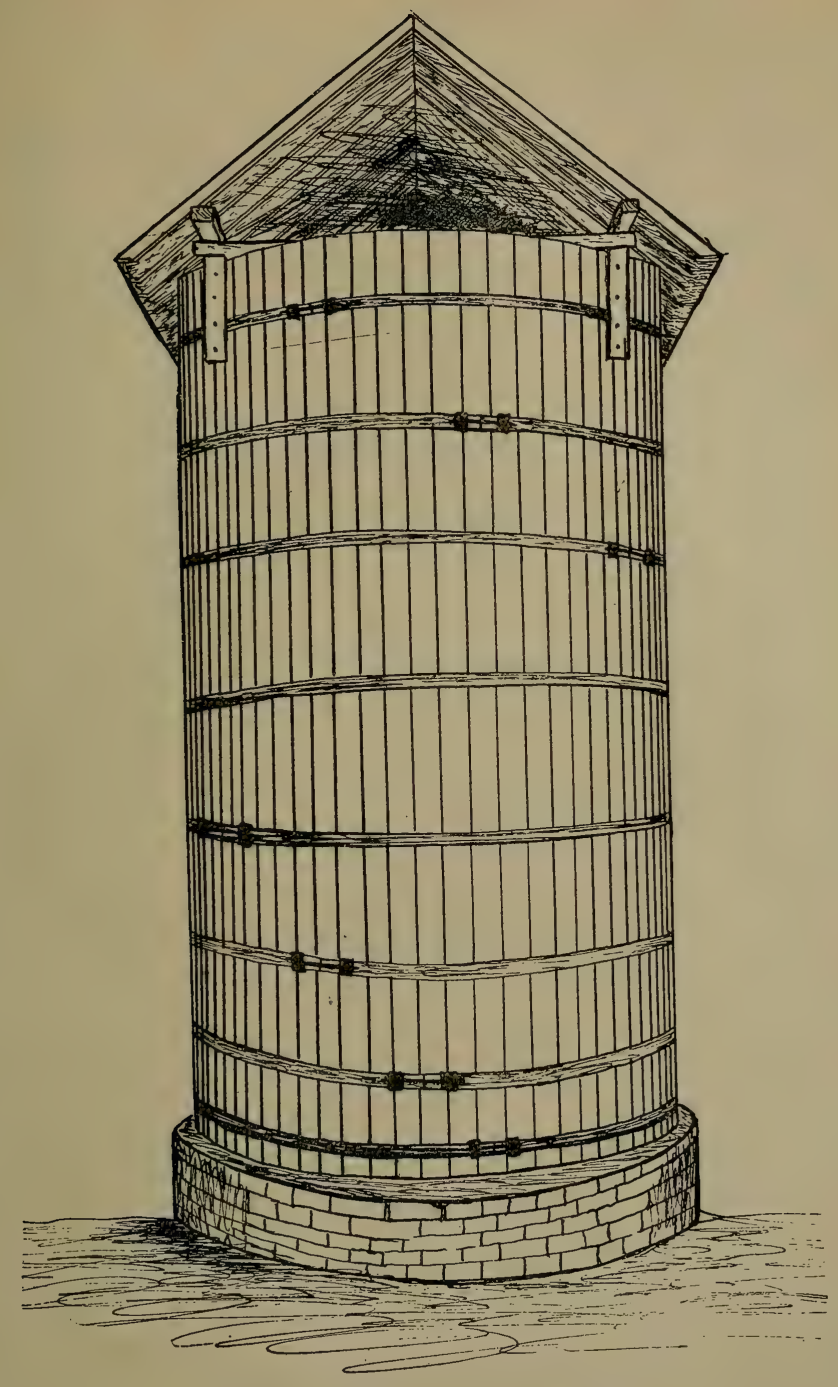

Fig 35. Exterior View of Stave Silo

With roof and lugs properly distributed. 
is constructed, the cracks of which are battened. This roof is intended simply to ward off storms and would seem to be too costly for the benefits accruing. When a roof is wanted, it would seem wiser to build a better one, as for instance, on the plan shown in Fig 35 ; or a conical roof

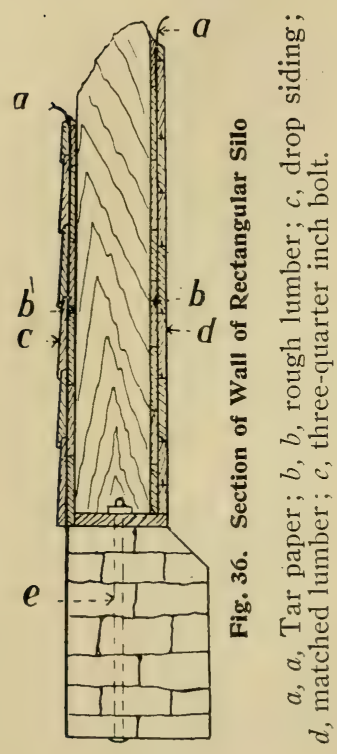
may be constructed as shown in Fig 29. The style of roof last mentioned, however, requires some considerable degree of skill to construct it properly.

\section{THE RECTANGULAR SILO.}

The rectangular and the square silo fits better into the space obtainable in an oblong building than any other form of silo that can be built. This fact will be at once evident if it is remembered that when thus located there is absolutely no other waste of space than that occupied by the walls of the silo. And since one and sometimes two walls of the building may be utilized when constructing such silos, they will continue to be erected, notwithstanding the objections arising from the presence of corners and from the liability to spread because of the pressure of the silage.

The Foundation.- Much of what has been said with reference to the foundation of the stave silo 
will apply equally to the foundation of the rectangular or the square silo. Usually the walls should not be less than two feet thick, and as with the stave silo they may be sunk into the ground to the depth of three to four feet and the space inside excavated as a receptacle for silage. (See Page 297.) The wall should extend far enough upward to prevent the sills from coming anywhere in contact with the earth.

The Sills.-Commonly the sills consist of planks of the same material and of the same size as the studs, that is to say, of planks $2 x i o$ inches. They are laid on the foundation walls and framed so as to overlap one another at the corners, and are bolted down to the wall by means of upright iron rods or bolts laid in the wall while the foundation was being built, as shown in Fig. 36. These rods are of iron and they should rise up at the corners and at intervals between the corners which vary with the size of the silo. The favorite distance varies from, say, three to five or six feet. If the space inside the foundation walls is to be used as a receptacle for silage, the inside of the sills should be so nearly flush with the inside of the wall that when both are lined the inner wall will be quite plumb where the cement lining of the foundation and the wood lining of the walls meet. But when the floor of the silo is about level with the top of the wall, the sills may occupy the central part of the top of the wall rather than the space only toward the inner side of the same.

The Floor.-The same general principles are to be followed in making the floor of the rectangular 
silo as in making the floor of the stave silo. (See Pages 282 and 299.)

The Studs.-The size of the studding used in the framework of the walls varies with the dimensions of the silo. The same is true of the spacing and bridging of the studs. The larger the silo, and more especially the greater its hight, the larger should be the studs where no girts are used and the more closely should they be spaced and bridged. In silos twenty-four to twenty-eight feet high it has been found necessary to use studs 2 XIO inches or $3 \times 8$ inches, to place them not more than twelve to twenty-four inches apart and to bridge between each pair of studs in not less than three places.

By bridging is meant the nailing of short pieces of narrow boards or miniature scantlings between the studs. They are cut at both ends with a proper bevel so that they may be easily nailed to the studs. Even when thus constructed, walls have been known to spread somewhat. But where partitions are used, it is not necessary to use studs so heavy, nor to place them so close, since the iron rods which run through the partitions effectually aid in preventing spreading. The studs are usually toe-nailed to the sills below, hut in some instances they are mortised into the same. When toe-naileci, several large spikes are driven into each. Plates of the same material should be laid on top of the studs and spiked to them when the size of the material will admit of this, but when it is of thicker size than the studs, the latter should be mortised into the plates. The method more commonly adopted is to simply fasten the studs by spiking them both above and below. The plates 
should be a little narrower than the studs when an outer lining is used to furnish ventilation to the air space between the inner and outer linings. The plates, like the sills, are put on the four sides of the silo and they are also spliced at the corners.

In building silos in the past, the aim has been to get studs as long as the intended hight of the silo, but since lumber of such great lengths must continually become scarcer and higher in price, of necessity, more attention will have to be given to the use of girts in the future. If girts were made to extend around the middle of the silo, the studs would only require to be one-half the usual length. If mortised into the girts, and moreover, if one or more partitions were used, and if one rod in each partition were also run through the girts on the sides of the silo, spreading would be most effectively prevented. The girts, like the plates, should be a little narrower than the studs in silos with an outer lining, and for a similar reason.

The Inner Lining.-The amount of lining required will depend almost entirely on the character of the climate. Ordinarily, when rectangular silos are built inside, one thickness of boards laid over tarred paper will suffice. When but one layer of boards is used, the lumber should be jointed and not more than one inch thick. Boards not more than six to eight inches wide will probably be better than those wider, on the principle that narrow boards for flooring are preferable to those wider. The tarred paper is tacked onto the studs. The strips of the same are p11t on perpendicularly and are made to overlap where they meet on the studs, so that both 
may be tacked to the stud nearest to the place of the overlapping:

When putting on the lining it is important that the boards shall be so put on as to aid in binding the corners of the silo. This may be done by having each alternate board extend to the outside of the studding of the walls which stand at right angles with the board. Both ends of each board thus extencled can then be nailed to a stud properly adjusted in each of the two walls just referred to. This can only be done, however, when the boards used in lining are of an equal width.

When it is deemed necessary to put on two thicknesses of boards, that first put on should be nailed directly to the studs and in a horizontal position. These boards need not be planed, but the end sought will be better secured if they are jointed. A lining of tarred paper is then put on over the boards. Over the tarred paper a second lining of jointed boards is nailed. Inch boards are commonly used, but those somewhat less in thickness will suffice. The boards of the second lining should break joints with those of the first, as shown in Fig. 36 .

The Outer Lining.-When the silo is built within another building, no outer lining is usually necessary. When one or two sides of the building also form the outer walls of the silo, the siding that has been used upon either will usually answer also for the outer lining of the silo, and without any change. When the silo extends upward through the roof of a building, the outer lining of the part which thus projects may be similar to the siding of the building. When the silo is built without, it may 
be necessary in very cold climates to have two thicknesses of boards for the outer lining, with tarred paper between, as shown in Fig. 36. But usually a covering of drop siding, such as is ordinarily used, will suffice. In mild climates an outer covering may not be necessary, except for the purpose of hiding the uncouth appearance of an uncovered frame.

Partitions.-When partitions are used in a silo with a width of not more than sixteen feet, they may ordinarily consist of planks two inches thick and held in place at either end by a groove formed along the wall to receive them. (See Page 285.) When filling a silo with a partition of such material, it will be necessary to fill on both sides of the partition or to brace one side while the other is being filled. In a silo twenty-four feet in hight, three iron rods of about three-fourths inch iron should run through the partition at suitable distances from one another and in grooves made for them between the planks. (See Page 287.) The rods should be threaded at the ends and should have under the burrs washers of metal of sufficient size to prevent the burrs from drawing into the wood. When thus protected, the walls of the rectangular silo cannot spread.

The Corners.-In each inside corner a scantling should be placed on end and spiked to the walls so as to present a beveled edge on the inside. A scantling $2 x_{4}$ inches or $4 \times 6$ inches ripped diagonally through the center, that is to say, from two opposite corners, will furnish the requisite material for corners. The beveled edge should of course be planed.

The Doors. - The doors, as in the stave silo, should be placed one above another. (See Page 305.) 
They may also be of the same size as those described in the stave silo, where the distance between the studs will admit of making them thus, and they may be similarly distanced. They may likewise be beveled on the edges and held together by bars bolted to the outer edge of the wall before the doors are cut out. A simpler form of door has been made by cutting out an opening of sufficient size between two studs and holding together the part of the lining thus cut out by bars nailed or bolted to them on the outside. When in place they rest against strips nailed to the two sides of the two studs adjacent to the opening for the door. When the doors are in place they are covered with tarred paper to aid in excluding the air. Where an outer lining has been put on, openings to correspond with those of the inner lining may be marle on the same general plan.

The Roof.- It is only when the rectangular silo extends up through the roof of the outbuilding, or when the silo is built outside that it requires to be roofed. The plates which are spiked onto the top of the studs, or which have the latter mortised into them, should be less wide than the studs that ventilation may be provided for the air space between the inner and outer linings of the wall. Plates are frequently used no thicker than the studs, but in silos possessed of much width it would be no more than pruclent to use plates somewhat thicker. The size of the rafters used should be regulated by the size of the silo. When in position they are notched where they rest on the plates and are spiked and toenailed to the same. If narrow boards or $2 \mathrm{x}_{4}$ scantlings are nailed or spiked to opposite rafters and not 
far up from the plates, they assist materially in preventing the silo from spreading. But there is no necessity for nailing them thus to each pair of rafters. The covering of the roof may consist of boards and shingles, or indeed, of any of the materials used in covering roofs that may be desired. In the gable should be a hinged door to admit green food when the silo is being filled. It should be not less than two and one-half feet wide to admit carriers such as are commonly used when silos are being filled; but sometimes the gable end is left open. There should also be at least one cupola or ventilator on the ridge of the roof to furnish egress to the gases which are generated by the fermentation of the silage. If the roof of a silo is closed tightly, premature decay in the roof would result.

\section{BUILDING STONE SILOS.}

It is almost certain that the stone silo will grow in favor with the passing of the years because of its greater relative duration. This will at least prove true in localities abundantly supplied with stone. The greater relative first cost of constructing stone silos is probably more than anything else responsible for the infrequency with which such silos are found. Future experience, however, is likely to show that when the greater duration of stone silos is taken into account, they will prove the cheapest by far in the end. The objections have been brought against them that they are damp, and that frost easily penetrates them, and both objections are true in the absence of certain precautions when building them. 
Excessive dampness may be prevented by making an air space in the wall while it is being built, or by lining the wall on the inside with one thickness of brick and by giving due attention to ventilation.

The danger from frost will not be present except in cold climates. The air space in the wall. or the inner brick lining above referred to will also help materially to ward off frost. When neither is present, protection may be afforded by covering the outer wall with a lining of boards nailed to studding so as to form an air space between the lining and the wall. The aim should be, however, to construct the wall so that such lining on the outside would not be necessary. A stone silo properly built should last indefinitely without any form of renewal except in the inner lining and in the covering over the framework of the roof.

Forms of Construction.-Stone silos may be built square, rectangular or round and they will usually be located outside, but may also be placed inside the barn or stable. The aim should be wherever practicable to build them round. When this cannot be done, the corners inside should be rounded more or less to facilitate the settling of the silage.

The Foundation.- The foundation of the stone silo may be made in the same way as the foundation for any structure in which permanency is desired. Every care should be taken to preserve it from the action of frost when built in a cold climate, lest cracking of the walls should follow. As the structure is heavy, the founclation should go down to solid earth. If the drainage below is not complete it should be made so by laying tiles under the wall or adjacent 
to and a little lower than the bottom of the same. The ground should also slope away somewhat from the outside of the wall.

The Floor.-The floor in the stone silo may be similar in construction to that in the stave silo. (See Page 282 and also Page 299.)

The $W$ alls.-The thickness of the walls should be determined by the size of the silo. The larger the silo the greater the pressure, and the greater the pressure the thicker should be the wall. It is at least questionable if the wall of any stone silo should be less than fifteen to eighteen inches in thickness, and the necessity will probably seldom arise for making the wall more than twenty-four inches thick. Whether the wall with an air space or the solid wall with a brick lining inside will be the more efficacious does not appear to have been determined as yet. In southern climates where the danger from frost does not exist, the solid wall without an air space or brick lining should answer every purpose.

The Inner Lining.- The walls inside should be coated with cement of an excellent quality. If laid on a brick lining it will last for many years where frost does not penetrate the wall. In a stone silo built by W. C. Edwards, M. P., of Rockland, Ont., the cement lining has been in place for ten years and is still in faultless condition. The stone wall is two feet thick. It is faced inside with one tier of bricks laid with the side to the wall, and the cement lining is plastered on the bricks. This fact is in conflict with statements made, which claim that it is necessary to apply cement of the consistency of whitewash every two or three years to the inner lining of stone 
silos. Whether the cement would last as well on properly built stone silos without the brick facing insides does not appear to have been determined, but there would seem to be no good reasons why it should not.

The Outer Lining.-Where stone silos are properly constructed, there should be no necessity for an outer lining of wood in any climate where corn can be successfully grown for the silo. The stone silo referred to in the preceding paragraph is located between the forty-fifth and forty-sixth parallels of north latitude, and in a climate that is stern and rigorous. The larger portion of the wall, which is twenty-six feet high, is unprotected, and yet Mr. Edwards testifies that no trouble whatever has arisen from the action of frost.

Where it is deemed necessary, however, to protect a stone silo by lining it outside, the lining can best be nailed to upright studs laid into the outer wall while it is being built, but of course studding may be used that is not thus laid into the wall. The studs or strips thus placed do not require to be any nearer than will suffice to properly sustain the siding. Drop siding will be suitable.

The Roof.-The roof of the stone silo when built outsicle may be constructed on the same plan as that of any other silo. But because of the greater duration of stone silos, it will probably pay to take special pains in the selection and use of material lasting in character, as, for instance, metal roofing. And since the stave silo is frequently built and used from year to year without any form of roof there would seem to be no good reason for not similarly 
using the stone silo where the climatic conditions are suitable.

The Doors.-Provision ought to be made for the door spaces when the wall is being built. These should be on one side of the silo and above one another, as in the stave silo. The size of the door spaces should be about the same, that is to say, about I 8x24 inches, or perhaps a little larger than that, because of the greater thickness of the stone wall. The material for the doors within and without will of course be wood, with tarred paper on the surface next the air space and also on the beveled edges. These beveled edges will fit into a corresponding bevel on the four edges of the inner and also on the outer surface of the wall, which border on the open space left for the doors. But the bevel on the outer side is much less important than that on the inner side, and may be dispensed with altogether. The doors on both sides may swing on hinges of suitable construction, or they may be simply put in place while the silo is being filled.

In deep and wide stone silos it may be necessary to strengthen the walls, to some extent, with iron bands encircling them, or with iron rods running up and down, as, for instance, near the doors. 


\section{CHAPTER V.}

CROPS SUITABLE FOR THE SILO.

It would seem to be possible to preserve in the silo with more or less of success any of the crops that are ordinarily grown in this country as food for live stock. Nevertheless, the exact methods to be followed in storing many of these crops so as to properly preserve them have not yet been fully determined. The relative suitability of crops for being made into silage is determined by various considerations. Chief among these is the ease with which they may be preserved in the silo. But prominent among the same are the following: I, The readiness with which they may be grown in ample supply. 2 , The ease with which they may be put into the silo and taken out of the same. 3, The facility with which they may be preserved by other methods. Corn for instance is more easily preserved in the silo than winter rye and it also produces more food per acre. On these grounds therefore it is so far the more suitable food of the two for being made into silage. Clover is more easily handled than rape, hence it is so far a more suitable silo crop. Sorghum is more difficult to cure in the dry form than peas and oats, hence it is more suitable than the latter for siloing.

The relative suitability of the following plants for being made into silage will now be considered, 
viz. : Corn, sorghum, non-saccharine sorghum, leguminous plants other than clover, plants of the clover family, millets, the common cereals, field roots, rape and sunflowers. With the exception of sunflowers, the Author believes the above have been named in about the order of relative suitability, giving corn the first place.

Corn.-Corn is pre-eminently the soiling plant of the United States and Canada. It would probably be correct to say that more corn is made into silage in these respective countries than all other crops combined. The high adaptation of this plant for the silo is based on such considerations as its wide distribution, the certainty with which it may be grown, the ease with which it is handled and cured, the large amount of food which it produces and the high character of the same, the aid which it renders in preserving other crops put into the silo along with it, and the difficulty frequently experienced in curing corn out of the silo. It is distributed so widely that it may be grown for silage in nearly every state in the Union and in nearly every province of Canada. Even where it does not become sufficiently advanced to produce soft grain it may be cured in the silo. It is one of the most certain crops of the farm, and when grown for silage, it is even more certain than when grown mainly for the grain product, since it may be cured in the silo before it is fully matured.

All things considered, no other crop is more easily handled in the green form, and none have been cured in the silo with so much certainty, so small a number of failures and so little loss. Likewise considered, no other crop produces so large an amoun $\hat{\imath}$ 


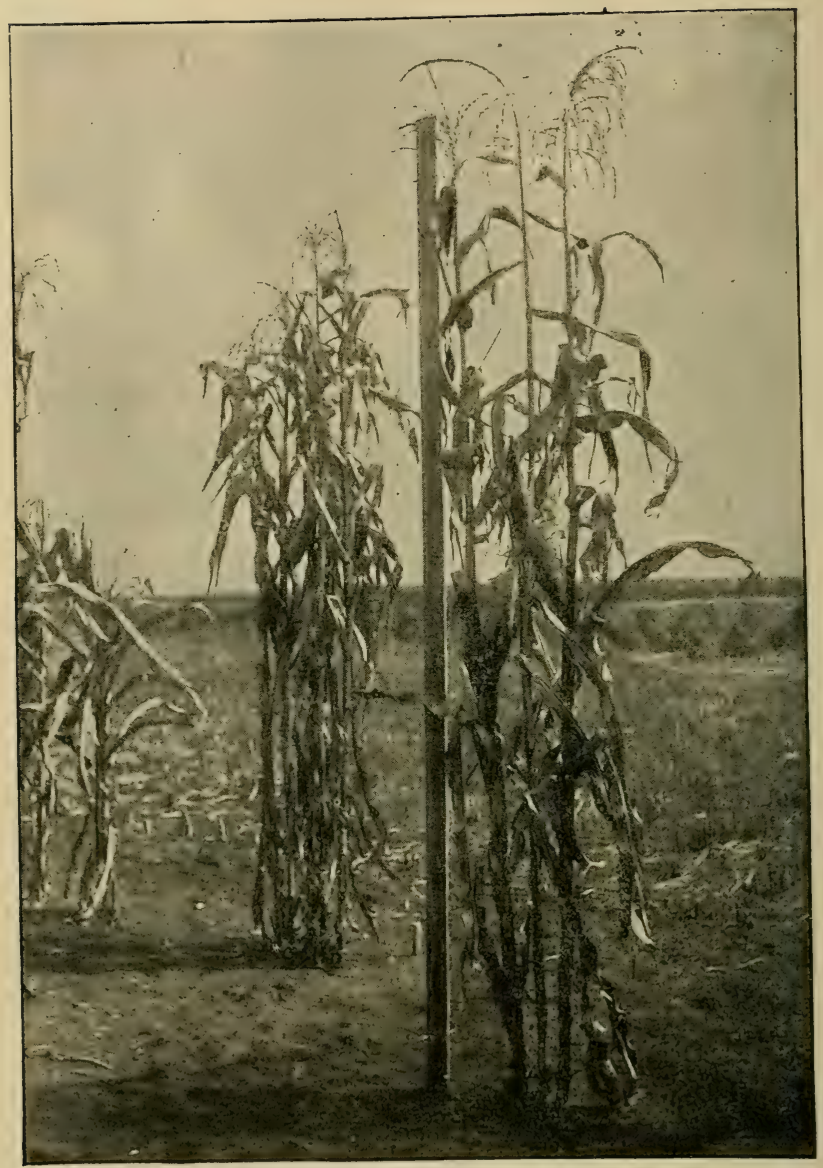

Fig. 37. Elephant Fodder Corn Minnesota University Experiment Farm. 
of food per acre that is so highly palatable and nutritious and over so wide an area. Various other crops, as clover, soy beans and cowpeas may be better preserved along with corn, as for instance, in alternate layers, than when put into the silo alone. Since in some sections corn is not easily preserved in the shock, the stack or the barn, the percentage of loss in those areas is reduced when corn is cured in the silo.

So completely adapted is corn to the requirements of silage making that where it can be grown successfu1ly from year to year it is questionable as to whether very much attention should be given to the siloing of other crops. Were it not that it is rather low in protein, the propriety of growing other crops to blend with it or to feed along with the silage made from it might well be questioned. Since the protein required to balance the ration can usually be procured more easily in the cured form, it is commonly more advantageous thus to procure it. Probably the soy bean, the cowpea and the sunflower, plants that are rich in protein, furnish exceptions.

Sorghum.-The suitability of sorghum for the silo is, in some respects at least, not very far different from that of corn, but since sorghum has not heretofore been grown to anything like the same extent as corn in those areas where the silo is most needed, its merits as silage food are but little known, and since its keeping qualities outside of the silo are in several respects superior to those of corn, the same necessity has not been felt for curing it in the form of silage. And when thus cured, sorghum silage has usually been found more acid than silage made from corn. 


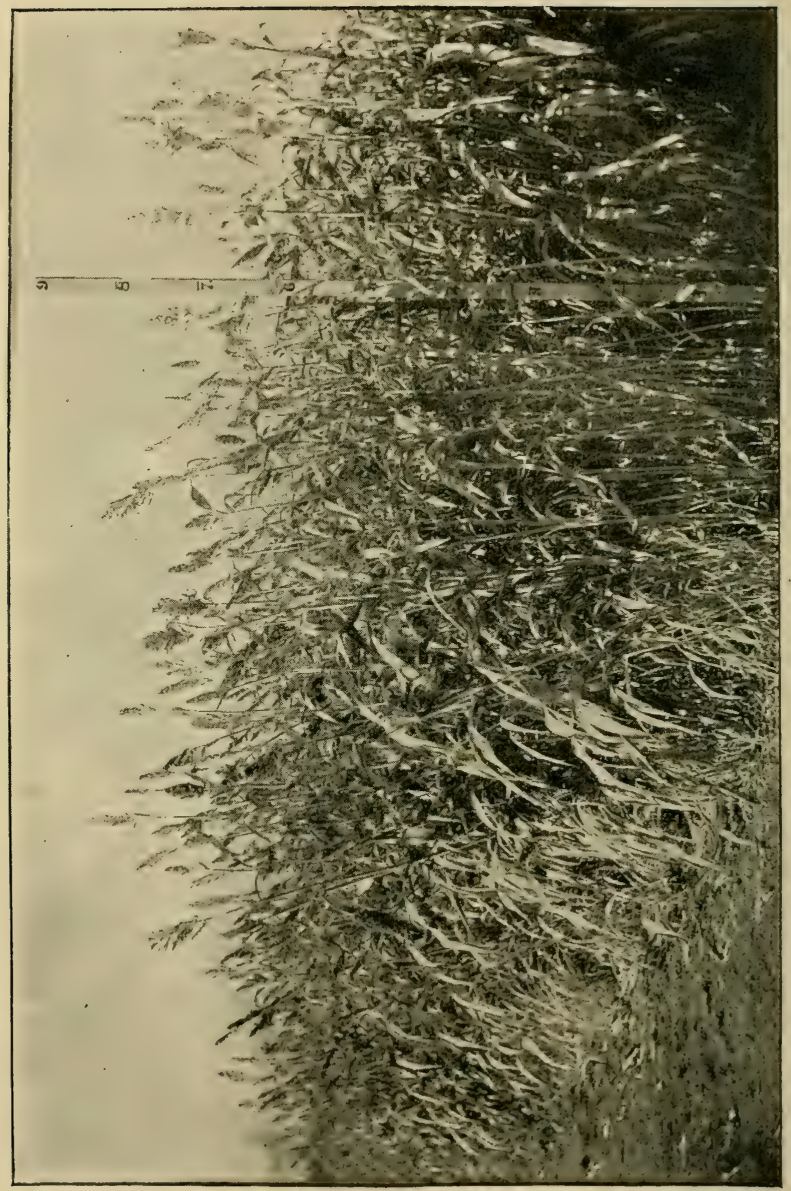


For autumn feeding it would seldom probably be . advantageous to make sorghum into silage since it may be fed so conveniently at that season from the shock or heap, as the case may be. But for late winter and spring feeding, in climates subject to alternations of high and low temperatures in winter, it is perhaps better preserved in the silo. Alternate freezing and thawing tend to affect adversely the value of its saccharine content.

The Non-Saccharine Sorghums.-The value of the non-saccharine sorghums as silage is probably not far different from that of sorghum, although experience in storing these crops in the silo is so limited that their relative value for making silage should be spoken of with a prudent reserve. Since they are grown in areas where the need of silos is not so imperative as where corn grows at its best, there is not the same necessity for making them into silage. They are grown to the greatest extent in dry areas where the fodder is not much liable to injury from rain when exposed in stacks, either in the autumn or winter. There should be no difficulty in preserving any of the non-saccharine sorghums in the silo, but, since they are usually less succulent than corn, they should be put into the silo at a somewhat less advanced stage of development.

Leguminous Plants Other Than Clover.-The chief of these, under conditions that now prevail in the United States, are the ordinary field pea, the common vetch, the soy bean and the cowpea. Thesc can all be preserved with more or less of success in the silo, but when preserved thus without admixture or alternation with other crops, as corn, in instances 
too numerous, the success attained has been only partial. This would seem to be true even of soy bean and cowpea silage. Silage made from these crops is too frequently acid in character, and in too many instances it has become more or less decomposed and off in color and smell. And these facts are probably true in a greater degree of the common pea and the common vetch than of the soy bean and the cowpea. This would seem to indicate that the two plants first named are usually put into the silo in a form too succulent. Whether the numerous failures in the attempt to preserve these crops in the silo arises from want of knowledge of the proper methods of doing the work, cannot as yet be stated with certainty, but there would seem to be no good reason why it should not be possible to preserve them with more uniform success than has heretofore been attained.

The same necessity does not exist for preserving the common pea and the common vetch in the silo as for preserving the soy bean and the cowpea. Since the two former may under average conditions be easily cured in the dry form. They are so fine in foliage that they readily give up their moisture when being cured. Not so however the soy bean and the cowpea. They are so coarse of straw that so much time is necessary to cure them properly and also so much handling, that unless great care is exercised in doing the work, the value of the hay thus made will be greatly impaired through the loss of the leaves.

When the soy bean and the cowpea are stored in the silo it should, when practicable, be along with corn or sorghum in some of its varieties. Some 
persons recommend storing these foods in alternate layers, since they consider it more practicable to store in layers than to mix the food, as it is easier to handle first one food and then the other when storing, than to handle the two simultaneously. The mixing of the food may be done when feeding it. But, if it is thought better to mix them at the time of storing, no serious obstacle stands in the way. This method of storing tends to make a more perfectly balanced ration. The proportions of each product required to make a balanced ration will vary with variations in the analyses of the crops. But even when these crops are stored thus, it may not always be wise to store them in those proportions that will exactly adapt the food to the needs of the animals to which it is to be fed. It may be impossible to do so because of a preponderance in the supply of one or the other of the crops grown. If it is true that corn, or sorghum exercises a preservative influence on the other foods, it would seem to be necessary to have a considerable preponderance of them in the silo.

It is easily possible to grow the soy bean and the cowpea so that they will be in season for being put into the silo when corn or sorghum are also in season. But the same cannot be said of the common pea or the common vetch.

The horse bean has been grown to determine its value for silage at least in an experimental way in the vicinity of Ottawa, Ont. The object sought was to increase the protein content in the silage. Where the beans can be profitably grown and mixed with corn in the silo, the plan of using them thus would seem to be commendable, but the areas in 
which horse beans and corn can both be grown successfully on this continent are not extensive.

Plants of the Clover Family.-Clover in all its forms may be made into silage both in the natural condition and after it has been run through a cutting box. It is more common however to preserve thus, only the medium red and the mammoth sorts. Alsike clover is more easily cured in the dry form than either of these, because of its fine growth and the frequency with which it is grown along with timothy. It is much easier to grow an equal or nearly equal mixture of alsike and timothy, than of the red clovers and timothy, and the timothy thus admixed with the alsike is favorable to quick curing in the latter. Alfalfa is more commonly grown in dry climates, hence the necessity for preserving it in the silo is not very great.

While fairly good silage may sometimes be made of clover when put into the silo without admixture, it does not seem an easy task to preserve it thus in a manner that will give entire satisfaction. In too many instances, when taken out of the silo, it is too dark in color and rank in odor to meet the requirements of those who are seeking the very best quality of milk. But the fact that it is sometimes preserved with a fair measure of sweetness would seem to indicate that it may always be so preserved if the conditions that govern the making of good clover silage were fully understood.

Clover is more easily preserved in the silo when admixed with corn, and when thus preserved the ration provided is in better balance than if it consisted only of corn, since the clover adds to the 
protein content which is too much wanting in the corn. But the first cutting of medium red clover cannot be thus mixed with corn, since the corn is not far enough advanced for being put into the silo when the clover is ready for being thus stored. Nor is corn sufficiently advanced for being preserved thus along with mammoth clover. But the second cutting of medium red clover is ready for being siloed at the same time as corn. Because of the greater difficulty experienced in many localities in curing the second growth of medium clover, on account of the increased dampness of the weather at that season there is sometimes much propriety in curing it in the silo. But under average conditions in the United States and Canada, the curing of clover in the old-fashioned way, with the exception stated, would seem to be preferable to curing it in the silo. In climates with much rainfall in harvest as that of Great Britain, it is different. In that country it may be the better plan to preserve clover in the silo.

Millets.-The different kinds of millet may also be preserved in the silo, although they are seldom thus handled and for the following reasons:I, They mature at a season of the year favorable to curing in the dry form, that is to say, they mature in the latter part of the summer. 2, Like ordinary hay they are easily handled in the field cured form. 3 . The method of preserving them alone or unmixed in the silo cannot be said as yet to have proved a decided success. Millet silage would seem to be more liable to mold than corn. This may not be true of pearl millet, but experience in siloing that product would seem to be entirely wanting. 
The plan of preserving millet, in some of its forms at least, along with corn may have some commendable features, since it is usually ready for being harvested about the same time as corn. There is the objection to it however, that it does not improve the feeding value of the mixture so much as a leguminous plant would, since the latter would be richer in protein. The more bulky kinds of millet and the soy bean may be successfully preserved together in the silo. They make a good food, as each plant would in a sense be the complement of the other. It has been recommended to put one load of each alternately into the silo when filling it, and to sprinkle several buckets of water over each load of millet when in the silo.

The Common Cereals.-Under this head only wheat, oats, rye and barley will be considered. There would seem to be but little reason for preserving these crops in the silo, even though they made good silage. The grain alone which they produce is usually more valuable than the silage made from them, since they must be made into silage while yet somewhat lacking in completest possible nutrition. Nor can they be readily preserved in the silo owing to the hollow and dry character of the stem. Silage as ordinarily made from these crops is much liable to injury from dry mold. This liability can of course be lessened by much tramping while the silo is being filled, and by sprinkling the mass freely with water occasionally, also by cutting the food a little earlier than it is usually cut. The Author made good silage from winter rye at the Ontario experiment station at Guelph in I89I. The rye was cut when 
fully out in head and was then run through a cutting box. The cattle to which it was fed ate it with evident relish. But while the rye silage was thus being fed, the exposed surface in the silo dried out so quickly between the feeding periods that the palatability of the silage was materially lessened, notwithstanding that it was being fed to a considerable number of animals.

All things considered, there would not seem to be any great necessity for making these crops into silage. The grain is usually more needed than the silage. They can usuaily be readily cured as hay when wanted in that form, and there is also less hazard on the whole in curing them as hay.

Ficld Roots.-There would seem to be no good reason why the attempt should be made to keep field roots in the silo under existing conditions, since they can be so easily preserved in cellars and pits. The only exception is the pulp made from sugar beets after the sugar has been extracted from them. And yet it is possible that the day will come when field roots will be run through a pulper and made into silage to secure greater convenience in storing and feeding. They could thus be stored in less space and they would be in condition that would fit them for being fed to any kind of live stock without further preparation.

It will perhaps, in all cases, be found more profitable to feed the tops of field roots directly to live stock than to try to preserve them in the silo. The labor of handling them thus is very much less than the labor of first putting them into the silo and feeding them out again, even though they could be 
cured with but little hazard. But it is pretty certain that they cannot be cured thus, because of the excess of moisture which they contain. This at least has been the outcome of experiments made heretofore to preserve the tops of field roots in the silo.

But it is different with beet pulp. The feeding value is not greatly reduced by taking so much of the sugar content from it. It is ordinarily not practicable for farmers contiguous to the beet factory to cart the entire product of the pulp from the same and to feed it on their farms. They cannot do so in cold weather and the time required would be too valuable unless when they lived near the factory. It would seem to be in a sense necessary therefore to store it in a silo of some kind near the factory and to feed it from the same. The product thus preserved has been made to furnish an excellent adjunct in feeding dairy stock and cattle and sheep that are being kept for breeding uses or that are being fattened.

Rape.-Experiments have been made to preserve rape in the silo, but so far as the Author has been able to ascertain, they have not been successful. Like the tops of field roots, rape is too watery to make good silage. It decays in the silo, turns black in color and becomes tainted with an offensive odor. Nor is there any real necessity for curing it thus. The labor of handling would be increased as compared with that entailed in feeding it directly as soiling food. Though preserved ever so well, it would have to be fed with much caution to milch cows lest taint might be produced in the milk. It would seem therefore to be a waste of time for any 
but experimenters to ever try to preserve rape in the silo.

The Sunflower.-The growing of sunflowers to be made into silage along with corn has been advocated by some high authorities and has been practiced to a very limited extent by farmers in some sections of Ontario. The object sought is to so increase the feeding value of the silage that the complement of grain to be added to the same when it is fed can be materially lessened. The sunflowers are grown in rows and cultivated much after the fashion of corn. The heads only are used. They are gathered, run through a cutting box and mixed with corn while the silo is being filled.

Large yields of heads have thus been obtained, as high in some instances as eight tons per acre. But it would seem questionable if this plant will ever be extensively grown for such a use and for the following reasons:- $\mathrm{I}$, The labor of gathering the heads is considerable. It must be done by hand. 2, The stalks which require much plant food to grow them have no feeding value. 3 , They also cumber the land and involve extra labor in removing them, for which there would seem to be no adequate compensation unless when they can be used as fuel. 


\section{CHAPTER VI.}

FILLING THE SILO.

When crops are preserved in the silo, much of the success in thus storing them depends upon such considerations as the stage at which they are harvested and the precise methods followed in storing. The expense incurred will also be materially affected by the way in which the work is done. The various questions which bear upon these points will now be considered.

Stage of Harvesting.- The stage of development at which crops should be harvested when put into the silo will vary with the kind of crop to be preserved. Corn is in the best condition for being harvested when the grain in the ear has reached the "glazed stage" or what is sometimes termed the "roasting stage." If put into the silo at an earlier period the corn is less nutritious than it would otherwise be, and it is also more likely to make silage unduly acid. If allowed to pass the stage indicated. the corn is somewhat liable to become more or less moldy. The mold thus formed is found in spots or masses interspersed through the silage. The over-acid condition is induced by over succulence in the corn, and the moldy condition by want of succulence. The remedy for the first consists in wilting the corn more or less before siloing it, and for the second, in cutting the corn at an earlier period. It 
should be possible in all instances to apply the last mentioned remedy, but not the first mentioned, since there are localities in which the season is too short to admit of corn reaching the roasting stage before the arrival of frost, and yet in these localities it may be desirable to make silage from corn.

The degree of the wilting will be dependent on the succulence of the corn. The less advanced the stage of the growth, the more should the corn be wilted. Good silage has been made at Indian Head, Can., from corn cut before grain had been formed in the ear. If corn should pass the proper stage of maturity before it is put into the silo, it will keep better if water is poured over the mass occasionally while the silo is being filled. The same result will measurably follow if some more succulent food, as clover or oats and peas are mixed with the corn.

When corn is struck with frost and is then allowed to stand uncut for some time subsequently, it will be greatly injured for feeding. But if, when thus stricken, the crop is at once cut and put into the silo, the value of the silage made from it, though reduced is not seriously impaired.

The exact stage of development at which sorghum and the non-saccharine sorghums ought to be cut have not yet been fully determined, but it will probably be found that the best stage for harvesting these crops will be when they are just a little short of maturity. But crops even of the same species are by no means equally succulent at the same stage of advancement. Much depends upon the climate, and season, and this fact must not be lost sight of when they are being'made into silage. 
The soy bean should be harvested when the beans are more or less grown in the pods, and the same is true of the cowpea and the horse bean. It is usually considered preferable to allow the pods to become well advanced, so as to increase the feeding value of the silage, but more experience is wanted in siloing these crops before the exact stage of growth can be certainly known at which they ought to be harvested.

Clover should be cut for the silo when coming into full bloom. If cut earlier it is too immature and is over succulent. If cut later it is lacking in succulence. Rye and wheat should be cut as soon as out in head, and the same is true of millets. Oats and peas grown together are ready when the pods in the peas are in process of filling. The seed of sunflowers should be allowed to become nearly matured before putting them into the silo. But from what has already been said, it will be evident that the period of harvesting may be varied somewhat by the treatment given to the crops while storing them.

Cutting Crops for the Silo.-The implement to be used in cutting crops for the silo will depend on the nature of the crop. Very frequently the field mower is used. The exceptions are, corn, sorghum the non-saccharine sorghums, sunflower heads, and in some instances such crops as rye and millet. Rye and millet are sometimes harvested with the ordinary binder. When thus harvested they are handled with but little labor. Some form of knife must be used in cutting off the heads of sunflowers. The best mode of cutting corn and sorghum for the silo will vary with conditions. When small quantities only are to 
be put into the silo, it is questionable if any implement used by hand is superior to the corn knife. But when large areas are to be cut, the corn binder should do the work satisfactorily and with despatch when the corn or sorghum stands fairly erect.

Conveying the Crop to the Silo.-Since crops for the silo must be harvested in the green form, they handle very heavily. The aim should be to convey them to the silo by that method that will involve the least expenditure in labor. Ordinarily therefore they should be loaded on conveyances which do not rise far from the ground. Careful attention to this matter will prevent the expenditure of muscle in a marked degree. Trucks with low wheels and covered with a broad platform are suitable for such work. The only objection to them probably is the heavy draught. A platform is sometimes made on which to load these crops, and when in use it is suspended underneath the front and hind bolsters of an ordinary wagon. It consists of two strong scantlings of hardwood of any length within the limits of practicability, and held together by crosspieces at both ends. Inch boards of some hard wood are nailed across these scantlings. If pine is the material used, the boards or planks should be thicker. The platform is suspended so as to come within about a foot of the ground. The green fód is placed on the same for conveyance to the silo.

In gathering some kinds of crops for conveyance to the silo, as clover for instance, a hay loader may sometimes be used with advantage. But when so used the green food must be lifted from the swath where the mower left it. Sunflower heads are 
usually cut with a strong knife and thrown directly into a wagon box. In this they are driven to where the cutting box is placed.

Whether crops should be wilted or not before being put into the silo, and also the degree to which they should be wilted, will depend largely on the natural succulence in the crop, and the stage at which it is cut. Crops that are quite succulent, as green clover, are more easily preserved when wilted more or less. On the other hand crops lacking in succulence, as winter rye, cannot be placed in the silo too soon after they have been cut. Corn cut at the proper stage may be put directly into the silo, but corn less mature should be wilted more or less according as it is lacking in maturity.

Putting Crops into the Silo.-Whether crops should be run through a cutting box or not before putting them into the silo will depend upon conditions. When but a limited quantity of silage is wanted, and where labor is not easily obtained, it may sometimes be wise to store crops in the silo in the uncut form. But this method of storing them is not always practicable. In a silo entirely above the ground, it would be almost impossible to get corn, for instance, into the same without excessive labor, and if put into a silo that goes far down below the surface of the ground it would be even more diffi. cult to get the corn out again. The only crops that could be stored in the over-ground silo withont excessive labor, are those which may be deposited in the same with the aid of the horse forks.

In a large majority of instances it will prove more satisfactory in many ways to store food in the 
silo after it has first been run through a cutting box, and for reasons as follows:- I, Much less labor is required to put it into the silo and to pack it so as to exclude the air. 2, It usually keeps better in the cut form. 3, Much less labor is involved in feeding the silage. 4, A smaller proportion will be rejected by the animals. 5, Meal may be mixed with the cut silage as may be desired. Whenever silage is fed in a large way, it will certainly pay well to run the food through a cutting box before it is stored rather than to store it in the uncut form.

Where corn, sorghum or the non-saccharine sorghums are to be run through a cutting box when put into the silo, the cutting box chosen should be strong, and when much work is to be done, it should be capacious, that the work may be done rapidly. It may of course be driven by any kind of power not unduly expensive. The tendency now is to prefer engine power to horse power.

The lengths to which the food should be cut is yet an unsettled point. In fact it will vary to some extent with the crops stored. All things considered, however, short lengths in the food cut are preferable to those longer. They may be packed more tightly and handled more readily when feeding than silage of longer lengths. Those from one-half to three-fourths of an inch, of such hard substances as corn or sorghum stalks, are in favor with many. Intermediate lengths, that is, lengths a little longer than the above, have been objected to because of the soreness of mouth sometimes induced in cattle, from biting on the ends of the cuts rather than on the 
sides of the same which they must needs do if the pieces are long. The only objection probably to the short lengths in the silage arise from the increased labor of cutting the food thus short. It would not seem to be necessary to cut soft-stemmed crops in lengths so short as those that are hard.

The expense of making silage is lessened by doing the work in such a way that all the workmen engaged shall be kept employed, that is to say, when the men in the silo do not have to wait for cut food, when the engine does not have to wait idly for the arrival of uncut food from the fields, and when the workmen in the fields do not have to wait for the return of the teams which draw the food. To arrange the work thus requires some executive tact, and where silos are numerous in any locality, it can be most cheaply done when done in a co-operative way.

Putting the Food Into the Silo.-The silo may be filled quickly and without any interruption save that which is made by taking the usual rest required by the workhands. Or, it may be filled slowly and at intervals as may be convenient. The intervals of cessation in filling should not at any time cover many days lest the exposed silage should begin to decay, unless it is absolutely necessary to wait after the silo has been partially cured for some other crop to mature. In such an event more or less of the food that was last put into the silo will be spoilecl. This ought to be removed before the filling of the silo is resumed. When but a short period is covered in filling the silo, although it should be filled to the brim, it will not remain full. 
The silage will continue to settle for several days, so that a large space will be left vacant above the silage. Where two silos are to be filled that are near at hand, the difficulty will be partially met by filling both at the same time, that is to say, by filling one in part and then the other in successive alternations until both are full. More time is thus given for the silage to settle. For the same reason, when a silo is being filled with a division in it, the two divisions should be likewise filled simultaneously. And when thus filled the danger from pressing the division away from the perpendicular is also obviated. But it has not yet been demonstrated that quick or reasonably slow filling materially affects the character of the silage.

The proper distribution of the food in the silo is a matter of no slight importance. When it is allowed to fall from the carriers which convey it to the silo, the mass rises up in the center in the shape of a cone. From this cone the food rolls down toward the sides of the silo. But in doing so, the lighter portions, as for instance the leaves of corn, are forced outward by the heavier portions, as the grain and stem. The quality of the silage, therefore, on the outer edges is frequently inferior to that in and near the center of the same, especially when it contains less grain. If, therefore, the quality of the silage is to be uniform in the silo, it must be carefully? distributed from the first.

But still greater harm will follow from allowing the silage thus to pile up in the center. It will not settle evenly. The pressure is greatest in the center, and the tendency in settling will be to draw away the 
food from the walls of the silo, and air will thus be admitted with the result that much of the mass on the outer edges will be spoiled. This condition is even more aggravated when such food as clover, for instance, is thus put into the silo with the horse-fork. Loss from this source may be prevented by first distributing the food evenly during the filling of the silo, and then tramping it so that the impaction of the mass will be about equal in all parts of the silo. The amount of tramping required will be least in the center of the silo and greatest on the outer edges. In the square or rectangular silo, particular pains should be taken to tramp down the mass firmly in the corners, or harm will follow from the admission of air. The amount of tramping required will vary with the nature of the food, the shape of the silo and the depth of the same. The less succulent the food and the more woody it is in character, the more should it be tramped. More tramping on the whole is necessary in a square or rectangular silo than in a round one, since the food settles more readily in the latter. Less tramping is needed in a deep silo than in a shallow one, since when the silo is deep, the silage sinks more under the pressure, as it were, of its own weight. It is evident therefore that much care should be taken to tramp down firmly the food in the upper portion of a silo whatever its shape may be or the extent of its depth.

In a large silo the distribution of the food may be facilitated by the introduction of a simple device. It consists of a platform or table made of boards and suspended far upward in the silo and equally distant from its walls. The food falls from the carriers 
onto the center of this table. As soon as it accumulates sufficiently on the same it rolls down over the outer edges, and is in consequence distributed over a considerable proportion of the surface of the silo.

Covering the Silage.-Various methods have been adopted of covering the silo to preserve the silage on and near the surface. They include the following:-I, Covering with old hay or straw in the cut or uncut form to the depth of from one to several feet. 2, Covering with some kind of cloth through which the air does not easily penetrate, and then placing over this a layer of hay or straw as mentioned above. 3, Covering with boards generally laid over a covering of straw and then weighting the boards with some heavy substance as stone or barrels filled with earth. 4, Sowing some kind of grain over the surface of the silage and then pouring or sprinkling water over it copiously so as to cover the mass with a dense growth of grain and grain roots.

The first method furnishes a cheap covering so far as material is concerned. Old hay fine in character such as is found in fence corners where blue grass has possession, makes a better covering than hay coarse in character, or than straw, since it lies more densely upon the silage. When either of the two last named substances is used it ought to be run through a cutting box. The tramping of the covering should also be given careful attention. And if a few buckets of water are at the same time thrown over the mass, it will help to exclude the air more perfectly.

The second method will probably preserve more silage than the first, but the covering thus provided 
is more costly. Whether the advantage will repay the additional outlay has not yet been proved.

The third method, thought at one time to be absolutely essential, has been almost entirely discarded, not because of its want of efficacy so much as because of the labor involved. The benefits derived from it are greater when some covering is put on as described above, before the planks are laid over the food and weighted with stone or indeed any other heavy substance. The advantage from thus weight-ing the silage will be lessened by giving much tramping to the food as the filling of the silo nears completion. No doubt there will be less waste of silage when food in the silo is thus covered and weighted. The saving thus effected in the silage will be more than is generally supposed, because of the salutary influence which the weighting exerts on the silage for some distance from the surface, even though it may not have lost its color. But as stated above, the practice is not in favor because of the cost involved.

The plan of covering silage by strewing grain, as oats for instance, over the top of the same, and then pouring water more or less copiously over the mass, is a good one. The heat engendered in the silo starts at once a rank growth in the grain. The growth of top and root become so dense as to go far toward excluding the air. And when the living mass falls down and decays, the influence exerted, for some time at least, is practically the same, hence there is usually but little loss in the silage. This plan has the merit of cheapness, of economy in labor required and of efficacy in a marked degree. 
But it should not be forgotten that by whatsoever method the silage is covered, there will be more or less of loss. Because of this, some silo owners have adopted the practice of not covering the silage at all. They argue that the greater waste of silage that follows is at least offset by the labor involved in covering the silage. This may be true of the more laborious methods adopted, as by weighting, but it is scarcely true when the comparison is made between no covering and covering with a growth of grain. To leave silage thus uncovered would only be commendable when the feeding of the silage is to begin at once.

Prescrving Grecn Crops Without the Silo.Crops are sometimes preserved in the green form without a silo. They are thus preserved in the stack and also under cover in the mow. The principle of preservation however is the same. Through the partial fermentation which the food undergoes, the air in the mass is expelled and through pressure induced by the green condition of the food, the air is kept excluded. This pressure is sometimes further increased by artificial means in some instances while the food is being deposited and in other instances subsequently. When food is thus stored the stack and also the mow becomes in a sense a silo.

Curing green food in the stack is somewhat: common in Great Britain, while the green food is being stacked heavy rollers are made to run over the green mass from time to time, or pressure is otherwise applied, and the food is thus preserved. While the practice may be a good one for farmers to adopt in countries with much rain in harvest, and where 
the winter climate is mild, it is at least questionable as to whether it ought to be introduced into localities where green crops can be cured in the dry form without much hazard. When the cold in winter is severe, the frost would penetrate more or less into the exposed surfaces and bind them together so as to interfere with handling the food at such times. The work of stacking the food in the green condition is also more or less laborious; nor is the green food when thus cured as easily handled as dry food. The possibility however of curing food thus is not to be called in question. Thus far, therefore, the way is prepared for those who care to do so, to follow such a system.

The method of preserving food under cover in the green form and yet not in a silo, has met with some favor in the United States, but only in limited areas. When thus preserved, it has been in mows or sheds, and tramped down during the filling process. Green clover has thus been preserved in some of the northern states. In the central and southern states cowpeas and soy beans have also been stored thus with success. And more recently reports have appeared in which it is claimed that sorghum may similarly be preserved.

That such crops as clover, cowpeas and soy beans may thus be preserved cannot be called in question and yet there is an element of hazard about their preservation by this method that should lead the unskilled in such work to refrain from undertaking it, until they have first made themselves familiar with the conditions that govern the successful curing of those crops in the green form in the mow. The 
degree of moisture in the crops, the amount of the tramping that should be given, and the size of the mow are all important considerations. Clover is commonly allowed to wilt a little before being thus stored and the same is true of cowpeas and soy beans. Some authorities claim that the wilting should be continued until it is no longer possible to wring much water out of the green mass. Much tramping is also considered advantageous, and a deep mow is preferable to a shallow one. Likewise outer walls smooth on the inside are more favorable to the settling of the food than those with horizontal timbers, as girts, to hinder the proper settling down of the same. Not a few who have tried to preserve food thus have signally failed. Closely connected with such instances of failure is the hazard of loss to the building as well, through fire produced by what is termed spontaneous combustion. But since cowpeas and soy beans are difficult to cure in the dry form without much loss of leaves, it may be wise to try and cure them thus, more especially when there is much hazard from rain. 


\section{CHAPTER VII.}

FEEDING SILAGE.

When silage has been properly covered in the silo, the waste from decay on the surface of the same should not extend downward more than a few inches. When not covered at all, the spoiled silage will extend downward at least a foot and in some instances to a distance considerably greater. After a time, decay below the surface practically ceases, hence subsequently there is but little further loss from this source, though the opening of the silo should be delayed for months after it has been filled. The silage also retains more or less heat for many months and this is favorable to feeding the same in cold weather.

Whon the Fecding May Begin.-The feeding of silage may be commenced the same day that the filling of the silo has been completed. When feeding begins thus early, there is naturally no loss of silage from decay, providing a considerable quantity of the silage thus removed from day to day. The Author has fed silage from the silo in this way and with results completely satisfactory. But it is not usual to begin feeding silage so soon after the silo has been filled, for the reason that other green food can he had that is more perishable in character.

Feed from the Top Dow'merard.-In feeding silage it is indispensable that the silo shall be opened 
at the top, and that in all instances the silage sha!l be fed from the top downwards. When silos were first introduced into America, the egregious mistake was made of opening them at or near the bottom. When thus opened the air is admitted so as to penetrate upwards more or less into the mass, and thus hasten its decay. Much of the silage above falls down from time to time and in such a loose condition it at once begins to spoil. It is necessary therefore, under all circumstances, to feed from the top downwards, but it is not absolutely necessary to feed from the whole surface of the silo at once. A section only of the mass of silage may be fed from until it is all gone, but when silage is thus fed in sections from the top to the bottom, there is more loss in silage than when it is fed from the entire surface, except when the size of the silo is too great for the number of animals that are being fed from it. This method of feeding silage therefore is only justifiable, when the quantity to be fed at one time is too small to admit of feeding from the whole surface without harm to the exposed portion of the silage.

No more of the product on the surface should be loosened up at one time than is wanted for immediate feeding, as when thus loosened and not soon fed, the quality of the food deteriorates. But when feeding from the whole surface of the silo it may be necessary. to remove the silage from only a portion of the surface when providing food to give the stock but one meal. Another part may be removed to furnish the next meal. 
Under such conditions it will be decidedly advantageous to have a covering, as of oiled cotton cloth, lying over the entire surface of the silo. Such a covering is not expensive, and it will tend to keep the silage on the surface in better condition for feeding. When such a covering is used it can be laid backward only far enough to make bare a sufficient space to furnish food for feeding at one time. The cover should be at once put back, and in this way the feeding progresses. But even when thus managed, it should be the aim to feed from every part of the surface, at least as frequently as once in two or three days. Such a covering will also prove helpful in protecting the surface silage from frost in coid areas, where there may be danger from such a source.

Fecding from a Part of the Surface.-When the silage is fed from only a part of the surface of the silo, that is to say, when a section of the mass only is being fed from, the side of the mass adjacent to that from which the silage is being fed is thus gradually exposed to the air. Because of such exposure the silage spoils for some distance in from the exposed side. The extent of the decay will depend in some measure on the length of the exposure and on the compactness of the mass. It will vary from a few to several inches. Because of this loss, the plan of feeding silage by this method should be avoided as far as may he possible. When silage is thus removed, some sort of hay knife should be used in cutting down the side of the mass. The surface exposed will then be smooth and the waste of silage will be much less in consequence. 
Because of this waste from feeding silage thus in sections, it may be better to have one or more partitions in the silo. This can be managed easily enough in a square or oblong silo, but it is practi. cally impossible in a stave silo, because of the resistance which a partition would offer to the tightening of the staves sometimes required with a stave silo. IVhen partitions are used, one section of the silage can be all fed out before another section is disturbed. But it should be remembered, as already intimated, that the greater the number of partitions in a silo the greater relatively is the loss of spoiled silage likely to be.

Conveying Silage to the Animals.-When the silo is not close to the place of feeding and when large quantities of silage are to be fed, it may be necessary to draw the silage in a cart or dray, from which it can be shoveled into the feed mangers. But when the silo is near to the place of feeding, the food can best be conveyed in a box truck or car, a hand cart or a basket. If conveyed in a truck or car, the track on which it runs should of course be laid in the feeding alley in front of the mangers, so that the silage may be shoveled from the car or truck into the mangers. When conveyed in a hand cart, one with three wheels and drawn or pushed by means of a short tongue is very convenient, since it may be easily moved from place to place and easily turned within a limited area. When fed in limited quantities the silage may be carried in a basket. When conveyed in a box car, truck or hand cart, the silage can be thrown directly into one or the other of these from the silo. A fork with several tines in 
it may be used with much effectiveness in lifting the silage in the silo, and the shorter the lengths to which the food has been cut, the more readily may it be removed. None of the silage thrown out of the silo should be allowed to remain unfed, or it will at once begin to deteriorate.

Carrying Silage Over to Another Season.-As previously intimated, it is possible to carry silage over from one season to another. But it cannot be thus carried over without some loss. As soon as the feeding of the silage ceases for the season, decay begins on the exposed surface and it penetrates the same to a certain depth, more or less according to the degree of compactness in the silage. In any event it will be spoiled to the depth of several inches, and up to the present time no effective method of preventing such decay has been discovered, which is not too costly to justify applying it. But before the refilling of the silo begins, the spoiled silage should first be carefully removed.

Adaptation to Different Classes of Animals.Although silage may be fed to horses, cattle, sheep and swine, it is not equally adapted to these various classes of animals, nor is it equally adapted to the needs of all animals of the same class. Much depends upon the age of the animals, the other food adjuncts that are commonly fed to them and the precise object or objects for which they are kept. It furnishes excellent food for colts, brood mares and horses that are not being worked. Only small quantities should be fed to horses that are being worked moderately and still less to horses that are being severely worked. Like all other green foods it 
induces too lax a condition of the bowels when fed in any considerable quantities to horses that labor hard.

The best results probably are obtained from feeding silage to milch cows. Because of its succulence it is favorable to milk production, and when properly preserved it does not in any way injuriously affect the quality of the milk. It also furnishes excellent food for young cattle, store cattle and cattle that are being finished for beef. But to obtain the very best results, the silage must be fed with judgment and discretion.

Silage furnishes good food for sheep of all ages, but in very cold weather caution should be used as to the extent to which it is fed. When fed freely at such a time, much of the silage will become cold before it is consumed, since sheep are usually fed in sheds in which the temperature within is not far different from the temperature without. It is not wise to feed green food in a cold condition at such a time when such feeding can be avoided. Since cattle sheds are usually warmer than sheep sheds, there is not the same objection to feeding silage to cattle thus protected in severely cold weather.

Silage has not proved a really good food for swine. It is usually too bulky and is in consequence not well adapted to the digestive system of swine. Nevertheless, a little of it may be fed to them with some advantage. Brood sows and store pigs will chew over the parts rejected by other stock and will doubtless get some benefit therefrom. But it is at least questionable as to whether silage should be fed in any considerable quantity to hogs that are being 
fattened. Something, however, depends upon the materials included in the silage.

Quantities of Silage to Feed.-Much difference of opinion exists as to the quantities of silage that may be fed with advantage. Some authorities claim that it may be made the sole food of animals for weeks and months in succession. That is not the view of the Author. Much of course will depend upon the character of the silage. When it has been well preserved, the silage is not markedly acid, but it is acid in some degree. Now that is not the condition in which nature provides green food for live stock, hence it does not seem wise to confine animals to a diet so acid. To test this question, the Authon fed steers that were being fattened on silage and meal for a period averaging about 140 days and during three successive experiments.

These experiments were conducted at the government experiment station at Guelph, Ontario, Can. The first experiment began in the autumn of 1889. Two steers were thus fed each winter. They were pitted against an equal number of steers that were fed meal, an average of thirty-three pounds of corn silage per day and all the cut hay they would eat in addition. A third lot of two steers were fed meal, cut hay and field roots. The amount of meal fed was practically the same in each instance. Of the six steers that were fed all the silage they would consume in addition to the meal, two died before the experiments were completed. The veterinarian of the station reported that death resulted from serious derangement in the rigestive organs caused by the acid in the silage. More or less trouble was also 
experienced with all the steers confined to the ration of meal and silage. They occasionally got "off their feed." The steers fed on the ration of meal, hay and roots were uniformly healthy and hearty throughout the experiment. With silage less acid, the fatal results chronicled might not have occurred. But since the silage fed was quite as well preserved as corn silage usually is, the inference would seem fair that there is an element of danger in feeding silage in unlimited quantities to farm animals for months in succession. The full details of these experiments are given in Bulletins XLIX, LXI and LXXXII, issued by the aforementioned station.

While it is impossible to state definitely how much silage may be fed for a prolonged period to cattle without crossing the danger line, in the judgment of the Author it is questionable if the amount fed daily to a mature breeding animal of the bovine species should exceed thirty to forty pounds per day. Of course for a limited period it may be safe to feed larger quantities, and it is possible that larger quantities than those named have been fed to breeding animals for a period somewhat prolonged without any apparent harm. Nevertheless, the conclusion would seem fair that there is an element of danger in feeding silage in unlimited quantities to animals for months in succession. The most intelligent feeders concur in this view, and it finds farthe: countenance in the craving which domestic animals manifest for a certain proportion of dry fodder while silage is being fed to them in large quantities.

Four to five pounds per day may be named as the maximum amounts to be fed to breeding ewes 
for months in succession, but it is possible, and indeed, it may be commendable to feed larger quantities for a limited period.

Any kind of fodder that is palatable and well preserved may be fed along with the silage. But when practicable the fodder thus given should be made as far as possible to give the entire ration the desired balance or equilibrium as to food nutrients. For instance, when corn silage is being fed, clover in any of its forms will make a ration more nearly balanced than would be obtained from feeding dry fodder, the product of corn, sorghum or any of the non-saccharine sorghums.

Feeding Grain or Meal with Silage.-Additional meal is frequently given to animals that are receiving silage. In all such instances the silage furnishes an excellent medium with which to feed the meal. It is the practice with some to mix the meal with the silage in a feed room before feeding the mixture. But the extra labor thus involved does not seem to be necessary, unless when other cut fodder is also to be mixed with the silage. The method of placing the silage in the feed manger and then scattering the meal over it is simpler, and it is probably quuite as efficacious. The animals mix the food measurably well while in the act of eating it. When the meal is fed thus, different quantities of the same or different kinds of meal may be fed as may be desired to the individual animals. Such variations in feeding the meal cannot be so well made. if indeed made at all, when the meal and silage are mixerl in the feed room. When other cut fodder is fed it would probably involve less labor 
to feed the silage and other fodder separately. This at least would sometimes be true. In such instances, the meal should be fed with the other fodder to induce a greater consumption of the same. Silage is more appetizing as a rule than other cut food, especially when the latter is fed in the dry form, hence it will usually be eaten with avidity without being admixed with meal. This is not true of some kinds of dry fodder, nor is it true probably to the same extent of any kind of fodder.

When feeding meal along with silage, the amount of grain that the silage may contain should be considered, and the amount of the meal fed regulated accordingly. For instance, while it may be necessary to feed ten pounds of silage daily to dairy cows receiving a large proportion of corn silage which has little or no grain in it, that amount might prove excessive when the corn silage contains relatively a large proportion of grain. It is practically impossible to know exactly the proportion of the grain which the silage contains, but a sufficiently approximate estimate may be made by the practiced feeder.

Attention should also be given to the constituents of the meal fed so as to balance the ration. For instance, should the silage contain much of the seed of the soy bean, it would be proper to add corn, or some other carbonaceous meal, with much freedom. But if, on the other hand, it should contain much corn and no other grain, it would be in order to add much bran or other nitrogenous meal.

Fecding Silage with Ficld Roots.-It is not common to feed silage and field roots together, for 
the reason chiefly that farmers do not commonly grow both crops to any considerable extent the same season. In some degree at least these foods serve the same end, that is to say, they furnish succulent food for animals at a season of the year when it cannot usually be obtained from other sources. Both are favorable to milk production, and when fed in moderation both serve as regulators of digestion. Field roots contain less dry matter, but they are considered, all in all, a more healthful food than silage. They are also looked upon as being more favorable to the robust dievelopment of young stock. But it is commonly believed that the cost of growing field roots is relatively greater. There does not seem to be much reason, therefore, for growing both foods in large quantities. Which of the two should be given the preference ought to be determined largely by the more favorable character of the conditions for growing one or the other. When both are grown, there is no reason why they should not be fed to the same animals, regulating the quantity of each accordingly. When both are fed, the plan of feeding silage in the morning and roots in the evening, or vice versa, will be found labor-saving as compared with feeding both twice a day, and the end sought should be realized as effectively.

When to Feed Silage.-When a large quantity of silage is being fed it should be given in two feeds daily, that is to say, morning and evening. When meal is to be fed twice a day, it may be well also to feed the silage twice a day, that the silage may be fed along with the meal as previously intimated. But when only a small quantity of silage is to be fed 
and no meal, the result from feeding only once a day will probably be quite as satisfactory as from feeding twice. The silage is usually fed before the bulky food, since the latter is the unlimited factor in the ration.

Some forethought should be exercised in adjusting the quantities of silage fed to the prospective needs of the animals. For instance, if the feeder has been feeding a certain amount of food daily, and if he has reason to fear that by continuing to feed thus the supply of silage will fail before the new grass is plentiful, it would be better to reduce the quantity of silage fed daily than to have the silage fall short before the period indicated. While green food is always more or less helpful in regulating digestion when dry food is being fed, it is never more helpful than toward the approach of spring. The system of the animals is much prone to become weakened at such a time, more especially in cold latitudes, hence the greater need for the adjustment of the food to the requirements of these under the conditions just named.

From what has been said it will be evident; first, that much has been learned during recent years with reference to silos and the making of silage; second, that when silage is properly cured and fed it is an economical and health-producing food; and third, that because of its economy and healthfulness this mode of preserving food is likely to grow in favor. Nevertheless, it ought to be borne in mind that many things are yet to be learned about silos and ensiling food in the same. The system is yet in the infantile stage. Many features of the work have not yet been 
362 SOILING CROPS AND THE SILO.

fully wrought out, and prominent among these are the construction of silos that will be sufficiently. durable, and the making of good silage with reasonable certainty from other products than corn. 


\section{NDEX}

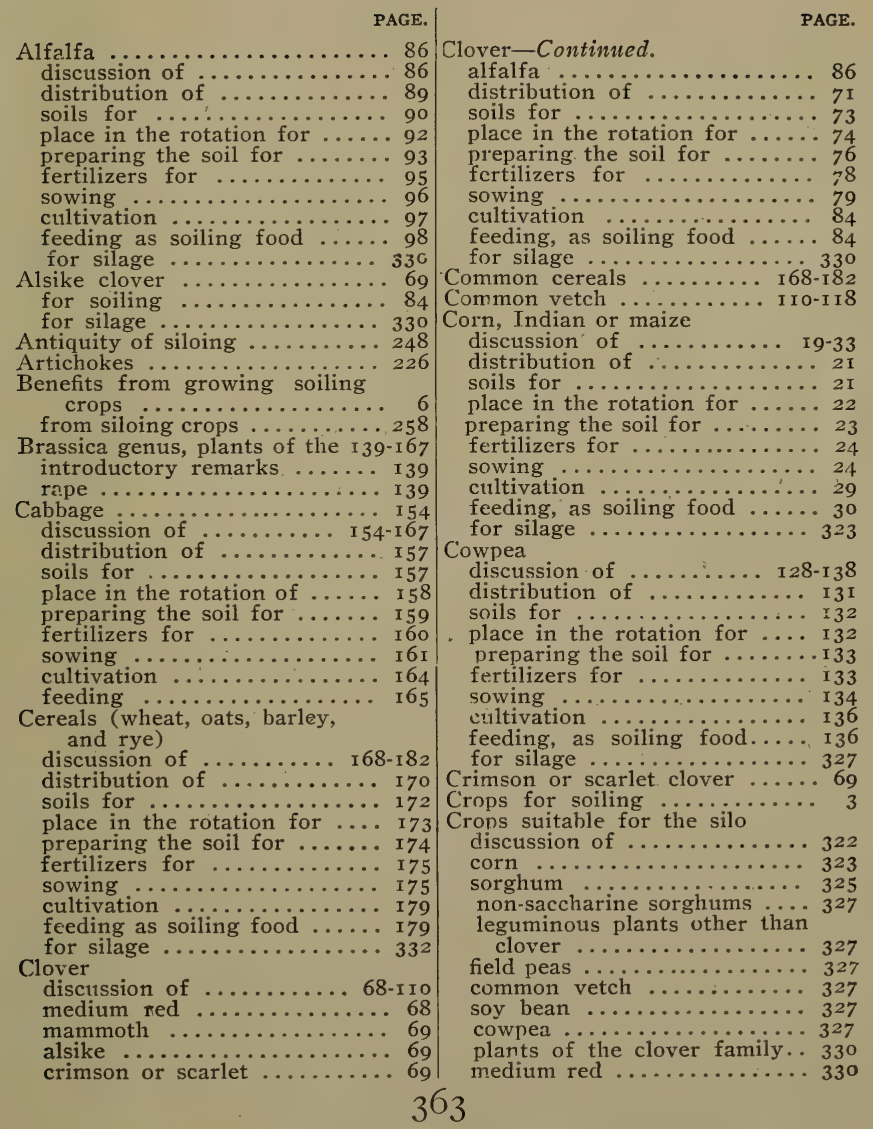




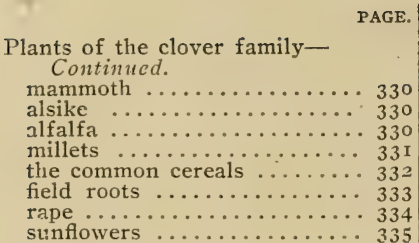

Dhourra ................ 54

Distribution of silos ............ 266

Ensilage or silage (definition) .. 246

Ensiling or siloing (definition) .248

Facts relating to silo construc-

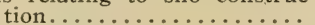

Feeding silage ................ 350

when it may begin .........350

feed from top downward .... 350

feeding from a part of the surface $\ldots \ldots \ldots \ldots \ldots \ldots 352$ conveying silage to the animals 353 carrying silage over to another season ........... 354 adaptation to different classes of animals $\ldots \ldots \ldots \ldots \ldots 354$ quantities of silage to fced ...356 feeding grain or meal with silage $\ldots \ldots \ldots \ldots \ldots \ldots, 358$ feeding silage with field roots $\ldots \ldots \ldots \ldots \ldots \ldots 359$ when to feed silage ........ 360

Field Peas

discussion of $\ldots \ldots \ldots \ldots$ I02-1 I0 distribution of $\ldots \ldots \ldots \ldots \ldots$ I0 soils for .................. 104 place in the rotation for .... I05 preparing the soil for ...... I0 fertilizers for ........... 106 sowing $\ldots \ldots \ldots \ldots \ldots \ldots$ 106 cultivation ............... 108 feeding, as soiling food ..... I09 for silage $\ldots \ldots \ldots \ldots \ldots \ldots .327$

Field Roots

discussion of $\ldots \ldots \ldots \ldots$ I95-204 rutabagas $\ldots \ldots \ldots \ldots \ldots \ldots$ I96 turnips .............. I 96 mangels ............. 197 sugar beets ............ 197 carrots .............. 197 distribution of $\ldots \ldots \ldots \ldots \ldots$ 196 soils for $\ldots \ldots \ldots \ldots \ldots \ldots$ I97 place in the rotation for..... I9 8 preparing the soil for ....... I 99 fertilizers for $\ldots \ldots \ldots \ldots \ldots 200$ sowing ............... 200 cultivation ........... 202 feeding, as soiling food .... 203 for silage $\ldots \ldots \ldots \ldots \ldots \ldots . .333$

Filling the silo ............. 336 stage of harvesting crops for the silo $\ldots \ldots \ldots \ldots \ldots . . . \cdots \cdots$ cutting crops for the silo .... 338 conveying crops to the silo ... 339
PAGE.

Filling the silo-Continued. putting crops into the silo ... 340 putting the food into the silo 342 covering the silage ........ 345

Flat pea $\ldots \ldots \ldots \ldots \ldots \ldots .220$

Grouping states and provinces.. 234

History of siloing $\ldots \ldots \ldots \ldots 245$

Horse Bean

for soiling $\ldots \ldots \ldots \ldots \ldots \ldots 2$ I 3

for silage ................ 329

Japan clover ............... 209

Jerusalem corn .......... 54

Kaffir corn $\ldots \ldots \ldots \ldots \ldots \ldots \ldots$ 5I

Kale ................ 216

Leguminous plants other than

clover ................ 102 for soilitig ............. 102 for silage $\ldots \ldots \ldots \ldots \ldots \ldots, 327$

The common vetch

for soiling $\ldots \ldots \ldots \ldots \ldots$ I I for silage ............... 327

The soy bean

for soiling $\ldots \ldots \ldots \ldots \ldots$ I 26

for silage $\ldots \ldots \ldots \ldots \ldots \ldots, 327$

The cowpea

for soiling $\ldots \ldots \ldots \ldots \ldots \ldots$ I 36

for silage $\ldots \ldots \ldots \ldots \ldots \ldots \ldots \ldots \ldots \ldots \ldots \ldots \ldots \ldots$

Lupines .............. 224

Mammoth clover

for soiling $\ldots \ldots \ldots \ldots \ldots \ldots, 84$

for silage $\ldots \ldots \ldots \ldots \ldots \ldots . \ldots \ldots$

Miangels $\ldots \ldots \ldots \ldots \ldots \ldots \ldots$ I97

Medium red clover

for soiling ............ 84

for silage $\ldots \ldots \ldots \ldots \ldots \ldots, 330$

Millets

discussion and classification

of $\ldots \ldots \ldots \ldots \ldots \ldots$ 18 8 -194

distribution of $\ldots \ldots \ldots \ldots \ldots$ I 85

soils for $\ldots \ldots \ldots \ldots \ldots \ldots \ldots \ldots$ I 87

place in the rotation for .... I 88

preparing the soil for $\ldots \ldots \ldots$ r 89

fertilizers for ............. I 90

sowing $\ldots \ldots \ldots \ldots \ldots \ldots$ I9I

cultivation ............ I92

feeding as soiling food ...... I93

for silage .............. $33{ }^{\mathrm{I}}$

Milo maize ................. 52

Miscellaneous plants ..... 205-23I

white clover ............205

sweet clover .............207

Japan clover ............. 209

sainfoin .............. 210

trefoil or yellow clover ....... 212

horse bean .............. 213

velvet bean $\ldots \ldots \ldots \ldots \ldots \ldots 2$ I 4

kale .................. 2 I 6

sand vetch $\ldots \ldots \ldots \ldots \ldots .217$

flat pea ................ 220

white mustard .......... 222

lupine .............. 224

spurry $\ldots \ldots \ldots \ldots \ldots \ldots \ldots .225$

artichokes ................ 226

prickly comfrey .......... 226 


\section{PAGE.}

Miscellaneous plants-Continucd. sunflower ..............230 sacaline .............. 230

Mustard, white .......... 222

Non-saccharine sorghums

discussion of $\ldots \ldots \ldots \ldots \ldots 55^{I-67}$

kaffir corn ............. 5 I

milo maize ............ 52

dhourra ............... 54

Jerusalem corn .......... 54

teosinte ............... 56

distribution of ........... 58

soils for ................ 6 I

place in the rotation for ......62

preparing the soil for ......6.63

fertilizers for ........... 64

sowing ................ 64

cultivation ............. 66

feeding, as soiling food .....6 67

for silage .............. 327

Objections to soiling ......... I5

Peas, field ............. I02-1 10

Preserving green crops without

the silo ............. 347

prickly comfrey .........226

Rape

discrission of ......... I 39-I 54

distribution of ........... I42

soils for ............... I43

place in the rotation for ..... I44

preparing the soil for ....... I45

fertilizers for ............ I46

sowing ................ I 47

cultivation ............. I49

feeding, as soiling food....... I 50

for silage .............. 334

Rectangular silo ........... 3ro

introductory remarks ....... 3 Io

foundation ............. 3 Io

sills ................ 3 II

floor $\ldots \ldots \ldots \ldots \ldots \ldots \ldots$ 3II

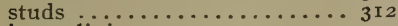

inner lining ............. 313

outer lining ............. $3^{\text {I } 4}$

partitions $\ldots \ldots \ldots \ldots \ldots \ldots \ldots$ 3 I 5

corners ................... I $^{1} 5$

doors $\ldots \ldots \ldots \ldots \ldots \ldots \ldots \ldots$ 3 5

roof $\ldots \ldots \ldots \ldots \ldots \ldots \ldots \ldots . \ldots \ldots$

Red clover, medium ......... 68

Roots, field ............. I95-204

Round wooden silo .......... 292

Rutahagas .................. I96

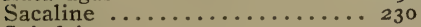

Sainfoin ................. 210

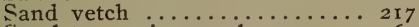

Scarlet or crimson clover ....... 69

Silage or ensilage (definition) .. 246

Silo

early ................ 250

modern ............. $25 \mathrm{I}$

not always a necessity ...... 265

distribution of ............ 266

division No. I-distribution in 267
PAGE.

Silo-Continued.

division No. 2-distribution in 267 division No. 3 -distribution in 267 construction, facts relating to...269 locating the silo ........... 269 forms of construction ....... 272 size $\ldots \ldots \ldots \ldots \ldots \ldots \ldots .274$ materials used in ........ 277 metals .............. 278 concrete or grout..........278 brick ................. 279 stone ................ 279 vrood $\ldots \ldots \ldots \ldots \ldots \ldots \ldots .280$ foundations ........... 280 floors $\ldots \ldots \ldots \ldots \ldots \ldots \ldots .281$

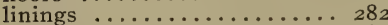
boards $\ldots \ldots \ldots \ldots \ldots \ldots \ldots{ }_{28} 8_{2}$ cement $\ldots \ldots \ldots \ldots \ldots \ldots \ldots .283$ water lime ............. 283 plaster ................ 284 shingles $\ldots \ldots \ldots \ldots \ldots \ldots \ldots .284$ bricks ................ 284 metals ............... 284 tarred paper $\ldots \ldots \ldots \ldots \ldots \ldots 285$ preservatives for lining ..... 285 partitions in silos .......... 286 doors in silos............ 288 roofing silos .............. 288 decay in silos.......... 289 building the silo ........... 292 round wooden silo ........ 292 round frame ............ 293 stave silo ............. 295 rectangular silo ........... 3 I stone silo .............. 3 I 7 crops suitable for the silo... 322 filling the silo ............ 336 feeding silage $\ldots \ldots \ldots \ldots \ldots 350$ Siloing or ensiling (definition) ..248 Siloing crops, benefits from ... 258 wholesale harvesting of crops 258 cured in showery weather.... 259 greell food all the year ..... 259 food more palatable ........ 26. economy in storage place $\ldots .262$ economy in labor when feed-

ing ................. 262 practical considerations ..... $26_{3}$ benefits do not apply equally .263 silos not always a necessity $\ldots 265$

Siloing, histery of $\ldots \ldots \ldots \ldots 245$ plan of the discussion ..... 245 definition of terms $\ldots \ldots \ldots \ldots 246$ ensilage or silage $\ldots \ldots \ldots \ldots 246$ siloing or ensiling $\ldots \ldots \ldots \ldots 248$ siloist ............... 248 antiquity of siloing $\ldots \ldots \ldots 248$ utilization of the idea...... 249 the ear!ier silos .......... 250 the modern silo ........... 25 I American progress in siloing. .253 mistakes made by early siloists 253 literature on the silo ...... 254 
Soiling crops, benefits from

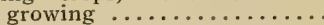

Soiling crops .............. adaptation in soiling crops ... partial and complete soiling .. benefits from growing soiling crops .................. increase in food supplies ...... less waste in feeding ........ sustains animals in better form. inquiry through poaching .... I influence on weed eradication.. I saving in land ............. I2 saving in fences ........... I 3 saving in fertility ......... I4 increase in animal production.. I4 sustaining the family cow .... I5 some objections to the soiling system .............. I $_{5}$ increased outlay for labor .... I 5 tax on attendants ........... I adjusting food supplies ....... I7 impaired stamina in the stock.. I8 Sorghum

discussion of $\ldots \ldots \ldots \ldots .34-50$ distribution of $\ldots \ldots \ldots \ldots \ldots 37$

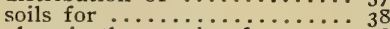
place in the rotation for ...... 38 preparing the soil for $\ldots \ldots \ldots 39$ fertilizers for.$\ldots \ldots \ldots \ldots \ldots$ 4 I sowing $\ldots \ldots \ldots \ldots \ldots \ldots \ldots, 42$ cultivation $\ldots \ldots \ldots \ldots \ldots \ldots{ }^{4} 6$ feeding, as soiling food ..... 47 for silage $\ldots \ldots \ldots \ldots \ldots \ldots, 325$ Soy bean

discussion of $\ldots \ldots \ldots \ldots$ I I 8-I 28 distribution of ........... 121 soils for ................. 122 place in the rotation for ..... I 23 preparing the soil for ...... I 124 fertilizers for $\ldots \ldots \ldots \ldots \ldots$ 1 24 sowing .............. I 24 cultivation .............. I 26 feeding as soiling food ...... I 26 for silage .............. 327 Spurry .................. 225 Stave silo ................. 295 foundation .............. 297 floor ....................29 299 staves ................ 299 setting up staves ............ 300
Stave silo-Continued.

PAGE.

splicing staves ......... 301

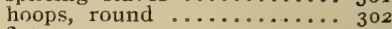

flat $\ldots \ldots \ldots \ldots \ldots \ldots \ldots \ldots . .304$

woven wire .............. 304

doors $\ldots \ldots \ldots \ldots \ldots \ldots \ldots 305$

shute $\ldots \ldots \ldots \ldots \ldots \ldots \ldots . \ldots . \ldots 307$

roof ................... 308

Stone silos ............. 317

form of construction ....... 3 18

foundation ............. 318

floor $. . \ldots \ldots \ldots \ldots \ldots \ldots . .319$

walls $\ldots \ldots \ldots \ldots \ldots \ldots \ldots$. 319

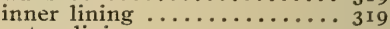

outer lining .............. 320

roof ....................... 320

doors $\ldots \ldots \ldots \ldots \ldots \ldots \ldots \ldots \ldots \ldots \ldots 3^{2}$

Succession in soiling crops..232-242

introductory remarks ....... 232

grouping states and provinces.234

section No. 1 -succession in.. 235

section No. 2 -succession in.. 236 section No. 3-succession in.. 237 section No. 4 -succession in.. 238 section No. 5-succession in.. 239 section No. 6-succession in.. 240 section No. 7 - succession in.. 240 section No. 8-succession in.. 24I

Sugar beets ............. I97

Sunflowers ............... 230

Sweet clover ............. 207

Teosinte .................. 56

Trefoil or yellow clover ..... 2I 2

Turnips ................ 196

Velvet bean ............... 2 I 4

Vetch, the common

discussion of $\ldots \ldots \ldots \ldots$ IIO-II 8

distribution of $\ldots \ldots \ldots \ldots \ldots$ III

soils for ................ II place in the rotation for ..... II 2 preparing the soil for ....... II 3 fertilizers for..$\ldots \ldots \ldots \ldots$ II 3 sowing $\ldots \ldots \ldots \ldots \ldots \ldots$ II 4 cultivation $\ldots \ldots \ldots \ldots \ldots \ldots$ II 6 feeding, as soiling food ..... II for silage $\ldots \ldots \ldots \ldots \ldots \ldots .327$ Vetch, sand ................ 217 Weeds eradication of, by soiling. . I I White clover ...............205 White mustard ................. 222 Yellow clover or trefoil ........ 212 


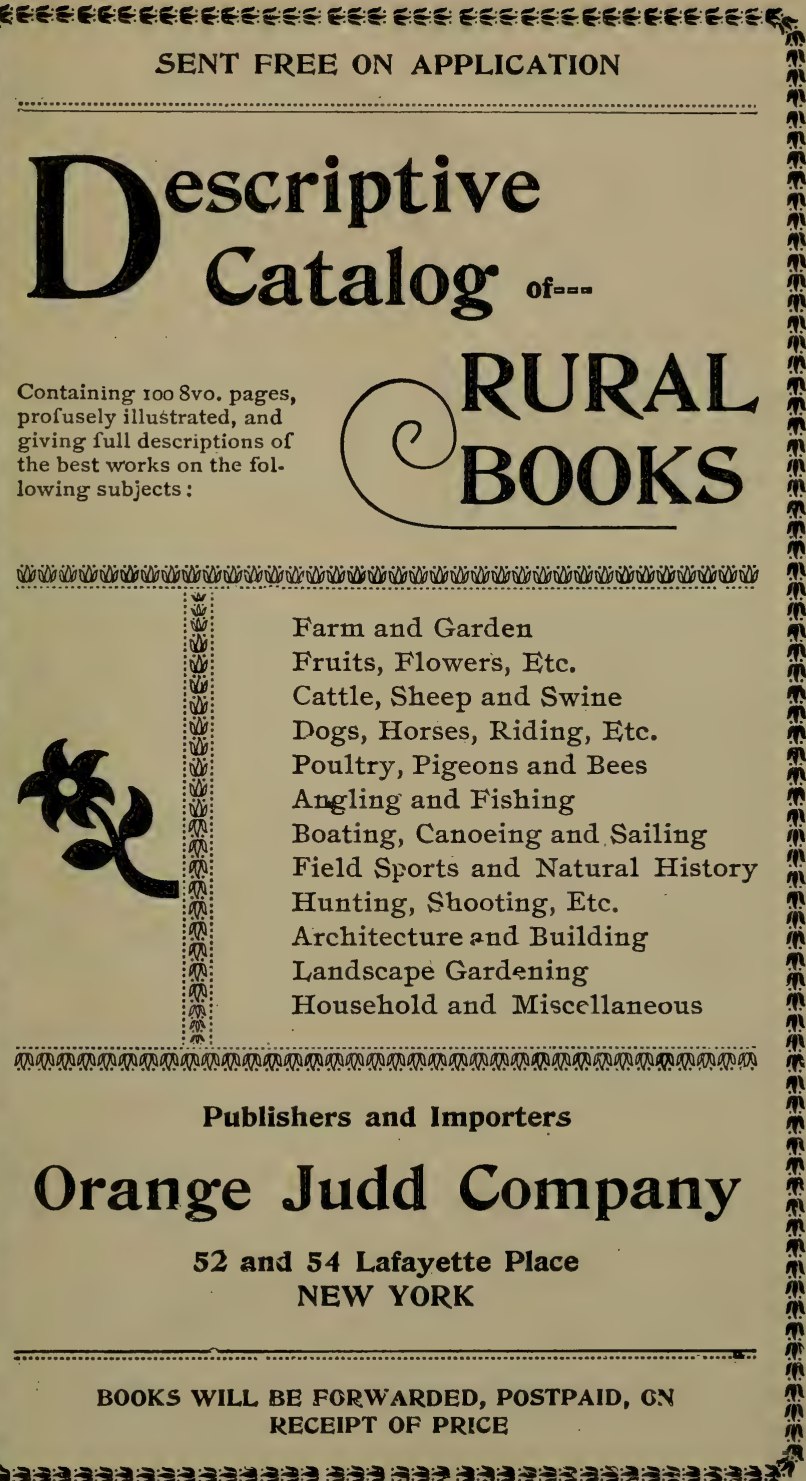




\section{Greenhouse Construction.}

By Prof. L. R. Taft. A complete treatise on greenhouse structures and arrangements of the various forms and styles of plant houses for professional florists as well as amateurs. All the best and most approved structures are so fully and clearly described that anyone who desires to build a greenhouse will have no difficulty in determining the kind best suited to his purpose. The modern and most successful methods of heating and ventilating are fully treated upon. Special chapters are devoted to houses used for the growing of one kind of plants exclusively. The construction of hotbeds and frames receives appropriate attention. Over one hundred excellent illustrations. specially engraved for this work, make every point clear to the reader and add considerably to the artistic appearance of the book. Cloth, $12 \mathrm{mo}$. $\quad \$ 1.50$

\section{Greenhouse Management.}

By L. R. Taft. This book forms an almost indispensable companion volume to Greenhouse Construction. In it the author gives the results of his many years' experience, together with that of the most successful florists and gardeners, in the management of growing plants under glass. So minute and practical are the various systems and methods of growing and forcing roses, violets, carnations, and all the most important florists' plants, as well as fruits and vegetables described, that by a careful study of this work and the following of its teachings, failure is almost impossible. Illustrated.

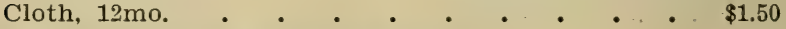

\section{Bulbs aad Tuberous-Rooted Plants.}

By C. L. Allen. A complete treatise on the history, description, methods of propagation and full directions for the successful culture of bulbs in the garden, dwel. ling and greenhouse. As generally treated, bulbs are alı expensive luxury, while when properly managed, they afford the greatest amount of pleasure at the least cost. The author of this book has for many years made bulb growing a specialty, and is a recognized authority on their cultivation and management. The illustrations which embellish this work have been drawn from nature, and have been engraved especially for this book. The cultural directions are plainly stated, practical and to the point. Cloth, 12mo. . . . . . $\$ 1.50$

\section{Irrigation Farming.}

By Lute Wilcox. A handbook for the practical application of water in the production of crops. A complete treatise on water supply, canal construction, reservoirs and ponds, pipes for irrigation purposes, flumes and their structure, methods of applying water, irrigation of field crops, the garden, the orchard and vineyard; windmills and pumps, appliances and contrivances. Profusely, handsomely illustrated. Cloth, 12ro. . . $\$ 1.50$ 


\section{Landscape Gardening.}

By F. A. Waugh, professor of horticulture, University of Vermont. A treatise on the general principles governing outdoor art; with sundry suggestions for their application in the commoner problems of gardening. Every paragraph is short, terse and to the point, giving perfect clearness to the discussions at all points. In spite of the natural difficulty of presenting abstract principles the whole matter is made entirely plain even to the inexperienced reader. Illustrated, 12mo. Cloth. . $\$ .50$

\section{Fungi and Fungicides.}

By Prof. Clarence M. Weed. A practical manual concerning the fungous diseases of cultivated plants and the means of preventing their ravages. The author has endeavored to give such a concise account of the most important facts relating to these as will enable the cultivator to combat them intelligently. $222 \mathrm{pp} ., 90$ ill., 12mo. Paper. 50 cents; cioth. . . . . . $\$ 1.00$

\section{Talks on Manure.}

By Joseph Harris, M. S. A series of familiar and practical talks between the author and the deacon, the doctor, and other neighbors, on the whole subject of manures and fertilizers; including a chapter especially written for it by Sir John Bennet Lawes of Rothamsted, England. Cloth, $12 \mathrm{mo}$.

\section{Insects and Insecticides.}

By Clarence M. Weed, D. Sc., Prof. of entomology and zoology, New Hampshire college of agriculture. A practical manual concerning noxious insects, and methods of preventing their injuries. 334 pages, with many illustrations. Cloth, $12 \mathrm{mo}$. . $\quad$. . . . . . . $\$ 1.50$

\section{Mushrooms. How to Grow Them.}

By Wm. Falconer. This is the most practical work on the subject ever written, and the only book on growing mushrooms published in America. The author describes how he grows mushrooms, and how they are grown for profit by the leading market gardeners, and for home use by the most successful private growers. Engravings drawn from nature expressiy for this work. Cloth. $\$ 1.00$

\section{Handbook of Plants and General Horticulture.}

By Peter Henderson. This new edition comprises about 50 per cent. more genera than the former one, and embraces the botanical name, derivation, natural order, etc., together witli a short history of the different genera, concise instructions for their propagation and culture, and all the leading local or common English names, together with a comprehensive glossary of botanical anc technical terms. Plain instructions are also given for the cultivation of the principal vegetables, fruits and flowers. Cloth, large 8vo. . . . . . . $\$ 3.00$ 


\section{Ginseng, Its Cultivation, Harvesting, Marketing and Market Value.}

By Maurice G. Kains, with a short account of its history and botany. It discusses in a practical way how to begin with either seed or roots, soil, climate and location, preparation, planting and maintenance of the beds, artificial propagation, manures, enemies, selection for market and for improvement, preparation for sale, and the profits that may be expected. This booklet is concisely written, well and profusely illustrated, and should be in the hands of all who expect to grow this drug to supply the export trade, and to add a new and profitable industry to their farms and gardens, without interfering with the regular work. 12mo. . . . . . $\$ .35$

\section{Land Draining.}

A handbook for farmers on the principles and practice of draining, by Manly Miles, giving the results of his extended experience in laying tile drains. The directions for the laying out and the construction of tile drains will enable the farmer to avo:d the errors of imperfect construction, and the disappointment that must necessarily follow. This manual for practical farmers will also be found convenient for references in regard to many questions that may arise in crop growing, aside from the special subjects of drainage of which it treats. Cloth, $12 \mathrm{mo}$.

\section{Henderson's Practical Floriculture.}

By Peter Henderson. A guide to the successful propagation and cultivation of florists' plants. The work is not one for florists and gardeners only, but the amateur's wants are constantly kept in mind, and we have a very. complete treatise on the cultivation of flowers under glass, or in the open air, suited to those who grom flowers for pleasure as well as those who make them a matter of trade. Beautifully illustrated. New and enlarged edition. Cloth, 12mo. • . . . . . . $\$ 1.50$

\section{Tobacco Leaf.}

By J. B. Killebrew and Herbert Myrick. Its Culturt and Cure, Marketing and Manufacture. A practical handbook on the most approved methods in growing, harvesting, curing, packing, and selling tobacco, with an account of the operations in every department of tobacco manufacture. The contents of this book are based on actual experiments in field, curing barn, packing house, factory and laboratory. It is the only work of the kind in existence, and is destined to be the standara practical and scientific authority on the whole subject of tobacco for many years. Upwards of 500 pages and 150 original engravings. 


\section{Play and Profit in My Garden.}

By E. P. Roe. The author takes us to his garden on the rocky hillsides in the vicinity of West Point, and shows us how out of it, after four years' experience, he evoked a profit of $\$ 1,000$, and this while carrying on pastoral and literary labor. It is very rarely that so much literary taste and skill are mated to so much agricultural experience and good sense. Cloth, $12 \mathrm{mo}$. . . $\$ 1.00$

\section{Forest Planting.}

By H. Nicholas Jarchow, LL. D. A treatise on the care of woodiands and the restoration of the denuded timberlands on plains and mountains. The author has fully described those European methods which have proved to be most useful in maintaining the superb forests of the old world. This experience has been adapted to the different climates and trees of America, full instructions being given for forest planting of our various kinds of soil and subsoil, whether on mountain or valley. Illustrated, $12 \mathrm{mo}$. . . . . . . . $\$ 1.50$

\section{Solls and Crops of the Farm.}

By George E. Morrow, M. A., and Thomas F. Hunt. The methods of making available the plant food in the soil are described in popular language. A short history of each of the farm crops is accompanied by a discussion of its culturc. The useful discoveries of science are explained as applied in the most approved methods of culture. Illustrated. Cloth, 12mo. . . . . $\$ 1.00$

\section{American Fruit Culturist.}

By John J. Thomas. Containing practical directions for the propagation and culture of all the fruits adapted to the United States. Twentieth thoroughly revised and greatly enlarged edition by Wm. H. S. Wood. This new edition makes the work practically almost a new book, containing everything pertaining to large and small fruits as well as sub-tropical and tropical fruits. Richly illustrated by nearly 800 engravings. 758 pp., $12 \mathrm{mo}$. $\$ 2.50$

\section{Fertilizers.}

By Edward B. Voorhees, director of the New Jersey Agricultural Experiment Station. It has been the aim of the author to point out the underlying principles and to discuss the important subjects connected with the use of fertilizer materials. The natural fertility of the soil. the functions of manures and fertilizers, and the need of artificial fertilizers are exhaustively discussed. Separate chapters are devoted to the various fertilizing elements, to the purchase chemical analyses, methods of using fertilizers, and the best fertilizers for each of the most important field, garden and orchard crops. $335 \mathrm{pp}$. 


\section{Gardening for Profit.}

By Peter Henderson. The standard work on market and family gardening. The successful experience of the author for more than thirty years, and his willingness to tell, as he does in this work, the secret of his success for the benefit of others, enables him to give most valuable information. The book is profusely illustrated. Cloth, $12 \mathrm{mo}$.

\section{Herbert's Hints to Horse Keepers.}

By the late Henry William Herbert (Frank Forester). This is one of the best and most popular works on the horse prepared in this country. A complete manual for horsemen, embracing: How to breed a horse; how to buy a horse; how to break a horse; how to use a horse; how to feed a horse; how to physic a horse (allopathy or homoeopathy); how to groom a horse; how to drive a horse: how to ride a horse, etc. Beautifully illustrated. Cloth, $12 \mathrm{mo}$. . . . . . $\$ 1.50$

\section{Barn Plans and Outbuildings.}

Two hundred and fifty-seven illustrations. A most valuable work, full of ideas, hints, suggestions, plans, etc., for the construction of barns and outbuildings, by practical writers. Chapters are devoted to the economic erection and use of barns, grain barns, house barns, cattle barns, sheep barns, corn houses, smoke houses, ice houses, pig pens, granaries, etc. There are likewise chapters on bird houses, dog houses, tool sheds, ventilators, roofs and roofing, doors and fastenings, workshops, poultry houses, manure sheds, barnyards, root pits, etc. Cloth, $12 \mathrm{mo}$.

\section{Cranberry Culture.}

By Joseph J. White. Contents: Natural history, history of cultivation, choice of location, preparing the ground, planting the vines, management of meadows, flooding, enemies and difficulties overcome, picking, keeping, profit and loss. Cloth, 12mo. . . . . . . $\$ 1.00$

\section{Ornamental Gardening for Americans.}

By Elias A. Long. landscape architect. A treatise on beautifying homes, rural districts and cemeteries. A plain and practical work with numerous illustrations anu instructions so plain that they may be readily followed. Illustrated. Cloth, $12 \mathrm{mo}$. . . . . . $\$ 1.50$

\section{Grape Culturist.}

By A. S. Fuller. This is one of the very best of works on the culture of the hardy grapes, with full directions for all departments of propagation, culture, etc., with 150 excellent engravings, illustrating planting, training: grafting, etc. Cloth, 12mo. . . . . . . $\$ 1.50$ 
(⿻)

(a)

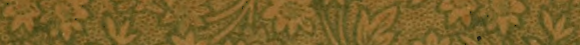

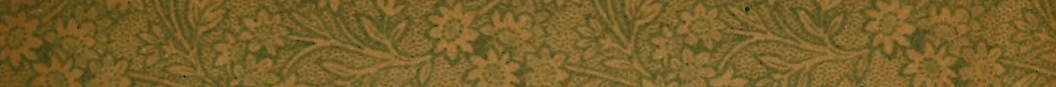

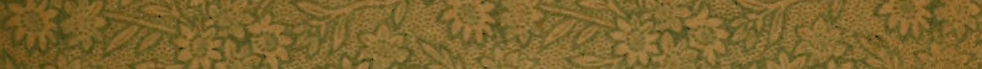

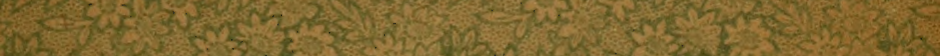

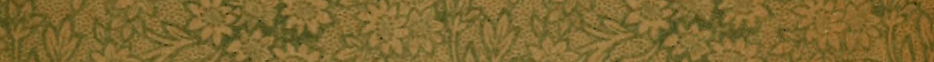

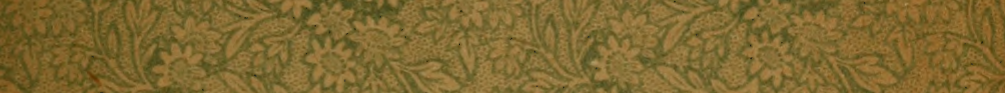
Lon

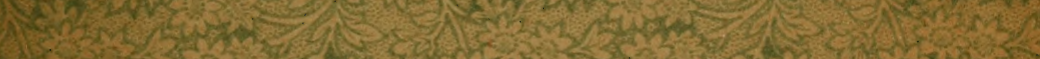

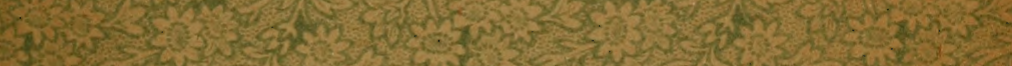

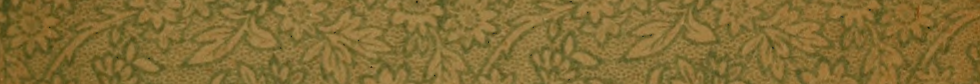
1.

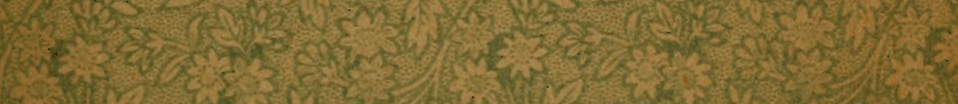
H

E. 35 -

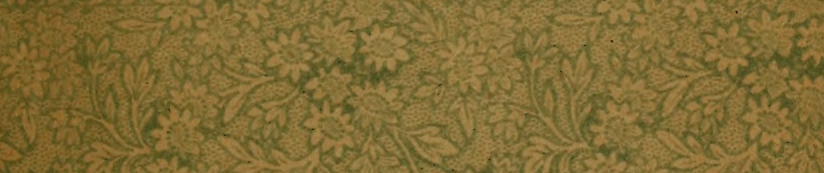

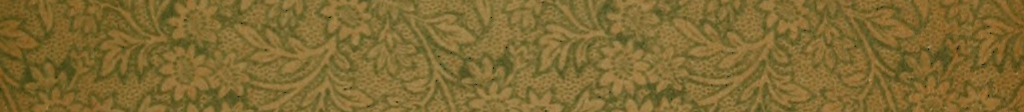

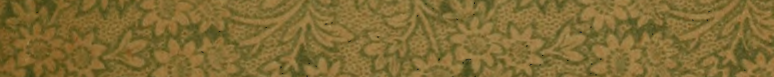

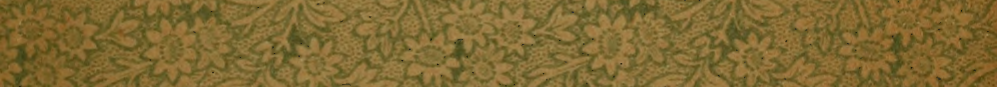

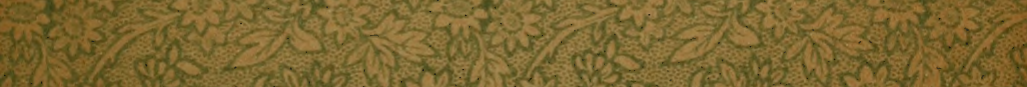

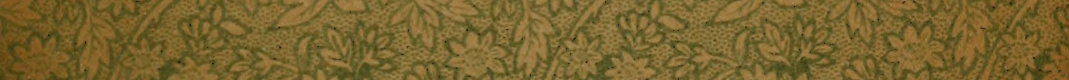

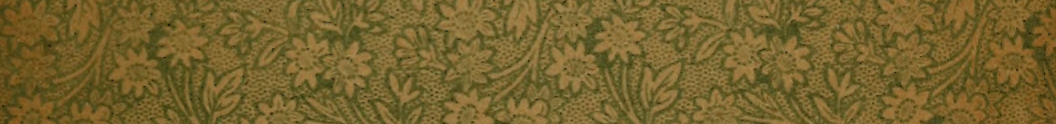
F. w.

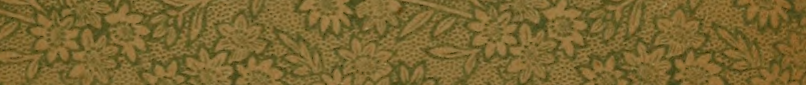

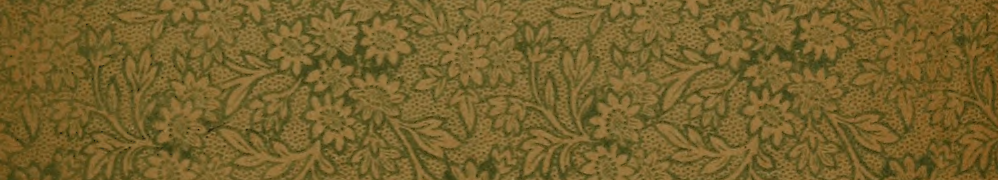

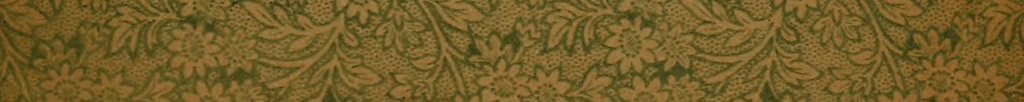

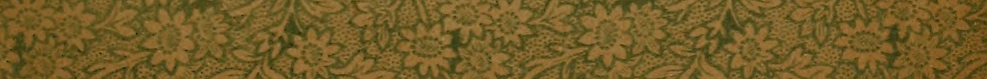

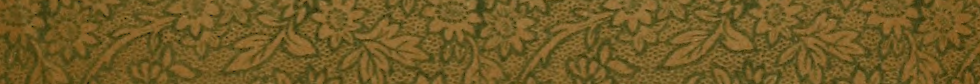

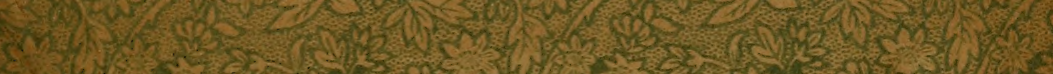
(6) 


\section{LIBRARY OF CONGRESS \\ || ||| ||||||||||||||||||-||||||||||||||||||||||| \\ ||||||||||||||||||||||||||||||||||||||||||||||||||||||||||||}

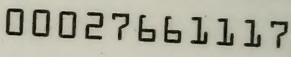

